\title{
Emotional Abuse of Children: Issues for Intervention
}

\author{
by Celia Doyle
}

A doctoral thesis submitted in fulfilment of the requirements for the award of Doctor of Philosophy of the University of Leicester

1998 
UMI Number: U105303

All rights reserved

\section{INFORMATION TO ALL USERS}

The quality of this reproduction is dependent upon the quality of the copy submitted.

In the unlikely event that the author did not send a complete manuscript and there are missing pages, these will be noted. Also, if material had to be removed, a note will indicate the deletion.

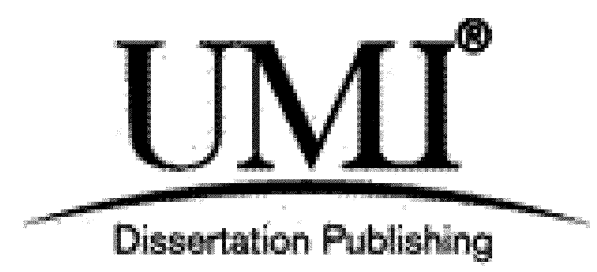

UMI U105303

Published by ProQuest LLC 2013. Copyright in the Dissertation held by the Author.

Microform Edition (c) ProQuest LLC.

All rights reserved. This work is protected against unauthorized copying under Title 17, United States Code.

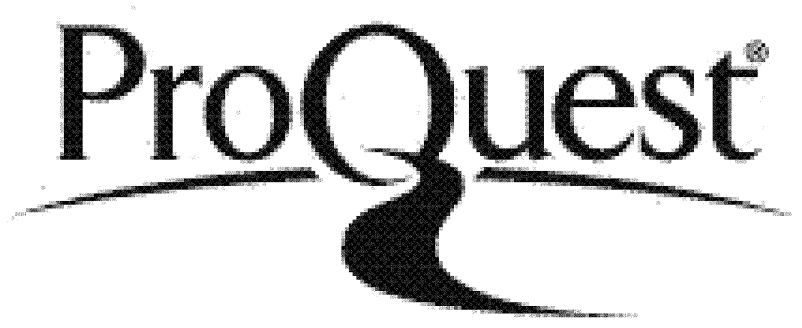

ProQuest LLC

789 East Eisenhower Parkway

P.O. Box 1346

Ann Arbor, MI 48106-1346 


\title{
EMIOTIONAL ABUSE OF CHILDREN: ISSUES FOR INTERVENTION
}

\section{AUTHOR: Celia Doyle}

\begin{abstract}
This study is an examination of the emotional abuse of children, where it is the main or sole form of abuse. The ultimate aim of this applied social work project is to make a contribution to intervention in cases of psychological maltreatment.
\end{abstract}

Intervention lacks credibility without some definition of the problem and an understanding of its prevalence, location and manifestation, as well as an appreciation of the type of intervention required. At the outset of the current project, an exploration of professional concerns, the wider context of child abuse and a review of the relevant literature revealed that, although defining emotional abuse has been partially addressed, there are substantial gaps and deficiencies in the knowledge of the prevalence, location, manifestation and intervention relating to emotional abuse. In order to facilitate intervention, these deficiencies were addressed in the current project.

Both quantitative and qualitative data was required in order to address different aspects of the issues to be explored. Triangulation was therefore an integral part of the design, information being obtained from three sources: semi-structured interviews with child protection professionals, a population survey and in-depth interviews with adult emotional abuse survivors.

The main outcome of the study was an increase in empirical knowledge in the areas of deficit and, consequently, a contribution to credible intervention. Specifically, a suggested operational definition and an indication of prevalence were both provided. Emotional abuse was found to occur in a broad range of families although it was more frequently located in those exposed to multiple stressors. It was most clearly manifested through behaviours which constituted a misuse of power. Concerning intervention itself, a notable contribution of the study was the identification of important life-lines for emotionally abused children. These provided the children with unconditional, positive regard and countered their sense of isolation and rejection.

WORD COUNT: 100,006 


\section{Contents}

ACKNOWLEDGEMENTS

INTRODUCTION AND OVERVIEW

Rationale

Identifying the Issues

i

Objectives

Structure of the Thesis

vii

Theoretical Perspectives

viii

Terminology

ix

Conclusion

CHAPTER 1. CHILDREN AND EMOTION

Social Construction of Childhood

Modern childhood

Children's Needs

Children's Emotional Development

Emotion as a social construct

Overview

CHAPTER 2. HISTORICAL AND POLICY CONTEXTS OF CHILD ABUSE

$\begin{array}{lr}\text { Historical Context } & 18\end{array}$

$\begin{array}{ll}\text { The Roots of abuse } & 18\end{array}$

The 'rescue' model of intervention and state protection 20

The medical model and emergence of procedures $\quad 22$

$\begin{array}{ll}\text { Difficulties and dilemmas } & 25\end{array}$

$\begin{array}{ll}\text { The 'discovery' of sexual abuse and intervention re-evaluated } & 27\end{array}$

Change and the Children Act 1989

Present procedures for dealing with child abuse 32

$\begin{array}{ll}\text { Ecological theory } & 34\end{array}$

Necessary conditions $\quad 36$ 
$\begin{array}{ll}\text { Social Policy Contexts } & 37\end{array}$

$\begin{array}{ll}\text { Four welfare models. } & 38\end{array}$

$\begin{array}{ll}\text { Overview } & 40\end{array}$

CHAPTER 3.THE CURRENT DEBATE ON EMOTIONAL ABUSE 43

$\begin{array}{ll}\text { Terminology } & 44\end{array}$

Issues of Definition $\quad 45$

Abuse or neglect $\quad 45$

Intentional or unintentional harm $\quad 46$

Sustained ill-treatment or a single episode $\quad 48$

$\begin{array}{ll}\text { Present or future harm } & 49\end{array}$

$\begin{array}{lr}\text { Children's or parents' behaviour } & 50\end{array}$

Wide or narrow definitions $\quad 53$

A comprehensive definition $\quad 54$

$\begin{array}{lr}\text { Prevalence } & 56\end{array}$

$\begin{array}{ll}\text { Location } & 57\end{array}$

Social and Cultural Contexts $\quad 58$

$\begin{array}{ll}\text { Type of child } & 59\end{array}$

$\begin{array}{ll}\text { Manifestation } & 61\end{array}$

$\begin{array}{ll}\text { Parental behaviour } & 61\end{array}$

Children's response $\quad 63$

$\begin{array}{ll}\text { Intervention } & 64\end{array}$

$\begin{array}{ll}\text { Overview } & 67\end{array}$

CHAPTER 4. THE RESEARCH DESIGN 70

$\begin{array}{ll}\text { Methodological Considerations } & 71\end{array}$

$\begin{array}{ll}\text { Applied social work } & 71\end{array}$

$\begin{array}{ll}\text { Aspects of the objectives } & 72\end{array}$

$\begin{array}{ll}\text { Researching sensitive topics } & 75\end{array}$

$\begin{array}{ll}\text { Theoretical framework } & 75\end{array}$

$\begin{array}{ll}\text { Funding } & 76\end{array}$

$\begin{array}{ll}\text { Data Sources } & 76\end{array}$ 
$\begin{array}{ll}\text { Data Collection Methods } & 77\end{array}$

$\begin{array}{ll}\text { Samples } & 79\end{array}$

$\begin{array}{lr}\text { Register cases } & 79\end{array}$

Population sample $\quad 82$

Survivor interview sample $\quad 84$

$\begin{array}{lr}\text { Measures } & 86\end{array}$

Register cases: key worker interview schedule $\quad 86$

Population survey: questionnaire. $\quad 95$

Survivor interviews $\quad 99$

$\begin{array}{ll}\text { Ethical considerations } & 100\end{array}$

$\begin{array}{ll}\text { Register cases } & 100\end{array}$

$\begin{array}{ll}\text { Population survey } & 100\end{array}$

$\begin{array}{ll}\text { Survivor interviews } & 101\end{array}$

$\begin{array}{ll}\text { Procedure } & 101\end{array}$

$\begin{array}{ll}\text { Register cases } & 101\end{array}$

$\begin{array}{ll}\text { Population survey } & 103\end{array}$

$\begin{array}{ll}\text { Survivor interviews } & 104\end{array}$

$\begin{array}{ll}\text { Data Analysis } & 104\end{array}$

$\begin{array}{ll}\text { Missing data } & 107\end{array}$

$\begin{array}{ll}\text { The Independent Judge } & 107\end{array}$

Identifying 'Emotionally Abused' Groups 108

$\begin{array}{ll}\text { Register cases } & 108\end{array}$

$\begin{array}{ll}\text { Population survey. } & 109\end{array}$

$\begin{array}{ll}\text { Presentation of Findings } & 111\end{array}$

FINDINGS

PREFACE: SAMPLE PROFILES 113

$\begin{array}{ll}\text { Register cases } & 113\end{array}$

$\begin{array}{ll}\text { Population survey } & 114\end{array}$

$\begin{array}{ll}\text { Survivor interviews } & 115\end{array}$

CHAPTER 5. FINDINGS: EXTENT OF EMOTIONAL ABUSE 116

$\begin{array}{ll}\text { Definitions } & 116\end{array}$

$\begin{array}{ll}\text { Register cases } & 116\end{array}$

$\begin{array}{ll}\text { Population survey } & 117\end{array}$ 
Damaging nature of emotional abuse 123

Emotional abuse as the main form 125

Happy versus unhappy childhood. 126

$\begin{array}{ll}\text { Other Distress } & 127\end{array}$

$\begin{array}{ll}\text { Bullying } & 127\end{array}$

$\begin{array}{ll}\text { Discrimination } & 128\end{array}$

$\begin{array}{ll}\text { Separation and loss } & 128\end{array}$

$\begin{array}{ll}\text { Uncertainty about responsibility } & 129\end{array}$

Categorisation of each sample group $\quad 129$

Prevalence of other forms of abuse 129

$\begin{array}{ll}\text { Sexual abuse } & 130\end{array}$

Physical abuse $\quad 130$

$\begin{array}{ll}\text { Neglect } & 131\end{array}$

$\begin{array}{ll}\text { Overview } & 132\end{array}$

CHAPTER 6. FINDINGS: LOCATING EMOTIONAL ABUSE 135

Type of Child 135

Gender of subjects 136

Age of subjects $\quad 137$

$\begin{array}{ll}\text { Birth/bonding problems } & 140\end{array}$

Ordinal position of subject $\quad 141$

Family Profiles $\quad 142$

Family size $\quad 142$

$\begin{array}{ll}\text { Ages of parents } & 144\end{array}$

Partnerships and caregiver changes $\quad 146$

$\begin{array}{ll}\text { Social support of isolation } & 151\end{array}$

Cultural heritage $\quad 153$

Class dimensions 155

Potential Stressors $\quad 156$

$\begin{array}{ll}\text { Economic status } & 156\end{array}$

$\begin{array}{ll}\text { Accommodation } & 158\end{array}$

Socio-economic deprivation $\quad 161$

Physical disability issues 162

Learning disabilities $\quad 164$

$\begin{array}{ll}\text { Mental health } & 164\end{array}$ 
Substance misuse

Bereavement and loss

Parental experience of childhood abuse

Stressors: an overview

Overview

180

CHAPTER 7. FINDINGS: MANIFESTATION OF EMOTIONAL ABUSE

Parental Behaviour

Categorisation process: register cases $\quad 185$

Types of abusive behaviour

Responsibility

Determining responsibility

198

Responsibility identified

Manifestations in the Children 201

$\begin{array}{ll}\text { General indicators } & 201\end{array}$

$\begin{array}{ll}\text { School career } & 208\end{array}$

No evident 'harm' 211

$\begin{array}{ll}\text { Overview } & 212\end{array}$

CHAPTER 8. FINDINGS: INTERVENTION 214

$\begin{array}{ll}\text { Referral Information } & 214\end{array}$

Person or agency responsible for referral $\quad 214$

$\begin{array}{ll}\text { Reason for referral } & 218\end{array}$

Interventions Offered or Imposed 221

Types of interventions $\quad 222$

Numbers of interventions $\quad 229$

$\begin{array}{ll}\text { Removal and legal intervention } & 231\end{array}$

Registration $\quad 233$

Evaluation of Practice $\quad 234$

Working in partnership $\quad 234$

Anti-discriminatory practice 235

Subjective evaluation of intervention 236

Population survey and survivor evaluations 239 
Life-lines for Children $\quad 240$

Family members $\quad 241$

Schools $\quad 243$

Friends $\quad 243$

$\begin{array}{ll}\text { Professional help } & 244\end{array}$

Religious groups $\quad 245$

Non-human life-lines $\quad 245$

$\begin{array}{ll}\text { Overview } & 246\end{array}$

CHAPTER 9. REVIEW AND IMPLICATIONS

FOR POLICY AND PRACTICE 249

Overview of Issues Relating to the Project Design 249

Overview of Findings $\quad 254$

Definition 254

$\begin{array}{ll}\text { Prevalence } & 257\end{array}$

Location 260

Manifestation 264

$\begin{array}{ll}\text { Intervention } & 267\end{array}$

$\begin{array}{ll}\text { Tertiary/residual intervention } & 269\end{array}$

$\begin{array}{ll}\text { Secondary/institutional intervention } & 271\end{array}$

Primary/developmental intervention $\quad 275$

$\begin{array}{ll}\text { Conclusion } & 277\end{array}$

POST SCRIPT: TOWARDS A PRACTICE GUIDE 281 FOR INTERVENTION

Part 1. Recognition $\quad 282$

Introduction and definition $\quad 282$

Power issues $\quad 282$

Intent $\quad 282$

Cultural aspects $\quad 283$

Emotional distress $\quad 283$

Determining the presence of emotional abuse 283

Part 2. Intervention 292

Registration

Describing and communicating abusive behaviour

Children in need 293

Providing assistance $\quad 293$

Challenging oppression $\quad 293$

Lifelines and supports for children $\quad 294$

Summary of intervention $\quad 294$ 


\section{Appendices}

APPENDIX 1: Inquiry Reports 305

$\begin{array}{ll}\text { APPENDIX 2: Interview Schedule } & 307\end{array}$

APPENDIX 3: Population Questionnaire 312

APPENDIX 4: Practice Guide Evaluation 318

APPENDIX 5: Discriminant Function Analysis: Supplementary Information $\quad 325$

REFERENCES 329 
Figure 1. Emotional abuse: problems of intervention. iii

Figure 2. Theoretical stages of human development. 5

$\begin{array}{ll}\text { Figure 3. Maslow's theory of human need. } & 10\end{array}$

Figure 4. Proportion of respondents in each group. 133

Figure 5. Categorisation of emotionally abusive behaviours 184

Figure 6. Register cases: frequency of types of emotionally abusive behaviours

\section{LIST OF TABLES}

Table 1. Numbers of emotionally abusive experiences recorded by self-defined emotionally abused and final group allocation.

Table 2. Population survey: outcome of negative experiences.

Table 3. Population survey: categorisation into 'Non Abused', 'Other Distress' and 'Emotional Abuse' relating to sample group.

Table 4. Population survey: recall of severe physical punishment by age group.

Table 5. Population survey: age when emotional abuse stopped.

Table 6. All groups: ordinal position of subject child.

Table 7. All groups: numbers of children per family.

Table 8. All groups: numbers of caregiver changes per subject child 150

Table 9. All groups: ethnic origin of subject child.

Table 10. All groups: social class of family of subject child

Table 11. Register cases: estimated income group of carers of subject child. 
Table 12. Population survey: financial situation of respondents' childhood families

Table 13. Population survey: housing problems experienced by respondents' childhood families.

Table 14. Population survey: recorded housing problems in respondents's childhood.

Table 15. All groups: living conditions in the subject child's home.

Table 16. Population survey: Socio-economic deprivation score according to group.

Table 17. All groups: physical disability of a member of the subject child's family.

Table 18. All groups: mental health problems recorded in member of subject child's family.

Table 19. All groups: alcohol problems recorded in member of subject child's family.

Table 20. All groups: incidence of child deaths in subject child's family

Table 21. Register cases: parents' own childhood experience of abuse.

Table 22. Population survey: stressor score by type of stressor on respondents childhood families.

Table 23. Population survey: number of stressors on respondents childhood families.

Table 24. Discriminant function analysis : classification results for unselected cases.

Table 25. Discriminant function : comparison with individual independent variables

Table 26. All groups: person deemed responsible for the abuse

Table 27. Register cases: frequency of indicators in children identified by category 
Table 28. Register cases: frequency of indicators in children by numbers of categories

Table 29. Register cases: profile of school careers of subject child 208

Table 30. Register cases: source of referral by type of child 215

Table 31. Register cases: reason for referral by type of child 218

Table 32. Register cases: overview of interventions offered 229

Table 33. Register cases: reasons for removal from home 231

Table 34. Register cases: legal steps taken 232

Table 35. Register cases: key worker evaluation of the effects of intervention on the subject child

Table 36. Register cases: key worker evaluation of the effects of intervention on siblings.

Table 37. Register cases: key worker evaluation of alternative intervention

Table 38. Practitioners' evaluation of sections of Practice Guide

Table 39. Discriminant function analysis: summary table 


\section{ACKNONLEDGEMENTS}

This study would not have been possible without the help of everyone who provided answers to my questions whether over the phone, in writing or face-to-face. Many social workers generously gave up time which they could ill-afford given the pressured nature of their jobs. Several hundred students sacrificed coffee and lunch breaks to answer questions which for some inevitably awoke painful memories. To all these I am most grateful. But above all profound gratitude goes to the twelve volunteers who allowed me to intrude into their personal lives and who, with such courage, shared their experiences in order to help other children.

I could not have reached the social workers without the assistance of several chairpersons of area Child Protection Committees, Directors of Social Services and other social services managers. Similarly, I would not have had access to students and survivors without the cooperation of the heads of several colleges, deans, course leaders and lecturers. I am deeply grateful to all these key professionals for their permission and help.

Tribute is also due to those important people who gave me assistance with the processes of research and thesis writing. The warmth and encouragement of the staff of the School of Social Work at the University of Leicester has been a sustaining force for the past six years. Particular thanks go to Martin Shaw, Pauline Hardiker and, above all, to Professor Jane Aldgate for her constructive supervision and encouragement. Nene College and its staff have also played a essential role in helping me through the research and writing process. College funding has enabled me to pursue the research more effectively. I very much appreciate the observations and advice of Professor David Briggs, Professor Helen Rainbird and Dr Ian Buchanan.

I am deeply, deeply grateful to Dr Gill Penny who has, with remarkable patience, generosity and wisdom, fulfilled the roles of both supervisor and line-manager.

Finally, my warmest thanks go to my family; to my brothers who have helped me with the vagaries of computers and have been ready at the end of the phone to provide sympathy and advice, and to my mother for her help on the domestic front. Deepest gratitude and affection is reserved for my late husband, John, who despite his failing health so consistently sacrificed his own needs to provide me with moral and practical support, and for my own children whose cheery grins and tolerance of maternal foibles have been such a source of strength and inspiration. 
INTRODUCTION AND OVERVIEW

\section{RATIONALE}

'Emotional abuse' is a child protection registration category (Fogarty 1980, Home Office 1991). It is recorded separately when it is 'the sole or main form of abuse'. Although in England it is one of the smaller categories, it is increasing at a marked rate. The 'emotional abuse alone' registrations rose from 2,800 in 1992 to 4,400 in 1994, an increase of 57 per cent. 'Physical abuse alone' registrations rose in the same period from 9,100 to 10,700 , a 17.6 per cent increase. (Department of Health 1995a). Given this rise in registrations, an increased demand for information from child protection workers is anticipated.

This research underpinning this thesis is a quest for answers, information and understanding relating to emotional abuse. Initially it was prompted by two recent cases. They were separate but similar in that the subjects were girls rejected by their parents when the other children in their families were well-cared for. The rejection manifested itself in a variety of ways including locking the girls away for long periods, constant hostile references to them, refusal to give them any demonstrative warmth, ignoring their birthdays and excluding them from family festivities.

These children and their plight were known to the authorities for seven years in one case and nine years in the second, before their lot was improved. For much of the time intervention appeared to be ineffective. While there were research findings and policy documents directed towards children suffering from sexual and physical abuse or neglect, there seemed little to guide practitioners in cases of 'emotional abuse'. Stern (1987) noted that 'All abused children could be said to be emotionally abused, but, when emotional abuse occurs in isolation, it presents the greatest difficulty in unambiguous diagnosis and this, in turn, renders legal action complex and contentious' (p.38). 
This project is a search for understanding in order to make matters less ambiguous and thereby assist practitioners intervene effectively in cases of emotional abuse where it is the sole or main form of abuse.

This is an applied social work research project, social work being defined, by the Central Council for the Education and Training of Social Workers (CCETSW), as:

... an activity which enables individuals, families and groups to identify personal, social and environmental difficulties adversely affecting them. Social work enables them to manage these difficulties through supportive, rehabilitative, protective or corrective action. Social work promotes social welfare and responds to wider social needs. (CCETSW 1989 p. 8)

Applied social work integrates knowledge from a range of associated disciplines. Accordingly, this project draws particularly on psychological and sociological insights with lesser contributions from commentators from history, anthropology, law and social policy (CCETSW 1989).

\section{IDENTIFYING THE ISSUES}

As a preliminary to the research, following the example of Lourie and Stephano (1978), a workshop was held, attended by nearly thirty social workers and health visitors, in equal proportions, from Northamptonshire. They were asked if they experienced any particular problems intervening in cases where emotional abuse was the sole or main form. They identified a range of problems, summarised in Figure 1. 
Figure 1. Emotional abuse: problems of intervention

* It is impossible to define 'emotional abuse' properly.

* There are no tangible signs.

* Emotional abuse is never a 'one-off'; it is a gradual process so takes a long time to recognise.

* There is no real 'base-line' between what is acceptable and what is not.

* Most parents inadvertently emotionally abuse at some time therefore it is difficult to determine when intervention is needed.

* Most emotional abuse is unintentional therefore it seems wrong to label some parents as emotionally abusive when it is not their fault.

* Distinguishing if a child's disturbed behaviour is due to emotional abuse or to another factor.

* It is difficult to be certain that we not condemning as 'emotionally abusive' cultural, class or minority-group child rearing practices.

* The effects of intervention may be as abusive as the parents' behaviour.

In three subsequent workshops, held in Yorkshire, Kent and Sussex, these issues were examined by multi-disciplinary groups of child protection workers. Most were social or health workers but there were a few education and police representatives. In total, there were just over a hundred participants. They acknowledged the problems identified in Figure 1. But in response to a series of questions, verbally administered by the researcher, there were differences over the issues that caused most concern. For example, the 'no tangible signs' was seen as a problem by only 12 percent whereas most $(90 \%)$ felt that the effects of intervention may be as emotionally abusive as the parents' behaviour. This latter concern indicates that a substantial number of child protection professionals from a range of disciplines doubt the effectiveness of aspects of current intervention. 
The concerns identified in Figure 1 can be classified broadly into three main strands of inquiry. The first is how to define emotional abuse. The second pertains to the difficulty encountered in recognising emotional abuse. The third relates directly to intervention strategies.

While practitioners provided some indicators of issues for intervention, an examination of the wider context of child abuse and its associated literature provided additional ones. Frude (1996) points out that information about a particular syndrome or phenomenon should be "provided systematically to answer the questions: "What is X?" "How common is it?" "How can we identify it?" "What causes it?" and "What can we do about it?" (p.76). This project set out to examine, then present, information which might contribute to answering these questions.

When physical and sexual abuse were 'discovered' from the late 1960s onwards, early concerns focussed on terminology and definition, ie 'What is it?' (Kempe and Helfer 1968, Schechter and Roberge 1976, Kempe 1978). This was followed by attempts to determine the prevalence of the problem ie 'How common is it?' (Creighton and Owtram 1977, Baker and Duncan 1985). Subsequently, there were studies of the characteristics of child abuse. Epidemiological studies (eg Gil 1970, Creighton and Owtram 1977) attempted to identify the types of families in which abuse is most likely to be located. The manifestation of abuse in both parental behaviour and in physical, developmental and behavioural signs in children were also important aspects of research (Meadow 1989a). The examination of location and manifestation reflects an attempt to answer the questions 'How can we identify it?' and 'What causes it?'. Intervention itself, 'What can we do about it?' was also an area of exploration although even by the late 1980s Jones et al. (1987) observed 'There is a paucity of research into effective treatment and intervention methods' (p.31). More recently, however, there has been more research into intervention, particularly in cases of physical and sexual abuse (Gough 1993). All these aspects of the wider context are explored more fully in the discussion of the historical and policy contexts and the current debate (Chapters 2 and 3). 
It seems, from a review of the literature encompassing the wider context, that before practitioners and policy makers can intervene effectively in child abuse cases, several preliminary queries have to be addressed. For this project, five lines of inquiry have therefore been chosen for investigation, with particular reference to emotional abuse. They have been selected on the basis of current practitioner concerns combined with predominant themes within the literature and the wider context of child abuse. The five are: definition, prevalence, location, manifestation and, finally, intervention. The first four areas appear to be necessary preliminaries to a focus on intervention itself. The five chosen do not, however, reflect all possible areas. For example, much of the research especially in relation to sexual abuse has been forensic in nature, ie it has looked at the motivation of perpetrators and the precise nature of 'offending behaviour' (eg Finkelhor 1984). This has not been included in this study because in emotional abuse, compared to physical or sexual assault, the illegality of the abusive behaviour is far less easy to establish.

The five areas identified for examination are detailed below:

Definition: A working definition for the purpose of exploring the issues is required. An ultimate objective will be to suggest an operational definition of emotional abuse for use by practitioners.

Prevalence: There are different implications for intervention if a problem is one that occurs rarely and can be dealt with individually as opposed to one which is widespread and requires both an individualised response and changes in social policy. Therefore it is expedient to establish how widespread emotional abuse is.

Location: It is important to ascertain the location of emotional abuse. Professionals need to know where to look for the problem and where to direct resources. Identifying the location of emotional abuse requires an exploration of a range of factors such as its association with particular types of children or sorts of families or certain social groups. An example of the importance of accurately locating a problem was demonstrated in relation to child sexual abuse. Early studies concentrated on 'father-daughter incest' of 
pre-pubertal and pubertal girls (Nakashima and Zakus 1977, de Younge 1981). Practitioners and theories of intervention (Julian and Mohr 1979, Herman 1981) focussed on this group until experience and research confirmed boys and very young children had been left at risk (Bolton et al 1989, Chasnoff et al 1986, Finkelhor et al 1988).

Manifestation: The fourth area is the manifestation of emotional abuse. The signs of abuse can be detected in either the abusers' behaviour or in the condition and response of the victim, or both. In the recognition of physical abuse, professionals seek clues in parents' behaviour such as overt violence to the child or delay in seeking treatment for injured children. They also look at signs in the victims which can include the nature of any injuries or affective and behavioural signs in the child, such as 'frozen watchfulness' (Speight 1989 p.6). In sexual abuse 'grooming' by perpetrators or sexualised behaviour in victims are both signs (Doyle 1994). Sometimes recognition is based on just one manifestation. However, recognition is usually based on a combination of signs relating to the perpetrators as well as the child.

Intervention: The fifth area incorporates issues of intervention and has two purposes. The first is to address professionals' concerns that the effects of intervention, especially if it involves removal from home, could be more damaging than the original emotional abuse. The second is to identify positive aspects of intervention which can usefully be retained or introduced.

This research project is exploratory, seeking information about the definition of emotional abuse, its prevalence, location and manifestation as well as direct aspects of intervention.. However in relation to current intervention there is inevitably an evaluative process. Research and guidance (eg La Fontaine 1990, Department of Health 1991) relating to child sexual abuse was a necessary response to the fact, established by public inquiry (Butler-Sloss 1988), that practice fell short of a satisfactory standard. The practice experience of the present researcher and the results of the four workshops indicate that intervention in emotional abuse could similarly benefit from additional information and guidance. As an applied social work project it also provides suggestions about the form the guidance might take. 


\section{OBJECTIVES}

In summary, this research has five main objectives:

1. To offer an operational definition of emotional abuse of children;

2. To provide some estimate of the prevalence of emotional abuse, where it is the main or sole form of abuse.

3. To increase understanding of the location and the context in which emotional abuse, as the main or sole form of abuse, occurs.

4. To increasing understanding of the manifestation of emotional abuse in both abusers and the abused.

5. To explore issues of intervention. This includes an examination of current responses and identification of interventions which appear to be helpful, thereby providing guidance for future intervention.

\section{STRUCTURE OF THE THESIS}

The thesis is divided into three main parts. The first sets the research into context. The second is a description of the research design. The third part is a presentation of the findings and a review of their implications. Because this is an applied study, a guide to practice arising from the study has been added as a post script.

The early chapters are concerned particularly with the way key issues are defined and recognised. The ways in which 'children' and 'childhood' are conceptualised are examined because this influences the way that professionals and society respond to child protection issues. Similarly, an exploration of what 'emotion' means when applied to 'children' is necessary because this will affect the concept of, and response to, the 
emotional abuse of younger people. (Chapter 1). This is followed by a recognition of the emerging construct of child abuse. Emotional maltreatment is placed in the context of the general response to child abuse and child care policy (Chapter 2). The current debate relating to emotional abuse, when it is the main or sole form, is examined through a review of the literature dealing specifically with emotional abuse (Chapter 3 ). Details of the research design, evolved from issues emerging from the current debate are provided (Chapter 4). The findings are then presented on the basis of the five themes to be explored: definition; prevalence (estimating the size of the problem); the location (the types of child, parents, family and sectors of society in which it occurs); its manifestation (abusers' behaviour and the response of the abused); and intervention (Chapters 5 to 8). A critical review of the research, reflecting on the implications for future intervention and research is provided (Chapter 9).

Finally, as a post script to the main study, the practical application and guidance for intervention provided by the research findings is considered. This section introduces the idea of a practice guide for child protection workers. The production of a precise practice guide is not an objective of the research. It does however demonstrate one of the tangible ways in which the findings could be applied.

\section{THEORETICAL PERSPECTIVES}

There have been a range of theoretical approaches to child abuse in general although none except ecological theorists (Garbarino and Gilliam 1980) have specifically addressed emotional abuse. Ecological theory (described more fully in Chapter 2) provides the framework for this present project.

The discussion of ecological theory is located within the analysis of historical and policy contexts. This is because theories relating to child abuse have evolved from early ones focussing on the pathology of parents to the later social structural and cultural explanations (Department of Health 1995b). This development of theoretical perspectives, which accompanied increased professional and public recognition of different types of 
abuse, is outlined in greater detail within the historical context of abuse (see Chapter 2). It is acknowledged that models integrating person-centred and societal approaches are now 'broadly accepted'(Department of Health 1995b). Ecological theory, applied to child abuse, is an example of an integrated model because it subsumes person-centred approaches, such as ethological theories of bonding (Kennell et al 1976) as well as societal approaches, such as social structural theories (Gil 1970) focussing on environmental stressors (see Chapter 2 for further explanation).

\section{TERMINOLOGY}

The use of the phrase 'emotional abuse' is discussed in the opening section of the literature review. Some commentators use alternative terms to describe this form of ill-treatment (see Chapter 3). However, emotional abuse is a category on child protection registers (see Chapter 2 for description of registers) and for this reason it is the term adopted throughout this study.

Because this is an applied social work project, it seems judicious to use terms, where appropriate, which are consistent with contemporary laws and procedures. Therefore, in keeping with the terminology used in the Children Act 1989 and in child protection procedures, the word 'child' refers to people aged from birth to seventeen years old. Notwithstanding, the term 'child' - even when freed from the added complexities of distinctions between infant, child and adolescent - reflects a complicated and controversial concept. This concept is further discussed in the next chapter.

The term 'black' with the lower case ' $b$ ' is used throughout rather than the upper case 'Black' which is widely used as a political term to denote all those people who suffer discrimination because of their colouring (eg Ahmad 1990). This usage has recently been challenged and Mason (1995) argues that 'it is doubtful whether it was ever wholeheartedly welcomed by many of those to whom it was intended to refer' (p.17).

Before proceeding further with this study, it is appropriate to comment on the language 
used in this work. Words are powerful tools that can both reflect discrimination and perpetuate it. For example, the constant reference in everyday speech to chairmen suggested that only men could command and control meetings. The constant use of the word 'black' in a negative context has had implications for the way black people are conceptualised (Klein 1985). In these instances there is a clear case for seeking an alternative vocabulary. As far as possible in this study, every attempt has been made to avoid negative, discriminatory terms.

However, there comes a point at which the language will become totally impoverished if every word that has the slightest discriminatory allusion is excluded. It is therefore better to attempt to change the image rather than the word. An example is the word 'case', which could be seen as impersonal and possibly derogatory, but it is a convenient term to describe the unit of study or intervention and can be applied to an individual, family or non-related group.

Finally, words that in one generation have no negative connotation and are not offensive can become discriminatory or insulting in the next. For example the phrase 'colour-blind' - referring to discrimination through ignoring the structural inequalities encountered by black people - was freely used by authors such Dominelli (1988) to challenge racism. However as Preston-Shoot (1995) pointed out, this phrase 'is not acceptable to some disabled people'. It is therefore acknowledged that terms which, at the time of writing this thesis are acceptable, may be unacceptable for readers in the future.

\section{CONCLUSION}

This project emerged from the concerns of the researcher and immediate colleagues, arising from specific cases, about the lack of information and guidance on emotional abuse where it was the main or sole form of abuse. These concerns were echoed and articulated by larger groups of professional child protection workers. These, and additional issues, have also been the preoccupation of commentators examining other forms of child abuse. 
The combination of these concerns and issues provided five themes which formed the framework for the examination of emotional abuse.

The project looks at issues of intervention with the objective of making a contribution to practice. It seeks however to illuminate issues rather than to impose solutions. Although in relation to current intervention there is inevitably an evaluative aspect, this project is primarily exploratory in nature. It explores issues of definition, prevalence, location, manifestation and intervention in relation to the emotional abuse of children. 


\section{CHAPTER 1}

\section{CHILDREN AND EMOTION}

Penhale and Kingston (1995) argue that elder abuse can only be understood in relation to the social construction of old age, 'Currently held ideologies about old age and ageing may create environments which encourage the development and perpetuation of abusive situations' (p.230). A similar view is echoed in relation to domestic violence (Johnson 1995, Imam 1994). Writing for black women subjected to domestic violence, White (1985) notes 'Rigidly defined sex roles, combined with historical traditions that oppress women, contribute to the social acceptance of your partner's abusive behaviour' (p.13). Similarly, Vizard (1989) notes the abuse of people with learning disabilities occurs within a social context which affords them 'low status and marginalisation' (p. 25) while Craft and Brown (1989) add that they 'need services which are able to compensate for their relative vulnerability and lack of status' (p. 76).

These extracts suggest that, in order to recognise, understand and intervene in any form of abuse, the context in which it occurs and the way its victims are viewed have to be identified. The purpose of this chapter is therefore to identify current social constructions of the concepts 'child' and 'childhood' and review contemporary understanding of children's development and needs.

This chapter, reflecting the conventions of social work, draws on perspectives from historical/sociological analysts as well as psychological theories.

\section{SOCIAL CONSTRUCTION OF CHILDHOOD}

A range of commentators (Benedict 1955, Aries 1962, Postman 1983, Hendrick 1990, 1992, Stainton Rogers 1992) have observed that in different times and places young people are viewed and treated very differently compared to contemporary British responses to 'children'. Aries and Postman, for example, argued that young people beyond the 
infancy stage in medieval Europe were treated as 'small adults' with no special identity as 'children'. These writers argue that 'childhood' and the people in this state ie 'children' may be relatively modern social constructs. Pilcher (1995) notes 'Childhood has to be understood as a social construction, as a way of understanding and making sense of the early period of the human life span which varies across cultures and across time' (p.35).

The way that societies, groups and individuals construct childhood will influence views about what constitutes appropriate intervention in the lives of young people. Boyden (1990) illustrates this when she argues how inappropriate the Northern industrialised concept of childhood is when exported to the non-industrialised South. Even within the European context, Solberg (1990) notes, in contrast to accepted views in Britain, Norwegian children from the age of ten are often in charge of the home while their parents work. They are seen as 'responsible, independent and "big"; to some extent they are adult like' (p.135).

The constructed nature of the concept of childhood has inevitable implications for a study on the emotional abuse of children because it will influence views on how younger people should be treated, what constitutes 'ill-treatment' and what is deemed 'appropriate' intervention. Similarly, it will have an impact on the way people, including research participants, evaluate their own as well as other people's childhoods. The following section therefore examines current Western concepts of childhood and children.

\section{Modern Childhood}

Hendrick $(1990,1992)$ argues that the contemporary British concept of childhood is a complex one. He traces how modern childhood has been constructed from different forms in the past two centuries. He notes that earlier in the seventeenth century children were viewed as the depraved inheritor of original sin whose will had to be broken. Towards the end of the century and in the next emerged increasingly more benign concepts of children. Hendrick's view is supported by reference to Locke (1690) who contended that the children were 'blank slates' whose parents have a duty to care for and instruct them 'with 
tenderness and affection' (p.35). Rousseau (1762) went further and argued that children were born innately good. He was 'associated with something more potent and lasting with the whole Romantic conception of children as creatures of deeper wisdom, finer aesthetic sensitivity and a more profound awareness of enduring moral truths' (Grylls 1978 p.35)

Hendrick (1990) observed that by the time of the Industrial Revolution, in contrast to Rousseau's vision, the concept of the 'delinquent' child had emerged. Whether innately good or bad such a child was corrupted by poor environmental conditions in which criminality flourished. There was a major concern about "the "precocity" of working children: [who had] a too detailed knowledge of the adult world and its pleasures' (Hendrick 1990 p.42). Alongside this was "the image of the "innocent" child who needed to have the protection, guidance, discipline and love of the family' (Hendrick 1990 pp.4344). But the family was that experienced by the middle-classes who found the families of the working classes wanting by their own standards. (Hendrick 1990, Gittins 1993).

By the latter half of the nineteenth century there was, according to Hendrick, the growing belief that society needed 'educated men who could be reasoned with' (p. 45). Hence the beginnings of universal compulsory education for all children in the wake of the 1880 Education Act. Gittins (1993) observing the impact of the movement towards universal education comments 'Legislation on education achieved a more rigid and separate definition and concept of childhood and children's dependency' ( p.144).

Hendrick (1990) points to two further constructs of twentieth century children: the 'psycho-medical child' and the 'welfare child'. Gathering the majority of children together in schools revealed the extent of ill-health and malnutrition in the young population. At the same time classrooms gave psychologists and other social scientists a captive population in which to make scientific observations. This led to the rapid expansion of the understanding of child development, educational and child psychology. 
In the modern construct of the child there are echoes of the attitudes to children of the past two centuries including the idea that they are innocent and should be kept in a state of blissful innocence. According to Ennew (1986) the separation of the adult from the child's world can be understood as a period of quarantine where children are kept away from adult infections of sex, violence and commerce. The tension between retaining children's innocence while protecting them from exploitation results, for example, in ambivalence towards self-protection campaigns (Elliot 1985).

Current concepts of children are influenced not only by past constructs but also by what is now known of child development. Different researchers have focussed on various aspects of development (see Figure 2). Freud (1916-17) examined psycho-sexual development. Erikson (1965) provided a lifespan perspective on general personality development. Piaget (1983) was mostly concerned with cognitive functioning, including concepts of moral maturation upon which Kohlberg (1976) built his theories. Donaldson (1992), who extended Piaget's work, provided a broad framework for the development of conscious thought. Harris (1989) has examined emotional development.

There appears to be a consensus that up to the age of about seven years children have some qualitative differences in functioning when compared to older people. After this, however, there is less certainty. The uncertainty has increased due to criticisms levelled at the various developmental theories. For example, Freud's critics have pointed to his theory being based on a false premise that his female victims of incest were fantasising and 'the truly ignorant and offensive ways Freud sometimes analyses women' (Flax 1990 p.50). In relation to Piaget's (1983) theory, the final formal operational stage cannot form a demarcation between child and adult because it does not appear in all cultures (Fishbein 1984, Dasen 1977). Donaldson (1978) and Light et al. (1979) have demonstrated that Piaget had sometimes underestimated children's capacities. Kohlberg (1976) similarly has a number of critics, notably Gilligan (1977) who argues that his stages are based on male perceptions of morality. Other researchers (Colby et al 1983) have shown that many adults do not develop beyond the 'conventional level' reached at about the age of eight years. 
Figure 2. Theoretical stages of human development

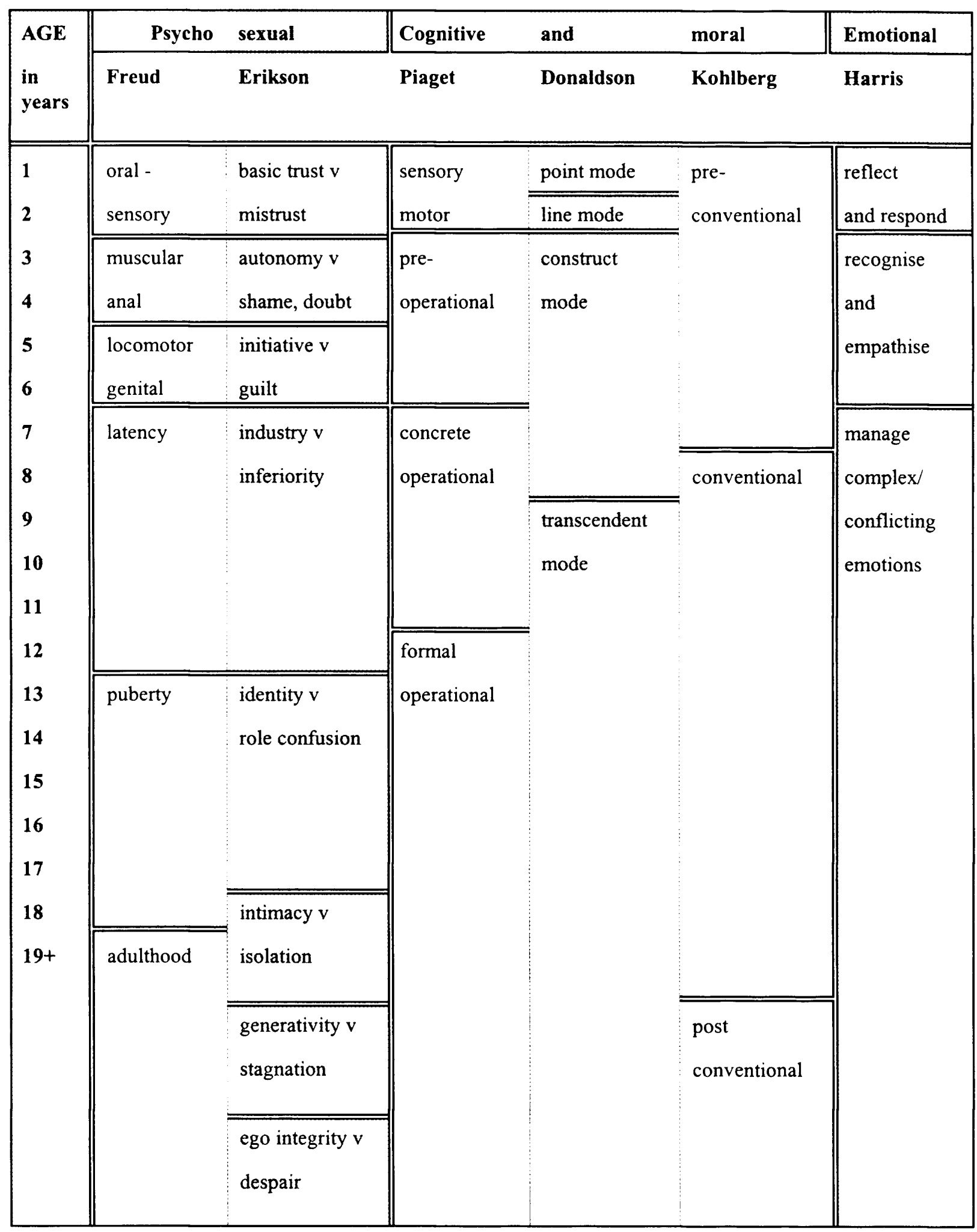


The idea that current concepts of childhood and of children are difficult to identify precisely is further evidenced in Britain by legal difficulties and debate. Pilcher (1995) argues that children are legally controlled in what they may or may not do based solely on their chronological age, while Holt (1975) observes 'we act as if the differences between any sixteen-year-old and any twenty-two-year old were far greater and more important than the differences between someone aged two and someone aged sixteen, or between someone aged twenty-two and someone aged seventy' (p.21). Nevertheless, enshrined in English and Welsh law, in the wake of the case of Gillick $v$ West Norfolk Area Health Authority [1986] A.C. 112, is the idea of 'competency'. A person under 16 has a number of rights such as instructing a solicitor and consenting to, or refusing, medical or psychological examination or treatment whenever they are deemed to have sufficient understanding to make an informed decision (see Masson and Morris 1992 p.130) Other aspects of the complexities of the concept 'child' are reflected in the current debates about the age of consent, particularly to homosexual relations, and the age of criminal responsibility (Pilcher 1995).

Pilcher (1995) illustrates the conflicts in the current social construction of childhood, in some senses children are seen as 'innocent, happy, apolitical, asexual, vulnerable, as in need of protection and dependent' (p.35). In contrast to this there are more negative aspects. The concept of children's lack of competency and physical immaturity has, according to Pilcher (1995), led to the differential distribution of power, responsibilities and resources between children and adults. Despite the fact that they are demarcated from adults by their physical vulnerability, children remain the only citizens who can legitimately be physically assaulted (Children's Legal Centre 1988). Hockey and James (1993), Hillman (1993), Pilcher (1995) and Holt (1975) all point to current negative attitudes to children. Pilcher argues that the positive physiological features of children: health, energy, vitality and enthusiasm are seen as something they will 'grow out of' ( $p$ $35)$. With the exception of health, their other features - energy, vitality and enthusiasm are viewed as disruptive. 
Hockey and James (1993) also argue that groups of people which include children and the 'elderly', who are largely prevented from participating in the labour market, are seen to have a lesser claim to personhood. Sociology books (including Pilcher 1995) and psychological works (eg. Gross 1992, Hayes 1994, Harris 1989) constantly refer to a child as 'it' and yet when writing about adults of unknown gender they will use alternative strategies. This reflects how far children are objectified by society and treated as objects of study by researchers and academics. In relation to social work practice there is the danger that a vulnerable child is treated - inappropriately in the view of Butler-Sloss (1988) - as ‘an object of concern' (p.245).

This objectification of children is reflected in another tension that has not been fully resolved. There still exists 'the basic concept of children as property' (Garbarino and Garbarino 1986 p. 11). In contrast to this, the Arab philosopher, Kahlil Gibran (1923), asserted that children are not property. He wrote:

Your children are not your children.

They are the sons and daughters of Life's longing for itself.

They come through you but not from you, And though they are with you yet they belong not to you (p.81)

\section{CHILDREN'S NEEDS}

The increasing understanding of development in early life, as summarised in Figure 2, has benefited the youngest people in society through the identification of their vulnerability and lack of capacity. Just as greater knowledge of mental ill-health, disease processes and learning disability can lead to more humane treatment of people affected by these conditions, so children's limitations can be treated with more consideration. The theories of Freud, Bowlby and Piaget, for example, all emphasised the immediate and longer term benefits of a psychologically nurturing early environment. Applied to practice, theories such as these have, for example, led to the abandonment of huge, mechanistic residential institutions which provided adequate physical extra-familial care for children but failed 
to address their emotional requirements. 'The large institutions have already disappeared or will soon disappear - and not only in Western Europe' (Gottesman 1994 p. 4).

Nevertheless, research directed towards identifying children's psychological needs has not been without controversy and contradictions. Freud (1916-17) advocated the presence of both parents, arguing that this met children's need to work satisfactorily through specific psycho-sexual developmental stages. In contrast, the work of Bowlby $(1951,1965)$ and Winnicott (1964) emphasised the importance to children of a secure attachment to a mother figure, with the father only required to 'support the mother emotionally' (Bowlby 1965 p.14). Subsequent research (Tizard and Hodges 1978) appeared to confirm Bowlby's theory that the failure to meet early needs for 'attachment' led to disturbed behaviour in later life whereas more recent researchers have emphasised the need for emotionally nurturing fathers and other carers as well as a lone 'mother figure' (Rutter 1981, Chibucos and Kail 1981, Lewis 1986, Lamb 1987).

Subsequent to Bowlby's revelations about the need for a secure attachment figure, professionals concerned about child welfare looked beyond this basic attachment requirement to other needs. Kellmer Pringle (1974) identified four main ones: for love and security; for new experiences; for praise and recognition; for responsibility. The Royal College of Psychiatrists (1982) identified five: physical care and protection; affection and approval; stimulation and teaching; consistent, age-appropriate discipline and control; the opportunity to acquire autonomy. Cooper (1985) extended this list to seven adding 'security' and substituting two separate ones 'responsibility' and 'independence' for the 'opportunity to acquire autonomy'.

Nevertheless, theories of child development can be used to construct an ideology of children as less than fully human, half-formed and therefore not requiring all the rights and dignity accorded to 'adults'. Holt (1975) talks of modern children being regarded as 'a mixture of expensive nuisance, fragile treasure, slave and super-pet' (p. 22). A recognition of children's needs can lead to a benign commitment to provide what is required. But if children are seen as having special needs which are different from general human needs, 
the construction of children as not fully human will be perpetuated. Harding (1991), reviewing Kellmer Pringle's model, notes '[Children's] psychological needs are constructed as somewhat different from those of adults ... The emphasis on children as psychologically different from adults means that their rights are also different from adult rights' (p.71-72). Harding (1991) explains that this can lead to a fundamental denial of human rights, reinforcing the view of the child as not fully human.

A further concern, raised by Woodhead (1990), about the concept of separately identified children's needs is that if concepts of childhood and children are socially constructed then the idea of their needs is also socially constructed. Woodhead adds:

Children's psychological needs are at the heart of contemporary public concern ... It is widely regarded as a progressive and enlightened framework for working with children ... My conclusion provocatively, is that our understanding and respect for childhood might be better served if 'children needs' were outlawed from future professional discourse.

Another problem associated with Kellmer Pringle's identification of needs is that it fails to embrace all children. She states that the need for praise and recognition is required in order to grow from 'a helpless infant into a self-reliant, self-accepting adult ...' (1974 p.28). If children need praise solely in order to develop into satisfactory adults, then the logical conclusion is that those with terminal illnesses and limited life expectancy do not require praise and recognition. Similarly the 'need for responsibility' appears to exclude children whose learning or physical disabilities are so severe that they are never likely to exercise responsibility for other people. These young people are in danger of being excluded from the discourse if children's needs are only judged by their long-term consequences rather than 'here and now' quality-of-life considerations.

An alternative strategy is to adopt a model of 'human needs' which can be seen to be universal and then to proceed to identify the appropriate mechanisms by which these are met depending on age, cultural context and capability. For example, the need for nutrition is through milk for the neonate or through highly spiced food for older people in some cultures and blander fare in others. 
Turning to recent needs concepts, Doyal and Gough (1991) reduce basic human needs, on a cross-cultural basis, to two: health and autonomy. But this reductionist approach does not provide a particularly useful framework for child protection workers. Maslow's (1970 pp.35-46) identification of human needs provides a more functional and detailed structure. His theory is summarised in Figure 3.

Figure 3. Maslow's Theory of Human Need.

NEED FOR SELF-ACTUALIZATION

Self-fulfilment, 'becoming everything that one is capable of becoming'

ESTEEM NEEDS

Firmly based, usually high, evaluation of self, respect of others, self-confidence.

BELONGINGNESS AND LOVE NEEDS

Affectionate relationships with people in general, roots, origins, love.

\section{SAFETY NEEDS}

Security, stability, protection, freedom from fear, from anxiety and chaos; need for structure, order, law, limits.

PHYSIOLOGICAL NEEDS

Hunger, sex, thirst, physical homeostasis.

In order to operationalise the above model (Figure 3) in work with children some modification is required. Maslow (1970) believes that self-actualization is a characteristic of maturity. His examples of people who he believed achieved self-actualization (p.152) were mainly aged over 60 and were also nearly all men. This is not therefore likely to be a useful concept when applied to younger people of both sexes. In terms of children, 'fulfilment' may be a more appropriate term and concept than 'self-actualization'. The 
need for fulfilment may be met, particularly in babies and younger children, by enabling them to reach their developmental potential or 'milestones', whereas for older children and adolescents a sense of mastery and self-fulfilment may be as important.

The capacity of children to recognise emotions in themselves and respond to those felt by others (summarised in Figure 2) requires examination because without this capacity concepts such as a 'sense of mastery', 'self-fulfilment' or even 'emotional abuse' itself would have little meaning. The following section therefore discusses current understanding of the way children's emotional capacities develop.

\section{CHILDREN'S EMOTIONAL DEVELOPMENT}

Montessori (1970) observed 'Generally we tend to consider the [young] child as a physical vegetable' (p.33). She continued:

It is clear that those of us who thought that the only utilizable psychological facts were those pertaining to the conscious mind and to linguistic expression must have thoroughly neglected the very young child. The conviction that nothing can be offered the infant except physical care has obscured facts of the greatest importance (p.118).

Darwin (1872), observing his son, hypothesised that babies have an innate ability to recognise emotions in others. Subsequent researchers have shown that there appears to be universal and innate expression of emotions (Harris 1989). Experiments have also shown that young babies can connect disparate signs - such as the sound of laughter with a smile - of the same emotion. (Walker-Andrews 1986). Reviewing the research, Harris (1989) asserts 'from about ten weeks, babies appear to react differently and appropriately depending on the emotion that the mother expresses' (p.19)

There is evidence that before the end of the first year babies are also influenced by the caregivers' display of emotion. Klinnert (1984) showed that babies would be less likely to approach a new toy if their mothers looked fearful. Similarly Sorce et al (1985) 
replicated the 'visual cliff' experiment of Gibson and Walk (1960) in which babies were encouraged to crawl over glass which appeared to be a steep drop. When babies were unsure about whether to cross it, most crawled across if the mother smiled but did not do so if she seemed apprehensive.

Dunn et al (1981) noted that children of two to four years of age frequently comforted a baby sibling. By 14 months the younger children actively sought comfort from their older siblings and some would reciprocate by giving consolation. Children of this age also attempted to offer solace to parents. This demands the memory and the recognition of what was soothing in the past plus an ability to anticipate that this will console the other person.

Dunn and Munn's (1985) research also showed that very young children are capable of quite sophisticated teasing, such as taking away a sibling's 'comforter'. This again requires a degree of strategic planning as well as a recognition of what will distress another person. It also appears that even very young children can recognise another person's distress without feeling the same upset and generally they can recognise feelings in other people that do not mirror their own. For example, in Harris' (1989) experiment, children of three could recognise that an elephant character Ellie, who liked milk, would be happy if she found milk in a bottle, even if the children themselves preferred coke. By six years old, most children could also recognise whether or not Ellie would be disappointed if she was expecting something else.

These various researchers also demonstrated considerable differences between children. Dunn and Kendrick (1982) noted that those children who seemed to delight in teasing rarely offered comfort. Harris (1989) concludes some differences may be due to whether or not children have been physically mistreated by carers. In his studies, abused children at best 'mechanically patted' another distressed child although more frequently they became hostile or upset and fearful themselves. Sometimes they alternated between attacking and comforting the child. 
Babies and younger children can show ambivalence such as that shown by one-year-old babies towards a parent who is temporarily absent as observed by Ainsworth (eg Ainsworth and Wittig 1969) in her attachment studies. However, Harter and Buddin (1987) noted that young children under about six, while able to show ambivalence, are unable to cope with the idea of two basic feelings occurring simultaneously. This capacity is not shown until they are aged about eight years. This has implications for those working with abused younger children because, while they may have every reason to harbour strong feelings, they may not be able to describe or acknowledge feelings of both anger and love towards their caregivers.

Harris et al (1987) demonstrated that, while children aged about five could identify and discuss simpler emotions like happiness, those aged about seven added more complex ones such as guilt and pride. Children over 10 years identified increasingly subtle emotions like relief.

There are also age differences in the experience of shame and guilt. Most young children have little sense of shame about stealing as long as there are no adverse repercussions. By the age of six, they sense shame if someone else knows what they have done. By about eight years old. they acknowledge they could feel ashamed of themselves without anyone else being present to condemn them. But there are variations between individual children even within these age bands. Hoffman and Saltzein (1967) noted that children whose parents use reasoning and explanation in preference to punitive methods are more likely to experience and confess guilt.

Another complexity of emotion is the difference between experiencing a feeling and displaying it. In a study by Cole (1986), girls as young as three concealed their disappointment at receiving a disliked present when in the presence of the donor but openly expressed dissatisfaction in the donor's absence. In a similar experiment, Saarni (1984) showed that girls were more likely than boys to hide their negative feelings. Similarly, older children, aged about 10, were more likely than younger children to conceal disappointment and more aware that they were doing so. In a study by Gross and 
Harris (1988) it became apparent that children as young as six have an ability to understand that not only can people hide their feelings but other people will be deceived by this. 'This insight required considerable conceptual sophistication. It requires the ability to work simultaneously with two different views of what is going on: a view of the actual state of affairs, and also of the state of affairs that is apparent to an onlooker' (Harris 1989 p. 140).

A further level of sophistication is the ability not just to control the expression of emotions but the emotions themselves. Harris (1989) found that children as young as six can think of ways of making themselves feel happier when they are ill by engaging in strategies such as play to distract themselves. By the time children are ten, they can think more systematically of ways of changing their emotions. Harris' interviews with boys aged eight sent to boarding school demonstrated that they had a wide range of strategies for dealing with homesickness. He concluded:

Boarding schools may have a long-term impact on the emotional lives of their pupils ... they foster in some children a particular style of coping whereby distress ... is actively suppressed from consciousness rather than confided (p.169).

Research to date is showing that any concept of the child as a 'physical vegetable' is untenable even in the youngest infants. What all these studies show is that children from a very early age have a remarkable degree of sensitivity to emotions in themselves and others.

\section{Emotion as a social construct}

Postmodern social constructuralists (Rosaldo 1984, Lutz 1988, Gergen 1991) argue that emotions are so closely related to social norms that they are culturally variable social constructs rather than a universal experience of feeling. Gergen (1991) cites as an example the emotion 'liget', an anger/yearning/energy among males from the Ilonget tribe that has no apparent Western equivalent.

However, Harris (1989) argues that 'children do not begin their emotional lives by learning 
a script from their culture. They are born with the capacity to experience basic emotions' (p.103). There has been a wealth of research evidence that basic emotions are universal and therefore not just a social construction (Ekman 1971, Eibl-Eibesfeldt 1975, Woodhead et al 1995).

Children may learn different cultural emotional displays and different mechanisms for controlling emotions, as Harris' boarding school study showed. Even different sectors within a culture may have to follow different rules, for example nurses and doctors are expected neither to feel nor to express panic at the sight of blood (The Lying Game, BBC1 29 May 1997). It appears that generalisations can be made about children's emotional experiences but account must also be taken of their cultural context.

Account has also to be taken of other individual differences. The emotional impact and response of each child will also depend on the environmental context and on the child's temperament. Studies (Thomas and Chess 1977, 1982, Buss and Plomin 1984, Earls and Jung 1987, Kagan 1988, Maziade et al 1989) have demonstrated that children display temperamental differences from birth and these show stability into middle childhood and beyond.

\section{OVERVIEW}

This chapter has introduced the concept that there are widely differing views of children and childhood. From one perspective children are seen as innocent and special, requiring a childhood in a caring family and to be uncontaminated by the adult world. Other perspectives are more negative with children seen as objects, subhumans, disruptive nuisances or parental property. Even the scientific study of children provides only qualified answers about the nature of children and childhood. There are contradictions and possible deficiencies in the various developmental theories. Moreover, some psychologists take a life-span perspective, identifying qualitative developmental changes, including cognitive ones, throughout life (Arlin 1975, Vygotsky 1978, Baltes et al 1980, Kohlberg and 
Ryncarz 1990, Fischer et al 1990). The result is that it is difficult to achieve a general consensus about the appropriate biological, psychological or social divide between 'children' and 'adults'.

The implications for child protection workers is that different people even within the same society or culture, and certainly between societies or cultures, will have very different views of how children should be defined and treated. Furthermore, concepts of child and adult are constantly changing. In addition there is doubt about whether or not it is possible or even desirable to identify specific children's needs. This uncertainty and the various differences of perspective mean that intervention in the lives of younger people will be fraught with difficulty. It also means that child care policy and protection will be a far from exact science.

In conclusion, modern children are set apart from adults, made objects of study and concern and relegated to a state of relative powerlessness. They have an evident capacity to recognise and respond to emotions from an early age. They experience developmental changes and have substantial needs although how far developmental stages and needs, particularly in older children, can clearly be distinguished from those of adults is a matter of debate. Intervention in the lives of children will evidently be influenced by the way they are viewed and their development and needs understood. The present research was undertaken against the background of the recognition that key concepts are subject to change and reconstruction. This includes the concept of 'child abuse' itself which is explored further in the next chapter. 


\section{CHAPTER 2}

\section{HISTORICAL AND POLICY CONTEXTS OF CHILD ABUSE}

The preceding chapter explained how it can be argued that the concepts of 'child' and 'childhood' are socially constructed. Similarly, 'child abuse' can be viewed as a social construct. Hallet (1995) explains that this is not to deny the reality of children suffering at the hands of adults but rather that 'which may have been long experienced as private pains of sorrows, become defined as public ills' (p.23). This chapter traces the way in which child abuse has been constructed. It surveys the different responses to abuse over recent decades. It looks at the way that different causal theories of child abuse have emerged and have been revised in the light of increased knowledge. The last section on policy contexts looks at how intervention may be influenced, not just by differing constructs, but by different approaches to public policy. These are themselves influenced by alternative constructs of child, childhood and abuse.

Since the 1960s, there has been an 'outpouring' of works on child abuse and 'many hundreds of new papers are published annually' (Jones et al 1987 p.31). This chapter can only review some of these writings. Reports of public inquiries into child deaths and maltreatment have provided major contributions to the debate on child abuse. The issues raised by many of these reports will be discussed. A full list of the reports is provided in Appendix 1.

Differing perceptions of child abuse will have an impact on the definition, identification of prevalence and recognition of emotional abuse and as a consequence will influence intervention. As Manning (1985) states, social problems are not just 'what people think they are but rather what powerful and influential people think they are' (p.5). It is therefore necessary to see how far powerful sectors of society have conceptualised child abuse in general and emotional abuse in particular. It is also important to recognise the different perspectives of policy makers. Among the more powerful and influential sectors in society are politicians, legal and law enforcement agents, professional groups and, within limitations (see McDevitt 1996), the news media. 


\section{HISTORICAL CONTEXT}

The history of child abuse has been detailed by a number of commentators (Parton 1985, Vizard 1987, Parker 1995). The purpose of this chapter, therefore, is not to provide a general historical perspective on child protection. Instead it offers a background history against which intervention issues relating to emotional abuse can be more readily understood. As Milliham et al (1986) observe 'it is difficult to understand the present without, at least, some glimpse of the past' (p.13).

By tracing political, public and professional attitudes to child protection, it is possible to identify the changing social construction of the concept of 'child abuse'. This section locates the debate on emotional abuse in the wider discourse on child protection. A further objective of this section is to demonstrate how far issues relating to intervention in child abuse cases have encompassed cases of emotional abuse.

\section{The Roots of Abuse}

Hallet (1995) notes that to claim that child abuse is a social construction is not to deny that the abuse of children has probably always existed. Child abuse shares the dynamics common to all forms of oppression. Studies have shown that wherever there is an imbalance of power between two or more parties there is the potential for injustice and oppression . For example, in relation to racism, power 'is a crucial concept in race and ethnic relations' (Cashmore 1988 p. 226). Similarly, in relation to both elder abuse and domestic violence commentators have noted that the greater the dependence the greater the risk of serious assault and other maltreatment (Johnson 1995). Thompson (1993) describes the mistreatment of children as 'the abuse of parental power, or the power of adults over children in general'(p.45).

Six main sources of power are identified by Handy (1985). His analysis which relates to organisations can be transferred to wider society. The most commonly abused sources of power are physical, position and resource power although people who exploit others may rely on forms of expert power. Others use personal magnetism or subversion to 
disempower others.

In abuse cases, the power holders are motivated to misuse their power. The reasons for this are varied. They may boost their own sense of mastery by wielding a petty tyranny over others using 'ways of instilling fear and coercing compliance' (Mullender and Morley 1994 p. 7). They may have a 'history of socio-pathic behaviour' (Phillipson and Biggs 1995 p.231) At the other end of the spectrum they may be in state of extreme stress and find relief in acting out their tensions against people too weak to retaliate or protest (Eastman 1994, Hocking 1994).

Potential abusers are only able to mistreat those whom they regard as 'inferior' or less than human. Writing of sex abusers' attitudes to their victims, Mezey et al (1991) record 'Generally, the men were unable to see these children as having separate personalities with their own needs, feelings and wishes. The children were either narcissistically identified with as extensions of themselves or were simply "objects". One man described his daughter as "a blob" (p.16). In relation to those who abuse people with disabilities, Walmsley (1989) notes that society tends to 'perceive handicapped people as inferior and not having the same rights as everyone else. Transgressing normal boundaries thereby becomes less of an issue'. Hostage takers similarly objectify their hostages in order to use and abuse them to achieve their ambitions. (Miller 1978 p.133). The Holocaust, Die Endlosung, could only happen because Jews and other minority groups were portrayed as subhuman (Hull 1969, Cashmore 1988).

A 2nd century Chinese poem The Orphan by an anonymous writer gives a catalogue of mistreatment of an orphan at the hands of his older brother and sister-in-law and illustrates the existence of abuse throughout time, place and culture:

My tears flowed continually.

Since alive, I was not happy

It were better to die ...

I want to send a letter

To my father and mother beneath the earth

'My brother and sister are hard to live with for long'. (Davis 1962 pp.iii-iv). 
Children by their small physical size and their general lack of experience of life can readily be overpowered. 'The dramatic imbalance of power and socially sanctioned routine subordination of children means that they are often malleable "objects of victimisation", (Kitzinger 1990 p.163). It seems probable that there have always been instances of people, including some parents, who taking advantage of their superior power, have mistreated children.

Nevertheless, ancient writings extol the care provided by parents (Mascaro 1962 p.81) and contain injunctions to care for vulnerable children (Orchard and Fuller 1966 p.65, Dawood 1990 p.61). Meanwhile, revisionist historians (eg Pollock 1983, Shahar 1990, Grylls 1978) have rejected the concept of de Mause (1976) that, in the past, adults were universally cruel or, at best, ambivalent to children, and are only now motivated to socialise and help them. Boswell (1989) pointed out 'Romans looked up to see, in the centre of their city the statue of a wolf who had suckled two abandoned children... Kindness to abandoned children, their culture subtly insisted, resounds to everyone's glory' (p.433). Shahar (1990) provides eloquent testimony to the care and kindness of medieval parents, and wider society, towards young children. Despite this, systematic and comprehensive, legally sanctioned state protection of children has not been in evidence prior to the twentieth century. It is this modern policy that is discussed in the following sections.

\section{The 'Rescue' Model of Intervention and State Protection.}

Many commentators trace the origins of modern state child protection policy to the developments in the nineteenth century (Jones et al 1987, Reder et al 1993, Parker 1995). Initial concerns were for children outside the parental home or who were orphaned. But there were mounting concerns about children in the domestic situation. In the 1870 s and 80s animal welfare workers like Berg and Gerry in America and Samuel Smith in England used animal protective legislation and resources to protect children from abuse in domestic setting (Weddell 1958, Lazoritz and Shelman 1996, Behlmer 1982). 
There are, for the purpose of the present research, several relevant features. Firstly, child protection policies can trace their roots to animal protection work and consequently the 'rescue model'. The social construct of child abuse was that of overt child 'cruelty' in which parallels in domestic animals could be found. This meant that there was little consideration of the subtleties of emotional abuse as the sole form of abuse. Secondly, child protection was left largely to voluntary agencies such as the National Society for the Prevention of Cruelty to Children (NSPCC). Apart from providing a legal framework within which voluntary organisations could operate, the state did not take a prominent role. Thirdly there was still a reluctance to believe that children could be mistreated by their natural parents. This led to the emergence of causal theories attributing child abuse to parents who were dissolute and criminal, hence the prosecutory powers of the NSPCC, or mentally ill, hence the Infanticide Act of 1938 (Jones et al 1987 p. 44). This developed into the 'psychopathic' theoretical causal model (Department of Health 1995b).

Parker (1995), Behlmer (1982) and Harding (1991) give an account of child protection between the two wars as a period with few relevant developments except the 1933 Children and Young Persons Act. Although there was concern with children's physical fitness and moral environment, 'children were not a major focus of government policy' (Harding 1991 p. 89). But a change in direction in child care and policy was highlighted by the case of Dennis O'Neill. The resulting 1949 Monckton report (Appendix 1) and Curtis committee deliberations were 'followed by the Children Act of 1948, which for the first time established a social service specifically for children who for various reasons were unable to live with their parents under normal home conditions' (Leeding 1976 p.1).

There were now agencies concerned primarily with child care and protection in both the voluntary and state sectors. Although the new state child care officers were primarily concerned with the welfare of children in local authority care, they were increasingly intervening to prevent family breakdown (Willmott 1967).

Throughout this period, there was concern about the emotional wellbeing of children. The main focus was on 'maternal deprivation' (Bowlby 1951, 1965, Rutter 1981). Fyvel 
(1961), for example, directly attributed the increase in 'juvenile delinquency' to working mothers through maternal deprivation (see pp 127-130). This period also saw the growth of the child guidance service for emotionally troubled children (Willmott 1967)

\section{The Medical Model and Emergence of Procedures}

The next landmark case was that of Maria Colwell (Appendix 1). There were several developments which converged just prior to Maria's death and explain the response to the case. The first was the gradual identification of the 'battered-baby' syndrome (see Jones et al 1987); a term used 'to characterize a clinical condition in young children who have received serious physical abuse, generally from a parent or foster parent'. (Kempe et al. 1962 p.17).

At the same time, adult psychiatry was improving medical intervention for mothers suffering from post partum psychoses, 'the present fashion of treatment is to admit both mother and child to hospital and encourage mothering to continue under supervision' (Anderson and Trethowan 1967 p.210). Increasingly there was the belief that the 'batteredbaby syndrome' could be similarly identified and treated, before children were seriously injured or killed, by medical management.

The focus at the time on the maltreatment of babies coinciding with Bowlby's (1951, 1965) theories of maternal attachment and Harlow's (1959) primate studies led to causal theories based on ethological observations of poor bonding between parents and their newborn offspring (Kempe and Helfer 1968, Lynch and Roberts 1977, Kennell et al 1976, Jinadu et al 1982). But as Harding (1991) notes the dominance of medical practitioners in child abuse cases at this time ensured that the focus on the pathology of individual abusers remained.

Although the management throughout Britain was primarily medical, the need to include the social services, NSPCC and police was recognised. A 1972 Government (DHSS) circular The 'Battered Baby' syndrome' recommended case conferences to coordinate professional involvement. When a baby, Graham Bagnall died at the hands of his parents 
two subsequent inquiries (Appendix 1) identified shortcomings such as failures by the health services to communicate effectively and the confusion of roles between the social services and the NSPCC.

The first Bagnall report (Appendix 1) made it clear that the social services had a primary responsibility for the care and protection of children. However, at the time, the social services were in the middle of a major upheaval with separate welfare services becoming 'a unified social service department' (Seebohm 1968 p. 44). Social workers were no longer specialist and became 'generic', taking on a mixture of client groups.

It was in this climate that details of the death of Maria Colwell emerged. There was considerable publicity given to the case. The social worker was vilified and physically assaulted in the street (Jones et al 1987). The case 'became front page news and the effect of this and a succession of later enquiries was to have a profound effect on popular and professional consciousness' (Hallet 1995 p.26). It has left social workers with a legacy of fear of public vilification and exposure (Parton and Thomas 1983).

Maria was aged eight when she died. This brought schools and educational psychology services into the forefront of child protection work. The change of focus from abuse to babies to children of all ages lead to the emergence of new causal theories. They remained person-centred but were no longer narrowly confined to ideas of mother-infant bonding. Instead, based on psychodynamic and social learning theories (see Bandura, 1965, 1973, Browne and Lynch 1995, Muller et al 1995, Cerezo and D'Ocon 1995), the idea of a cycle of abuse handed down from one generation to the next emerged.

In the wake of the Colwell case and associated developments, there were a number of procedures which, with modifications, are still in existence. They were designed so that all the agencies - educational, social services, medical and police - worked together. Area Review Committees of senior personnel from the key agencies were formed, based on local authority areas. They were charged with drawing up procedures, including the registration of children deemed to be the subjects or potential subjects of physical abuse. 
Subsequently, the NSPCC estimated in 1977 that 4,700 children in England and Wales, aged 0-14 per year were physically abused by their parents but by 1986 that estimate had risen to 9,590 (Taylor 1992). The idea that children were safe in their homes was diminishing. The substantial increase in numbers of reported cases can be accounted for in several ways. After the publicity of Maria's death there was heightened public and professional awareness of child abuse. There was now a mechanism for managing cases and the register meant that injuries and killing of children were formally recorded as child abuse cases. Prior to this they may have been constructed differently. For example, in Lincolnshire in 1972, when a mother drowned her three children in the local river it was construed as an adult mental health problem rather than a child care one.

As more cases were reported, the boundaries of what constituted abuse enlarged. No longer were children seen to be just 'battered'. The next child to be subject to a public inquiry, David Naseby (Appendix 1), was originally taken to hospital with scratches. Scalds, burns, bites, shaking sequelae, suffocation and poisoning were all being presented as child maltreatment. Recognition was given to Munchausen syndrome by proxy, the term describing "children whose mothers invented stories of illness about their child and substantiated the stories by fabricating false physical signs' (Meadow 1989b p.37).

By the mid-1970s the term 'non-accidental injury' was substituted for 'battered-baby'. There was also a growing recognition of physical abuse by acts of omission, that is 'physical neglect'. The first death through neglect examined by a public enquiry was that of Steven Meaurs (Appendix 1). It was increasingly appreciated that extensive injuries can be caused by acts of omission. This is illustrated in a recent inquiry report into the death of 'Paul'; 'Photographs taken after his death show burns over most of his body derived from the urine staining, plus septicaemia with septic lesions at the ends of his fingers and toes'(Bridge Child Care Consultancy 1993 p.7)

The fact that children were now registered meant that identified cases could be subjected to scrutiny. Gil (1970) discovered in his research in the 1960 s that children on the 
American Child Protection Registers (solely for physical abuse and neglect in that decade) came from the poorer socio-economic classes. He advocated a social structural causal theory, arguing that child abuse is not the result of individual pathology but of the structural inequalities and deprivation suffered by many families. Pelton's (1978) studies led him to a similar conclusion. He argued that the 'myth' of the classlessness of child abuse and neglect serves to support 'the prestigious and fascinating psychodynamic medical model approach' (p.613). There appeared now to be two causal theoretical perspectives which were in direct opposition and seemed irreconcilable. One perspective espoused by psychodynamic theories located the cause of abuse in the individuals involved and the other, advocated by social structuralists such as Gil and Pelton, located it in adverse environmental and societal conditions.

The focus at this time was almost exclusively on the physical aspects and ramifications of abuse and neglect. Emotional abuse or even the emotional consequences of physical abuse and neglect rarely formed part of the child protection discourse. There were some exceptions such as the study of 'consciously rejected children' by Pemberton and Benady (1973) and the focus on abuse linked to emotion and development by Helfer et al (1976). Notwithstanding, even as late as 1987, Jones et al identified the 'definition, characteristics and incidence' of emotional abuse as one of the subjects which seemed 'ripe for further study' (p.40).

\section{Difficulties and Dilemmas}

Although there was increasing experience among social workers in dealing with cases of physical abuse and neglect, difficulties remained. A major one was highlighted by the Lester Chapman Inquiry (Appendix 1). Aged nine, he ran away from home for the fourth time after having been physically injured and died trapped in a sewage sludge. The report commented on the failure of professionals to define his injuries as abuse. They 'would have amounted to the offence... of causing grievous bodily harm, had they not been in the course of chastisement by a mother of her son'. (Berkshire County Council 1979 p.42-43). This shows it was, and is, very difficult for child protection workers to decide the baseline between 'lawful' parental behaviour and abuse. 
The case of Lester Chapman is significant for another reason. This was largely a case of emotional abuse (Jones et al 1987). He did not die through direct physical assault or neglect. It was his deep unhappiness caused by intimidation, stress and being used as a weapon in the parents' marital battles that led him to run away on one of the coldest nights of the year with no thought for his personal safety or survival (Reder et al 1993). Despite this, there is little evidence that the debate about emotional abuse gathered even a fraction of the momentum that accrued to physical abuse in the wake of the Colwell and Beckford cases or to sexual abuse as a consequence of the Butler-Sloss (1988) inquiry.

Meanwhile another dilemma emerged. There was increasing concern, influenced particularly by social structural theorists such as Gil (1970) and Pelton (1978), about the imposition of the standards of one part of the community on another. Professionals, who were by definition middle class, were charged with imposing their own standards in judging working class families whose child care practices may be different from middle class ones but no more abusive.

The desire not to be judgemental led to the failure to protect some children. The Malcolm Page inquiry illustrates this. Mr Page was a stock controller and 'was not rich, but had enough money to care for his family' (Denham 1981 p.12). Both health visitors and social workers visited regularly while Malcolm died of neglect and starvation. They were eager not to impose 'middle-class' standards. But investigating Malcolm's death the police faithfully recorded the dire standards in the home which were seen as unacceptable by the subsequent inquiry.

There were similar concerns about imposing cultural standards on minority ethnic groups. The reports on Jasmine Beckford, Tyra Henry and Sukina (see Appendix 1) all indicate how this can leave black children unprotected:

We know from experience that agencies that are moving towards trying to be more sensitive and understanding towards the racial and cultural needs of their client group, do risk failing to recognise the particular needs of an individual child. (Bridge Child Care Consultancy 1991 p. 84). 
Another dilemma for child protection workers was how to distinguish between an accident and non-accidental injury, between intent and ineptness. The debate was intensified after the death of Lucie Gates (Appendix 1). There had been concerns about poor standards of care but care proceedings were not sought. Then Lucie aged two died when, having been left alone, an electric fire had fallen on top of her. Although this was an 'accident' in that no one had deliberately pushed the fire on her, her mother was convicted of manslaughter. This illustrates the principle that parents are given power to promote the welfare of their children and when they clearly fail to use this power they are deemed abusive.

With the paramountcy of medically driven intervention in child protection there was a problem of the recognition of emotional abuse. Because attention centred on those cases with substantial medical involvement and physical signs, emotional abuse was only given attention when manifested as 'non-organic failure to thrive' or 'Munchausen syndrome by proxy'. Despite this, emotional abuse was not completely overlooked. It was acknowledged but not vigorously addressed. In a circular (DHSS 1980), the government recommended that severe neglect and emotional abuse be added to the register categories. Sexual abuse however was excluded unless there was physical injury.

\section{The 'Discovery' of Sexual abuse and Intervention Re-evaluated.}

During the Victorian era there had been concern about the sexual exploitation of child labourers in agriculture and industry. Child prostitution was widespread. But 'consistent with a world view that associated sexual probity with bourgeois respectability most Victorians who wrote about incest linked it to poverty, overcrowding, and the promiscuous habits of the poor' (Olafson et al 1993 p. 8).

A change came in the early 1980 s when professionals began to appreciate that children were likely to protect their parents and cover up abuse rather than make false allegations (Cameronchild 1978, Zemdegs 1980, Doyle 1985). Feminist writers meanwhile were highlighting issues of power and exploitation (Campbell 1988) and challenging the belief that women and girls made spurious accusations of rape (Kennedy 1992). 
Researchers (eg Soothill and Gibbens 1978, Finkelhor 1984, Abel et al 1987, La Fontaine 1990) and survivors (eg Angelou 1984, Fraser 1989 and Ben 1991) disputed the previous assumption that sexual abuse was confined to a few incestuous fathers and, separate from them, paedophiles preying on unrelated children (de Younge 1981). There was a growing understanding that sexual abuse was widespread and perpetrators in a variety of contexts targeted and groomed their victims (Mezey et al 1991). This lead to more focussed treatment and prevention programmes (Wyre 1992, Gough 1993)

The recognition not only of widespread physical abuse but also of sexual abuse, led feminist commentators (eg Kitzinger 1994, MacLeod and Saraga 1988) to question the values and culture of a society in which such abuses can flourish. They identified 'the need to challenge broader social attitudes towards sexuality and violence' (Kitzinger 1994 p.246). Ennew (1986) highlighted the unofficially sanctioned use of women and children as sex objects. Gelles and Cornell (1985), argued that there is a level of domestic violence to partners, children and dependent older people which is condoned by the absence of any real efforts to oppose it. Gil (1970) earlier had similarly argued for less physical chastisement and a change in 'childrearing philosophy and practices' (p.141). These commentators all located the cause of abuse in the culture and accepted norms of particular societies and 'social cultural' causal theories gained increased credence throughout this period.

In Britain, recognition of sexual abuse began to escalate. NSPCC staff, for example, were 'increasingly invited to conferences concerning gross neglect and sexual abuse' (Jones 1979 p.19). When in 1986 sexual abuse was finally included on the register the numbers of recorded cases rose substantially. The estimated number of sexually abused children in England and Wales rose from 2, 932 in 1985 to 6,330 in 1986. (Taylor 1992).

Child sexual abuse became the focus of concern during the 'Cleveland' crisis of 1987 when 'the local authority acting under former legislation had applied for and obtained 276 place of safety orders over a seven month period' (Bell 1990). There are many perspectives on what took place in Cleveland and different interpretations of events (see Butler-Sloss 
1988, Bell 1988, Campbell 1988, Richardson and Bacon 1991). Here only the features that are relevant to the purpose of the present study of emotional abuse will be discussed.

First, there are the implications of events in Cleveland in relation to evidencing cases. Professionals had tended to rely on medical evidence in order to protect children from physical abuse. With sexual abuse there appeared to be greater uncertainty because in most cases there were no physical signs. Hobbs and Wynne (1986) offered a concrete physical sign when they published details of anal dilatation in relation to sexual abuse in children. Much of the Cleveland controversy centred on the reliability of using this physical sign to diagnose abuse (Butler-Sloss 1988, Wyatt and Higgs 1991, Hobbs and Wynne 1993). The relevance for emotional abuse was that the emphasis in child protection work shifted from the detection of physical 'signs' to greater reliance on a full comprehensive assessment, including signs in the children's behaviour and development and their comments and disclosures.

Secondly, the media reporting of events in Cleveland increased the pressure on child protection professionals who felt condemned if they did not remove children in possible danger but equally culpable if they did (Parton 1992).

In the wake of the Cleveland crisis came allegations that children were being ritually abused especially in relation to satanic cults (McFayden et al 1993). These were again the subject of media interest. La Fontaine (1994), who found little to substantiate satanic involvement, commented 'A belief in evil cults is convincing because it draws on powerful cultural axioms. People are reluctant to accept that parents ... will harm their own children ... but involvement with the devil explains it' (p.31). As in Victorian times, public disinclination to believe in abuse by parents is still apparent.

The dilemmas of intervention in sexual abuse cases were similar to those of physical abuse, such as identifying which behaviours outside the mainstream, eg co-sleeping arrangements, were acceptable and which abusive. (Lau 1991). This included the concern 
not to impose 'Eurocentric' standards on black and Asian families when it came to sexual conduct. Ahmad (1989) recalls being consulted about a sexually abused 'Punjabi girl':

Although the school was aware of this abuse for some time, no action was taken as the 'culturally sensitive' school was anxious to check whether 'incest was accepted in Punjabi culture'. (p.24).

Another dilemma, highlighted by events in Cleveland and the Orkneys (Clyde 1992), was whether intervention, particularly if this involved removing children from their homes, caused more emotional damage and distress to children than the alleged abuse. The doubts about the desirability of taking children away from their families further increased at this time because two instances of sexual abuse in institutions had recently come to light, in Lewisham (Lawson 1985) and in Northern Ireland (Hughes et al 1986).

As institutions came under scrutiny, a public inquiry that dealt specifically with emotional abuse was held in Staffordshire (Levy and Kahan 1991). Some children's homes in Staffordshire had implemented a disciplinary and control regime termed 'Pindown'. From its introduction in 1983, children as young as nine were locked in solitary isolation with no books or toys or other diversions for up to 27 days. They were prevented from attending school during that time. Several children were repeatedly put in Pindown. At this point emotional abuse was highlighted. However, a year later the trial of Frank Beck eclipsed the Pindown scandal. Beck was found guilty on 17 counts of sexual and physical assault, including four offences of buggery and one of rape during his career as Officer in Charge of a number of Leicestershire children's homes (Kirkwood 1993).

These revelations had an impact on professionals. Contrary to popular opinion, child protection workers had never removed children from their parents lightly. (Dingwall et al 1983). Nevertheless, it appeared that some abuse could only be stopped by removal from home. But the Pindown (Levy and Kahan 1991), Utting (1991), Department of Health (1992) and Kirkwood (1993) reports all confirmed concerns about abuse in care. Furthermore, Christopher Pinder had been killed by his adoptive mother in 1980 while 
Shirley Woodcock was killed in 1982 by her foster mother (see Appendix 1). The biographies of Graham Gaskin (MacVeigh 1982) and Phil Quinn (1988) described gross abuse in foster homes. In addition, it was realised that paedophiles target jobs and situations in which they have ready access to children. Beck himself had applied to be a foster parent (Kirkwood 1993).

This left workers in the 1990s unsure about how best to manage cases of child abuse, including those of emotional abuse. Because of the highlighted problems of removal and a 'care career', alternative interventions were welcomed.

\section{Change and The Children Act 1989}

Practitioners working in the early 1990s, the period when the current research was undertaken, were influenced by the events, outlined above, of the previous two decades. In addition there were three other aspects of policy influencing their practice.

First, to avoid some of the precipitate action, such as that witnessed during events in Cleveland, professionals are currently exhorted work in partnership with parents and consult them and include them in the decision-making processes whenever possible (Marsh and Fisher 1992, Department of Health 1995c).

Secondly, the present study was undertaken while the Children Act 1989 was in force. This comprehensive piece of legislation covers most aspects of child welfare, including child protection, day care provision for children and children in divorce and domestic disputes.

Among its main principles are:

* the requirement to take account of the children's feelings, wishes and cultural background s. 1 (3a), s.22(5);

* the welfare of the child is paramount; 
* a court order should only be made if one is better than no order at all s.l (5);

* a more flexible range of legal provisions $s .8, s .16, s .31, s .43, s .44, s .46$.

* families of children 'in need', should be supported s.17. Such children are broadly defined in the act as any who would not achieve or maintain a reasonable standard of health and development without additional assistance, s. 17. (10).

* to obtain a protective court order, it has to be demonstrated that the child is suffering, or is likely to suffer, 'significant harm' s.31 (2a). (Adcock et al 1991). Section 9 (b) clarifies that 'harm' includes 'forms of ill-treatment which are not physical'.

* parents still retain 'parental responsibility' if their children are taken into care s.2, s33.(3b).

Thirdly, procedures and registers now incorporated all forms of abuse and by the 1990s professionals were questioning whether procedures originally introduced to cater for nonaccidental injury were appropriate for the management of all the recognised forms of abuse. Gibbons et al (1995), who examined the procedures, commented:

Cases of neglect and emotional abuse are more likely to disappear from the child protection system without any services being offered. A more appropriate service might be offered if cases of neglect and emotional abuse were first assessed as 'children in need' (p.116)

\section{PRESENT PROCEDURES FOR DEALING WITH CHILD ABUSE}

In order to set issues of intervention and the research design in context, this section summarises the procedures currently in operation for potential cases of child abuse, including suspected emotional abuse.

At present children protection workers act within the framework of the Children Act 1989 and current procedures. Intervention is undertaken in England and Wales by multidisciplinary teams:

The protection of children requires a close working relationship between social services departments, the police service, medical practitioners, 
community health workers, schools voluntary agencies and others ... There must be a recognised forum for developing, monitoring and reviewing child protection policies. The forum is the Area Child Protection Committee (ACPC). (Home Office 1991 p.2)

When concern about the protection of a child is raised, the matter will be investigated usually by the social services department, often jointly with the police. However, under the Children Act 1989 s.47 (9) other agencies such as education, health and housing authorities have a duty to assist the investigation.

An assessment of risk is undertaken and, if required, a strategy to protect the child is devised. In cases of probable risk, a case conference is convened to share information between all the professionals concerned with the case and wherever possible with the parents and children. The conference will make recommendations about future action. Its members will decide whether or not to place the child's name on the Child Protection Register. A key worker, defined as 'social worker allocated specific responsibility for a particular child' (Home Office 1991 p.123), will be appointed to coordinate the case.

Each area covered by an ACPC has a register central to that area. This is a list of all the children in the area who are thought to be suffering from or likely to suffer significant harm. It is worth quoting the section 'The Purpose of the Register' from Working Together (Home Office 1991) in full:

The purpose of the register is to provide a record of all children in the area for whom there are unresolved child protection issues and who are currently the subject of an inter-agency protection plan and to ensure that the plans are formally reviewed every six months. The register will provide a central point of speedy inquiry for professional staff who are worried about a child and want to know whether the child is the subject of an interagency protection plan, The register will also provide useful information for the individual child protection agencies and for the ACPC in its policy development work and strategic planning. (p. 48)

Children are registered under four main categories: Neglect; Physical Injury; Sexual Abuse; Emotional Abuse. There was a fifth 'Grave Concern' category but this was 
discontinued in 1991. In some instances children are registered in more than one category. However, in cases of emotional abuse, there is an emphasis on only using the category where it is this predominant form. The following guidance is given:

Emotional Abuse: Actual or likely severe adverse effect on the emotional and behavioural development of a child caused by persistent or severe emotional ill-treatment or rejection. All abuse involves some emotional illtreatment. This category should be used where it is the main or sole form of abuse. (Home Office 1991 p. 49).

\section{ECOLOGICAL THEORY}

As different forms of abuse were recognised and non-medical professions came to the fore, different causal theories emerged. Those focusing on individual pathology gave way to ones implicating social deprivation or culture. The Department of Health (1995b) publication summarising recent British research findings, notes that the integrated model is now the dominant one. This is echoed by commentators such as Herzberger (1993) who is critical of much child protection research to date and 'the failure to address child abuse from a multitheoretical and multivariate perspective' (p. 34). She points to the deficiency of research which is narrow and taken out of context and concludes 'Studies that address the myriad causes and consequences of aggression toward children will contribute more to our knowledge than studies of single variables out of context and in isolation' (p38). Similarly, Herbert (1991) warns of the dangers of over-emphasising single variable theories. Reflecting on bonding theory, he writes 'humane ideas of maximising contact between mother and child' become oppressive 'when elevated into dogmas' (p.91).

In relation to sexual abuse, integrated approaches (eg Finkelhor 1986) have provided a firmer foundation for intervention than single perspective approaches, For example, Anna Freud's assertion, espousing an exclusively psychodynamic perspective, that 'children, because of oedipal fantasies' may be 'willing victims of [sexual] assault' (Freud 1981 p. 34) seems to be out of place given what is now known about the power of perpetrators' grooming behaviour (Singer et al 1992). 
The ecological model, conceptualised by Bronfenbrenner (1979) and applied to child abuse by Belsky (1980), is a multivariate, integrated one. It main proponents Garbarino and Gilliam (1980) explain 'using the word ecological we mean to convey an interest in the way the organism and its immediate environment (the ecological niche) affect and respond to each other' (p.21). They argue in child abuse cases the relationship between parents and abused children can only be understood by taking into account the environment surrounding the family and its effect on their relationships. They also believe that children need a healthy environment if they are to grow up well-adjusted.

Ecological theory draws on the concept of systems. It 'looks at maltreatment across levels of social systems (from the microsystem to the macrosystem)' (Garbarino and Gilliam 1980 p.xiv). But it is more developmental than General Systems theory applied to families (Jackson and Weakland 1961, Lask 1987) There is the image of 'nests'. 'An individual's environment, particularly a child's environment, can be understood as a series of settings each nested within the next broader level from the microenvironment of the family to the macroenvironment of the society' (Garbarino and Gilliam 1980 p. 79).

One of the strengths of the ecological approach is that it integrates the evidence of the other theories. For example, a poor microsystem can lie in parental deficiency related to poor bonding or to poor modelling, 'parents who mistreat their children appear to have had little chance to rehearse the role of caregiver. They often were maltreated as children' (Garbarino and Gilliam 1980 p.29). But social impoverishment worsens psychological stresses and child abuse is likely to be associated with a combination of poor parenting skills and social distress. Garbarino and Kostelny (1992) found that 'child maltreatment is a symptom of not just individual or family trouble but neighbourhood and community trouble as well' (p.463). Through their research they found a relationship between a downward spiral in socioeconomic conditions and increased rates and severity of child abuse. This view was supported in research by Coulton et al (1995) and by Krishan and Morrison (1995) in Canada which found a similar relationship. 


\section{Necessary conditions}

Garbarino and Gilliam (1980) distinguish between 'sufficient conditions' for child abuse, (which include factors such as caregiver vulnerabilities or oppressive macrosystems such as discriminatory social policies) and 'necessary conditions'. They identify two necessary conditions, social isolation and the misuse of power.

\section{Social isolation}

This is the 'isolation of the parent-child relationship from potent prosocial support systems' (p.33). Garbarino and Gilliam (1980) draw on Young's (1964) earlier study which identified social isolation as a theme. She concluded '[abusive parents'] behaviour must be to some extent the result of their social isolation (p.85). Isolation can occur because of failure of the community networks to support the family or because of the caregivers refusal or inability to use support networks. The emphasis on western society on privacy and individualism compounds this problem. The idea of social isolation has, however, been brought into question by recent research by Coohey (1996) who found all the maltreating mothers in her study had at least eight important network members.

\section{Power Issues}

General Systems theory (von Bertalanffy 1973) was criticised by feminist writers such as MacLeod and Saraga (1988) who argued that the dysfunctional family system theory as espoused by therapists such as Minuchin (1974) and Mrazek and Bentovim (1981) fails to address power relations within the family. Ecological theory in contrast acknowledges social cultural environments which permit the abuse of power. Moreover Garbarino and Gilliam (1980) make explicit the pivotal role of power. 'The central issue in mistreatment is the misuse of power' (p.32) and the way a culture defines the rights of children.

To conclude this section, ecological theory which subsumes and integrates earlier individualistic and societal causal theories will underpin the design of this thesis. 


\section{SOCIAL POLICY CONTEXTS.}

Any examination of emotional abuse which has the objective of contributing towards intervention requires a rudimentary evaluation of present practice. Commenting on the fact that social workers have traditionally 'turned their backs on evaluation', Everitt et al (1992) note that one of the objections to traditional positivist, evaluative research is the fact that practice is decontextualised 'separated for evaluation from its social political and economic context'. (p.117). Stevenson (1992 p.25) also highlights the importance of recognising the 'ideological battleground' in which child protection is located. In acknowledgement of these concerns this section looks at the social policy contexts within which child protection workers may work.

Harding (1991) identified four main perspectives on child care policy. The first is the 'laissez-faire' approach. Fundamental to this approach is a distrust in the state. It is associated with capitalist societies where it is felt that the state should keep out of private areas of citizens' lives. The second perspective is the 'modern defence of the birth family and parent's rights'. This holds that the birth/biological family is of supreme importance for both children and parents and should be maintained wherever possible. The proponents of the third perspective 'state paternalism and child protection' envisage a substantial role for state intervention in order to protect children from cruelty or inadequate care. It is the parents' duty to care properly for the child and if this duty is not met the state may intervene even to the point of removing the child.

The final perspective is 'children's rights and child liberation'. From this perspective children are entities separate from their parents. Their viewpoint and wishes are important. Radical proponents of this view (for example Holt 1975) argue that children should be free of both state and adult control. The less radical view (Freeman 1993) is that children should be enabled to express their own views, feelings and choices without these being imposed by adults who 'know what is best' for each child. An objection to children's rights, raised by Harding, is that if children have full adult rights to self-determination then logically they should equally bear adult responsibilities. Supporters of children's rights, 
responding to this would point to the fact that many children do in fact cope with 'adult' responsibilities. They include child carers of physically or mentally ill family members (Dearden and Becker 1995, Francis 1995, Rickford 1995), children of some substance addicted parents (Children's Society 1995) and children who intervene between warring parents to prevent them damaging each other (National Children's Homes 1994).

\section{Four Welfare Models}

Hardiker et al (1991) offers an alternative model of social policy which can be related to child care policies. The authors also explore different types of preventative activity in relation to perspective. Because they apply the model directly to working with child protection cases this is of particular use in the study of child abuse intervention. The authors identify four main approaches.

\section{The Residual Model}

This is a radical right or radical consensus model. Values of individualism and freedom are emphasised. Individuals should provide for their own and their dependents' needs. Welfare is best provided through voluntary agencies, extended families or private enterprise. The care of children is not part of the state's function. It should only intervene if the child is in grave danger. Commentators observe that during the late 1980s and 1990s - the time spanned by this research - this has been one of the prevailing models (Sapey 1995). Stevenson (1995) noted, 'The British public has been brain-washed by constant references to public expenditure as somehow undesirable, even wicked' (p.4).

The level of prevention is Tertiary. Intervention is reserved only for families whose children are in immediate danger of coming into care. There is an exclusive concentration on statutory work with interventions kept as short as possible.

\section{The Institutional Model}

Here individual freedoms are modified by some state intervention in order to mitigate the more negative consequences of economic vagaries. The role of the state is not to promote welfare but to maintain the status quo. Individuals are still largely responsible for their own 
welfare but the state supplements these efforts and those of the voluntary and private sectors. The difficulty of parenting in modern capitalist societies is recognised and assistance is therefore forthcoming.

The prevention level is Secondary and is well illustrated by the main Barclay Report (1982). It includes advice and information services and family support but is targeted at vulnerable groups in order to prevent a problem from becoming greater. It is evident in many of the provisions of the Children Act 1989 and the philosophy underpinning the act. There is the belief in the importance of partnership with parents (Marsh and Fisher 1992, Department of Health 1995c) and the state's duty to support parents who are struggling especially with children 'in need' ( $s .17)$.

\section{The Developmental Model}

This is a democratic socialist perspective. The state through parliamentary democracy attempts to create greater social justice. It has a proactive role in promoting welfare. The voluntary and private sectors supplement state provision. Social and personal problems are seen as due to inequalities in the distribution of power and resources. Families and parents who run into difficultly do so because of the disadvantages they face in terms of social inequalities. The aim of intervention is not to control, punish or change parents but to challenge the economic, social and political processes which generate social problems.

Under this model the level of prevention is Primary. Welfare services take into account social inequalities but are universal and accessible to members of the community whether or not a family is viewed as vulnerable.

\section{The Radical/Conflict Model}

Social conflict is seen as inevitable in a capitalist society until the social order is transformed into a more just - and presumably non-capitalist - society. There is conflict because while the welfare state is an essential part of addressing inequality it is also seen as masking oppression and reinforcing social inequalities. Families themselves should be made fully aware of the structural injustices so that they can exert control over their own 
lives. This is reflected in certain aspects of anti-oppressive practice espoused by social workers who argue professionals should also be empowering the victims of injustices to challenge them directly "The voice of the "expert" should not substitute for that of the oppressed' (Gambe et al 1992 p.99). Hardiker et al (1991) do not offer a level of prevention associated with this model.

\section{OVERVIEW}

For centuries children have been both protected and abused. The present day understanding and construct of child protection can be traced to the late 19th century. It is only in the past twenty years that the extent of child abuse in its various forms has became apparent and the general population and professionals alike are still struggling with this concept.

Child protection has, for the past twenty years, been a rapidly changing area of concern. Consequently, a flexible innovative response, such as provided by an organic team, may be required. Yet most statutory workers with the lead responsibility for child protection operate within a bureaucracy with its slow, mechanistic inflexible response (see Burns and Stalker 1966, Litterer 1983).

Professional workers have an added burden; they have been forced to recognise that when children are abused by natural parents there is no certainty that removal from home will guarantee that abuse stops and their well-being will be promoted by substitute carers.

Over time different causal theories have arisen. The Department of Health (1995b) notes that 'Today it is broadly accepted that a combination of social, psychological, economic and environmental factors play a part in the abuse or neglect of children' (pp. 21-22). In more recent years the ecological approach which integrates these factors has emerged as a comprehensive one embracing the complexities of child abuse. It recognises the interplay between individual and relationship factors and the impact of wider environmental considerations. In tune with social structural theorists and advocates of children's rights it acknowledges the central role of adults' power over children. 
An appreciation of the social policy and organisational contexts within which child protection professionals operate helps to explain the constraints under which they work. This is important because although a particular intervention may appear to be ideal it may not be feasible given particular constraints. The recognition of the historical legacy and social policy contexts also promotes an appreciation of the tensions in child protection work. For example, professionals may see the need to provide services for all families to ensure that the most vulnerable ones obtain a service. However, if the predominant social policy of the time is a 'laissez-faire' one then the professionals will struggle to provide the services. Consequently, there is the potential for conflict and disillusionment.

Child protection has been a high profile activity for some twenty years. Yet emotional abuse, as the main or sole form, has only been the explicit subject of attention on a few occasions. In 1980 it was included, without much debate, as a registration category then again when the Pindown scandal came to public notice. The reasons for the low profile of emotional abuse are speculative. One possible reason is that once improved physical conditions for children were secured by the mid-Twentieth century, emotional abuse was recognised and managed without recourse to formal procedures. Harding (1991) commenting on the inter-War years catalogues evidence of the 'insensitivity to psychological, as opposed to physical well-being' of children during this period (p.90). But by the 1950s it was recognised that 'What we require for our children nowadays is much more than freedom from hunger and suffering. It is a definite affection and personal encouragement' (Weddell 1958 p.12).

An alternative reason may be related to the role and power of the different professions. The recognition of physical abuse was spear-headed by the powerful medical profession (eg Kempe and Helfer 1968). A second powerful agency, the police, then became involved because serious physical assault is a police matter (Newberger and Bourne 1978). Physical neglect which in its extreme form involves the medical and police services has, since 1975, been the subject of four public inquiries (Koseda, Meaurs, Page and 'Paul' see Appendix 1). Child sexual abuse took much longer than physical abuse to be acknowledged. Finkelhor (1984) argued that this was due to the fact that doctors were less involved 'few 
victims of sexual abuse show any medically significant traumas' (p.10).

Emotional abuse only enters indirectly into the domain of the medical profession. Hobbs (1992) argues that paediatricians have a central role in child abuse but he fails to mention emotional abuse in his review of child protection issues. Similarly, there are very few laws that relate directly to emotional abuse therefore the police may feel less involved.

Alternatively, it could be that emotional abuse has in fact been included in the concern about child protection but because so many different terms are used to describe emotional abuse, the various strands have not been drawn together in the same way that they have with other forms of abuse. The current debates, including issues of terminology, are addressed in the next chapter.

This present chapter has shown that in order to respond to cases of child abuse, practitioners and policy makers have had to address issues additional to those concerned directly with intervention itself. Firstly, the problem required definition, hence the importance of the contribution of Kempe et al (1962) and Schechter and Roberge (1976). Then there needed to be some estimate of its extent (Taylor 1992). There was a debate about where abuse is located (Gil 1970, Pelton 1978). The manifestation of abuse, especially relating to signs and symptoms in the children, was another area of controversy, especially during the Cleveland crisis (Butler-Sloss 1988). These issues required clarification before practitioners and policy makers could determine if the responses, whether in terms of procedures, laws or resources offered, were appropriate. The next chapter, therefore, looks at the current debate on emotional abuse, not only in relation to intervention itself, but also through the additional four background themes of definition, prevalence, location and manifestation.

\section{Note}

1. All the children mentioned by identifying name in this chapter have been the subject of a public enquiry. Details of the resulting reports are provided in Appendix 1. 


\section{CHAPTER 3}

\section{THE CURRENT DEBATE ON EMOTIONAL ABUSE}

The emotional needs of children have been part of child welfare concerns since the publication of Bowlby's (1951) research. But it was not until 1980 that, in Britain, emotional abuse was included as a registration category. As demonstrated in the previous chapter, emotional abuse as such does not appear to have dominated the child abuse debate but neither has it been a topic that has been ignored. This chapter therefore looks at the recent past and current discourse on emotional abuse.

Emotional abuse is different from the other commonly identified forms of abuse in that it underlies all others (Brassard and Gelardo 1987, Navarre 1987, Claussen and Crittenden 1991). However it can also occur in the absence of physical or sexual mistreatment (McGee and Wolfe 1991a). In the key Home Office (1991) publication for child protection professionals, the emphasis is on separating out emotional abuse as a specific category when it is 'the main or sole form of abuse' (p. 49). This chapter will therefore concentrate on the literature which specifically addresses this form of mistreatment where it occurs as the only or predominant one.

The overwhelming majority of works directly relating to emotional abuse take the form of a discussion of the issues. Only a small proportion describe formal research on the topic. There are several projects which study child abuse in general and include emotional abuse (Wiehe 1990, Jones and McCurdy 1992, Moeller and Bachman 1993, Ney et al 1994, Nicholas and Bierber 1994, Verdugo et al 1995). Iwaniec (1995) combines research and professional experience of emotional abuse although her focus in on pre-adolescent children.

There is evidence of recent research activity on emotional abuse of children in universities at the level of masters degrees and doctorates although to date they appear not to have resulted in publications. Roll (1995) for example provided a general overview of emotional abuse. Kell (1993) examined attitudes to the concept of emotional abuse. Brougham (1996) 
looked at professional intervention in registered cases.

In order to address issues of intervention in cases of emotional abuse, other related subjects of definition, prevalence, location and manifestation have to be addressed. The literature is reviewed in relation to these topics as well as to intervention itself. Before these issues are explored the terminology used by commentators requires clarification.

\section{TERMINOLOGY}

While many writers use the phrase 'emotional abuse', some use other terms to discuss the same issues. As Navarre (1987) observes 'In professional literature the terms psychological abuse, emotional abuse and mental cruelty have been used interchangeably' (p.45). Garbarino, one of the most prolific commentators on the subject, includes a range of terms in his titles: 'emotional maltreatment' (Garbarino and Garbarino 1986); 'the psychologically battered child' (Garbarino et al. 1986); 'emotional abuse' (Garbarino 1978). An alternative phrase that writers use is 'psychological maltreatment' (Brassard et al. 1987). Shengold (1989), meanwhile, refers to 'soul murder'.

O'Hagan $(1993,1995)$ argues for a clear distinction between emotional and psychological abuse and throughout his writing uses the phrase 'emotional and psychological abuse' in full. However this seems to be an unnecessary convention. Psychologists themselves dispute whether there is any meaningful distinction between emotion and cognition (Gray 1990, Panksepp 1990). Furthermore, when a prepubertal girl is raped by her father she is physically, emotionally/psychologically and sexually abused. However professionals do not continually refer to all forms of abuse although they will acknowledge their presence. Instead, they use the one with the most immediate impact or distinguishing feature. In the instance of the raped girl 'sexual abuse' would be the usual term. In cases in which a child suffers mainly or solely psychological maltreatment then the phrase 'emotional abuse' is appropriate as this conveys to both professionals and, equally importantly, to the general public the essence of the impact on the child. 
In summary, all references including the key words emotional, mental or psychological followed by a term which indicates some form of mistreatment - abuse, battering, maltreatment, cruelty, neglect have been considered in this review.

\section{ISSUES OF DEFINITION}

The majority of works discuss the definition of 'emotional abuse'. Some authors deal with it as a preliminary in order to develop additional arguments (eg Glaser 1993, Iwaniec 1995). Others devote the whole work to issues of definition (eg Besharov 1981, McGee and Wolfe 1991a, 1991b). Most authors allude to the fact that there is no one agreed definition nor even one which is used repeatedly such as the widely accepted definition of sexual abuse provided by Schechter and Roberge (1976) and adopted by Kempe (1978).

The problems of definition which reoccur in the literature relate to six main themes. The first is the distinction if any, between abuse (commissions) and neglect (omissions). The second is the distinction between intentional and unintentional behaviour. The third relates to how far it is persistent and sustained in nature. The fourth revolves around issues of damage. The fifth is whether identification should be through the child's 'symptoms' or the parent's behaviour. The final theme questions how wide or narrow any definition should be. These themes will be examined in the following sections.

\section{Abuse or Neglect?}

In physical maltreatment it is relatively easy to distinguish between 'abuse' which usually refers to acts of commission - hitting, shaking or burning - and 'neglect' which involves acts of omission such as failure to nourish or to provide a safe environment. In contrast, in psychological maltreatment, it appears less easy to distinguish abuse from neglect, ie acts of commission from those of omission, despite the attempts of Patterson and Thompson (1980) and Junewicz (1983) to do so. To illustrate this, Egeland and Erickson (1987) quote the parent of a 2-year-old girl 'I try to keep her away from me. I ignore her. I treat her like an adult so she'll hurry up and be one' (p.110). Here the mother's behaviour is a combination of acts of omission (rejecting, neglecting her needs and ignoring) with 
those of commission (consciously treating her in too adult a fashion).

Coulshed (1990) has no doubt about encompassing omission and commission. 'Emotional abuse is a diffuse concept; its effects are often suppressed; it includes acts of omission (such as ignoring a child), as well as commission (such as verbal abuse)' (p.23). Rohner and Rohner (1980) similarly disregard the distinction between commission/omission and abuse/neglect. They view the term 'parental acceptance' as synonymous with words like warmth and affection, 'parental rejection' is used synonymously with 'emotional abuse' which encompasses hostility and aggression as well as indifference and neglect.

Kell (1993), while recognising overt acts of commission, also uses Maslow's (1970) needs model (see Chapter 1) as a way of identifying emotionally abusive omissions. She argues that the failure to meet basic needs is an omission by carers which can constitute abuse. Montgomery (1989), while recognising the differences between omission and commission also dismisses them and, like Kell, introduces the concept of positive obligations:

Lawyers might be more comfortable with a distinction drawn between neglect and abuse which was based on the distinction between acts and omissions, but in the context of protecting children's welfare, this distinction is unattractive. Omissions may be just as damaging as positive acts. As parents clearly have an obligation to care for their children, there is no conceptual difficulty in accepting that their duties include positive obligations to promote the well-being of children and not just a requirement to refrain from injuring them (p. 25-26).

\section{Intentional or unintentional harm}

The issues of intentional or unintentional harm are closely related to the debate on omission versus commission. Sexual abuse is confined to acts of commission with intent (although many perpetrators would claim they had no intention to cause harm, see Li et al 1990). Physical 'abuse' usually refers to an act of intent on the part of the care givers whereas 'neglect' is often viewed as unintentional, caused by ignorance and inadequate parental resources (a view discussed by Stevenson 1996). But this distinction is not clear cut. Parents who harm their baby through violent shaking rarely 'intend' harm. Instead, 
they lose control and use their physical power to meet their own need for relief from frustration instead of meeting the child's need to be kept safe. Conversely, it is difficult to absolve the parents of any intent to harm in cases such as the neglect of Heidi Koseda (see Appendix 1); she 'must surely have asserted [her] existence by crying for nurturance which the parents must have ignored' (Reder et al 1993 p.47)

In one of the earliest contributions to the discussion in relation to emotional abuse, Lourie and Stephano (1978) reported on a workshop on the topic:

While some participants felt that parental intent to injure was a necessary parameter in calling a situation abusive, others felt that it should not enter into our definition so that abuse of unconscious origin would not be excluded... For example, when a parent displays severe and repeated scapegoating behaviour that leads to severe depression in the child, the situation is emotionally abusive regardless of whether or not the parent intended to be abusive towards the child (pp. 202-203).

Navarre (1987) identifies three dimensions intent, action and outcome

Many abusive acts are perpetrated with the best of intentions but have severely aversive outcomes ... in other cases, the adult and child may be so enmeshed in a self-perpetuating pattern of interaction that the adult is incapable of perceiving or responding to some or many of the child's needs. (p.47).

Covitz (1986) regards emotional abuse as unintentional 'In almost every case [emotional abuse] is the opposite of what the parents intend; they want to be nurturing and helpful, but it doesn't work out that way' (p.3). Whiting (1978) similarly talks about psychiatric and child clinics filled with 'children [who] have been subjected to emotional abuse, almost none of which was inflicted maliciously or deliberately by the parent or caretaker'. (p. 210) Bourton (1991) concurs:

The term 'emotional abuse' is itself unfortunate, for, while the end result may be emotional abuse, there is usually no intention to abuse. More likely there are two sets of victims: the parent and the child. (p.45).

Szur (1987) makes the arresting observation 'People responsible for physical or sexual abuse attempt to keep it hidden from others; in emotional abuse they often manage to keep 
it hidden from themselves. At some level, though, there is unease and guilt'. (p.107). Coulshed (1990) having asked her acquaintances about their unhappy childhood experiences writes 'Most viewed such psychological mistreatment as common and part of the way in which adults unintentionally relate to children' (p.23).

In contrast, Garbarino (1978) states 'emotional abuse is the wilful destruction or significant impairment of a child's competence' (p. 92) [Garbarino's underlining]. Here intent is a significant factor. Carter (1983) while expressing concern about the distinction between intentionality and unintentionality offers an adaptation from Gil (1971):

(Emotional) abuse of children is the intentional, non-accidental use of psychological force or intentional, non-accidental actions of omission on the part of a parent or other caretaker, in interaction with a child in his care, aimed at hurting, injuring or destroying that child (p. 32).

Given the polarised positions of most of the commentators, either for or against intent, it appears that issues of intent are not the deciding factor. Instead it is perhaps more appropriate to return to Montgomery's (1989) conclusion in the previous section, that parents are charged with promoting the well-being of their children and judgements should be based on how far, intentionally or unintentionally, they are failing to use parental power to do so.

\section{Sustained ill-treatment or a single episode}

The wording of the definition of emotional abuse in 'Working Together' (Home Office 1991) emphasises its sustained nature, 'Actual or likely severe adverse effect on the emotional and behavioural development of a child caused by persistent or severe emotional ill-treatment or rejection' (p.48). Several authors emphasise that emotional abuse has to be persistent, occurring over a prolonged period rather than a single episode. Hunter (1990) cites the 1989 Scottish Office definition which includes repeated and persistent parental behaviour. Skuse (1989a) refers to the 'habitual verbal harassment... threat and ridicule' (p.23). O'Hagan (1993) says that the key words in relation to emotionally abusive behaviour are 'sustained' and 'repetitive'. Vachss (1997) states 'it is always a course of conduct not a single event' (p.1). 
Dean (1979) similarly defines emotional abuse as 'a chronic attitude or act on the part of a parent or caretaker that is detrimental to, or prevents the development of, a positive selfimage in the child' (p.19). Yet despite this she gives an example of a single incident in which parents, punishing their teenage daughter for coming home late, shaved off her hair which severely distressed and traumatised the young woman for a long period of time afterwards. Yates (1982) cites an example of a single incident when an 8-year-old girl wearing a dog harness was tied to a parking meter outside a shop while her mother took her other children inside to do the shopping. The mother laughed when the girl's siblings baited her, barking at her and telling her to 'fetch'. (p. 588)

Most emotional abuse is likely to be an accumulation of individually 'minor' episodes. But the examples cited by Dean (1979) and Yates (1982) show that emotional abuse is similar to other forms which can often occur in the context of 'lesser' abuse. There is persistent 'heavy' chastisement (physical abuse), grooming (sexual abuse) or marginal care (neglect), punctuated by more severe individual episodes.

\section{Present or future harm}

Garbarino and Garbarino (1986) argue that future harm is an essential component, 'The normal course of emotional development serves as a backdrop against which to recognize and identify emotional maltreatment' (p.2). They also state that not only is the children's development impaired but they are likely to become victimisers of their own children. A similar view is taken by Covitz (1986).

Carter (1983) criticises these perspectives because of the failure of the behavioural sciences to demonstrate a proven cause-effect between childhood experiences and adult functioning. Furnell (1991) endorses this view "The gathering of convincing evidence that establishes causal links in a satisfactory manner for a sceptical outsider may be extremely difficult' (p.118). He also argues that, whatever the future consequences, it is unacceptable for a child to be made to suffer in the here-and-now (Furnell 1986).

The Home Office (1991) seems to indicate that both present and possible future damage 
can be indicators given the 'Actual or likely severe adverse effects' part of its definition. This view is endorsed by Iwaniec (1995). Psychological abuse can cause long term damage to many victims. Vachss (1997) emphasises this and writes about their 'life-long drive for approval' (p.1). Gross and Keller (1992) found that psychological abuse seemed to lead to a lower self-esteem and more depression in adults abused as children. But behaviours that might cause suffering in the present should not be ignored. It has been established (see Chapter 1) that even very young children are not 'physical vegetables' and that from an early age children are sensitive to emotions in themselves and others.

\section{Children's or parents' behaviour.}

Lourie and Stephano (1978) identify another definitional dilemma, related to the previous section. During the workshop upon which their article is based, participants perceived a dichotomy which 'concerned the focal point of this definition - child behaviour or parental actions? Should this definition be based on manifestations of mental injury in the child, or should it concern parental actions which are injurious or potentially injurious' (p. 201).

On the whole, the law demands evidence of injury to the child. Commenting on American law, Ronnau and Poertner (1989) note 'although a social worker may feel that a father's constant yelling damages his child's self-esteem, a judge requires "proof" of a cause-andeffect relationship ... [and] will want to know the specific harm to the child in more behavioral terms' (p.429). In Britain the concept of 'significant harm' is a fundamental concept of the 1989 Children Act, while ethical dimensions are largely ignored. Langone (1992) criticises these perspectives. He argues that to abuse is to 'wrongly' use someone and this failure to respect another person is ethically wrong regardless of the effects. Patterson and Thompson (1980) similarly cite 'lack of respect' as the major constituent of emotional abuse. Here there are echoes of the sexual abuse debate, central to which is the morality of exploiting children who cannot give informed consent (Finkelhor 1979a) .

One problem of defining emotional abuse on the basis of effects on children is that they vary. 'At this time we are unable to predict with any certainty which forms of mental cruelty will endanger someone's emotions... serious mental cruelty did not appear to 
always result in the worst outcomes' (Coulshed 1990 p. 23). Similarly Garbarino et al. (1986) talk about 'stress resistant' children; 'we find parents who maltreat the child, yet the child does not manifest any of the corresponding personal characteristics, perceptions, or behaviour problems' (p.45). Anthony and Cohler (1987) devote a substantial work to the topic of the 'invulnerable' child. In their chapter devoted to abused children, Farber and Egeland (1987) argue that few emotionally abused children remain unscathed, particularly if abused from their earliest years. They also feel that factors such as secure attachment, an easy temperament, a stable male parent figure and a supportive network for the mother were all positive factors. But because Farber and Egeland focus on abusive mothering, with no mention of fathers who abuse, these factors may not be true in all cases. Jacoby (1986) offers another factor, 'We know sometimes children are able to survive abuse if they find someone - a teacher, an aunt or uncle - who makes them feel valuable and worthwhile in spite of what their parents say' (p.6).

A related problem encountered when defining emotional abuse on the basis of the child's behaviour or condition is highlighted by Whiting (1978). She describes workshop participants who 'found great difficulty in distinguishing between emotional disturbance and emotional abuse. The emotionally abused child was not easily distinguishable from the emotionally disturbed one' (p. 210).

In an early but comprehensive review of the medical, legal and behavioural literature on emotional abuse, Kavanagh (1982) found that 'no objective, abnormal physical or psychological syndrome has been reliably demonstrated in the child whom most would describe as emotionally abused' (p.175). Just as there is no evidence of a direct causilinear link between childhood abuse and adult malfunctioning, similarly there is no exact link between parental behaviour and manifestations of disturbance in children (Egeland 1991, Glaser 1993).

One area where the link between emotional abuse and the child's state should be clearer is that of non-organic failure-to-thrive (Thompson and Jacobs 1986, Iwaniec et al. 1988, Heger and Youngman 1989, Skuse 1989b). But even this sign is subject to considerable 
uncertainty and debate (Ayoub and Milner 1985, Kershaw 1986, Kay 1988, Batchelor and Kerslake 1990, Hanks and Hobbs 1993). Moreover, as Trowell (1983) indicates, failure to thrive is only one of several manifestations of emotional abuse

The dilemma is summarised by Lyon (1981) 'often a circular reasoning is used whereby a diagnosis is defined in terms of behaviour and then proved by reference to that behaviour' (p.88)

Many of the commentators, conversely, analyse and define abuse solely on the basis of parental behaviour (Miller 1981, 1987, Leisnik-Oberstein 1983, Jacoby 1986, Hickox and Furnell 1989, Grusec and Walters 1991, Klosinski 1993). Skuse (1989a) gives a definition which points to the abusers' behaviour 'Emotional abuse refers to the habitual verbal harassment of a child by disparagement, criticism, threat and ridicule, and the inversion of love; by verbal and non-verbal means rejection and withdrawal' (p.23). Glaser (1993) records a wide range of parental behaviours: persistent negative attitudes; promoting insecure attachment; inappropriate developmental expectations; emotional unavailability; failure to recognize the child's individuality and cognitive distortions or inconsistencies.

O'Regan (1990) citing an American study by Baily and Baily (1986), noted that 85 percent of American practitioners favoured basing the definition on parental behaviour alone compared to 8 percent who believed that the child's presentation was the prime consideration.

However, when defining emotional abuse, Garbarino and Gilliam (1980) highlight the impact on the child. It is, they propose 'the willful destruction or significant impairment of a child's competence' (p. 70). However, they then identify emotional abuse on the basis of parental behaviour - discouraging attachment or punishing operant behaviour or selfesteem or interpersonal skills. Garbarino et al (1986) identify certain parental behaviours such as rejecting or terrorizing, as indicators of abuse but they also recognise the importance of the impact on the child. Kavanagh (1982) and Bourton and Burnham (1992) similarly argue that both parental behaviour and the effect on the children have to be 
considered. The Home Office (1991) definition also suggests account should be taken of both the 'actual or likely' effect on the child and 'emotional ill-treatment or rejection' (p. 49) which relates to the carers' behaviours.

It seems that, as with other forms of abuse, parental behaviour which is judged to be inappropriate is a defining factor. Nevertheless, any definition also has to take account of any potentially negative impact on the child.

\section{Wide or narrow definitions}

Covitz (1986) by implication encompasses a very broad definition of emotional abuse. In his book he defines nearly every form of negative parental behaviour as abusive. Patterson and Thompson (1980) define an emotionally abused or neglected child as any 'who for whatever reason fails to achieve his maximal developmental potential at any time' (p.61). Carter (1983) criticises this on the basis that it leads to maximum state intrusion and fails to see the child in context, instead seeing him or her 'in isolation, dissociated from interactions with and membership of a family, a class, a community and a culture.' (p. 35).

O'Regan (1990) warns against a definition resulting in every parent being potentially 'condemned as abusive' (p.119). Giovannoni (1991) and Thompson (1991) point to the dire resource implications of a wide definition. Garbarino and Vondra (1987) take the debate further by expressing concern about widespread political suspicion of a broad definition and its implied attempt to increase the intrusion of the state into family life. They argue it would be politically unwise, ethically unacceptable, administratively monstrous and scientifically uncertain to do so.

Lourie and Stephano (1978) suggest that two levels of definition - one clinical, the other legal - should be adopted. These definitions would be linked to a two tier service system resulting in maximum service intervention with minimal legal intervention. They then identified twelve parental behaviours which would be abusive if provided in too great or too sparse a quantity but they do not appear to offer two distinct levels of definition. They merely propose a non-judgemental intake system but in situations requiring immediate 
controls then 'a narrow definition of emotional abuse - one that would require community intervention into family life - would be used' (p.204). In a similar vein, McGee and Wolfe (1991a) argue for a separate definition for use by researchers. Haugaard (1991) however challenges this maintaining that any definition must also be relevant to those who will be using the research. Despite this he believes that several narrow specific definitions are more useful than one that is broadly based.

\section{A Comprehensive Definition}

There appear to be a number of conclusions which can be drawn from the current debate on defining emotional abuse. Firstly, it is apparent that it is manifested through both acts of commission and omission. A single behaviour can incorporate both. For example, locking a child away for over-long periods involves both the act of locking up and the omission of any companionship for the child. Secondly, intentionality does not appear to be a major definitional feature, just as intention to harm is rarely a characteristic of physical abuse and neglect. Thirdly, emotional abuse is usually identified by its sustained and chronic nature but acute, single episodes, such as an incident of gross humiliation are equally emotionally abusive. Fourthly, damage can be both immediate and longer term. Fifthly, identification is primarily through the abusers' behaviour although account is also taken of the effects on the child. Finally, it is difficult to formulate a definition that is not too exclusive nor over-inclusive and it may be necessary to use a different definition for different purposes.

One definition seems to address many of the issues highlighted by the other commentators. It was first formulated in the early 1980s (Hart et al 1983) and again presented and further described by the same authors five years later (Hart et al 1987). It is worth quoting in full:

Psychological maltreatment of children and youth consists of acts of omission and commission which are judged on the basis of a combination of community standards and professional expertise to be psychologically damaging. Such acts are committed by individuals, singly or collectively, who by their characteristics (eg., age, status, knowledge, organizational form) are in a position of differential power that renders a child vulnerable. 
Such acts damage immediately or ultimately the behavioural, cognitive, affective, or physical functioning of the child. Examples of psychological maltreatment include acts of rejecting terrorizing, isolating, exploiting, and mis-socializing. (p.6)

One drawback, with this definition, is the potential confusion between the phrases 'psychologically damaging' and the acts which damage the 'physical functioning' of the child. The confusion is however more apparent than real. Children who are physically damaged might consequently have impaired physical functioning such as a badly broken leg resulting in permanent mobility problems. Children who are psychologically, but not physically abused, can nevertheless have impaired physiological functioning such as the terrorised child who becomes enuretic or the humiliated, overweight teenager who subsequently suffers from anorexia nervosa.

However, the positive contribution of the definition is that it addresses most of the issues already discussed and it also introduces significant additional ones. The authors encompass acts of omission as well as those of commission. They include the concept of immediate damage alongside harm to future functioning. While recognising the importance of the effects on the child they define abuse on the basis of parental behaviour and give examples of the abusive behaviours.

The reference to abusers being 'in a position of differential power that renders the child vulnerable' signals that emotional abuse is not just confined to the parent-child relationship but to other situations where one person, even another child, abuses power. This has echoes of the sexual abuse debate where initially only parent-child incest was of central concern and sibling sexual abuse was dismissed as 'children's play'. That was until survivors' accounts (eg Bain and Sanders 1990, Doyle 1990, Wiehe 1990) indicated that exploitation by another powerful child could cause suffering similar to that perpetrated by an adult. The research by Wiehe (1990) shows this holds true of emotional abuse as well.

The definition, likewise, signifies that children can also be abused by adults other than parents. There are several examples in the literature (Krugman and Krugman 1984, Hart 
et al 1987, Nesbit 1991, Bannister 1992).

Finally, Ranney and Cottone (1991) comment 'Emotional abuse as a social (not physical) phenomenon, cannot be defined outside of a social consensus' (p.444). The Hart et al definition acknowledges that the acts have to be set into a cultural perspective and judged on 'the basis of a combination of community standards' in addition to expert professional opinion. This addresses concerns, also encountered in other forms of abuse (see Chapter 2 ), about imposing of the standards of powerful groups on less powerful ones.

\section{PREVALENCE}

At the time of writing, no studies of prevalence or incidence relating to emotional abuse have been widely disseminated. Creighton (1992), for example, excluded emotional abuse in her estimates of nation incidence of forms of abuse. On the basis of registrations it would appear that emotional abuse, as the main or sole form, is the least prevalent of the four main types of abuse. Between 1989 and 1995 there was a rise of emotional abuse registrations from 4 percent to 13 percent of the total but this was still much lower than the other forms (Department of Health 1995a). However, such official statistics of incidence are deemed to be poor indicators of the size of any abuse problem (Ghate and Spencer 1995). The main problem with the registers is that not all abused children are registered while children who are 'at risk' but not actually abused are (Creighton 1992). The issue of how widespread the problem is, cannot therefore be dealt with in detail through the literature.

Iwaniec (1995) argues that the relatively few registered cases 'should not in itself be taken to suggest there is no significant problem' (p.6). Child abuse is often inflicted in the private domain and therefore only a small proportion is likely to come to the attention of officials (Taylor 1992). Coulshed (1990) asked 'friends, relatives and colleagues if they had had a happy childhood'. She admits 'the scientific research[er] would pale at this kind of enquiry' (p.23). Nevertheless, as she also says the findings are worth reporting. She records a considerable catalogue of unhappiness which suggests that emotional abuse could 
be widespread.

Estimating the extent of the various forms of abuse is difficult. Because child abuse is socially constructed (Hallet 1995) different researchers have used different definitions of abuse to collect data relating to prevalence. To highlight the difficulty, even in a form of abuse which might seem clear-cut, ie fatal physical abuse, the debate is contentious. Pritchard $(1992,1993)$ argued that child deaths for which parents were responsible declined in the 1970s and 1980s but Creighton (1993) responded that this was due not to a reduction in fatal abuse cases but to differences in recording practices.

Even greater problems were encountered with sexual abuse. Finkelhor (1986), Salter (1988) and La Fontaine (1990) in examining prevalence rates from a range of studies noted that the figures vary considerably depending on how sexual abuse is defined and the size and type of sample. Nevertheless, there appears to be a consensus that prevalence is considerably greater than Weinberg's (1955) estimate that only one-in-a-million of the population was the victim of incest. The experiences of those researching sexual abuse have found retrospective population studies a useful indicator of its extent (Baker and Duncan 1985, Finkelhor 1986, Ghate and Spencer 1995) and this is the method adopted for this study.

The focus for this study is on prevalence - ie the proportion of the population who are victims of this form of abuse, rather than incidence - ie the numbers of new cases occurring in a given period of time. While prevalence is difficult to determine, incidence is fraught with even greater problems and is therefore not attempted (see Finkelhor 1986 p. 18). Ghate and Spencer (1995) also argue that prevalence rates provide 'estimates closer to a "true" rate than do incidence studies' (p.2).

\section{LOCATION}

The location of emotional abuse is not easy to determine. Garbarino and Ebata (1983) and Garbarino and Vondra (1987) discuss the dilemmas posed by the social context of abuse. 
A central problem relates to sources of information. Certain types of families and children may more readily come to official notice, so abuse may feature more in those instances than in others.

\section{Social and Cultural Contexts}

Two British studies demonstrate the predominance of reported emotional abuse in the less affluent socio-economic groups. Furnell et al. (1988) looked at 170 children referred for emotional abuse to the Children's Panels in one region of Scotland between 1980 and 1984. Analysis of these produced a profile of multiple social disadvantage and risk of alcohol or drug abuse. In each year about half the children lived in families where the available parent/s were unemployed. Well over half of the cases each year were in the poorest sector (social class V). At no time in the study were children from the wealthier sectors (social classes I and II) in evidence. The authors suggest one reason for the over-representation of the poorer socio-economic groups is that emotional abuse, in common with physical abuse, could be correlated to environmental and family stresses associated with low incomes. An additional or alternative reason advanced by Furnell et al. (1988) is that, because their study examined referred instances, it was more likely to include those families who were vulnerable to suspicion and external vigilance. Furnell et al's (1988) findings may be more about referral processes than about the dynamics of emotional abuse. This view of referral processes is similar to Smith's (1978) conclusion from her study of the treatment of poor, black families in the States 'Individuals of like social classes and race tend not to report each other... middle class and upper income families rarely get reported. It is simply made easier for them to maintain anonymity' (p.109).

A much smaller piece of research is described by Hickox and Furnell (1989). They looked at seven parents, legally established as emotionally abusive, with a closely matched group of 'problem' [sic] parents using day nursery facilities. They found that the abusive parents were less likely to be supported, had poorer coping strategies and experienced a more abusive childhood than parents in the control group.

Egeland and Erickson (1987) address the issue of socio economic status and refer to earlier 
research by Elmer (1977) which indicated that abuse is often to be found in homes characterized by general disruption and deprivation and children's development is as likely to be affected by class membership as by abuse itself. But Covitz (1986) cites numerous examples of children from the wealthiest sectors of American society who consider themselves to have been emotionally abused. In some cases, cited by Covitz, the parent's wealth itself was deliberately used to control or humiliate the children, in other instances, such as that of 'Vincent' (p.86), one parent pursued a luxurious life-style while the children were forced to live frugally. Both Watts (1988) and Covitz (1986) provide examples which show that emotional abuse can be present in all socio-economic groups in society.

Cultural issues in the sense of ethnic and racial ones present even greater complexities. An article by Rohner and Rohner (1980) addresses issues of culture in detail. The authors examined the literature on child rearing in a range of different cultures and asserted that whole societies, such as the Ik people in the mountains of Uganda, could show an indifference towards their children that would be regarded in the West as emotionally abusive. Korbin (1978) argues that Western cultures have decreased children's sense of self-worth and self-esteem by their failure to allow children to make an important contribution to the well-being of their households through 'adult' work activities. The juxtaposition of these two articles demonstrates that, rather than being an absolute concept, 'emotional abuse' is constructed from the perspective of different cultural values.

\section{Type of Child}

None of the studies identify a particular type or category of child who is susceptible to emotional abuse. Creighton (1992) looked at children registered as emotionally abused and found that both genders were equally represented. All ages were affected although Creighton found that the average age was 7 years. Jones and McCurdy (1992), reviewing all forms of abuse, found no distinguishing features in emotional abuse cases, although children older than 12 years were deemed to be most at risk.

Some commentators, however, have identified children who appear more vulnerable or 
who suffer from multiple oppressions. These include children from minority ethnic groups and those with disabilities. Jones and Jones (1987) view racism specifically as a societal form of emotional abuse encompassing '(a) excessive negative experience...acts of commission - and/or (b) a deficiency of positive experiences - acts of omission' (p.147). Reschly and Graham-Clay (1987) add 'Prejudice and cultural bias are among the most intractable, pervasive, and damaging of all the kinds of psychological abuse of children' (p.137). O'Hagan (1993) similarly contends that an attack on a child's race, creed, culture and language, which is at the root of racism, is an attack on his or her identity, which is a form of psychological abuse.

At an individual, intra-familial level, Lau (1991) describes the racist assaults by adoptive cousins on a black African Caribbean boy of white adoptive parents. Also, at the individual level, Banks (1992) points to the emotionally abusive nature of the rejection of dual heritage (mixed race) children by one parent when there has been an acrimonious separation from the other parent. He cites the example of eight-year-old Nathan whose mother would say, in his presence, " "Every time I look at him [the child] he reminds me of that black bastard and what he did to me"'(p.12).

There is an increasing literature concerning the physical and sexual abuse of children with learning disabilities although few specifically address emotional abuse. One article looks at the emotional abuse of learning disabled children in schools (Nesbit 1991). A second article (Verdugo et al 1995) examines all forms of intra-familial abuse in a group learning disabled children. The authors conclude that nearly 10 percent of their sample were subjected to this form of abuse. They used an ecological theoretical framework and the severity of abuse increased, not only in relation to parental and environmental factors, but also in relation to factors within the child such as functional and language impairment. The authors argue that children with learning disabilities are likely to be particularly susceptible to physical neglect and emotional abuse. Iwaniec (1995) also highlights the increased vulnerability of children who do not necessarily have recognised disabilities but have inborn characteristics, such as hypersensitivity or withdrawal responses to new stimuli, which make them difficult to manage. 


\section{MANIFESTATION}

Emotional abuse can be identified either through the acts of omissions and commissions of the abusers or through the response of the victims, or both.

\section{Parental behaviour}

Several researchers have scrutinized mothers' attitudes and behaviours. Leisnik-Oberstein et al (1995), for example, examined psychologically abusing mothers and found that, in common with other abusing parents, they had a high level of hostile feelings associated with low coping skills, negative childhood upbringing and strain. It is a matter of concern that these and similar projects (eg Egeland and Erickson 1987) appear to 'mother-blame' putting the full weight of responsibility for children's welfare on the mother and equating 'mothering' to parenting. There is a marked lack of research into the role of father-figures in child abuse in general (Haskett et al 1996) and emotional abuse in particular.

Many commentators try to identify abusive parental behaviour on the basis of categories of carer behaviours. Jacoby (1986) uses the 'four D's' - deprivation, distancing, depreciation and domination. She provides a case example to illustrate each of these.

Grusec and Walters (1991) offer five categories: 'harmful disciplinary practices'; 'lack of responsibility and warmth'; 'exposure to deviant models'; 'extreme overprotection'; 'exploitation'.

Hickox and Furnell (1988) assign all the cases they reviewed to one of four groups depending on parental behaviour and conditions: 'mental illness'; 'unsatisfactory parentchild relationships'; 'unsatisfactory child rearing methods'; 'unsatisfactory life-style'. The last of these four could prove controversial if applied in a blanket form to the life style of a particular section of society such as travelling people. The word 'unsatisfactory' is difficult to operationalise because of the value judgement implied by the term.

Hart et al (1987) offer eight 'domains' through which emotional abuse can be identified. 
These include four situations where societal conditions are probably of more importance than the caregivers' behaviours - living in dangerous environments, substance abuse by children themselves, cultural prejudice, and institutional abuse. Both these authors and O'Hagan (1993) include sexual abuse although, nowadays, this is usually recognised as a form of abuse in its own right. This leaves three domains, echoing Grusec and Walters (1991) - mental cruelty, influence by negative or limiting models, and stimulation deprivation.

Perhaps the most functional categorisation is given by Garbarino et al. (1986). It links quite closely to the parental behaviours suggested in the comprehensive definition by Hart et al (1983, 1987). Both identify rejecting, terrorising and isolating but Garbarino et al (1986) have 'ignoring' and 'corrupting' instead of 'exploiting' and 'mis-socialising'. They provide an explanation of the meaning of each category. For example, among terrorising would be threats of severe or vague, but sinister, punishments. They relate the perpetrator's behaviour to the age of the victim: infancy, early childhood, school age and adolescent. They argue that behaviours which might terrorise an adolescent may have little meaning for a baby. But Thompson (1991) highlights the difficulties that these categories might create given their very different meanings to different groups. Moreover, Garbarino et al (1986) fail to take account of the child's capacity, condition and situation. Two 8-year-old children, one with and one without severe learning and communication difficulties, may be terrorised by very different behaviours.

Davis (1996) scrutinised verbal aggression, one particular form of emotional abuse. He looked at threats to children to physically punish and hurt them. He used naturalistic observation in public places in America such as shopping malls. The adults' behaviour described encompassed terrorising, verbal denigration and humiliation. What emerged were often extreme threats, 'I'm gonna punch you in the mouth' or 'knock the shit out of you' for misdemeanours such as a toddler squirming in a baby seat or another toddler 'lagging behind'. He concludes 'threats of corporal punishment may be an especially denigrating and potentially harmful form of verbal aggression. They can instill fears of physical pain and symbolically reduce children to physical objects' (p.301). This research 
is an echo of an earlier British project by Yule (1985) whose findings were similar.

Vignettes were used by Burnett (1993) in his survey of the psychological abuse of latency age children. He sent out 20 short case descriptions to 1,413 people of which 833 were returned from 'citizens' and 452 from social workers. Two vignettes were used to describe ten parental behaviours and well over two thirds of the respondents felt that nine out of the ten were abusive. There are similarities in the degree of consensus between this and a study undertaken with Arabian students (Haj-Yahia and Shor 1995) in which vignettes covering all forms of abuse were assessed by the students. They showed greatest consensus $(94.8 \%)$ in the vignette describing emotional abuse. What is interesting about these two studies is that, although difficulties of definition and identification have been highlighted by many commentators (see above), the respondents, whether professional, student or 'citizen', were largely in agreement as to what constituted emotional abuse and also agreed about what was serious and what was less so.

\section{Children's response}

The complexities of trying to recognise emotional abuse through its manifestations in the child has been discussed and will depend on the context, the temperament of the child and other available support. However, some authors have attempted to classify emotional abuse based on the manifestation in the child. Hunter (1990), for example, offers a framework based on the condition of the victims: severely neglected children; the exploited child; the rejected child. This springs from an analysis of children's needs (see Chapter 1) which has its foundation in the work of Kellmer Pringle (1974).

Dean (1979) offers a three fold classification: emotional neglect; emotional assault; emotional abuse. The distinction, according to Dean, between emotional assault and abuse is that in the first the victim feels 'attacked' and 'vulnerable'. In the second the 'victim may not realize he is being abused and the abuser may not recognize his abusive behaviour' (p.19). This is useful in drawing attention to the fact that not all abuse may be recognised by the victim or perpetrator. But the practicalities for child protection workers of trying to operationalise this subjective distinction is not addressed. 
One of the very earliest research projects was by Pemberton and Benady (1973) who looked at a clinical sample of 12 'consciously rejected children' using 12 matched children, who were referred to the clinic for other reasons, as a control. They found considerable behavioural difficulties and marked problems in interpersonal relationships in the subject children while their parents experienced substantial marital instability. However, this study highlights the problems of determining to what extent the behaviour and relationship difficulties are a cause or an effect of the rejection.

Egeland and Erickson (1987) set out to determine how far abusive parental behaviours influenced the social and emotional development of children. They undertook a longitudinal study of 267 primiparous pregnant women with a significant number of 'risk' factors - low socio-economic status, young age, lack of support, chaotic living conditions and substantial life stresses. Ninety-six babies were defined as maltreated including 19 whose parent were 'psychologically unavailable'. A control group was selected. All the samples were then observed at intervals up to school age. Children in all the maltreatment groups functioned poorly and the psychologically unavailable category fared worst of all on a number of rating scales. Finally, Coulshed's (1990) research found that respondents who had suffered isolation and rejection rated their self-esteem as 'low' but most adversely affected were those who had been terrorised by threats of abandonment.

\section{INTERVENTION}

The majority of authors either decline to consider intervention or do so in the context of the difficulty of formulating a definition appropriate for both treatment and legal action (Lourie and Stephano 1978, Dean 1979, Trowell 1983, Montgomery 1989). Other writers discuss the difficulty of obtaining sufficient evidence for court but without explicitly stating why using legal authority is the preferred course of action (Furnell 1986, Hunter 1990). Fortin and Reed (1984) and Melton and Thompson (1987) go one stage further in warning about the effects of court action and the helping system in compounding the emotional abuse. 
Brougham (1996), looked at the professional response to emotional abuse through a content analysis of the files of 22 children from 11 families in one local authority. She concluded that professionals tend to underestimate the 'serious long-term effects which can result from emotional abuse' (p.56). She also noted that in case conference professionals focus on parents to the exclusion of any concern about the children's feelings or wishes. The child protection plans emanating from the conferences rarely recommended any therapeutic intervention for the children. She also noted a neglect of a consideration of the power relationships in families and the 'low status' of women and children reflected in the decisions made.

One of the earliest intervention strategies was suggested by Mulford (1958) who recommended a casework approach based on both the children's and parent's needs. One of the most recent strategies advocated by Glaser (1993) also advocates recognising both sets of needs and working directly with the parents and with the children.

Another early project was undertaken in Australia by Carter (1983). She sought the opinions of social workers on how they viewed emotional abuse. She then asked a group of 41 mothers their opinions of discipline and punishment. Many parents showed extensive negative attitudes to their children. From this Carter concluded that there needed to be more 'facilities where the family can be dealt with as a system' (p.114). Ranney and Cottone (1991), likewise, recommend a family systems intervention in cases of emotional abuse. However, systems theory (see Chapter 2) has been criticised by feminist writers such as MacLeod and Saraga (1988) because it fails to address the realities of power relations in families.

Iwaniec (1995) provides a comprehensive and accessible guide to a range of possible interventions including family work, group work, partnership with parents and helping strategies with children. Her focus is on helping those children who are failing to grow and thrive especially where there are problems of attachment and bonding, rather than other forms of emotional abuse such as terrorising associated with witnessing domestic violence (Higgins 1994). 
A substantial discussion of intervention is offered by Garbarino et al (1986). As proponents of the ecological theoretical approach to child maltreatment, they recognise that emotional abuse has many facets and one single intervention would not be appropriate in every case. They take a broad eclectic approach. They suggest that in those cases involving multiple socioeconomic deprivations, intervention is focussed on alleviating environmental stresses; this can be either through a community approach and/or on a case by case basis such as helping an unemployed father obtain retraining. In other instances the root cause is tense and unsatisfactory family relationships either between children and parents or between the parents themselves. In these cases the authors advocate a range of marital counselling and family, group and individual therapies to resolve the relationship issues, The third set of problems are related to family isolation and the solution is to mobilise community support. These authors also recognise that not all cases of psychological abuse are intra-familial; consequently they look at the assessment, supervision, support and training of child care workers in residential establishments.

Garbarino and Garbarino (1986) suggest a five point plan: improved communications between professionals, parents and the community ; child care instruction for expectant parents; the use of every opportunity to encourage the expression of warmth and positive regard for a child; self-help groups to encourage skills of nurture; research to find out the cause and significance of anti-child values.

Compared to the plethora of interventions for adult survivors of sexual abuse (see Doyle 1994 p.258), Cook (1991) appears to be one of the few writers to focus specifically on help for adults coping with the aftermath of emotional abuse. Although the setting is a college counselling service the intervention described would be appropriate for adult survivors of emotional abuse coming to the attention of other agencies. She advocates a sensitive recognition of problems followed by helping the students talk about home-life and a referral for professional help where necessary. She also identifies the helping process.

Finally, several authors look beyond the parents, family, local community and child care institutions to society in general. Fortin and Reed (1984) make the point that 'The broader 
cure, however goes deeper: to the basic attitudes and values from which child abuse and child protection are addressed. Basic to our system is an emphasis on parental rights as opposed to the rights of children' (p.118). Hart (1988) looks at prevention and emphasises the need for 'a positive ideology of children, valuing them in their own right rather than primarily for the manner in which they meet the needs of others' (p.249). Coulshed (1990) argues that all adults should be taught about children's emotional, as well as physical and social, development. She echoes the words of Butler-Sloss (1988) that children should be treated not as objects of concern but as people in their own right.

\section{OVERVIEW}

Compared to the literature on physical and sexual abuse, that on emotional abuse is relatively sparse (Doyle 1996a). However, since Carter wrote in 1983 about the 'scanty publications available', much more has been written directly on the topic.

While the concerns of practitioners (see Figure 1) and the literature associated with the wider context of abuse have provided the broad areas for research, the current literature specifically devoted to emotional abuse have indicated which topics require a particular focus.

Issues of definition are prominent and discussed extensively in the current literature. However, the merit of the comprehensive one provided as early as 1983 by Hart et al. has perhaps been underestimated. As a result of the review of the current debate their original definition, with modifications, will be used as the working definition for this research (see Chapter 4). This is because theirs is a comprehensive definition which appears to address, either directly or indirectly, issues highlighted by a substantial number of other commentators. It identifies the need to take account of acts of commission and omission by power holders as well as the effects on the child both immediately and in the longer term. In addition, it addresses the concerns identified by professionals (see Introduction and see Figure 1) in the current literature and historically in relation to other forms of abuse, about imposing the mores of one group on another and defining any practice which 
departs from them as abusive. Hart et al advocate taking account of 'community standards' as well as professional opinion.

The definition also acknowledges the place of power in relation to abuse. Power issues have emerged as significant in relation to sexual abuse. This has many similarities to emotional abuse, to the extent that some commentators (Hart et al 1987, O'Hagan 1995) have seen sexual abuse as a variant of emotional abuse. In addition ecological theory, which provides a framework for this research, identifies the misuse of parental power as one of the necessary conditions for the occurrence of abuse.

Given the extensive debate in the literature about the definition of emotional abuse, issues of definition, while not ignored, will not be the central focus of the current study.

Attempts to estimate the prevalence of emotional abuse have not been addressed in the literature. This may be associated with the perceived problems of definition. It is however important, as the recognition of sexual abuse has demonstrated, to have some idea of how widespread a problem is. Prevalence therefore is one of the five key issues examined in the present project.

In terms of location, issues of class, culture and social context also remain unresolved. Furnell et al (1988) found emotional abuse was more readily identified among socially and economically disadvantaged classes but cases cited by Covitz (1986) counter this. Further research is evidently needed to clarify these issues and consequently location is an area addressed in detail in this current project.

In order to facilitate recognition and intervention, the characteristics of abusive behaviour need to be identified. The review of the literature showed how a number of commentators have tried to identify and classify abusive behaviour. Recognition is also facilitated if the impact on the victims and their responses are examined. Further information about the manifestation of emotional abuse is sought in the present project. 
In relation to intervention, Garbarino et al. (1986) stand out as offering a comprehensive set of guidelines although their work is not very recent and is situated in the North American social context. Iwaniec (1995) provides considerable guidance which is both contemporary and relevant to the British context. However, her focus is explicitly on 'children within the age group $0-12$ ' (p.xiv) and is largely based on research into nonorganic failure-to-thrive and psychosocial dwarfism. Without more research uncertainty about appropriate intervention, relevant to all cases which British child protection workers may encounter, remains. The current project seeks to complement the work of Iwaniec and therefore focuses less on failure-to-thrive and more on the broad spectrum of emotional abuse, encompassing the full 'registerable' age range ie from 0-17 years.

Overall, while many works discuss emotional abuse the published research projects into all aspects of emotional abuse have been limited both in number and scope. Rosenberg (1987), Garrison (1987) and Haugaard (1991) all emphasise the need for further research into this form of abuse. The present project therefore attempts to meet this need, with a particular emphasis on those areas which, as identified through a review of the literature, have been less well served by researchers to date. 


\section{CHAPTER A}

\section{THE RESEARCH DESIGN}

This chapter describes the research design adopted for the study including the method of obtaining information from three research populations and the characteristics of those populations.

The overall aim of this study is to look at issues of intervention and, as an applied social work project, to provide a contribution to competent intervention in cases of the emotional abuse of children. In reaching this aim five factors, identified in the Introduction, are explored. These are:

Definition: intervention requires an operational definition. The definition by Hart et al (1983) provides the foundation for a working definition for the purpose of the current research. However, the extent to which this could be operationalised by practitioners is a matter of exploration during the course of the study.

Prevalence: a broad indication of the size of the problem is required. This is likely to influence decisions about whether to intervene on a case by case basis or whether changes in public policy are required.

Location: in order to intervene it is necessary to know where abuse is to be found and where resources should be targeted. This involves examining in what type of child, family and situation abuse occurs.

Manifestation: intervention requires an appreciation of those parental behaviours which might be deemed abusive and the possible signs in the victims.

Intervention: for the purposes of this study there are two components. The first is an examination of intervention to date because it is only from a knowledge of current practice that the need for additional courses of intervention can be established. The second is the 
identification of good practice and helping strategies which could usefully be retained and more widely introduced.

\section{METHODOLOGICAL CONSIDERATIONS.}

Five factors were taken into consideration in formulating the design:

a) The nature of the research, that is an applied social work project;

b) Aspects of the objectives itemised in the Introduction and in the previous section;

c) The sensitive nature of the research topic;

d) The ecological theoretical framework;

e) Resource limitations.

\section{Applied social work}

As an applied social work project it is guided by recent developments in social work research. Everitt et al (1992) for example reject the positivist traditions on the grounds that social work is 'uncertain, complex, spontaneous and concerned with individual difference' (p.8). Moreover, social workers' recognition of 'society as stratified by gender, race, class and age, leads to a questioning of the notion of value-free observation' (Everitt et al 1992 p.8). Cheetham et al (1992) similarly advocate that account is taken of the complexity of social work:

There are understandable suspicions of research which appears to deal in simple inputs and outputs and to inhabit a world devoid of conflicting objectives, unintended outcomes, huge and complex suffering, grand goals but limited means of relief (p.6).

This means that strategies such as 'triangulation', that is 'different ways of collecting data on the same issue to ensure more reliable results' (Everitt et al 1992 p.90), taking multiple perspectives, combining qualitative with quantitative approaches, giving voice to less powerful sectors and adopting a broad eclectic theoretical perspective are increasingly used in social work research. The present research incorporates these strategies. 


\section{Aspects of the objectives}

The working definition of emotional abuse for this study is adapted from the one provided by Hart et al (1983) (see Chapter 3). However, the original requires certain boundaries and modifications.

The focus will be on carers who abuse, despite the validity of the phrase 'acts committed by individuals, singly or collectively, who by their characteristics (eg age, status, knowledge, organizational form) are ... '. Bullying in school, racism or homophobic insults, are all types of emotional abuse and social workers have a responsibility to challenge every form of maltreatment. Non-carer abuse will, therefore, not be dismissed completely in this research. But, this is an applied social work project and is designed to address the primary concerns of practitioners. As Montgomery (1989) indicated, parents are the people primarily responsible for the protection of their own children. The various protective systems are designed to protect children in those cases where they cannot turn to their natural protectors because their carers themselves are responsible for the abuse. Hence the focus in this project will be on parents or substitute parent figures as abusers. A parallel can be drawn with physical abuse where social workers would not be expected to deal with every incidence of assault and bullying in school or among neighbours. Parents, schools or, in extreme cases, the police would normally deal with such cases leaving social workers to concentrate on children abused by their carers. Only rarely is abuse by unrelated adults the focus of social work concern (Farmer and Owen 1995).

The present research, is also designed to address practitioners' concerns about those instances of emotional abuse where there is an absence of other forms of abuse. In such cases there is a lack of physical injuries or disclosures of sexual abuse. Therefore, the part of the Home Office (1991) guidelines which limit the 'emotional abuse' category to cases where emotional abuse is the predominant form has been added to the working definition.

The phrase 'and youth' has been omitted. This is a pragmatic decision to simplify the definition. Most of the procedures and legislation such as the Children Act 1989 encompass young people up to the age of 17 within the terminology 'child'. 
A further modification is the exclusion of the phrase 'Examples of psychological maltreatment include acts of rejecting, terrorizing, isolating, exploiting, and missocializing' This is because the validity of these categories of emotional abuse have yet to be established.

The working definition of emotional abuse for the purpose of this study is therefore:

Emotional abuse of children, as the sole or main form, consists of acts of omission and commission which are judged on the basis of a combination of community standards and professional expertise to be psychologically damaging. Such acts are committed by parent figures who are in a position of differential power that renders the child vulnerable. Such acts damage immediately or ultimately the behavioural, cognitive, affective and physical functioning of the child.

Central to this definition are several concepts:

* Acts of omission and acts of commission are both constituent elements of emotional abuse.

* Abusers are carers in a position of differential power to the victims.

* They use their power in a way that adversely affects the child either immediately and/or in the longer term.

* Judgements are made by combining 'community' standards and professional opinion.

In order to explore the concepts enshrined in this definition, they had to be applied to identified cases of emotional abuse. One data source, therefore, was registered child protection cases, established as ones in which emotional abuse was the main or sole form of abuse (see Chapter 2). Another source was the personal accounts of survivors who identified themselves as emotionally abused as children.

Turning to the remaining objectives, identification of prevalence and location requires quantifiable answers to questions such as; How many people are affected? Are there more boys than girls? The answers to such questions will take the form of numbers. Identifying 
the manifestation of a problem and discovering how people can be helped requires descriptions in words. While it might be useful for practitioners to know how many emotionally abused children are likely to be 'terrorised', it is even more useful to know what is meant by terrorising behaviour, with the provision of examples from people who have witnessed what they believe is terrorising behaviour or from those who experienced it as children.

Issues of intervention require both a 'provider' and 'consumer' perspective. The providers are, in the main, child protection professionals. The consumers are the children who are being emotionally abused. However for ethical reasons (see below) children's perspectives have to be provided by adults who were emotionally abused. Account can be taken of these two perspectives through data gathering from both professional workers as well as former victims of abuse.

Brannen (1992) points out that traditionally quantitative and qualitative methods have been kept apart by epistemological gulfs; the positivist, deductive, empirical tradition versus the naturalistic, inductive one. However, it is now firmly established that in many instances the two can be used in the same study (Jick 1983, Hammersley 1993, Banister et al 1994, Mason 1994). Bullock et al (1992) commenting on social policy research note:

Quantitative approaches can provide authoritative survey data and relate diverse factors. They can also assess the incidence, epidemiology and boundaries of problems of the situation under scrutiny ... Qualitative approaches in contrast lead to a much greater understanding of the meaning and context of behaviours and the processes that take place within observed patterns of interrelated factors ... However, it is noticeable that few social policy studies have exclusively adopted one approach at the expense of the other (pp.85-86).

This present study is no exception. Issues of prevalence and some aspects of location, manifestation and intervention require numerical description and measurement. Issues relating to manifestation and appropriate forms of help require illustrative, qualitative data. 


\section{Researching sensitive topics}

Renzetti and Lee (1993) define sensitive research as any that deals 'with behaviour that is intimate, discreditable or incriminating' (p. ix). Emotionally abusive behaviour fits the first two conditions. This study also conforms to the definition of sensitive in that it has 'potential consequences or implications, either directly for the participants in the research or for the class of individuals represented by the research' (Seiber and Stanley 1988 p.49). For this reason, ethical considerations form an important aspect of the research design.

While feminist theory does not dominate the design, notice was taken of Eichler's (1988) advice to avoid sexist research and of Mies' (1983) argument that participants should be treated as people with real emotions and feelings. This was particularly important in relation to interviews with the survivors of emotional abuse. Here, Oakley's (1981) critique of traditional research interviews and their failure to recognise the imbalance of power relationships informed the research design. So too did Bergen's (1993) advocacy of 'empathetic listening' and a non-exploitative approach to the conduct of sensitive interviews.

Finally, the Cleveland report asserts, 'The child is a person and not an object of concern' (Butler-Sloss 1988 p. 245). This influential statement means that it would be difficult now in research relating to child protection to fail to take heed of these words when formulating the research design.

\section{Theoretical Framework.}

Ecological theory provides a framework for investigation and informs the issues to be explored. Information was sought about problems relating to individuals, their relationships and environmental stresses. These comprise the 'sufficient' conditions for abuse. Account was also taken of the two 'necessary' conditions for abuse which are a) social isolation and b) power relationships between adults, especially parents, and children. 


\section{Funding}

Several authors (Finkelhor 1984, Brannen 1992, May 1993) point out that funding constraints cannot be ignored. The present study, having minimal funding, had to cope with these constraints. This meant compromises were inevitable. For example, truly representative general population samples are difficult to obtain without substantial funding, so that researchers have had to rely on more accessible population groups such as students (eg Finkelhor 1979b) or television or other media audiences (see La Fontaine 1990). In this study, accessible, rather than representative, population groups have had to be used

\section{DATA SOURCES}

Traditionally, according to Hallet (1995), there have been three main sources of data with which to estimate prevalence:
a) clinical samples;
b) registrations of acknowledged cases;
c) general population surveys.

Hallet (1995) notes that studies of clinical populations tend to be small and any control groups used are unlikely to representative of the general population. Registered cases may not be representative of all the cases occurring in the community because they might be skewed towards those sectors of society who are the focus of state scrutiny (Furnell et al 1988). There are difficulties with population surveys due to differing definitions and views of what constitutes abuse. Surveying children themselves poses substantial ethical and logistical difficulties. But adult memories, as the debates on eye-witnesses and 'false memory syndrome' have shown, are not wholly reliable (Loftus et al 1978, Loftus 1993, Nursten and Smith 1996). However, by combining two or more data sources - official, population and individual accounts - some of the deficiencies of each may be compensated for by another.

In order to obtain information about the validity of the working definition and about 
prevalence, location, manifestation and intervention, a triangulated research design was therefore chosen. There were three main data sources:

A semi-structured interview with a sample of professionals.

To provide information about location, manifestation and current intervention.

A questionnaire based population survey

To provide information about prevalence, location and some limited information about manifestation and past intervention.

Open, in-depth interviews of people who identified themselves as emotional abuse victims. To provide primarily information about helpful intervention strategies with some illustrations of manifestation.

To avoid confusion and repetition the following labels will be used:

'Register cases' - to indicate information gained from interviews with key workers of children currently on the register.

'Population survey' to refer to the information gained from a sample taken from a larger population of adults on a variety of training courses, through their responses to a questionnaire.

'Survivor interviews' to refer to the information gained through in-depth interviews with adults who were emotionally abused as children. The interviewees themselves will be referred to as 'survivors' or 'volunteers'.

\section{DATA COLLECTION METHODS}

The means of collecting the data depends on the nature of the research problem. In relation to prevalence and location quantifiable data was required. For this, a form of survey was 
appropriate, 'Since experimentation cannot be used to investigate a wide range of macrosocial processes there is often no alternative to considering variation across cases in a systematic fashion' (Marsh 1982 p. 147). Quantifiable survey information has to be collected in a structured form (Marsh 1982). Two main options were questionnaires and structured interviews. Both were employed in the present survey. May (1993) identifies collecting data through questionnaires as a rapid and relatively inexpensive method. This was the most appropriate method for collecting data from several hundred people in a relatively short space of time.

However, this is contrasted to qualitative data which is most appropriately collected in an open, unstructured format. The questions relating to abusive behaviours, the responses of abused children and the type of help that could be offered to them requires qualitative exploration. Open-ended questions on questionnaires can be used but interviews 'permit exploration of issues' (Banister et al 1994). Both were used in the present study.

Semi-structured interviews of key workers were employed for the register cases because both structured, quantifiable and unstructured, exploratory answers were required,. These were conducted over the telephone. The main advantage of using the telephone was that a much wider geographical area could be covered making the final sample more representative of registered children nationally. Using the telephone avoided having to use interview office space. Telephone interviews also reduce interviewer influences (Frey 1989). The interviewee would not be seeking non-verbal cues of approval so could provide opinions in a less self-conscious manner.

In the key worker interviews, face-to-face contact was unnecessary because there was no need to be unduly sensitive to nonverbal communication nor to have sight of any case records. In contrast, when arranging the survivor interviews every effort was made to facilitate face-to-face interviews. Fuller and Petch (1995) argue that user perspectives are 'most readily sought through direct face-to-face interviews' (p.42). Some possible increase in interviewer influence and decrease of data quality was a necessary concession because the more sensitive nature of the survivor interviews meant that monitoring of nonverbal 
cues of distress or reluctance to answer was important. Notwithstanding, survivor volunteers were given the option of a telephone interview if they wanted to avoid visual contact. However, all the survivors chose face-to-face interviews.

\section{SAMPLES}

\section{Register cases}

Information was gained from a sample of 112 children registered in the 'Emotional Abuse' category of local registers (see Chapter 2). These were cases which had been defined in a multi-disciplinary forum as having been, or likely to be, emotionally abused. Given the Home Office (1991) guidance in these cases, emotional abuse was likely to be the main or only form of abuse.

\section{Choice of Sample of Professionals}

The key workers in a sample of registered cases were chosen as the most appropriate people to interview. This was because, although they were social workers, they were operating within, and coordinating, a multi-disciplinary team. To a great extent they could represent all child protection professionals. They had a clearer overview of the progress of the case than professionals from other agencies and they also represented the main providers of child protection intervention.

It was decided to approach a number of local authorities and seek their permission to interview the key workers of cases in the Emotional Abuse category of the local ACPC. register.

\section{Participating Local Authorities}

The choice of the numbers of local authorities and cases sampled were based on Creighton's (1992) study. The work of the NSPCC research unit has been well respected over the years and practitioners have viewed their register report series (NSPCC 1975, Creighton and Owtram 1977, Creighton 1980, Creighton 1984, Creighton and Noyes 1989, Creighton 1992) as a useful source of data. The most recent research (Creighton 1992) 
was based on 12 local authority registers. These included 114 children in the emotional abuse category. It was therefore decided that for the present study approximately 100 cases, from 12 authorities, should be sought. In order not to over-burden any single authority it was decided to limit the number of cases to 12 per register. Theoretically this would have given a sample of 144 cases, however because some of the smaller authorities had slightly fewer than 12 appropriate cases, the available cases would be nearer the target of approximately 100 children.

The endorsement of the Association of Directors of Social Services (ADSS) was a useful preliminary to an approach to local authorities. A research proposal and outline was sent to the ADSS Service Evaluation, Research and Information Committee. The Committee decided to recommend the project to Social Services Departments.

Twenty local authorities were selected primarily on the basis of geographical and demographic factors to ensure a spread throughout England with a balance between rural and metropolitan areas. The fact that the interviews were to be by telephone meant that geographical distance was not a constraint. Account was also taken of the analysis of rates of registration as identified by Little and Gibbons (1993) to ensure that the local authorities in the sample were representative and the resulting cases selected would not be atypical of registrations in the country as a whole. Finally, the advice of current researchers was taken on those local authorities unlikely to be able to participate.

Of the 20 local authorities, three declined due to problems of reorganisation. Twelve agreed to participate. These included four county councils from predominantly rural areas located in middle, eastern, western and southern England. There were five London metropolitan authorities representing very different areas and political affiliations. The final three participants were metropolitan boroughs - from the north-west, north-east and the Midlands. These initial 12 authorities provided a variety in terms of geographical location and type of authority. Of the remaining five authorities, three did not reply and two were unsure; their agreement was not pursued. 
The twelve participating authorities were English. Consideration had been given to including areas in Scotland, Northern Ireland and Wales. But Scotland and Northern Ireland have some different legal and policy provisions while in Wales local authority reorganisation was more imminent that it was in England. There was the possibility that Welsh authorities would have been re-organised out of existence during the period of the research. A decision therefore was taken to limit the scope of the research to English authorities.

Below is a list of the estimated population of the authorities at the start of the research:

County Councils:

1652,740

2554,400

$3 \quad 590,900$

$4 \quad 1,000,400$

Total for county councils: $\quad 2,798,440$

London Metropolitan Boroughs

$5 \quad 187,100$

$6 \quad 245,739$

$7 \quad 132,200$

$8 \quad 263,000$

9169,700

Other Metropolitan Areas

$10 \quad 997,000$

11206,467

$12 \quad 467,500 \quad$ Combined total for all metropolitan boroughs: $2,668,370$

(Source: Social Services Year Book 1990/91, ed. Lodge 1990)

The combined population total for the four county councils was similar to that for the eight metropolitan boroughs. The differing population sizes in individual authorities meant that there were differences in numbers of registered cases. For example, London borough No. 7 (population 132,200) had nine families on the register in the emotional abuse category while county council area No. 4 (population 1,000,400) had over 90 families 
Permission to interview the key workers was given by the Director of Social Services in all cases. This decision also had to be endorsed by each ACPC because of the multidisciplinary nature of the registration process.

\section{Population sample}

The victims of child abuse and the clients of child protection services are children themselves. It would therefore have been most appropriate to survey children to obtain their views about how they are being treated. However, a study by Higgins (1994) of children caught up in domestic violence shows how very difficult it is for them to articulate their concerns. Furthermore, expecting children to make a negative evaluation of their parent's functioning is unrealistic given what is now known about adaption processes such as the 'accommodation syndrome' (Summit 1983) and the Stockholm syndrome (Doyle 1985, 1990). It was therefore decided to target adults.

The feasibility of a large scale representative sample such as that undertaken by Baker and Duncan (1985) in relation to sexual abuse was explored but it was beyond the resources available to the present project.

Given constraints of time and finance, it was decided to survey students associated with a College of Higher Education (HE). As a convenience sample, they were not representative of the general population. Nevertheless, they can provide a useful perspective. Finkelhor (1986), reviewing and collating a number of research studies on sexual abuse, noted that, 'College samples composed primarily of young adults do not have consistently higher or lower prevalence rates than community samples that include a greater age range' (p. 28). In addition, attempts were made to increase the diversity of the students. A mixed sample, as with mixed methods, can provide the opportunity for the deficiencies in one sample to be compensated for in other samples. Therefore, three main groups of students were chosen.

First, there was a group of undergraduate students. They were taking a range of qualifications including Bachelors degrees and BTec diplomas. The individual courses 
were chosen at random resulting in a broad spectrum of arts, science and social science students. Nearly one in three young people now enter higher education (Dearing 1996, HESA 1996). Therefore, this type of student group will represent a varied cross-section of young people. First-year students were targeted because, although their cohorts contained a few mature students, the vast majority were young people in the 19-21 age group. A disadvantage of this group was their lack of distance from childhood, limiting their ability to evaluate factors such as long-term damage or the effectiveness of any help given. Nevertheless, a substantial advantage was that they were likely to have clear memories of childhood having only recently undergone the transition to adulthood. For the sake of convenience they have been labelled the 'undergraduate' group.

In order to increase the diversity of the student sample and to counter some of the disadvantages of the undergraduate group, Access students were included in the study. These are mature students who for various reasons were not able to take advantage of higher education after completion of secondary education. Time may have clouded their memories of childhood events but they had the advantage of being able to reflect upon their past experiences. Permission was given to survey all the cohorts of Access students attending during the spring term at two Further Education Colleges geographically close to the Higher Education College.

Finally, groups of helping professionals - mainly primary school teachers, social workers, care staff and nurses - on in-service training courses were included. This broadened the diversity of the population sample because the majority were not graduates but, like the Access group, they were likely to be older than the undergraduates. Furthermore, in order to gain insight from survivors about intervention they found useful, helping professionals were targeted on the basis they might be more able to reflect on their experiences than other students. Permission was given by relevant training officers and course leaders to survey helping professionals on all available child care-related, in-service training courses in the county in which the Higher Education College was situated during the same spring term. 
It was decided to distribute approximately 500 questionnaires. Just over half were distributed to the undergraduate group and the rest to the mature students, divided between Access students and helping professionals. This mixed sample gave a balance of recent memory versus considered reflection, educational advantage versus disadvantage, lay opinion versus professional insight.

It was anticipated that much of the data would be subjected to chi-square tests of significance. This requires a balance between total sample and cell sizes greater than five (see Coolican 1994 p.266). It was estimated therefore that for statistical validity at least 25 people who could be clearly defined as emotionally abused were required. The preferred target however was 100 to provide a more appropriate comparison with the register cases. Because there was no guide to prevalence in the literature it was not known whether the minimum of 25 would be achieved, therefore plans were drawn up to distribute a further 500 questionnaires. However, an initial review of the responses to the first batch indicated that the minimum of 25 had been comfortably achieved. In total 504 questionnaires were distributed, of which 429 were completed and returned. This represents a response rate of 85 percent. Of the 281 distributed to the 'undergraduates' 235 were returned $(83 \%$ response rate). Of the 120 and 103 given to the professional and Access groups respectively, 105 and 90 were returned (response rates of $87 \%$ ).

\section{Survivor Interview Sample}

The primary objective of these interviews was to explore ways that survivors believed they had been helped. Their views could then form the basis of suggestions for intervention in future cases. Practitioners have enhanced interventions with the victims of sexual abuse by taking account of survivors' views of what helped them (Bass and Davis 1990) rather than imposing remedies prescribed by professionals.

The need to conduct the research in an ethical and sensitive manner (Bergen 1993, Renzetti and Lee 1993, Seiber 1993) outweighed all other considerations. There could be no coercion in order to obtain an equal balance of males to females or representatives from each ethnic group. Similarly, a target number was not set in order to avoid any element 
of coercion.

Interviews with survivors were undertaken with people who participated in the population survey and who were willing to be interviewed. They were not selected at random, nor were they designed to be representative of the parent population. An additional final sheet was added to the questionnaires given to the 'professional' and 'Access' groups to obtain the 'survivor' sample. This sheet asked respondents who identified themselves as having been emotionally abused whether or not they would be willing to be interviewed (see Appendix 3).

It was decided to confine the request for volunteers to the professional and Access groups most of whom would be at least in their mid-twenties. This was because the other questionnaires were distributed to first-year undergraduates, many of whom were living away from home for the first time. Because the questionnaires were disseminated early in the spring term, it was unlikely that many of these students would have had time to build up strong local supports. They would have less experience of reflecting upon and coping with their experiences than older people. They may not have been in a position to appreciate the impact of talking to a stranger about their painful experiences especially when that stranger was a researcher and not a counsellor. Therefore, they might not have been able to give fully informed consent to the interview.

Twenty-two people volunteered but, of these, four had not been emotionally abused by their parents. One had suffered from racism and three from general discrimination and bullying during their childhood. They were allocated to the 'Other Distress' group and were not appropriate candidates for the in-depth interviews. Three telephone numbers were not obtainable. A further three moved out of the area to new jobs before the interviews could be arranged. This left twelve people who were interviewed.

There is no claim that this twelve is representative of the general population. Instead the survivor interviews employed a method reflecting the case study approach. Smith (1993) comments that this approach is neglected in academic psychology because of: 
psychology's wish to emulate the natural sciences with what is perceived as being their concern with the universal and general, and the employment of appropriately rigorous statistical measurements. Ironically then, a number of philosophers of science point to a much more pluralistic definition of what science is for (p.254).

In support of his view, Smith cites Allport's (1951) comment 'Again and again we meet the biased and superficial objection that personal documents are not, and cannot be, scientifically employed because they deal with single cases' (p.140).

Twelve volunteers will not provide statistics that can be generalised to the population as a whole but they can provide insights into the kinds of help which some emotionally abused children have found useful and which professionals can explore further with the children that they are currently trying to assist.

\section{MEASURES}

\section{Register cases: Key Worker Interview Schedule}

The interview schedule (see Appendix 2) was devised with the objectives of the study in mind. From the register cases information was required about location, manifestation and intervention. In addition, the appropriateness of the working definition had to be explored. Issues of prevalence were left to the population survey. The schedule was influenced by the under-pinning ecological theoretical framework of the study taking into account factors in both the individual family members and the social context.

An initial version was piloted with eight independent social workers. Most were guardians ad litem. Because they were all independent, there was no possibility that they would be selected as one of the key workers for the main study. They were asked to chose a case which was no longer on the register. This was to avoid the possibility of one of the cases discussed inadvertently forming part of the main study.

Four pilot interviews were conducted over the telephone and four were face-to-face. Tape 
recording was used for two telephone and two face-to-face interviews and contemporaneous notes for the remaining four. The interviews were then written up. A combination of telephone interview with contemporaneous notes proved to be the most time and cost efficient technique without any apparent loss of essential details.

The original interview schedule which had been developed from the literature search and with the objectives of the study in mind, was modified slightly in the light of the pilot interviews.

While it was necessary, in order to address issues of intervention, to identify a referral point, the pilot interviews had demonstrated that in many cases of emotional abuse the situation had caused concern to the authorities for many years. Farmer and Owen (1995) similarly found "many of the cases were already "known to social services"' (p.84). There were often changing socio-economic situations with different accommodation, family composition and stresses over time. In the 'already known' cases it was difficult to identify the time of referral. In these cases the event which precipitated the emotional abuse registration was used as a point of reference.

\section{Location and type child and family}

It was necessary to describe the family relationships without using names. For the sake of clarity only one child was identified for each family, even when several children from the same family were registered. Matters were straightforward when the subject was the only child in the family or the only child to be abused. Where several children in the same household were emotionally abused the key worker was asked to nominate as subject the child they deemed most vulnerable in the group. It was also important to chose only one child per family because the statistical analysis of the parental and family features would have been skewed if there had been a number of very large families from which all the children were registered.

To assist later analysis a different code was allocated depending on whether the subject was: 
the 'only child' in the family;

the 'singled-out child' which referred to those cases where despite a number of children in the family only one child was abused;

the 'group child' that is the nominated subject where a group of children in a family were registered for emotional abuse;

\section{Type of child}

The preliminary questions about the child's gender and age at referral were designed to determine whether abuse was more likely to be found in one sex or age group. Ecological theory takes account of the contributory role of problems relating to the child such as bonding failure (Lynch and Roberts 1977). Information about problematic birth circumstances was sought as well as health or disability problems in the child (see Appendix 2).

\section{Family structure}

The pilot demonstrated that a degree of flexibility had to be exercised in seeking information about family structure because it could change over time. Some families were re-constituted or remote from the traditional stereotype of the two-parent nuclear family.

\section{Social class, income and housing}

Given the debate on the role played by socio-economic deprivation in abuse cases highlighted by Gil (1970) and more recently emphasised by ecological theorists Garbarino and Kosteleny (1992), information was sought on the three key determinants of socio-economic deprivation (Alcock 1993), occupational social class, finance and housing.

The Registrar General's classification was used to determine class. Before this decision was reached, recent authors were consulted (Marshall et al. 1988, Saunders 1990, Bottomore 1991). The purposes of the class analysis proved decisive in the choice of the Registrar General's system. The first purpose was to examine whether emotional 
abuse was associated with just one or all sectors of society. To facilitate intervention, the result would have to be conveyed to a range of helping professionals, only a small percentage of whom would be sociologists. Authorities on the subject of class such as Marshall et al (1988) tend to favour a class schema like that devised by Wright (1978, 1985). However his terminology 'bourgeoisie', 'semi-credentialed workers' and 'proletarians' are likely to be unfamiliar and not readily understood by nonsociologists. Furthermore, using the Registrar General's classification meant the findings could be compared with population profiles from the 1991Census and other government documentation.

Another reason for seeking social class based on occupation is that this facilitates an examination of socio-economic deprivation. Alcock (1993) highlights occupational disadvantage as one indicator of socio-economic deprivation. He distinguishes between those who have privileged access to jobs in the core labour market (with relative security, including fringe and welfare benefits) and those with non-privileged access who have to take insecure jobs with few benefits.

It is acknowledged that the Registrar General's classification is a far from perfect system 'The coding of occupational groups and employment statuses provides notoriously unreliable results' (Marshall et al 1988 p.20). The pilot interviews demonstrated that it was difficult to identify whose occupation should be used to determine class. In re-constituted families there may be four or more parent figures. The assumption that the father is the 'head of household' and his occupation is the one that counts is no longer tenable. Even by 1971, Land (1976) had noted that nearly two million women under retirement age were the chief economic providers in their households. It was therefore decided that the occupation of all the subject child's carers would be sought. The occupation of the child's 'main provider' whether mother figure or father figure was used to determine class. However, when it was unclear who the main provider was, then the father's occupation was used for the purposes of classification in order to facilitate comparison with other studies. 


\section{Cultural heritage}

The cultural heritage of the family was explored in order to determine how far emotional abuse is found across cultural groups and to ascertain how far child-rearing practices which might be different from those of the majority culture were being labelled 'abusive'. However, a decision had to be made whether to use standardized categories or non-standard ones based on the key workers' definition. With the nonstandard option there are evident dangers of absurd ones being offered; Ahmed and Sheldon (1993) cite the example of 'Urdu children'. On the other hand the same authors warn against standardization of categories as this 'will give them a spurious air of validity, as "natural" objective, and universal entities'. They add 'the need for and policy relevance of such data requires careful consideration'. (p.129). It was therefore decided that the interviewees would be asked to give details of the cultural heritage in a non-structured format although in analysing this data a more structured categorisation would be required.

The pilot demonstrated the clarity with which questions about ethnicity had to be asked because one pilot interviewee when asked 'What is the family's cultural heritage?' responded with 'Well I don't think they like the theatre much' !

\section{Stressors}

Following Gil's (1970) contention that environmental stress plays a role in abuse cases, information about factors such as poor housing was sought. Following the ecological model, interpersonal and intrapersonal sources of stress were also examined. Early piloting had indicated that the deaths of close relatives particularly other children could affect parental functioning. Key workers were asked 'Has any member of the family suffered significant losses or bereavement?' Miscarriages and abortions were included as the significance of the loss associated with death in utero is often underestimated (Hopper 1994). If a miscarriage reaches case records it is likely to be all the more significant.

Given the longstanding emphasis on the 'cycle of deprivation' or 'intergenerational 
transmission' of forms of abuse (Herzberger 1993) information about parental experiences of childhood abuse was sought through the question 'Has there been a history of abuse in the family'?

\section{Relationships}

The pilot study showed that relationships appeared to be an important dimension. Key workers were asked about relationships between various family members and extrafamilial people. Social isolation, highlighted by ecologists Garbarino and Gilliam (1980) as an essential factor, was explored explicitly by the question Ts the family isolated?'

\section{Manifestation}

\section{Parental Behaviours}

The review of current literature (Chapter 3) demonstrated that commentators on emotional abuse have attempted to categorise emotional abuse cases on the basis of parental behaviours. It appeared useful to test some of the categories. Those identified by Garbarino et al (1986) were used as a starting point with additional categories added as a result of other examples in the literature. However, key workers were asked an open question about parental behaviours they deemed abusive. While some descriptions evidently fell within the pre-determined categories, a more detailed categorisation was undertaken in the analysis stage.

\section{Child Responses}

In much of the literature, the emphasis is on indicators of an adverse impact of the abuse on the child. Questions about the subject child and, where relevant, other children in the household were asked in order to see whether there was a relationship between parental behaviours and the children's response. 


\section{Intervention}

Progress through the child protection system

Referral: Several other studies (eg Hallett and Stevenson 1980, Dingwall et al 1983, Gibbons et al 1995) have analysed how a case is referred to authorities and the relationship between management of the early referral and the later progress of the case. Therefore close scrutiny of this is not the purpose of this study. However, questions were asked about the referral and subsequent responses in order to gain some insight into present intervention.

Removal/legal action: Addressing concerns about children being forcibly removed and unnecessary legal action (Butler-Sloss 1988, Clyde 1992, Cleaver and Freeman 1995 see also Figure 1), one question was asked about whether the child or any emotionally abused siblings had been removed 'temporarily or permanently'. A second question asked about care proceedings or other legal action (see Appendix 2).

Assistance offered: Information was sought about assistance offered to the family. This was in order to gather together a range of possible interventions. It also meant that an innovative intervention in one local authority area could be offered as a model for others.

\section{Evaluation of intervention}

In order to determine if further guidance for intervention is required some evaluation of current practice was necessary. Pietrzak et al (1990) identify four different research methods of evaluation: service audit, direct observation, testing and survey. The costs of the first three would have been prohibitive and would have failed 'to capture all relevant aspects of the topic under study'(p.29).

Survey methods emerged as the most appropriate technique although the drawbacks of this method were recognised. Self-report is subjective, and possibly biased and incomplete. In order to overcome some of the concerns about subjective self-report, attempts were made to introduce a number of more objective and quantifiable 
measures into the evaluation, resulting in the use of a combination of indicators.

\section{Range and Type of Assistance:}

Key workers were asked what assistance was offered. This was then recorded, whether or not the assistance was accepted by the family. It was beyond the scope of research to explore in detail why some offers of assistance were not accepted.

The number of interventions was recorded. A basic count has validity because if it was found that families with a complex number of issues were only offered one resource or type of help then it raises doubts about the appropriateness of the intervention. The count however was a rough guide rather than a precise instrument. This was because referral to a particular resource such as a family centre may involve several different interventions which are part of one 'package' of assistance.

The range of professionals involved in the intervention was explored. This was because there is the requirement (eg Home Office 1991) that agencies should work together not only at the investigative stage but in the later management of cases.

\section{Principles of Good Practice}

This was difficult to determine and not all aspects of good practice could be examined. It was, for example, beyond the scope of the project to look at appropriate record keeping. However, two important areas were subject to scrutiny:

Working in partnership with parents: The Children Act 1989 and other government and professional practice guidelines (Department of Health 1995c, Masson 1995) promote working in partnership with the parents and the avoidance of unnecessary or oppressive legal action.

Anti-discriminatory practice: Thompson (1993) argues 'Good practice is antidiscriminatory practice' (p.10). He defines this as intervention 'which takes account of oppression and discrimination' (p.11). This in turn involves challenging stereotypical 
images of minority groups, recognising their context and demonstrating nonjudgemental attitudes. Specifically in relation to child protection, it requires the avoidance of pathologising child rearing practices which are not part of the mainstream culture.

It was recognised that these would be difficult to identify but blatant examples of oppressive legal action and discrimination could be detected by the researcher who was experienced in qualifying and post-qualifying social work training in which these issues are a paramount consideration (CCETSW 1989).

\section{Key Worker Evaluation}

Another way of assessing effective intervention was to ask the key worker for an evaluation of the intervention. In the past, concern has been expressed that social workers do not undertake evaluation or only do so 'up-to-a-point'(Preston-Shoot and Williams 1988). However, this has changed in recent years. Since the 1980 s there has been an emphasis on the provision of quality in services (Social Services Inspectorate 1992, Cassam and Gupta 1992, Kelly and War 1992, Alaszewski and Manthorpe 1993) and evaluation is an essential component of quality assurance. There has been an increasing emphasis on evaluative research in social work practice. (Cheetham 1994 ). Journals allied to social work provide evidence of practitioners' evaluations of many aspects of social work including community work (Gordon et al 1988), groupwork (Pritlove 1990) and individual counselling (Mancoske et al 1994). Furthermore, the various child abuse inquiries over the past twenty years have made workers question their practice (Reder et al 1993). Finally, there is the explicit requirement of the Central Council for Education and Training in Social Work (CCETSW) that qualifying social workers are competent in being able to 'Contribute to the evaluation of the effectiveness, efficiency and economy of services' (CCETSW 1995 p.35).

Key workers were therefore asked to evaluate how far they felt that the response to date had improved the quality of life for the subject child and, where applicable, for other children in the family. A supplementary question asked whether, with hindsight, any 
other interventions would have been appropriate.

\section{Power issues}

Enshrined in the working definition used for this study is the concept of the misuse of authority or the failure to use appropriately - by acts of omission or commission - by caregivers 'who are in a position of differential power that renders the child vulnerable'. Ecological theory also suggests that the misuse of power by carers is a necessary condition for abuse. The parameters of the misuse of power is enshrined in the Criminal Justice Act 1991. It encompasses the exercise of power which is harsh, cruel, unjust or used in a 'wrongful manner', or the imposition of unreasonable or unjust burdens. In addition an essential aspect of the misuse of power which results in abuse, is that the victims are objectified by disregarding their needs, rights and human dignity.

Recognition has been afforded to feminist concerns that although there are substantial numbers of male abusers (Lacharite et al 1996), 'our understanding of child abuse is based almost entirely on research on mothers' (Langeland and Dijkstra 1995 p.4). Stark and Flitcraft (1988) demonstrate that 'abusing parent' is often an euphemism for 'mother'. This is evident in a number of studies (eg Egeland and Erickson 1987, Cerezo and D'Ocon 1995). Milner (1993) highlights the fact that men are generally allowed to 'escape' involvement in the protection process.

In acknowledgement of these concerns, there was no direct question about the 'perpetrator'. This was to avoid the possibility that, given societal expectations of women, mothers would be cited when in fact father figures could equally have been failing to use parental power appropriately. Key workers were instead asked open questions (see Appendix 2) exploring whether or not they considered there was a misuse of power and, if so, who they felt was ultimately responsible. They were also asked if there was evidence that the child's needs, rights and human dignity were being disregarded and, if so, by whom. 


\section{Population survey}

The questionnaire (see Appendix 3) was designed to meet the objectives of the population survey which included an attempt to determine the prevalence of emotional abuse. The experience of trying estimate the size of a problem - as exemplified by sexual abuse (Finkelhor 1984) - demonstrates that although the indication of prevalence obtained by survey should be viewed with considerable circumspection, it is better than a guess. Another objective was to provide further information about where to look for emotional abuse, supplementing data already provided by the survey of key workers. Some exploration of usefulness of the working definition, as well as additional information about manifestation and helpful intervention, constituted the final objectives.

In designing the questionnaire a number of balances had to be achieved. The first was the need to ask questions enabling comparison with the key worker responses but to phrase them in a way which was acceptable. The second was obtaining sufficient information to meet the objectives of the project but without making the questionnaire too long.

A questionnaire designed for the BBC Childwatch programme in 1986, obtained from ChildLine, was used as a starting point. It contained a section on emotional abuse but because this came after a general interview schedule, substantial changes had to be made. Nevertheless there were several useful sections which were adapted for the present study.

A preliminary questionnaire was designed and extensively piloted using three groups. Twelve volunteer, final-year social work students assisted with the first version. Thirty-three helping professionals from a range of disciplines involved in a workshop on emotional abuse then assisted with the second pilot. Several of them had already identified themselves as survivors of emotional abuse and they provided judgements about the sensitivity of the questionnaire and the possible effects on survivors. The final version was piloted on a group ten of professionals who were working with the 
survivors of abuse and attending an in-service course on that topic. This version was confirmed and used in the main study.

\section{Family characteristics}

Questions about family characteristics were designed to explore the location of emotional abuse. They were designed to encompass a variety of family structures (see Question 7, Appendix 3). Deaths of siblings and miscarriages were included after a suggestion by a respondent to the first pilot.

The Registrar General's classification was used as a basis of social class identification, taking account of the same considerations as in the key worker schedule. Trying to gain information about the economic status was more complicated because an annual income of $£ 2,000$ in 1949 may compare very favourably to one of $£ 3,000$ in 1989 . It was decided that the best indicator of the family's financial well being was to ask if, during their childhood, respondents considered their family had sufficient or insufficient money for essentials. While what is essential to one person may not be to another, nevertheless Question 12 'How often were your carers short of money for essentials?' was able to give some indication about how far family finances were experienced as stressful. Respondents were also asked to identify whether or not their family had had accommodation problems. Question 15 'During your childhood did your carers have any housing or accommodation problems? YES/NO If yes, please give brief details. 'A combination of class, finance and housing can be an indicator of socioeconomic well-being or deprivation (Alcock 1993).

\section{Exploration of experiences of abuse}

A range of questions were devised to explore the manifestation of emotional abuse especially in relation to the subjective experience of abuse. Respondents were asked to identify whether or not they had suffered one or more of the four main forms of abuse. It was decided not to provide definitions because a comprehensive definition for each would have resulted in a long, semantic, complicated section. Nowadays, child abuse is widely publicised and featured in the media (Kitzinger 1994). It was decided that 
respondents would have a reasonable idea of what constituted abuse, this included emotional abuse given the findings of the studies of Burnett (1993) and Haj-Yahia and Shor (1995). Furthermore one of the main purposes of the project was to explore what is perceived by the term 'emotional abuse'. To have imposed a definition may well have led to the loss of valuable information. However, to have given a definition for the other forms of abuse and not to emotional abuse may have led to bias in responses. It was preferable for questions about each form of abuse to be couched in the same terms.

A list of potentially emotionally abusive experiences was adapted from the ChildWatch survey (see Appendix 3). These were in the form of statements, in reply to the question 'Which. if any, of these things happened to you?' Examples included 'Made to feel frightened because of threats', 'Made to feel I did not exist'. They broadly reflected the categories of emotionally abusive behaviour described by Garbarino et al (1986) and other commentators (see Chapter 3). There were additions to the ChildWatch original based on examples and information gained from the literature and the pilots. The statements were a mixture of acts of commission and omission. For example, 'Verbally abused' (commission) and 'Not shown any affection' (omission). The purpose of this section was to gain an idea of how emotional abuse was manifested and to validate the response to the question, 'Do you think that you were emotionally abused'. If respondents had ringed 'YES' by mistake then they would not fill in any of the checklist experiences. On the other hand if someone had ringed 'NO' either by mistake or because they were unwilling to label themselves 'abused' then the list would give them an alternative way of expressing their childhood experiences.

Because child protection workers are primarily concerned with protecting children abused by carers, it was important to find out if the respondents had suffered maltreatment at the hands of their carers or other people outside the family. Questions were therefore sought about who was responsible for any mistreatment. 


\section{Intervention}

There were a series of questions (30 to 33) about the type of help given or desired which were designed to explore issues of intervention. There was also an open invitation (Question 34) to respondents to add any other details 'Please feel free to write below and overleaf'

The final section - designed to explore both aspects of the definition and the need for intervention - about the damaging nature of the experience was adapted from the ChildWatch survey. An additional category 'Damaging for a long time, but not permanently damaging' was added after the first pilot at the suggestion of a respondent.

At the end of the questionnaire, respondents were not only thanked but advised that if answering the questionnaire had awoken painful memories there was a counselling service available to them.

\section{Survivor interviews}

The open, in-depth interviews were not piloted. However, the researcher was an experienced interviewer who had undertaken similar interviews with the survivors of sexual abuse by siblings (Doyle 1996c)

At the start of the interview it was explained to the volunteers that the very fact that they had become a professional worker or undertaken an Access course demonstrated that they had survived their experiences with a degree of 'success'. They evidently felt that they were worth training and had some knowledge or skill to offer or share with others. The purpose of the interview was to explore with them what had helped them cope with the adverse experiences that they had described on their questionnaires. Hopefully strategies that had helped them may have be useful for other children.

The interviews were unstructured apart from these introductory statements about the purpose of the interview plus a limited number of prompt questions. The emphasis of the interview was on what had gone right rather than what had gone wrong, recalling 
positive memories as much as negative ones. The prompt questions included one about experiences in school if these were not volunteered by the interviewee. They were also asked about extended family support and friendships. Another potential question explored whether they had any non-human supports. The purpose of these questions was to give interviewees 'permission' to talk more widely if they were under the impression that they should confine the information given to human supports within their immediate family.

No direct questions were asked about distressing childhood experiences. However, some interviewees wanted to give details of these, thereby providing insights into the realities of experiencing emotional abuse.

\section{ETHICAL CONSIDERATIONS}

The ethical guidelines of the British Psychological Society were consulted and used as the basis for ethical considerations.

\section{Register cases}

The ethics of using information from the register was discussed with the chairperson of the ACPC or Register holder of each area. It was generally agreed that the research would ultimately have direct relevance for their authority's 'policy development and strategic planning' (Home Office 1991 p.48). It was therefore an appropriate use of information on the register.

Consideration was given to whether or not family members should also give their permission. This was discussed with the relevant managers. The general consensus was that because the children were registered and the research was to be used in policy development and strategic planning this was not necessary. Identifying details were not divulged, case records were not being scrutinised nor were family members being interviewed; there was therefore no breach of confidentiality. Nevertheless, it was agreed that if individual key workers felt that they should inform or seek the permission 
of the family, this would be respected. The only key worker who refused to participate did so because she felt she needed the permission of the family and was not prepared to seek it because she feared a violent reaction on the part of the father. Her concerns were respected and accepted.

\section{Population survey}

Every attempt (see below) was made to ensure that only those respondents who wished to participate did so and that any peer pressure was minimised. Efforts were made to ensure that the information given was confidential. Only the researcher and the independent judge had sight of the original questionnaires.

It was recognised that responding to the questionnaires could evoke distressing memories and emotions in some of the respondents. All the participating colleges had a counselling service and the head of each service was consulted. Their advice was sought about ways of supporting distressed respondents. They all agreed to a note being included on the questionnaire advising respondents about the availability of their college counselling service in the event of emotional difficulties being encountered as a consequence of the research.

\section{Survivor interviews}

There were four main ethical considerations: informed consent; power in the researcher/informant relationship; confidentiality; the researcher's duty not to harm the informant. In recognition of the informed consent requirement, only 'mature' students were asked to volunteer and they were given detailed information about the nature and purpose of the research. Regarding power relationships, the participants were viewed as associates in the pursuit of improved services for abused children. They were given the power to chose the location, timing and conduct of the interviews. Confidentiality was ensured by altering identifying details. In order to avoid harm, there was no pressure on participants to provide details of their negative experiences although ample time was left to ensure they had sufficient opportunity to unburden themselves. Where participants appeared to need further help or advice, provision was made for them to be 
linked to a counselling service or provided with relevant information.

\section{PROCEDURE}

\section{Register Cases}

\section{Approach to Key Workers}

The register holder in each local authority provided a list of the children on their register under the Emotional Abuse category. This was forwarded to the researcher. In the larger authorities where the list exceeded twelve key workers, twelve were selected at random. In the smaller authorities where the list was twelve or fewer, all key workers listed were interviewed. However, one complication was that in one large local authority, despite the Home Office (1991) guidance that the emotional abuse category should be used only where emotional abuse was 'the main or sole form' several children were registered in two or more categories. This meant that a check with the selected key worker had to be made to ensure that the case for potential inclusion was not a dual registered one.

One disadvantage of telephone interviews is the difficulty establishing that the researcher is bona fide. This was overcome by setting up the interviews by both telephone and letter. Dillman et al (1976) found that pre-letters lead to lower refusal rates and higher data quality. Managers therefore informed the key workers of the research by memorandum. The researcher then contacted the key workers by telephone to see if they were willing to participate and, if so, a date for interview was set. The arrangements were then confirmed by letter.

The permission of staff selected for interview was sought. Many of the social work managers indicated that they would expect their staff to agree to participate. Nevertheless, one key worker (see above) refused to discuss the family with anyone outside her authority and this was accepted. 


\section{Interviews with key workers}

The key worker was telephoned at a pre-arranged time. Sometimes they had been suddenly called out on an emergency. Where this happened they were contacted again later and a new date set. The interview usually lasted between thirty and forty minutes. After the interview the participant was sent a personal letter of thanks with a bibliography on emotional abuse. They were also invited to have a reciprocal half hour's consultation on any case. To date four social workers have availed themselves of this.

Consideration was given to tape-recording the interviews. This was rejected because the pilot interviews had not demonstrated its benefits. Furthermore, local key workers indicated they would worry about confidentiality and their 'performance' being captured live on tape. In addition, the quality of the recordings in the pilot interviews was poor while obtaining improved technical equipment was beyond the project budget. Another disadvantage of using tape recordings is the time taken to transcribe them. The researcher had more than 15 years' experience making contemporaneous notes in child care cases coming to court. While acknowledging the differences between social work and research interviews, Fuller and Petch (1995) argue that 'social workers are already (or should be) expert interviewers and recorders of data' (p.10). It was therefore appropriate for the answers to be written down contemporaneously and word processed immediately after the interview.

\section{Population Survey}

The leaders of each HE or training course selected for inclusion were approached and their cooperation obtained. The exact classes were chosen on the basis of guidance from the leaders. For example, a Tuesday morning session might be preferable because it was very much better attended than a Friday afternoon one. Where the leaders were not personally taking the session the agreement of the member of staff doing so was also obtained.

The same format for distribution and collection of the questionnaires was used with all 
courses. During a session, usually just before a lunch or coffee break, the purpose of the research was out-lined by the researcher. All the students were asked if they would accept a questionnaire. If they wished to complete it they were given the opportunity to do so during the break. They were encouraged to do this independently rather than discussing their answers with fellow students. They were asked to return the questionnaire, whether or not they had filled it in, to a sealed box with a slit in the top. This was then collected after the break. The questionnaires were designed with a front and back sheet so that it was impossible to see whether students were returning a blank or completed questionnaire. Students who wished to complete the questionnaire in detail could do so out of sight of their companions during the break. People who did not wish to respond would not be put under peer pressure to do so because everyone took away and returned a form making it difficult to distinguish those who had replied from those who had not.

\section{Survivor Interviews}

The volunteers were contacted through the telephone number they had provided. The rationale for the interview was explained and the volunteers were asked if they would still be willing to participate. A date was then set when both researcher and volunteer had at least two hours free and they could meet together at a mutually agreeable location. Most interviewees chose either their home or an appropriate room in one of the participating colleges. In one case however the volunteer asked to be interviewed in the open air on a college campus. He explained that he did not want to be 'closed in' with his memories.

It was recognised that for some of the interviewees this was the first time that they had been given 'permission' to talk about the emotional abuse. Because the interviews were unstructured the volunteers were not prevented from articulating their distress or anger.

From the outset it was explained to the volunteers that the information they gave would be written up and disseminated in some form. However, all identifying details would be excluded and their names changed. All understood that this and raised no objection. 
As with the key worker interviews, recording was, with participants' permission, through handwritten, contemporaneous notes, word-processed without delay after the interview. Tape recording was considered too intrusive.

Volunteers were verbally thanked at the end of the interview and the commitment to obscure identifying details reiterated.

\section{DATA ANALYSIS}

At the end of the data collection an analysis was undertaken of:

112 semi-structured interviews given by key workers;

429 completed questionnaires from the population survey;

12 in-depth interviews with adult survivors of emotional abuse.

In some instances, such as determination of a prevalence rate, or the life-lines for survivors, quantitative and qualitative data was analysed separately. In others, there was triangulation of the quantitative and qualitative data 'to check the different findings against each other' (Bryman and Burgess 1994 p. 222). However, more commonly there was an integration of the two types of data. Integration of qualitative and quantitative data involved using both to explore themes and to address particular topics (Mason 1994).

The qualitative data was analysed using guidance relating to applied policy research (Ritchie and Spencer 1994, Dey 1993). This requires familiarization, identifying a thematic framework, indexing and charting and, finally, interpretation. The unstructured interviews, for example, were analysed using a thematic framework, identified after familiarization with the collected data. The purpose of the interviews had been to explore what had helped the survivors cope with their abusive experiences particularly during childhood but also later in life. The themes in relation to the various life-lines were identified. 
All replies to the questionnaire and interview schedule that were quantifiable were entered onto SSPS for Windows. There was some basic numerical data such as ages and numbers of siblings which could be directly entered.

Most of the remaining information was coded into categories. The majority of these were relatively self-evident or those, such as income bands for the register cases, had been predetermined. In other instances, there was, as Dey (1993) suggests, an interactive process whereby suggested preliminary categories were modified by the process of assigning data to categories. Some potential categories - such as the designation of survey respondents as emotionally abused or not and the delineation of abusive parental behaviours - were not only open to dispute and interpretation but were also critical as they underpinned much of the rest of the study. In these instances an independent judge was used (see below). Details of the categorisation of emotionally abusive behaviour using the independent judge is provided in Chapter 7 .

Because most of the data was allocated to categories, the main statistical test applied was Chi Square using SPSS (Windows). Some responses which could be scored, such as the number of children in a family or the number of stressors encountered by a family, were subjected to the appropriate statistical test. In the absence of normal distribution of the scores these were non-parametric.

One score, that for 'socio-economic deprivation' (the SED score), requires explanation. It was derived from Alcock (1993) who, drawing on the classic work on poverty and deprivation by Townsend (1979), identified three indicators of deprivation: financial deficits, housing problems and employment vulnerability. Population survey respondents recording lack of money for essentials attracted one point. Those reporting accommodation problems were given one point. Social class was divided into two groups reflecting the 'power-model' of two classes, one with resources, training or skills which gives them bargaining power in the labour market and the other without these advantages (Reid 1977). Those with 'non-privileged access to the labour market' and with few negotiable resources (Alcock 1993) - ie those from the semi- or unskilled 
or benefit-dependent classes - were allocated one point. This resulted in a potential SED score of between 0 and 3; the higher score indicating the respondents' family's increased vulnerability to socio-economic deprivation.

Wallston and Shelton-Smith (1994) note that 'examining one isolated factor at a time does not allow for the conjoint influences among the factors' (p.158) They also observe that this is a conspicuous deficit where the topic of study is 'multidetermined' and complex. Taking account of this view, discriminant function analysis was employed in this project to examine how far variables in combination have greater predictive power than individual variables examined in isolation from others. Although other multivariate tests, such as logistic regression, are able to provide information from sets of predictor variables, using discriminant function analysis not only allows for the use of categorical dependent variables but can be employed to predict membership of two or more pre-defined and distinct groups.

The accuracy of the loading of the data was checked twice then rechecked using the SSPS 'Value labels' facility. In the process of analysis any unexpected or contradictory data or results were subjected to further checking.

\section{Missing data}

There was relatively little missing data. There was almost no missing data in the key worker interviews because it had been possible for the interviewer to ensure that the data was collected and the questions asked had all covered information that should be readily to hand. The only area of uncertainty was the childhood experiences of the parents. In the population survey there was a response rate of 85 percent to the questionnaire. Nine percent were not returned at all and 6 percent were returned to the box blank. Of those returned and filled in most of the questionnaires were completed. Where gaps were left the reason was usually self evident, such as where people who recorded adverse experiences which fell short of abusive ones did not answer questions exploring abuse. The questions, directed to those who were emotionally abused, about the type of help they had or would have liked to have had were less well answered. But 
on the whole missing data was not a major problem and in most cases were dealt with as 'not specified' or 'none identified'. Depending on the role of negative or absent data in the issue under scrutiny, cases with missing data were either excluded entirely from the analysis, excluded but noted or included under a code for 'not specified' or 'none identified'.

\section{The Independent Judge}

An independent judge was employed to provide reliability checks where categorisation was an important aspect of the analysis. These were, first the categorisation of the population respondents in to abused and non-abused groups and second the classification of emotionally abusive behaviour. She was not however used when categorisation was merely a convenient way of presenting findings rather than an essential outcome of the study such as the presentation of the different types of intervention offered.

The judge is a guardian ad litem with over 20 years experience in child care and protection work. She is also an experienced researcher having undertaken Department of Health sponsored research relating to child care issues. She was however completely independent of the study and was not directly involved in it in any other capacity.

\section{IDENTIFYING 'EMOTIONALLY ABUSED’ GROUPS.}

The findings are essentially related to the identification of two emotionally abused groups. This is so fundamental to the outcome of the project that the process of identifying the two groups is given in detail in this section. The two groups were a) the register cases and $b$ ) those people in the population sample who indicated that they were emotionally abused by their carers.

\section{Register cases}

These were judged to be emotional abuse cases by virtue of being in the "emotional abuse' category. Because the focus of this research is on emotional abuse as the main or 
sole form of abuse, dual registrations (ie children placed concurrently in two categories) were excluded.

During the interview process the key worker was asked to identify emotionally abusive behaviour on the part of the child's carers. This reflects the conclusion emerging from the literature (reviewed in Chapter 3) that 'the mainspring for intervention should be based on parental behaviour which is seen as inappropriate'. One important aspect of the working definition is that for a case to be 'emotional abuse' there has to be identifiable acts of omission and/or commission on the part of the carers.

\section{Population survey}

\section{Categorisation}

All the completed questionnaires were scrutinized and allocated to either:

Non-Abused (NA) group - here the respondents indicated no abuse of any form no undue negative emotional experiences and a predominantly happy childhood.

Other Distress (OD) group - these suffered a variety of averse experiences which could arguably be deemed emotional abuse in its widest definition (Hart et al. 1983) such as bullying by school mates or racist attacks from neighbours.

Emotional Abuse (EA) group - these were deemed to have been emotionally abused by their main carer. It is this group that would potentially be the focus of intervention by child protection workers.

\section{Allocation to the 'Emotional Abuse' group}

Allocation to the groups was based on to the replies to several key questions (see Appendix 3). Emotional abuse for the purposes of both this study and registration refers only to those cases where the child's carers are held responsible and where it is the main or sole form of abuse. In addition the working definition includes the idea that the carer's behaviour 'damages immediately or ultimately' the child's functioning. 
For the purposes of allocation to the EA group the most important response was a selfdefinition of being emotionally abused (a positive response to Question 22 'Do you think you were emotionally abused ?').

However, consideration was given to other indicators:

* filling in one or more of the boxes relating to negative emotional experiences in Question 23. ('Which, if any, of these things happened to you? Please tick appropriate boxes'). It is recognised that one tick in a box such as 'Made fearful due to witnessing violence' may represent several separate frightening incidents. However, each tick is described, for the purpose of subsequent analysis, as one 'negative experience'. It would be more accurate to use the term for each tick 'category of negative experiences' but this results in an unwieldy description. This was useful to indicate people who may have circled 'YES' to Question 22 by mistake or, conversely, people who had been emotionally abused but did not recognise or accept this as a label for themselves.

* identification as emotional abuse as the main form of abuse - involving scrutiny of answers to Questions 19, 20 and 21 ('Do you think you were physically abused/sexually abused/physically neglected?').

* identification of their carers as primarily responsible for their negative emotional experiences - determined by the responses to Question 24 ('Who do you consider was most responsible for your mistreatment?') and Question 25 ('Do you consider anyone else was also responsible for your mistreatment? If yes, please indicate who'.)

* the damaging nature of the experiences identified in Question 35. ('Which of these phrases describes how you feel your experiences in childhood have affected you in later life?')

In addition account was taken of the response to Question 18 about the happiness or otherwise of their childhood memories. 
Most of the respondents who indicated some form of distress or abuse but did not fit the criteria of:

* emotional abuse as the main or sole form;

* carers being primarily responsible;

* the experiences being damaging

were allocated to the Other Distress (OD) group.

The independent judge was employed to assist with allocation where cases could not readily be categorised. No328 provides an example of this. She did not think she was emotionally abused but believed that she had been subjected to harsh discipline, ticked three negative experiences, gave additional comments to indicate that she had not been valued and had had her confidence eroded. She held her father responsible and believed that her experiences were permanently damaging.

The three final groups NA, OD and EA were used for comparison both between each other and, where appropriate, with the register cases. The division into three groups rather than two ('emotionally abused' and 'not emotionally abused') was based on the need to examine whether, and in what way, emotionally abused children can be distinguished from both those who suffer no abuse and those who suffer abuse which falls outside the working definition of emotional abuse.

\section{PRESENTATION OF FINDINGS}

The findings are presented on the basis of the five main themes of the research; definition, prevalence, location, manifestation and intervention. Within these themes, specific topics are addressed, usually from both the professional and population/survivor perspectives.

An alternative, and perhaps more conventional, way of presenting the findings would have been to examine the outcome of each study separately; the key worker interviews, followed by the population survey then the survivor interviews. However, following 
Mason (1994) quantitative and qualitative data, as well as different forms of qualitative data, have been linked. As with Mason (1994) some types of data have been presented on its own. However, more often there is linking of different data through themes or addressing a particular topic from a 'variety of angles' (Mason 1994 p. 106). Therefore the location, for example, of emotional abuse has been presented as one issue regardless of whether the findings on that issue have been drawn from the register or population data.

Written quotations from the questionnaire and verbal comments from the key worker interviews and particularly the survivor volunteers were used as illustrations for a number of themes and topics. Comments are reproduced in italics in those instances where they were written by respondents or recorded verbatim by the researcher.

The next chapter looks in more detail at emotional abuse in relation to the first two issues of definition and prevalence. 


\section{FINDINGS}

\section{PREFACE: SAMPLE PROFILES}

\section{Register Cases}

There were 112 subject children. These were drawn from a widespread geographical area. Forty-nine (44\%) came from county council areas and $63(56 \%)$ came from metropolitan ones. There were no significant differences in the characteristics between families drawn from the two different areas. There were some differences in the help offered, depending on where the family lived and this will be explored further in the discussion on intervention (Chapter 8).

The register cases encompassed a variety of family situations. Twenty-three (21\%) were 'only' children with no siblings in the household. A further $32(29 \%)$ were deemed, by the key workers, to be 'singled-out' for abuse; their siblings were not subjected to the same mistreatment. The remaining $57(51 \%)$ were from families where all the children were deemed to have been abused. In these cases, one child was identified as the subject child who, for convenience, is referred to as the 'group' child. There were very few differences in the characteristics of the child or families based on type of situation. Where there are differences, for example birth history, these will be highlighted. Other characteristics of the child and family will be explored especially in the discussion on location (Chapter 6).

Register cases are likely to suffer from 'registration bias'. This was first highlighted by Gil's (1970) work where he found that most of the registered children were from poorer sectors of society (see Chapter 2). Children can only be registered if their mistreatment is discovered. It is more likely to be identified in those families coming to the notice of state authorities for other reasons such as receipt of state benefits. Those able to access private facilities are less likely to be closely scrutinised. Jones et al (1987) commented 'child care difficulties are probably also experienced by more advantaged members of society but are either hidden behind a semblance of competence and respectability or solved before crises develop, using knowledge or resources not readily available to the less well-off' (p.35). 
In the current register sample, proportionally more families were in the lower socioeconomic groups compared to the national profile. However, there were a number of families with substantial incomes, including a managing director with a timeshare apartment in Florida. In two families the children were privately educated. Nevertheless, because registered cases are likely to be biased towards socially disadvantaged families, the examination of the issues using a non-registered population is likely to provide a counterbalance. In this project the population survey provides this balance.

\section{Population Survey.}

The population survey contained three constituent sections: Undergraduate, Professional and Access students. Of the 429 respondents, 234 (55\%) were in the Undergraduate section, 105 (24\%) in the Professional section and 90 (21\%) were Access students.

The total population sample was examined for significant differences in the four descriptive variables of age, gender, class and ethnicity.

There was a significant difference in the ages of the Undergraduate respondents compared to the other two sections $\left(X^{2}=150.6, \mathrm{df}=4, \mathrm{p}<0.0001\right)$. Half $(117)$ of the Undergraduate section were aged under 20 years compared to just one Professional and no Access students. This was an expected finding because the current research was designed to include young people with recent memories of childhood as well as older respondents who could more readily use hindsight and greater life experience through which to evaluate their childhood. In subsequent analyses controls for age were undertaken.

There was also a significant difference in relation to gender. There were significantly more females in the Professional section compared to the other two $\left(X^{2}=16.9, \mathrm{df}=2, \mathrm{p}<0.0005\right)$. This in not an unexpected finding, given that as most of the section were social workers, nurses or teachers. As Fawcett (1988) observes 'alongside the teaching and nursing professions, social work is seen as a "female" profession' (p.12). In subsequent analyses controls for gender were undertaken. 
A less readily foreseen significant difference, relates to social class. Overall the Undergraduate section came from higher social class groupings than the Professional and Access sections $\left(X^{2}=15.59, \mathrm{df}=4, \mathrm{p}<0.005\right)$. The explanation for this may be traced to the fact that educational opportunity in Britain has traditionally been related to social class. Reid (1977) illustrates this, 'a social class V child is some fifteen times more likely to be a non-reader at age seven than a child from social class 1' (p.174). Equally traditionally, nurse, social work and primary teacher training and, more recently, Access courses have catered for those unable to take advantage of degree courses as school-leavers. Again, in subsequent analyses controls for social class were undertaken.

In the case of the other descriptive variable, ethnic group, there was no significant difference between the three sections of the population survey.

Findings relating to other variables did not alter substantially when controls for age, class and gender were introduced into the statistical analysis. Therefore, when presenting the findings of the population survey, the three sections will be combined unless there is an issue specifically relating to individual variables which warrants discussion.

\section{Survivor Interviews}

The twelve volunteers constituted three men and nine women. Although the male perspective was under-represented, it was nevertheless present. Ten survivors were white British and two were dual heritage (one Irish/Asian and the other English/African American). For one of the survivors, who had spina bifida, disability in childhood was a significant factor. The age range of survivors, at the time of the interview, was from 25 to 57 , so there was a diversity of generations. There were four Access students, four social workers, two teachers, a day centre worker and a health visitor.

The types of abusive experience varied. Three interviewees were 'only' children. Another four believed that they had been 'singled-out' for abuse while their siblings were favoured and well-treated. In the remaining five cases the interviewees felt all the children in their family were emotionally abused. 


\section{CHIPTER 5}

FINDINGS: THE DEFINITION AND EXTENT OF EMOTIONAL ABUSE

This chapter explores issues of definition and the extent of emotional abuse. The source of the findings relating to definition are the 112 interviews with the key workers and the 429 responses to the population survey questionnaire. In addition, using the 429 questionnaire responses, it was possible to identify members of a population who believed they had experienced childhood emotional abuse. From this, some estimate of prevalence can be attempted.

\section{DEFINITIONS}

\section{Register Cases}

A number of the salient features of the working definition emerged from the interviews with key workers.

First, the key workers were all able to give clear descriptions of emotionally abusive behaviour. Furthermore, they described both acts of omission and commission. For example, in 60 (54\%) cases they cited active rejection (eg 'mother took child to nursery and then did not want her back') combined with passive rejection (eg 'when child in hospital with broken leg, the parents did not visit. They never give her cuddles or show affection'). In a further 34 (30\%) of cases there was passive rejection (eg 'all the children lack stimulation and the third child is surplus to requirements') combined with acts of commission such as terrorising (eg 'children witness a lot of violence with father attacking mother with axes and knives') and isolating (eg 'children locked in bedrooms for long time'). This means that, although the emotionally abusive behaviour in some cases may consist predominantly of acts of commission or of omission, in most cases there will be evidence of both. This is a distinguishing characteristic of emotional abuse. It is unlike the other forms of maltreatment which are either commissions (physical and sexual abuse) or 
omissions (physical neglect).

The second point was that in all but one case the key worker held a parent responsible for the abuse because at least one was misusing his or her parental power. This supports the part of the definition which specifies that it comprises acts 'committed by parent figures who are in a position of differential power that renders the child vulnerable'.

The third feature was that, in all but four cases, the key worker identified children suffering from at least one sign of distress which, using their 'professional expertise', they attributed to the abusive behaviour of the parent figure. Signs included the fact that 61 subjects $(62 \%$ of the school-age children) encountered problems relating to education while $16(14 \%)$ were self-harming or had attempted suicide. Although a direct causal link between abuse and problems in children is rarely conclusive (Carter 1983, Furnell 1991), the signs indicate that abuse was damaging immediately (eg in the case of self-harm) or ultimately (eg as an outcome of the educational problems) the functioning of the children.

The register cases provide the professional perspective. However, although registration is largely a matter of professional judgement there was evidence that many of the families were also being judged on the basis of community standards. In eight cases (7\%) the referrals came from neighbours or extended family members. In addition 18 (16\%) referrals from the police had their origins in the concerns of family members or neighbours.

\section{Population survey}

Although the sample population completing the questionnaire was not representative of the general population of Britain, nevertheless a perspective more closely related to judgements based on 'community standards' is provided by the population survey. A number of features relating to the working definition also emerged from an analysis of the questionnaires.

Of the 429 respondents, $118(28 \%)$ defined themselves as having been emotionally 
abused. Most (85\%) of these, in response to Question 23 (Which, if any, of these things happened to you?), ticked four or more boxes. The average number of ticks for people identifying themselves as emotionally abused was 8.4 with a median of $8, \operatorname{SD} 4.7$ and a range of 0 to 19 .

Turning to issues of responsibility, $91(80 \%)$ of the 118 self-defined emotionally abused respondents held their parent primarily responsible for the abuse they suffered. Unlike the key worker interviews, issues relating to the abuse of power could not be readily explored through a questionnaire although the survivor interviews revealed power issues similar to those identified by the key workers.

Finally, in relation to the damage caused, $106(90 \%)$ questionnaire respondents believed their emotionally abusive experiences were damaging. Only $3(3 \%)$ did not believe that they had been damaged while $9(8 \%)$ gave no response. A substantial majority, $98(83 \%)$, believed that their experiences had been damaging for a long time or permanently.

The key worker interviews of registered cases provided one group of emotionally abused children. The second group was provided by those respondents who were allocated to an 'emotionally abused' category based on the salient features of the working definition.

\section{IDENTIFYING THE EMOTIONAL ABUSE GROUP}

The method of identifying the Emotional Abuse (EA) group was described in the preceding methodology chapter. This section looks in more detail at the decisions made concerning particular responses.

The final number of respondents deemed to be emotionally abused as the main or sole form of abuse was 124 , or 29 per cent of the total replies. This figure was arrived at mainly through a self-definition of emotional abuse. However, consideration was also given to a) the extent of negative emotional experiences, b) carers' responsibility, c) damaging 
outcomes. Account was also taken of the focus of the study on emotional abuse as the sole or main form. Finally, the recall of childhood as predominantly happy or unhappy was considered as an additional indicator in 'borderline' cases. A similar reliance on self-report from college students of a mainly unhappy or happy childhood was also used by Wright et al (1992) exploring the impact of parental substance abuse on children.

\section{Self-definition of being emotionally abused.}

In addition to the 118 people who considered that they had been emotionally abused, a further eight ( $2 \%)$ said that they were not sure whether they had been emotionally abused but went on to indicate abusive experiences. Combining the two groups, there were 126 $(30 \%)$ respondents who indicated that they had been emotionally abused.

A further 120 respondents indicated that they had suffered some form of distress, although they did not circle YES in response to question 22 . These were initially allocated to the Other Distress (OD) group.

Subsequently, 18 respondents in the preliminary OD group were allocated to the EA group while 17 respondents in the preliminary EA group were placed in the OD group. This was on the basis of additional considerations: the number of negative experiences; additional forms of abuse, the person held responsible; the damaging nature of the experiences; and, a deciding factor in some borderline cases, the memory of a mostly unhappy childhood. In addition after scrutiny, three of the 'not sure' respondents were allocated to the OD group and five to the EA group.

Space, as well as the tedium of repetition, precludes detailed description of the process of re-allocating all the doubtful cases. However, the way in which the eight 'not sure' cases were categorised provides a useful illustration of the process of allocation between the EA and OD group. 


\section{'Not sure' categorisation.}

Of the five cases allocated to the EA group:

No37 recorded five negative experiences, felt they were damaging in the long term and held her mother responsible for them.

No38 recorded nine negative experiences, judged they were damaging in the long term and held her father responsible.

No247 had eight negative experiences, felt they were permanently damaging and held both parents responsible.

No290 had six negative experiences which were permanently damaging and for which her mother was responsible.

No394 had seven negative experiences, felt they caused long term damage and held both parents responsible.

Of the three cases allocated to the OD group:

No330 recorded no negative experiences although she felt both parents were responsible for the (unspecified) 'mistreatment' and did not indicate how damaging she felt her parents' behaviour to be.

No331 recorded seven negative experiences. She felt they were damaging at the time although not in the long term but she held a non-relative, non-carer responsible. She was emotionally abused in the wider definition given by Hart et al (1983) (see Chapter 3) in which emotional abuse can be caused by 'any person ... in a position of differential power which renders the child vulnerable' but the working definition and potential registration criteria both require carers to be responsible for the abuse.

No382 had only one negative experience (Having my achievements derided). She held her father responsible and felt his treatment of her had been permanently damaging. There was no other additional information about how happy her childhood had been. This 
was a borderline case but the lack of further supporting evidence of emotional abuse meant that she was eventually allocated to the OD group.

These types of considerations were made in relation to all borderline and doubtful cases. Further illustrations of how account was taken of the various factors are provided in the following four subsections.

\section{Negative emotional experiences}

Of the 118 people who identified themselves as emotionally abused, seven respondents who ticked no negative experiences were re-allocated to the OD group. A further three only ticked two aversive experiences but remained in the EA on the basis of additional details given. For example No.45 added 'mother always took the micky out of me and embarrassed me'.

All the respondents originally in the OD group but reallocated to the EA group recorded at least three negative experiences and a further 13 (out of 18) had between five and 11 negative experiences.

After the cases were allocated to the groups, the EA group had a mean of 8.7 (SD 4.1, range of 2 to 19) negative experiences. In contrast, the OD group had a mean average of 2.6 (SD2.1, range of 0 to 11 ) negative experiences.

\section{Weighting}

Consideration was given to whether or not to weight some of the emotionally abusive experiences on the basis that 'being made fearful due to threats' could be seen as more emotionally abusive than, say, relentless teasing or being publicly humiliated. A participant in one of the early advisory groups, mentioned in the Introduction, observed 'What teenager isn't publicly humiliated by the mere appearance of their parents!'.

Despite this, it was decided that weighting would not be appropriate. It became apparent during the survivor interviews that what might seem a minor problem to one person can 
be a major one to someone else, depending on the circumstances and sensitivity of the victim. Pia, one of the interview volunteers, for example described (for her) a devastatingly humiliating experience when as a teenager her father weighed her on public potato-weighing scales.

Nevertheless, it could be argued that all children suffer some of the experiences such as being unfairly blamed and many adolescents feel that they have insufficient independence. Table 1 below shows that four people allocated to the NA group recorded one negative experience. Two felt unfairly blamed, one was not allowed any real independence and the fourth felt burdened by too many responsibilities. They did not appear to associate these experiences with distress, abuse, unhappiness or damage. This is in contrast to the people allocated to the EA group who recorded only two or three negative experiences. Here there was evidence of greater distress. For example, No 34 felt she was emotionally abused, made fearful due to threats, not allowed any real independence and verbally abused (eg ' $m y$ father has told me I am worthless'). She later added that in addition her father had had an affair ('I cannot forgive him and I have a deep distrust of men'). She believed that her childhood experiences caused long term damage.

Table 1. Numbers of emotionally abusive experiences recorded by self-defined emotionally abused and final group allocation.

\begin{tabular}{|c|c|c|c|c|c|c|}
\hline \multicolumn{4}{|c|}{$\begin{array}{l}\text { Answer to Question } 22 \\
\text { Do you think that you were emotionally abused? }\end{array}$} & \multicolumn{3}{|c|}{ Final group allocation } \\
\hline NO & Not Sure & YES & $\begin{array}{l}\text { Q.23 Number of } \\
\text { abusive experiences }\end{array}$ & Not abused & $\begin{array}{c}\text { Other } \\
\text { distress }\end{array}$ & $\begin{array}{c}\text { Emotional } \\
\text { abuse }\end{array}$ \\
\hline 190 & 1 & 7 & $\mathbf{0}$ & 179 & 19 & 0 \\
\hline 75 & 1 & 11 & $1-3$ & 4 & 70 & 13 \\
\hline 24 & 2 & 29 & $4-6$ & 0 & 26 & 29 \\
\hline 11 & 4 & 20 & $7-9$ & 0 & 5 & 30 \\
\hline 3 & 0 & 27 & $10-12$ & 0 & 2 & 28 \\
\hline 0 & 0 & 14 & 13-15 & 0 & 0 & 14 \\
\hline 0 & 0 & 10 & $16+$ & 0 & 0 & 10 \\
\hline
\end{tabular}


Table 1 demonstrates the numbers of abusive experiences in each of the self defined emotionally abused and non-abused groups compared to the final allocation to each group.

\section{Responsibility of carers.}

There were 22 respondents who felt that they were emotionally abused but in response to Question 24 indicated that their carers were not responsible. Ten were re-allocated to the OD group. Of these, two were sexually abused by people outside the household. One was 'disowned' by her father's family after his death. A respondent of Chinese origin was subjected to racist attacks. The remaining six were bullied by other children, two of these because of their sexuality.

There were three cases where the respondents held themselves responsible but it was evident from the account that the parents were inflicting the abuse. For example No47 described being threatened, unfairly blamed, not allowed independence, being told she must hold the same views as her parents and do as they say, made to feel not good enough, emotionally 'blackmailed' [sic], verbally abused and 'when bullied told it was my fault, I deserved it, I was not a nice person' She was also told by her parents that going to college was depriving the rest of the family and she should 'not be ungrateful as mum had to go through pain to have me'. When asked who was responsible for this catalogue of distress she wrote 'myself - due to naivety, stupidity, being stubborn'. These cases were allocated to the EA group.

In nine remaining cases allocated to the EA group, either the parents were not specifically held responsible in response to Question 24 but were implicated through responses to other questions or another family member acting as a carer was held responsible. For example, No304 commented 'Big brother acted like a father in making decisions for me'.

\section{Damaging nature of emotional abuse}

The working definition used for this study has the dimension 'damages immediately or ultimately' the functioning of the child. Account was therefore taken of how far the 
respondents believed their experiences were damaging.

The overwhelming majority of people $(82 \%)$ who identified themselves as emotionally abused believed their experiences were damaging over an extended period.

There were two male respondents who were allocated to the EA group despite the fact that they felt their experiences had had no effect. Both described a catalogue of emotionally abusive experiences for which their parents were responsible. One young man felt that emotional abuse was not as bad as other forms of abuse so that he believed he could not claim it was damaging. The second young man said it had no effect but if there was any it was to have 'toughened' him.

Table 2 below summarises the outcome indicated by the respondents according to the final allocation.

Table 2. Population survey: Outcome of negative experiences.

\begin{tabular}{||l|lc|ll||}
\hline \multicolumn{1}{|c|}{ Outcome } & \multicolumn{2}{|c|}{ Other Distress } & \multicolumn{2}{c||}{ Emotional Abuse } \\
\hline \hline no effect & 29 & $(24 \%)$ & 2 & $(2 \%)$ \\
\hline only damaging at time & 40 & $(33 \%)$ & 13 & $(10 \%)$ \\
\hline damaging long term & 19 & $(15 \%)$ & 63 & $(51 \%)$ \\
\hline permanently damaging & 4 & $(3 \%)$ & 46 & $(37 \%)$ \\
\hline positive outcome & 2 & $(2 \%)$ & - & - \\
\hline not specified & 28 & $(23 \%)$ & - & - \\
\hline
\end{tabular}

There were differences in relation to the perceived outcome between the three sections of the population survey. There were significantly fewer of the Undergraduate section who believed they had been permanently damaged compared to the Professional and Access sections combined $\left(X^{2}=18.24, \mathrm{df}=3, \mathrm{p}<0.001\right)$. There was not however a significant difference between the Professional and Access sections. The fact that fewer Undergraduate respondents recorded permanent damage might have been due to younger 
respondents, who were mainly in the Undergraduate section, encountering difficulty in determing whether or not their experiences were permanently damaging. No38, an undergraduate in the 20-39 age group, wrote, 'Damaging at the time but I can't say they were long lasting effects because it still affects me today. But I feel eventually I will be normal again'. Despite this, within the EA group, there were no significant differences between the age groups and their judgement of the outcome of abuse, nor between the different section when controlling for age. An alternative explanation could be that achieving a place on a degree or similar course gave the Undergraduates a more positive view of the outcome of their experiences.

\section{Emotional abuse as the main form}

There were 67 respondents who identified themselves as emotionally maltreated but also subject to another form of abuse. Of these 24 had suffered from three or more forms of abuse. Where the emotional abuse was a consequence of the sexual or physical abuse/neglect then the respondents were allocated to the Other Distress (OD) group. Respondents who indicated that the emotional abuse was the main but not sole form of abuse were allocated to the Emotional Abuse (EA) group. The decision was not always clear cut and the independent judge (see Chapter 4) was used to determine borderline cases, for example:

No 7, eventually allocated to the OD group, was sexually abused by her uncle. She felt emotionally abused and permanently damaged by the experience. It 'has left me incredibly insecure within emotional relationships and highly defensive'. When her parents eventually found out, they felt she could not cope with giving evidence so did not insist on prosecution and they also felt she was too young for counselling. She would have liked both and has sought counselling recently.

In contrast, No249 was allocated to the EA group. She indicated that she was sexually abused at the age of 8 but did not specify who the perpetrator was. But under the emotional abuse section she wrote:

I was abused and rather neglected from the age of 8 then taunted, belittled, 
ignored and humiliated, made to feel worthless etc from stepmother and dad. From the age of 10, I was expected to do everything - washing, clothes, food etc for myself. I was not allowed to be part of the family unless I was told I could eg go for a walk or church with the rest of the family.

Physical abuse presented further dilemmas. There was a considerable overlap between physical and emotional abuse. Most of the 47 respondents recorded physical abuse in the context of punishment. For example No35 felt she was physically abused formally smacked on bottom for misdemeanours' but went on to record a range of emotionally abusive experience unrelated to discipline.

A range of studies across cultures show that most parents use physical methods of punishment (Newson and Newson 1968, Vargas et al 1995, Doyle 1996a). It is possible that a person is likely to view physical punishment as abusive if they feel it was undeserved. This was found by Creighton and Russell (1995) who noted that in their study, respondents who were not close to their parents were more likely to feel they were punished unfairly, 'Whether the sense of unfair punishment led to these respondents not feeling close to their parents or whether not feeling close led them to perceive the punishment as unfair, is not known' (p.29).

There were some instances of severe physical mistreatment. No401 for example remembered being 'smacked - bruised - held by throat - choked'. However, in addition he recorded considerable detail of emotional abuse which remained even when the physical acts of abuse stopped. He feels that the emotional abuse is continuing even though he is in his twenties or thirties and has left home. Those who recorded emotional abuse which was additional to any physical abuse were included in the EA group.

\section{Happy versus unhappy childhood}

An additional factor taken into account with borderline cases was whether respondents felt their childhood was predominantly happy or unhappy. An example is No391 who did 
not indicate that she was emotionally abused but ticked three boxes, held her mother responsible and felt that her experiences were permanently damaging. In addition, she indicated that she remembered her childhood as mostly unhappy. Although a borderline case she was allocated to the EA group.

Of the respondents recording that they were emotionally abused, 51 percent remembered their childhood as predominantly unhappy with compared to 40 per cent who remembered a happy childhood. The remaining 9 percent remembered it as both or did not specify which. After allocation to groups the proportions were the same, with 51 percent of the EA group experiencing a mostly unhappy childhood. However in the OD group most $(87 \%)$ remembered their childhood as happy with only 5 percent as unhappy. In the Not Abused (NA) one person remembered her childhood as a mixture of both but the rest of the respondents (182) in the NA group recalled a happy childhood and none recalled an unhappy one.

\section{OTHER DISTRESS}

122 respondents were eventually allocated to the Other Distress (OD) group. Most of these had not defined themselves as emotionally abused but had experienced other distress. Some had suffered another form of abuse and emotional abuse was not a paramount factor. Others had defined themselves as emotionally abused. Although they could be viewed as such under a very wide definition, they were not suitable candidates for allocation to the EA group, given the working definition which requires an abuse of power for which the carer can be held responsible. The following sections give examples of the decision making process and also serve to illustrate the types of cases in the OD group.

\section{Bullying}

Three respondents who felt they were emotionally abused were the subject of peer bullying and were allocated to the OD group. Their parents appear to have attempted to be supportive although in one case they simply moved their daughter from school to school which exacerbated the problems. When she was at school (20 to 30 years ago) bullying 
was not a matter of public concern and her parents would have had access to little guidance; it was therefore judged that, however inappropriate their response, her parents were probably doing all in their power, given the understanding of bullying at the time, to help her and therefore could not be held responsible.

\section{Discrimination}

There were three respondents, placed in the OD group, who recorded experiencing emotional abuse due to society's attitudes. Two of these were 'gay' and faced discrimination because of this in their teens. The third was self-defined as 'Chinese' and was subjected to racially motivated physical and emotional assaults.

\section{Separation and loss}

The third cohort of those allocated to the OD group of self-defined emotionally abused respondents included two people whose parents had died. No168 explained 'After my mother died my father was unsure how to look after us'. No114 clarified 'Yes, from father's family - disowned me, treated me differently from my cousins etc. Father died therefore I could not be his child etc. '. Another respondent No330 indicated that she deemed her experience of being sent to boarding school as emotionally abusive. Similarly, No409 wrote 'sent away during school holidays to extended family as parents running hotel, they thought it was in my best interests'. Finally, No227 suggested that the fact that she was brought up by her mother alone and never knew her father or any details of him constituted emotional abuse.

\section{Uncertainty about responsibility}

There were four respondents who said they were emotionally abused but did not indicate who was responsible and did not give enough information for this to be determined. For example No22 filled in the first two sheets then added 'I have filled in the first few pages but felt the rest was too personal and would rather not have to fill it in. I hope you're [sic] research is successful though'. They were allocated to the OD group on the basis that there was no certainty that the parents were responsible. 


\section{CATEGORISATION OF EACH SAMPLE GROUP}

Table 3 demonstrates the proportions from each sample finally allocated to each category.

Table 3. Population survey: categorisation into 'Non Abused', Other Distress' and 'Emotional Abuse' relating to sample group

\begin{tabular}{|l|ll|ll|lc|c||}
\hline \hline Sample group & \multicolumn{2}{|l|}{ Not Abused } & \multicolumn{2}{|l|}{ Other Distress } & Emotional Abuse & Total \\
\hline \hline Undergraduate & 112 & $(48 \%)$ & 73 & $(31 \%)$ & 49 & $(21 \%)$ & $234(100 \%)$ \\
\hline Professional & 42 & $(40 \%)$ & 28 & $(27 \%)$ & 35 & $(33 \%)$ & $105(100 \%)$ \\
\hline Access & 29 & $(32 \%)$ & 21 & $(23 \%)$ & 40 & $(45 \%)$ & $90 \quad(100 \%)$ \\
\hline
\end{tabular}

While there were minimal differences between the expected and observed frequencies of the Professional section, there were significantly more Access students and significantly fewer 'Undergraduates' in the EA group $\left(X^{2}=18.9, \mathrm{df}=4, \mathrm{p}<0.001\right)$. This is not an unexpected finding because commentators such as Elmer (1977), Garbarino and Gilliam (1980) and Egeland and Erickson (1987) all point to the adverse impact of emotional abuse on development. Young people who have had abusive experiences might not be able to progress immediately to either higher education or to professional training.

\section{PREVALENCE OF OTHER FORMS OF ABUSE}

The population surveyed is not designed to be representative of the general population. Nevertheless, Finkelhor (1986) has shown that some college-based samples have provided a serviceable indication of the prevalence of sexual abuse in the general population. The present study could, therefore, similarly provide a useful estimate of the prevalence of emotional abuse. This is more likely to be the case if the percentage of sexual and physical abuse reported by the survey population bears some similarity to published prevalence rates of these other forms of abuse. 


\section{Sexual Abuse:}

In the present study 9 percent (39) of the population surveyed indicated that they had been sexually abused. The gender distribution was 11 percent (32) females and 5 percent (7) males.

Published prevalence rates for child sexual abuse vary from 6 percent to 62 percent of females and 5 percent to 16 percent of males (see Finkelhor 1986, Salter 1988). These were largely based on American studies. The differences depend on how narrowly sexual abuse is defined, the nature of the target population, the type of questions and mode of administration (Ghate and Spencer 1995). Creighton and Russell's (1995) self-report study indicated a rate at 16 percent, however they included exposure commonly referred to as 'flashing' whereas the respondents in the present study indicated sexual contact such as sexual 'touching'. Baker and Duncan (1985) interviewed 2019 people in Britain and 10 percent reported that they had been sexually abused before the age of 16; the gender ratio was 12 percent of females and 8 percent of males. The self-report rate of 9 percent in the present study (11\% female: $5 \%$ male) is similar to the Baker and Duncan self-report. La Fontaine (1990) also estimated a prevalence rate, close to that of the current study, of approximately 10 percent contact sexual abuse. Therefore, the prevalance rate for sexual abuse observed in this study is similar to those of other British studies.

\section{Physical Abuse}

In relation to the present population survey, 14 percent (58) recorded that they had been physically abused with a further 2 percent (7) recording 'not sure'. This 2 percent is probably a reflection of the uncertainty that exists about the dividing line between justifiable physical chastisement and physical abuse.

Two recent research projects indicate similar prevalence rates. The first was undertaken by Creighton and Russell (1995) in which about 16 percent of adult respondents recalled being severely or constantly beaten. Another recent study (Smith 1996, Smith et al forthcoming) estimated that about 14 percent had been subjected to physical punishment and control which could be considered severe. 
Creighton and Russell (1995) also observed that there were generational trends in relation to severe physical punishment. Although the younger age group (18-24 years) in their study recalled more punishment in general, only 12 percent recalled severe physical chastisement compared with 15 percent of 25-34 year olds and 20 percent of 35-45 year olds. There was a similar trend in the present study, as demonstrated by Table 4 .

Table 4. Population survey: recall of severe physical punishment by age group.

\begin{tabular}{|l|lc|ll|ll||}
\hline & \multicolumn{3}{|c|}{ Under $\mathbf{2 0}$} & \multicolumn{2}{c|}{$\mathbf{2 0 - 3 9}$ years } & \multicolumn{2}{c|}{$\mathbf{4 0 - 5 9}$ years } \\
\hline \hline Undergraduates & 8 & $7 \%$ & 13 & $12 \%$ & 3 & $30 \%$ \\
\hline Professionals & - & - & 11 & $16 \%$ & 7 & $20 \%$ \\
\hline Access & - & - & 12 & $17 \%$ & 4 & $21 \%$ \\
\hline All groups & $\mathbf{8}$ & $\mathbf{7 \%}$ & $\mathbf{3 6}$ & $\mathbf{1 5 \%}$ & $\mathbf{1 4}$ & $\mathbf{2 2 \%}$ \\
\hline
\end{tabular}

Again there are similarities between the prevalence of physical abuse in the current studies and in recent British studies.

\section{Neglect}

In the present population survey, $20(4.5 \%)$ of the respondents considered that they were physically neglected. Scrutiny of the cases indicated that five of the respondents were referring to emotional neglect despite the fact that Question 20 specified 'physical neglect'. Examples include No415 who wrote that her home 'had a feeling of emptiness', and No257 who commented 'I don't think my mum liked me much'. Excluding these five reduced the prevalence to 4 percent.

Of the remaining 15 , one indicated the neglect was being left alone in the evenings and another was left to let himself in after school from the age of 5 years. Six were not specific, making comments like 'I felt my needs were often overlooked' or 'They left me to my own devices'. No237 said that she was the only carer of herself and her three brothers. Two respondents, from relatively wealthy families, felt they were deliberately kept short of essentials 'Given things in a begrudging manner' and 'we were always 
second to my father's hobbies. The choir and cricket always came first'. Three respondents believed they were inadequately clothed. One of these was not washed and from the age of seven was left alone in the school holidays. Another lacked food and the basic necessities. The remaining respondent provided no written details.

Nearly half (9 out of 20) of the self-designated 'neglect' respondents felt that they were emotionally and sometimes also physically uncared for by step-parents. Their remaining birth-parent made little attempt to provide them with comfort and nurture. Overall, in 35 cases of children looked after by step-parents, a quarter $(26 \%)$ felt themselves to be uncared for.

It is difficult to compare figures from the present study to any others. In the literature there are no recent prevalence rates for neglect. This is partly due to the fact that "neglect has been neglected' (Stevenson 1996) and it might be due to the difficulty of determing when limited physical provision particularly among poorer families is due to economic deprivation, different class/cultural standards or negligent parenting.

In the present study, the more extreme forms of multiple physical neglect are absent. This is might be because substantial neglect leads to developmental and academic impairment (Minty and Patterson 1994, Kendall-Tacket and Eckenrode 1996). Children who are substantially physically neglected may, due to the sequelae of deprivation, be unable to achieve the academic standards required to aspire to higher education or professional training.

\section{OVERVIEW}

In the population surveyed, the prevalence rates for sexual and physical abuse appear to be commensurate with those of other relevant studies. This would appear to give credibility to the estimate, in the current study, of the prevalence of emotional abuse. The lack of certainty in relation to neglect reflects the lack of research in this area. 
Figure 4 provides a summary of the proportions finally allocated to each of the three categories: Not Abused (NA), Other Distress (OD) and Emotional Abuse (EA). These three groups form the basis of comparison when examining issues of location, manifestation and intervention considered in the next three chapters.

\section{Figure 4}

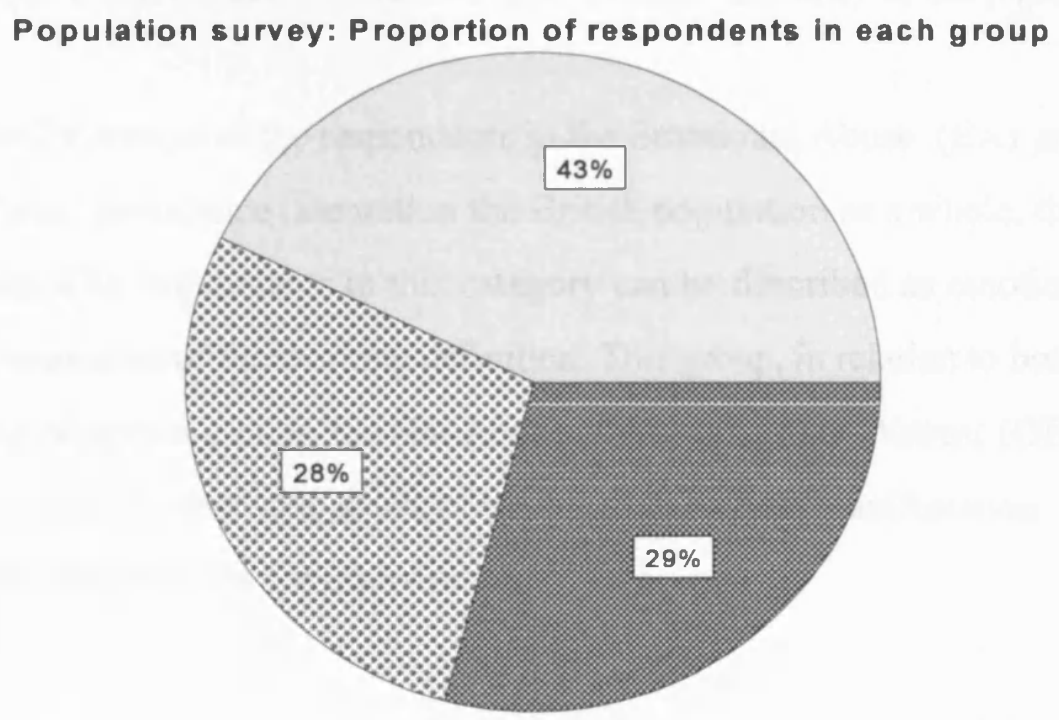

Not abused

Other distress

\section{Emotional abuse}

The figure of 29 percent of the research population experiencing emotional abuse is not a definitive figure. As with estimates of the prevalence of sexual abuse a change in the criteria results in a different rate. A more modest rate of 17 percent is achieved by restricting the EA category to those respondents who identified seven or more adverse experiences which were damaging in the long term or permanently. If the strictest criteria are used, ie including only those people who stated they were emotionally abused, ticked ten or more adverse experiences and said they were damaged in the long term or permanently, the prevalence rate falls to 10 percent. Alternatively, the social class profile of the Access students mirrors the national profile, it may therefore be that the 44 percent recorded by Access students is the 'true' prevalence rate. Further research into the 
prevalence of emotional abuse is evidently needed.

This does not mean however that the present study makes no valuable contribution to the understanding of the extent of emotional abuse. Despite its limitations, the current study has shown that 21 percent of those young people able to take advantage of higher education considered that they had experienced familial emotional abuse. This suggests that emotional abuse is not confined to a tiny 'deviant' minority of the population.

Although the 29 percent of the respondents in the Emotional Abuse (EA) group may not reflect the 'true' prevalence rate within the British population as a whole, they provide a starting point. The respondents in this category can be described as emotionally abused within the parameters of the working definition. This group, in relation to both the register cases and the other two groups, the Not Abused (NA) and Other Distress (OD) groups can be used to consider further the issues of the location and the manifestation of emotional abuse and the implications for intervention. 


\section{CHAPTER 6}

\section{FINDINGS: LOCATING EMOTIONAL ABUSE}

This chapter explores the location of emotional abuse, ie where it will be found and in what proportion. This can help to indicate which children are most vulnerable. Locating abuse also means investigating in what sort of family it is found and measuring whether it occurs more in one situation than another. Findings such as these can influence intervention because if, for example, emotional abuse is located exclusively in the poorest families then the alleviation of poverty is an evident starting point.

The data for the present section was obtained from both the population sample and from interviews with key workers with additional illustrations from the interviews with the survivors. In the earlier sections of this chapter most of the variables are examined separately. An overview of combinations of certain variables is presented in the latter parts of the chapter.

The lack of formal research into the emotional abuse of children - where it is the sole or main form of abuse - means that there are limited comparisons against which to set the present findings. However, Creighton (1992) provides data on 240 children registered as emotionally abused. In addition, the findings about location can be compared to what is known about other forms of child maltreatment; Creighton (1992) gives a profile of a further 5,488 children in the other register categories. Furthermore, Government statistics on the various relevant sections of the general population are used to set emotional abuse in context.

\section{TYPE OF CHILD}

Account has had to be taken of the fact that in some families only one child is abused whereas in others all or most of the children are suffering from emotional abuse. In the register cases, where all the children in a family were involved, the key worker selected the most vulnerable to be the subject child. 
In both register cases (based on key worker judgement) and the population survey (based on the response to the question 'Was any one else in your family mistreated?) it was possible to allocate subjects to one of three categories: 'only'; 'singled-out' and 'group' child.

For the sake of clarity, in most instances reference will be made to the subject child whatever the type of situation. However, where appropriate, a distinction will be made between the 'only', 'singled-out' or 'group' child.

\section{Gender of Subjects}

Register sample

In the present study of registered cases, 51 subjects (45.5\%) were boys and $61(54.5 \%)$ were girls. No statistically significant difference in the ratios between boys and girls were found when the different types of child (only, singled-out and group) were compared.

\section{Population survey}

In the population survey there were $285(66 \%)$ female respondents and $144(33 \%)$ male respondents. The female:male ratio in the EA category was 93:31 (75\%:25\%). When comparing the sex ratio between the NA and EA groups, controlling for age and class, there was no significant difference. Within the EA group itself, there was no statistically significant difference in the ratios between males and females when the different types of child (only, singled-out and group) were compared.

\section{Comment}

Creighton in an earlier study (1987) noted that more boys than girls were registered for emotional abuse. This continued to be the case in up to 1990 when for the first time girls were in the majority at 51 percent (Creighton 1992).

When discussing gender in relation to abuse, any conclusion has to take account of evidence (Nasjleti 1980, Finkelhor 1984, Bolton et al 1989, La Fontaine 1990) that suggests that men are less likely to admit to victimisation than women, possibly because 
society does not accept men's expressions of vulnerability and helplessness. Nevertheless, the findings of the present study suggest that there is little substantial difference in vulnerability to emotional abuse between the genders.

\section{Age of Subjects}

Disentangling the age at which children are subjected to emotional abuse is far from easy because, as identified in the literature (Chapter 3), there is likely to be an ongoing process rather than a single traumatic event. Because of this, data about ages at the onset and cessation of abuse were examined

\section{Age at onset of abuse}

\section{Register cases}

In the registered cases, the mean age of subject children at the time of referral was 7.69 years with a median of 8 years. The ages ranged from new born to 16 years $(\mathrm{SD}=3.97)$.

The 'singled out' children were significantly older than the others (Mann-Whitney $\mathrm{U}=682.5, \mathrm{Z}=1.97, \mathrm{p}<0.05$ ). The mean was 9.1 years and the median was 10 years (range $=2$ to 16 years, $\mathrm{SD}=3.69$ ).

\section{Population survey}

The average age at which the EA group remembered emotional abuse starting was 5.7 years $(\mathrm{SD}=3.4$ years $)$. In the $\mathrm{OD}$ group the onset was an average of 8.3 years $(\mathrm{SD}=3.2$ years). The difference was significant (Mann-Whitney, $U=2649.5, Z=5.08, p<0.001$ ). Intra-familial mistreatment therefore appears to start early than extra-familial abuse.

The 'singled-out' respondents in the EA group, as with the register cases, were significantly older than the 'group' subjects (Mann-Whitney $U=1017.5, Z=1.92, p<0.05$ ). The mean was 6.6 years and the median 7 years. It is difficult to identify a reason for this apart from the possibility that it takes time for abuse to be recognised by both other people and the victims themselves in a situation where all the other children in the family are wellcared for. 
The average age at which emotional abuse started may well be younger than that recorded because respondents were asked at what age they 'remember' it starting. Infantile amnesia is a well recognised phenomenon; 'when asked to recall childhood memories we recall most memories from around six and seven years, with this proportion decreasing sharply below these ages' (Coulson 1995 p.82). Therefore, very early experiences of abuse may remain unrecalled.

\section{Duration of abuse and age at cessation.}

This could only be examined through the population survey because in the register cases current abuse was still an issue.

\section{Population survey}

The mean age at which the emotionally abused group remembered the abuse stopping was 16.7 years $(\mathrm{SD}=3.6)$. This compares to the age of 14.2 years $(\mathrm{SD}=3.2)$ in the $\mathrm{OD}$ group. This difference is significant (Mann-Whitney, $U=2352.0, Z=6.23, p<0.001$ ). There was no significant difference, within the EA group, according to the type (only, singled-out, group) of respondent.

The duration of the intrafamilial emotional abuse appears to be longer than extrafamilial abuse or distress, such as school bullying, as demonstrated by the comparison between the two groups in Table 5 below.

Table 5. Population survey: age when emotional abuse stopped.

\begin{tabular}{|l|l|l|}
\hline \multicolumn{1}{|c|}{ When did abuse stop? } & Other distress & Emotional abuse \\
\hline \hline During childhood & $76 \%$ & $29 \%$ \\
\hline When left home & $3 \%$ & $17 \%$ \\
\hline In later adulthood & $12 \%$ & $19 \%$ \\
\hline Still continuing & $9 \%$ & $33 \%$ \\
\hline \multicolumn{2}{|c|}{ *table excludes $2 \%$ of the EA } \\
group' not specified'
\end{tabular}




\section{Comment}

Creighton (1992) recorded that between 1984 (when emotional abuse first became a register category) and 1990, the mean age of children registered for emotional abuse rose from 6.8 to 7 years. While similar to the present register cases, this is higher than the age recalled by the population EA group. It appears from these figures that there may be a time lapse between emotional abuse starting and its victims being referred for assistance.

The persistency of intra-familial emotional abuse, demonstrated by the 33 percent of the EA group who felt the abuse was continuing, is perhaps one of the notable differences between it and other forms of abuse. This is echoed by Creighton (1992) who noted that 'The children registered for emotional abuse stayed the longest' on the registers (p. 58). Agencies can do much to ensure that physical and sexual abuse and physical neglect stop - if necessary by separating victim and abuser. Emotional abuse, however, can start early and continue for a life-time.

This is illustrated by the case of Adam, an interviewee. Sexual abuse by his assistant scout master stopped as soon as Adam left the scouts. However, the verbal abuse and lack of interest in him shown by his father was something he had to contend with all his life. Adam was continually trying to win his father's affection. As his father was dying, Adam, aged in his late 40s, managed to say 'I love you father' to him but to Adam's devastation, his father died without reciprocating.

Similarly, the mother of another interviewee, Zoe, used to her hit without justification. Once, Zoe was sent to buy medicine but there was none in stock. 'Despite me giving her the money back, she gave me a good hiding'. This type of physical mistreatment stopped when she was about 14. But the emotional abuse continues, Zoe explained 'I still try to visit my mother but when I do my mother is very verbally abusive. She asks me why I am still alive instead of my father. When her freezer broke down recently she blamed me. I visit to keep the peace but one of my aunts still goes on at me for not visiting regularly'. 
Finkelhor (1986), examining sexual abuse, scrutinized all the research that indicated whether or not victims were more adversely affected by sexual abuse which was longer in duration. He concluded 'Given that the relationship between duration and impact is widely endorsed by clinicians as well, there is strong, if not conclusive evidence to establish the connection' (p.167). If this can be generalized to all forms of abuse, ie the longer the duration the more negative the outcome, then there are implications for children who are emotionally abused, even where it is the sole or main form of abuse.

\section{Birth/Bonding Problems}

Ecological theory incorporates the idea that problems related to family relationships such as birth problems and poor bonding can play a role in abuse cases.

\section{Register cases}

For the present study, data was collected from the key workers about bonding problems at the time of the subject child's birth. This included aspects of the child at birth being the 'wrong' type or gender or representing a negative reminder for the parents. It also included aspects of neo-natal separation highlighted by Kennell et al (1976).

If bonding renders some children more vulnerable then it should feature more prominently in 'singled-out' children rather than in 'group' children. The cases where the subject was an 'only' child were excluded because it was not possible to predict with certainty whether, had there been more children in the family, the subject child would have been singled out or whether all the children would have been abused. It was found that there were significantly more bonding problems relating to 'singled-out' compared to 'group' children $\left(X^{2}=8.4 d f=1, \mathrm{p}<0.005\right)$. The possibility that birth records were less available for 'group' children was considered. However this was unlikely given that the average age of the 'group' children was younger than 'singled-out' ones and the younger the child the more available the birth records.

\section{Population survey}

It was not possible to pursue this theme far in relation to the population survey. However, 
in all three cases of 'singled out' survivors interviewed there were problems surrounding conception and birth. Two were conceived illegitimately and were thus a negative reminder of the mother's 'infidelity' in an age when this was severely socially censured and the third survivor, the youngest in the family, felt that her conception had been a mistake and she had not been wanted by her mother.

\section{Comment}

In an early detailed study, Kennell et al (1976) concluded 'The affectional bonds a mother and father establish with their infant during the first days of life are crucial for his future welfare.' (p. 53). Where one child in the family is singled out for abuse, reasons for this will be sought by both the parents and professionals. It may therefore be that untoward events in the life of the singled-out child including negative birth incidents are likely to be explored, remembered and recorded. This could account for the difference between the two groups. Nevertheless, the findings do not confute the assertions about the importance of bonding by researchers such as Kennell et al (1976). For practitioners, these findings indicate that circumstances at the time of conception and birth are worthy of further scrutiny, particularly in relation to children 'singled-out' for abuse in otherwise apparently functional families.

\section{Ordinal Position of Subject and Siblings}

Register Cases

In the registered cases, 19 children were classed as 'only children'. In two of these cases older siblings had been permanently removed to adoptive parents. In two cases older siblings had died and in a further four the mother had had miscarriages. The impact of these type of losses will be examined further in the section on bereavement and loss below. Of the remaining registered cases, 53 (47\%) were eldest, 24 (21\%) middle, and 16 $(14 \%)$ youngest children in the family.

\section{Population survey}

In the population survey, $37(9 \%)$ children had no siblings. Of the remainder, $137(32 \%)$ were the oldest child, $103(24 \%)$ were middle children and $150(35 \%)$ were the youngest. 
Table 6 below shows the relationship of the ordinal position of the child to the experience of abuse.

Table 6. All groups: ordinal position of subject child.

\begin{tabular}{|c|c|c|c|c|c|}
\hline \multirow{2}{*}{$\begin{array}{l}\text { Ordinal } \\
\text { position }\end{array}$} & \multicolumn{4}{|c|}{ Population survey } & \multirow{2}{*}{$\begin{array}{l}\text { Register } \\
\text { Cases }\end{array}$} \\
\hline & Not abused* & Other distress & Emotional Abuse & TOTAL & \\
\hline only & $17(9 \%)$ & $9 \quad(7 \%)$ & $11(9 \%)$ & $37 \quad(9 \%)$ & $19(17 \%)$ \\
\hline eldest & $65(36 \%)$ & $36(30 \%)$ & $36(29 \%)$ & $137(32 \%)$ & $53(47 \%)$ \\
\hline middle & $36(20 \%)$ & $26(21 \%)$ & $41 \quad(33 \%)$ & $103(24 \%)$ & $24(21 \%)$ \\
\hline youngest & $64(35 \%)$ & $51(42 \%)$ & $35 \quad(28 \%)$ & $150(35 \%)$ & $16(14 \%)$ \\
\hline
\end{tabular}

* the table excludes one NA group respondent 'not specified'

\section{Comment}

Comparing the ordinal positions of the population survey respondents in the three groups, NA, OD and EA, there was no statistically significant difference between the groups. More 'eldest' children are registered. This may be related to the detection of abuse. Eldest children will be older and therefore more likely to be able to articulate the need for help. They are also more likely to be at school where their condition is monitored daily. If they fail to attend school they will also come to the attention of the authorities. The ordinal position of 'singled-out' children was predominantly the eldest in the register cases but the youngest in the EA group of the population survey. It is therefore concluded that there is no clear evidence to show that vulnerability to emotional abuse is associated with the ordinal position of the child.

\section{FAMILY PROFILES}

\section{Family size}

Table 7 below provides a summary of the sizes of the subjects' family in both the population survey and the register cases. 
Table 7. All groups: numbers of children per family

\begin{tabular}{|c|c|c|c|c|}
\hline & \multicolumn{3}{|c|}{ Population Survey } & \multirow{2}{*}{$\begin{array}{l}\text { Register } \\
\text { Cases }\end{array}$} \\
\hline & Not abused & Other distress & Emotional Abuse & \\
\hline $\begin{array}{l}\text { Mean number of children } \\
\text { per family }\end{array}$ & 2.8 & 3.3 & 3.5 & 2.8 \\
\hline $\begin{array}{l}\text { Range: numbers of } \\
\text { children per family }\end{array}$ & $1-10$ & $1-13$ & $1-12$ & $1-9$ \\
\hline $\begin{array}{l}\% \text { of families with less } \\
\text { than } 3 \text { children }\end{array}$ & $51 \%$ & $43 \%$ & $36 \%$ & $47 \%$ \\
\hline $\begin{array}{l}\% \text { of families with more } \\
\text { than } 6 \text { children }\end{array}$ & $6 \%$ & $11 \%$ & $17 \%$ & $5 \%$ \\
\hline
\end{tabular}

\section{Register cases}

These figures in Table 7 do not reflect the true family size. Often there were other children who were non-resident because they were adult, permanently in care or living with other relatives. Many families were reconstituted several times with different partners and stepor half-siblings moving into and out of the family.

\section{Population Survey}

The EA families were the largest in comparison to the NA and OD groups. This was statistically significant (Kruskal-Wallis, $X^{2}=12.5, \mathrm{p}<0.005$ ).

\section{Comment}

Creighton (1992) noted that in her samples large families were, compared to the national average, over-represented and this had 'been a consistent finding in previous years' (p.37). Data from the registered cases in both Creighton's studies and the present one have to be viewed with caution because of possible 'registration bias', ie more children in a family leads to increased agency scrutiny (more midwives, health visitors and schools involved) and this is likely to result in problems coming to light more readily. However, in this instance, the population survey, rather than register cases, revealed the larger size family 
related to emotional abuse. Therefore, in line with Creighton's findings and in registered and non-registered cases, larger families feature proportionally more in the abused groups. Despite this, looking at the ranges of both the registered cases and population survey, illustrated in Table 7, it is evident that emotional abuse can occur in any size of family.

\section{Age of Parents}

It was not possible to determine the average age of parents from the population survey because of the time-span covered. However, in the register cases, it was possible to determine the age of the parents of the subject child at the point of registration.

\section{Register cases}

The mean age of mother figures was 32.9 years. The mean for birth fathers was 38 years and for father substitutes it was 33.2 years. The age range of mothers was from 16 to 52 years, of birth fathers from 21 to 65 years and of father substitutes from 21 to 60 years. The present study revealed that 29 per cent of birth mothers, had had their first child when they were aged under 20 years old. This compares to a figure of approximately 5 percent nationally (Creighton 1992). The social class of the mother was not a statistically significant factor.

\section{Comment}

Several researchers note that in physical abuse the parents are young. Reder et al (1993), for example, surveyed 22 reports of inquiries into child deaths and found the average age of the mother with her first child was 18.5 years. Creighton (1992) noted that in the 18 years (1973-1990) of her research early parenthood was over-represented in the registered children's families.

Examining emotional abuse itself, Creighton (1992) found the average age for mothers was 30.9 years and 35.3 for father figures. These are slightly lower than those of the present study. Creighton also (1992) examined the age at which the parents of emotionally abused children had their first child and noted that 19 percent of the mothers were under 
20 when their first child was born. This, although lower than the percentage for physical abuse $(33 \%)$, is four times the national average. The present study indicates that in the register cases 29 percent of the mothers were under 20 compared to a national average of approximately 5 percent. It appears therefore that early parenthood may be associated with emotional abuse.

The figures from collations of public inquiries and register cases have to be regarded with circumspection. Public inquiries are usually only demanded in those cases in which social services have been involved and are therefore more likely to be registered ones. It is possible that younger parents, who have less time to build up finances, support networks and confidence in coping skills, are more likely to come to the notice of the various welfare agencies. They are therefore more likely to be subject to state scrutiny and become part of the procedures and registration system and more likely, if death occurs, to be the subject of an inquiry. However, Lynch and Roberts (1977) found that, using a control group, '50 percent [of abusing mothers] had their first child under the age of 20 compared with only 16 percent of their controls' (p.118). They comment that the abusing parents tended to be immature and look to their children to provide them with 'the love and care they have missed' (p. 118).

The calculations and comparisons for ages of father figures were less easy to access because precise details of many of the birth fathers in the register cases were not known. The association between the youthfulness of the father and abuse is not so clearly demonstrated in this study or in other comparable studies.

Further exploration of parental youthfulness would be useful partly to identify more clearly the role of young fathers and also because the reasons for the association between parental age and emotional abuse are not clear. Lynch and Roberts (1977), who talked about the developmental impairment of young abusive mothers, were writing at the time when predominant theories identified psychological factors within parents as the cause of abuse. Such parents might, as Lynch and Roberts surmised, have had an adverse childhood leading to problems with basic trust and identity. Alternatively, it could be that young 
parents have more environmental pressures. They have had less time to establish themselves financially therefore often have poorer accommodation, fewer amenities and more material worries. The issues of parental age is an example of how difficult it is to disentangle personal from material or environmental factors.

\section{Partnerships and caregiver changes}

\section{Partnerships}

\section{Register cases}

In the present study only $19(17 \%)$ of the subject children on the register were living with both natural parents, while $55(49 \%)$ lived at some time with a father substitute. Only four $(4 \%)$ lived with step-mothers. Seventy-four $(66 \%)$ of the subject children had lived with their mother alone. Only $6(6 \%)$ had at any time lived with their father alone.

\section{Population survey}

In the population survey, 60 percent of the EA abused group compared to 86 percent of the NA group lived throughout their childhood with both natural parents. In addition, 11 percent lived at some time with a natural mother and step-father compared with only 3 percent in the non-abused group. These findings are statistically significant, $\left(X^{2}=13.1\right.$, $\mathrm{df}=2, \mathrm{p}<0.005)$.

\section{Comment}

In a study of 12 'consciously rejected' children, Pemberton and Benady (1973) noted that 'marital disharmony' was significantly higher in their index group compared to the control. In the Reder et al (1993) study there was disruption in many of the parental partnerships.

Creighton (1992) notes that for all cases of abuse, including emotional, 'marital problems' was consistently recorded as a stress factor. In addition, 'the registered children were considerably less likely to be living with both their natural parents, and considerably more likely to be living with their natural mother and a father substitute than the national distribution of children from similar social classes' (p.25). Creighton gives a figure of 32 
percent for emotionally abused children living with both natural parents and 26 percent living with a natural mother and father substitute. This is a lower percentage of children living with a father substitute compared to the register findings in the current study. This could be due to the fact that Creighton takes a 'snap-shot' of children on the register in any one year, whereas the current study was able to explore whether or not there had ever been a stepfather present. The differences between the register cases and the population survey are less easy to explain. One possibility is that in those families where the mother is not a wage-earner and the father moves out (and before a step-father moves in), the mother may need state assistance and is therefore subjected to greater scrutiny. Child care problems are then more likely to be detected.

Despite some differences in figures between the population survey and register cases, the present study indicates that greater instability in parental partnerships occurs in the families of emotionally abused children than in non-abused children. This is supported by the studies of Pemberton and Benady (1973) and Creighton (1992).

It also appears from the present study that children living with stepfathers are more vulnerable. Researchers (eg Finkelhor 1986, Wilson and Daly 1987, La Fontaine 1990), Reder et al 1993) have highlighted the over-representation of stepparents in other forms of abuse, while Ward (1992) has highlighted the tensions in the stepparenting role.

\section{Domestic Violence}

Register cases

Of the register cases, domestic violence was a central issue in $29(26 \%)$ cases and was a substantial but peripheral one in a further $31(28 \%)$ cases. An example of domestic violence as a central issue is:

R40 There was a lot of violence between the parents. After the father left and the mother's boyfriend moved in, the father set fire to the house. The boy has talked of his father trying to strangle his mother. After threats by the father, the police searched the house and found he had planted a replica gun and put neat ammonia in the children's shampoo. The boyfriend tried 
to kill himself because of the stress caused by the father's threats.

An example of domestic violence as a peripheral issue is provided by:

R90 Both parents are multiple drug abusers. They spend their income on drugs and steal food and clothes for the children to the extent that in the foster home the children were bewildered by the foster parents shopping to buy what was required. The children are generally neglected and their home and possessions were destroyed by the father wielding an axe. One child 'surplus to requirements' is either ignored or baited by the parents. In addition the father threw a knife at the mother hitting the boy on the thigh; he now has a scar. All the children witness extreme marital violence with the father attacking their mother with knives and axes.

\section{Population survey}

There was no direct question about domestic violence in the population survey but 26 respondents explicitly identified the fact that they had experienced domestic violence in their childhood families. Of these, two felt that this had no effect on them, one believed his experiences had had a positive effect and a further six felt that the events had been damaging at the time but had no longer term effect. Of the remaining 17 , nine believed their experiences were damaging for a long time and eight believed they were permanently damaging. The accounts of those who felt they were permanently damaged indicated that they carried considerable burdens. For example:

No 235 had lived with both parents until she was 15 and was then looked after by her grandmother. Her father had a gambling compulsion. The bills were never paid and the children went hungry and were poorly dressed. Their house was small and cramped with no light bulbs. She was very frightened of the dark but when she cried about being sent upstairs in the dark she was threatened with being sent to a children's home. There was a lot of violence between her parents. She also recalled her mother having a miscarriage when she 'helped to put bits in bucket'. However, she was 
constantly emotionally and verbally abused by her mother 'She would say nasty names, swear at me, words I did not even know at that age'. She still has recurrent bouts of depression

Three of the twelve interviewees, Lynn, Jay and Roy, witnessed extreme domestic violence. Roy remembered 'Once dad put a stiletto heel through mum's skull'.

\section{Female violence}

Domestic violence is overwhelmingly an abuse of power by men (Mullender and Moray 1994). However, there were a few instances of domestic violence where the mother figure was the instigator of violence. Jay recalled 'My mother was very cold and harsh. She would be violent to my father... I would wait for dad to come home at night in order to stop mum and dad fighting'.

R34 There was extreme marital violence witnessed by the children. The mother frequently had broken bones. The mother could be as violent as the father and the police had to use riot shields to break up the fight. The mother had once smashed up the pub. The children had had 30 different addresses in five years.

\section{Comment}

Domestic violence in relation to ethnic origin and socio-economic status was examined. The figures are too small for any definite conclusion but domestic violence featured in all the main cultural groups and socio-economic groups on the register.

This section supports the view that all children witnessing emotional abuse should be viewed as potentially emotionally abused. Even where there is no physical assault, unexpressed hostility and anger can be damaging. Gemma, an interviewee, recalled that her parents never argued but there was an atmosphere of artificial restraint in her home. ' $I$ lived in a constant fear that some day the heavens would open and everything would blow up. I am still haunted by feeling of impending Armageddon'. 
In terms of intervention, a judgement may have to be made about whether what is being witnessed and reported is 'domestic violence', that is, the abuse of power by one or more people, or a 'clearing of the air' between two adults. It also has to be acknowledged that in different cultures there are different acceptable levels of emotional expression.

\section{Caregiver Changes}

A similar picture of family disruption emerges when caregiver changes are considered. Table 8 shows that nearly half $(49 \%)$ of the registered children experienced several caregiver changes. In the population survey 19 percent of the EA group had several caregiver changes compared with only 3 percent of the respondents in the group .

Table 8. All groups: numbers of caregiver changes per subject child

\begin{tabular}{||l||cc|cc|cc||}
\hline \multicolumn{7}{|c|}{ Population Survey } \\
\hline \hline & Not Abused & Other Distress & Emotional Abuse \\
\hline \hline Two parents, no change & $158(86 \%)$ & 89 & $(73 \%)$ & 75 & $(60 \%)$ \\
\hline Other carers, no change & 6 & $(3 \%)$ & 5 & $(4 \%)$ & 5 & $(4 \%)$ \\
\hline One change & 14 & $(8 \%)$ & 18 & $(15 \%)$ & 21 & $(17 \%)$ \\
\hline Several changes & 5 & $(3 \%)$ & 10 & $(8 \%)$ & 23 & $(19 \%)$ \\
\hline \hline
\end{tabular}

\begin{tabular}{||ll|}
\hline \hline Register Cases \\
\hline \hline 19 & $(17 \%)$ \\
\hline 2 & $(2 \%)$ \\
\hline 36 & $(32 \%)$ \\
\hline 55 & $(49 \%)$ \\
\hline
\end{tabular}

A comparison of the actual number of caregiver changes in each group showed that there were significantly more in the EA group compared with the other two groups (KruskalWallis, $\left.X^{2}=29.89, \mathrm{df}=2, \mathrm{p}<0.0001\right)$. A direct comparison of the NA and EA groups again showed significantly more caregiver changes in the EA group (Mann-Whitney, $U$ $=82.59, \mathrm{Z}=5.458 \mathrm{p}<0.0001)$.

\section{Comment}

In their sample, Creighton and Russell (1995) noted that those who recorded sexual abusive experiences in childhood were less likely to have been brought up by both natural parents ( $71 \%$ compared to $82 \%$ of non-abused respondents). They were also more likely to have been brought up by a single or step-parent due to divorce and separation rather than 
death of a parent. Similar changes of carer and family disruption has been recorded in physical abuse cases (Margolin 1992, Reder et al 1993).

The theme of abused children coming from disrupted families with a change of carers which has been found in other forms of abuse appears also to be a theme in cases of emotional abuse.

\section{Social Support or Isolation}

The ecological theoretical approach views social isolation as a key factor in abuse cases.. Given the time-span covered by the questions, it proved difficult to explore this through the population survey although the interviews provided a limited opportunity. It was however feasible to investigate this with the key workers in relation to the register cases.

\section{Register cases}

The social workers interviewed were asked what support the family had from either extended family members, friends or neighbours. The result was $41(37 \%)$ of the families were described as socially isolated because they had no contact with their extended family or friends. A further $10(9 \%)$ families had contact with unhelpful extended family members, for example, 'The maternal grandmother lives in a flat lower down in the block but is not helpful and is destructively powerful' (R53). Only one family with a negative extended family had other supports. This means that 50 families $(45 \%)$ had very little constructive social support.

Key workers expressed concern about the isolation of some of the children who had no relationships outside the home. For example, a girl (R104) aged 14 with spina bifida lived with her mother and sister, did not go to school or out to socialise and her extended family lived in Africa. One boy (R10) was 'over-protected', had no extended family and was not allowed to play with other children even in school at playtime 


\section{Population survey}

Although the population survey could not reveal the extent of social isolation it was factor impacting on several of the survivors who agreed to be interviewed. Both Adam and Kate remembered that they were isolated because they moved around so often that they could not make friends.

Pia noted that her family was 'very isolated on a farm miles away from any neighbours' The paternal grandparents had died and her mother had been brought up in care without knowing her parents so there were no known grandparents or extended family on her mother's side. There was an aunt and uncle who were quite caring but 'we did not see enough of them for them to be much support'. Pia also added 'Because we lived on an isolated farm, we were generally ostracised and bullied and seen as country yokels, I did not have a friend until after I was 17. Because of the isolation I never found out how other fathers behaved but I also felt that some of the incidents we were the only ones it happened to'. This sense of 'being different' in turn increased the children's isolation.

Roy and his mother were socially isolated because of his father's extreme violence to his mother compounded by the attitude the extended family who 'did not want anything to do with what was happening. They felt it was normal for a man to beat his wife and children'.

\section{Comment}

An association between social isolation and emotional abuse cannot be determined by the registered cases without knowing how many similar but non-abusive families are equally isolated. Nevertheless, many register families had no positive social support. As Pia's case illustrates, the isolation impacts on the children in several ways. They have fewer sources of help and friendships, they may be ostracised and bullied and they have no direct knowledge of how nurturing families operate. Moreover, they may believe they are the only ones being mistreated. Commentators on social isolation in abuse cases (Garbarino and Gilliam 1980, Coohey 1996) have concentrated on the isolation of the parents. The present study has provided some insight into the emotional impact of the social isolation on the children themselves and this may be an area worthy of further study. 


\section{Cultural Heritage}

In the population survey there was a relationship between self-identification of culture and of colour. One person who defined herself as African was white South African. The remaining four African respondents defined themselves as black. In the 'British' group there was one respondent, No388, who defined herself as black. She was adopted when she was a year old. There is no indication of whether her adoptive parents were white or black. All other 'British' respondents were self-defined as white.

Seven Asian respondents defined themselves as black while the remaining chose 'other'. Similarly of the eight 'Dual heritage' respondents, five were black and three 'other'. All 15 African Caribbean respondents were self-defined as black. The Other European group was divided into three black, one 'other' and the remaining 11 white.

Table 9 below shows the numbers of subjects in each heritage group. The register cases refer to the subject child.

Table 9. All Groups: ethnic origin of subject child

\begin{tabular}{||l|rl|rl|rl||}
\hline \multicolumn{5}{|c|}{ Population } & \multicolumn{2}{c|}{ Survey } \\
\hline \hline & Not Abused & \multicolumn{2}{l|}{ Other Distress } & Emotional Abuse \\
\hline \hline African & 3 & $(1.5 \%)$ & 1 & $(1 \%)$ & 1 & $(1 \%)$ \\
\hline Afr. Caribb'n & 2 & $(1 \%)$ & 6 & $(5 \%)$ & 7 & $(6 \%)$ \\
\hline Asian & 8 & $(5 \%)$ & 6 & $(5 \%)$ & 4 & $(3 \%)$ \\
\hline British & 163 & $(89 \%)$ & 102 & $(84 \%)$ & 103 & $(83 \%)$ \\
\hline Dual Heritage & 1 & $(0.5 \%)$ & 2 & $(1 \%)$ & 4 & $(3 \%)$ \\
\hline Other European & 6 & $(3 \%)$ & 5 & $(4 \%)$ & 4 & $(3 \%)$ \\
\hline
\end{tabular}

\begin{tabular}{|c|c|}
\hline \multicolumn{2}{|c|}{$\begin{array}{l}\text { Register } \\
\text { Cases } \\
\end{array}$} \\
\hline 2 & $(2.5 \%)$ \\
\hline 8 & $(7 \%)$ \\
\hline 3 & $(2.5 \%)$ \\
\hline 75 & $(66 \%)$ \\
\hline 10 & $(9 \%)$ \\
\hline 14 & $(13 \%)$ \\
\hline
\end{tabular}

In addition there was one person self-defined as a 'New Zealander' who was in the Emotional Abuse (EA) group.

\section{Comment}

The statistics relating to registered cases have to be treated with caution. This was because the eight metropolitan areas had proportionally large minority ethnic groups. For example, in one of the participating London boroughs 13 per cent of the population was African 
Caribbean. Using the 1991 census figures for the twelve local authorities, black families as a whole are not over-represented on the register. The register figures are too small to state whether or not any particular ethnic group is over or under-represented.

From the above table it is appears that minority ethnic groups are not over-represented in the emotional abuse groups. There was also no significant differences between the groups on the basis of self-defined colour categorisation. Small cell sizes precluded a test for significance based on the full range of cultural categories. However, it was possible to combine all the minority ethnic categories and compare them with the 'British' category. There were no statistically significant differences between the three groups (NA, OD and EA) in relation to the total number of respondents from minority ethnic cultures and British white respondents. But this does not mean that cultural perspectives and variations are to be ignored.

For example, in the population survey most of the African Caribbean respondents recorded that they experienced mistreatment predominantly in their teens. Fryer (1984) noted that African Caribbean people on arriving in England found 'the jobs they were offered were those the local white people did not want' (p.374). These jobs were often poorly paid. Gibson and Lewis (1985) point out that as young African Caribbean people particularly in poorer economic areas experienced racist attacks and the unsympathetic attentions of the police, their parents became 'paralysed with fear when their children were out of sight' (p.80). The consequent restrictions imposed by the parents were seen by the young people as oppressive and conflicts ensued.

What is apparent is that emotional abuse can occur in a very wide range of cultures, nationalities and religious groups. The nationalities represented by the emotionally abused children on the register and the population survey included: English, Welsh, Scottish, Northern and Southern Irish, French, Yugoslavian, Polish, Portuguese, Maltese, Algerian, Moroccan, Egyptian, Indian, Iranian, African Caribbean, white Australian/Maori, New Zealand, Guyanian, Mauritian, African American, expatriate white British/African. Religions represented include Protestant and Roman Catholic Christian, Jewish, Sikh, 
Hindu, Muslim, Jehovah Witness and one unidentified 'sect'.

\section{Class dimensions}

Table 10 below illustrates the class distribution of the various groups studied.

Table 10. All groups: social class of family of subject child

\begin{tabular}{|c|c|c|c|c|c|c|}
\hline \multirow{2}{*}{$\begin{array}{l}\text { Class } \\
\text { registrar } \\
\text { general }\end{array}$} & \multirow[b]{2}{*}{$\begin{array}{l}{ }^{*} \text { National } \\
\text { Statistics }\end{array}$} & \multicolumn{4}{|c|}{ Population Survey } & \multirow[b]{2}{*}{$\begin{array}{l}\text { Register } \\
\text { cases } \\
\end{array}$} \\
\hline & & Not Abused & Other Distress & Emotional Abuse & TOTAL & \\
\hline $\mathrm{I}$ & $8 \%$ & $21 \%$ & $17 \%$ & $6 \%$ & $16 \%$ & $4 \%$ \\
\hline II & $31 \%$ & $35 \%$ & $31 \%$ & $28 \%$ & $32 \%$ & $13 \%$ \\
\hline IIIa & $12 \%$ & $17 \%$ & $20 \%$ & $16 \%$ & $17 \%$ & $4 \%$ \\
\hline IIIb & $31 \%$ & $14 \%$ & $15 \%$ & $21 \%$ & $16 \%$ & $11 \%$ \\
\hline IV & $14 \%$ & $9 \%$ & $6 \%$ & $13 \%$ & $9 \%$ & $15 \%$ \\
\hline V & $4 \%$ & $2 \%$ & $5 \%$ & $8 \%$ & $4 \%$ & $23 \%$ \\
\hline forces & & $2 \%$ & $6 \%$ & $8 \%$ & $5 \%$ & $2 \%$ \\
\hline benefits & & $1 \%$ & 0 & $1 \%$ & $9 \%$ & $25 \% * *$ \\
\hline
\end{tabular}

\section{Comment}

A direct comparison with national statistics is not possible because of the problems of incorporating information about the proportion of the national population in the forces and on long term benefits. However the national statistics provide a template of the proportions of the population in the various occupational class groups.

The population survey indicates that emotional abuse occurs in all sectors and classes of society. The sample is not representative of the general population. Nearly three quarters (74\%) of the undergraduate group are from the professional, managerial and skilled nonmanual classes. The EA group, however, has a similar profile to the national one. This finding can be accounted for partly because more Access students recorded emotional abuse and their class profile was similar to the national one. The Access group had 48 percent in classes I,II and IIIa and a further 48 per cent in classes IIIb, IV and V compared 
to 74 percent and 22 percent respectively in the undergraduate group.

The registered cases have a substantial over-representation of families on long term benefits and in unskilled and semi-skilled occupations. This may not mean that emotional abuse is concentrated in lowest socio-economic groups. Instead families who have previous contact with welfare services are more likely to be investigated and "cases with many poverty indicators were more likely to be registered' (Gibbons et al 1995 p.81).

The findings of the present research reflect the apparently contradictory observations of Covitz (1986) who, using clinical cases, located emotional abuse in some of the highest socio-economic groups compared with Furnell et al (1988) who looked at registered cases and found the families were mainly drawn from the lower socio-economic groups. Child protection workers need to recognise that emotional abuse is located in all classes. However the reality of their work means that more often they will be aware of its occurrence in the poorest sectors of society, rather than the wealthiest and most powerful sectors.

\section{POTENTIAL STRESSORS}

Sources of stress can range from the environmental such as poverty and poor housing, to individual ones such as a significant bereavement. This section examines a range of potential stressors in the cases of abuse identified in this project. .

\section{Economic Status}

The income groups of the registered cases are indicated by the Table 11 and compared to the percentage of the general population of England and Wales. Figures from Social Trends 1995 produced by the Government Statistical Office indicate how far the distribution of income of the register cases is equal to the distribution of income in the population as a whole 
Table 11. Register cases: estimated income group of carers of subject child.

\begin{tabular}{|l|lc|l||}
\hline \multicolumn{1}{|c|}{ Income group } & \multicolumn{2}{|c|}{ Register Cases } & National Statistics* \\
\hline \hline Under $£ 15,000$ & 81 & $72 \%$ & $73 \%$ \\
\hline$£ 15,000-£ 29,999$ & 21 & $19 \%$ & $21 \%$ \\
\hline Over $£ 30,000$ & 10 & $9 \%$ & $6 \%$ \\
\hline
\end{tabular}

* Based on percentage tax-payers and unemployed in Social Trends 1995

The following results given in Table 12 give an indication of the economic pressures on the various families of the respondents in the population study.

Table 12. Population Survey - financial situation of respondents' childhood families

\begin{tabular}{||l|cc|cc|cc||}
\hline $\begin{array}{c}\text { Short of money for } \\
\text { essentials }\end{array}$ & Not Abused & Other Distress & Emotional Abuse \\
\hline \hline Always & 9 & $(5 \%)$ & 5 & $(4 \%)$ & 30 & $(24 \%)$ \\
\hline Sometimes & 56 & $(31 \%)$ & 66 & $(56 \%)$ & 57 & $(46 \%)$ \\
\hline Never & 118 & $(64 \%)$ & 48 & $(40 \%)$ & 37 & $(30 \%)$ \\
\hline
\end{tabular}

In the OD group three respondents did not specify their families' financial situation

\section{Comment}

The population survey demonstrates that persistent lack of money for essentials was more of an issue for the EA group (controlled for class, age and gender) than for the other two $\left(X^{2}=62.55, \mathrm{df}=4, \mathrm{p}<0.0001\right)$. It may be that the stresses of not being able to provide money for essentials contributed to the parents' emotionally abusive behaviour. On the other hand it could be that the lack of money was a result of other difficulties which caused family stress such as a parent's gambling compulsion or heavy alcohol consumption.

An alternative explanation is that non-abusing parents protected their children more effectively from the reality of material shortages. Three respondents in the NA group indicated that their parents may have been short of money but they were shielded from any 
financial problems. In contrast, in the EA group two respondents indicated that lack of material provision was part of the emotional abuse, the parents used money as a weapon or chose not to spend money on the children.

Finally, being 'short of money for essentials' is a subjective judgement and it may be that children who were happy at home were not worried by the lack of some material provision so did not feel their family was short of essentials whereas children who were unhappy at home might see the same level of barely adequate provision as a problem.

Compared to the national statistics, the figures from the register indicate that poorer families were not over-represented on the register. There is a discrepancy in terms of class because, when this was analysed, the lower occupational classes were over-represented. However, this demonstrates that total family income is no longer closely related to occupation-based class because in many families two parents were working in low-paid, unskilled occupations therefore jointly provided a family income above $£ 15,000$ a year.

\section{Accommodation}

\section{Housing problems}

Table 13 below shows the accommodation problems for the registered cases:

Table 13. Population survey: housing problems experienced by respondents' childhood families.

\begin{tabular}{|l|ll|ll||l||}
\hline & \multicolumn{2}{|c|}{ County councils } & \multicolumn{2}{|c||}{ Metropolitan b's } & Total - all areas \\
\hline \hline No problems & 35 & $(71 \%)$ & 30 & $(48 \%)$ & $65 \quad(58 \%)$ \\
\hline Moderate problem & 10 & $(20 \%)$ & 26 & $(41 \%)$ & $36(32 \%)$ \\
\hline Severe problem & 4 & $(8 \%)$ & 7 & $(11 \%)$ & $11 \quad(10 \%)$ \\
\hline
\end{tabular}

In the registered cases, 18 percent of families lived in owner occupier dwellings, 59 percent were in council houses, 10 percent lived in Housing Association property, 7 percent were in privately rented accommodation and 4 percent were in Bed and Breakfast provision. Finally, one family lived in a caravan and another in a squat. 
Table 14 demonstrates accommodation problems recorded in the population survey:

Table 14. Population survey: recorded housing problems in respondents' childhood

\begin{tabular}{||l|cl|cl|ll||}
\hline \hline Housing problems & \multicolumn{2}{|c|}{ Not Abused } & \multicolumn{2}{|c|}{ Other Distress } & \multicolumn{2}{c|}{ Emotional Abuse } \\
\hline \hline YES & 7 & $(4 \%)$ & 14 & $(12 \%)$ & 26 & $(21 \%)$ \\
\hline NO & 176 & $(96 \%)$ & 107 & $(88 \%)$ & 98 & $(79 \%)$ \\
\hline
\end{tabular}

* Excludes one of the OD group who did not comment on accommodation issues.

There were significantly more families with accommodation problems in the EA group compared to the NA or OD groups $\left(X^{2}=22.28 d f=2, \mathrm{p}>0.001\right)$. However, controlling for class, gender and age, it was found that there was no significant difference between the groups in the oldest age group. Because these respondents were over 40 years, this finding might reflect the accommodation problems generally experienced by many families in the aftermath of the pre-war Depression, the 1939-45 War and post-war austerity.

\section{Home conditions}

From the child's perspective the living conditions are probably as significant as the nature of the accommodation itself.

In some cases, poor housing conditions appear to contribute to the abusive nature of the situation. For example, in R88, a family, composed of mother, father and five children under seven years, lived in a two-bedroomed council house. The abuse mainly consisted of acts of omission with the parents ignoring the children. The key worker thought that the stress of living in such cramped conditions was a major contributory factor. Table 15 shows the proportion of families with unsatisfactory living conditions.

Table 15. All groups: living conditions in the subject child's home.

\begin{tabular}{|c|c|c|c|}
\hline & Not Abused & Other Distress & Emotional Abuse \\
\hline Satisfactory & $182(99.5 \%)$ & $112(93 \%)$ & $89 \quad(72 \%)$ \\
\hline Unsatisfactory & $1 \quad(0.5 \%)$ & $(7 \%)$ & $35 \quad(28 \%)$ \\
\hline
\end{tabular}

\begin{tabular}{|l||}
\hline Register Cases \\
\hline $67 \quad(60 \%)$ \\
\hline $45(40 \%)$ \\
\hline
\end{tabular}


Six respondents in the EA group and one in the OD group had an uncomfortable home because it was too immaculate, compared to 11 register cases. The only respondent in the NA group recording unsatisfactory conditions did so because the home was 'too disorganised and messy'. This compares with 13 respondents in the EA group with a similar observation. There were 31 register cases with untidy and insanitary home conditions. In addition, three registered children were living in very tidy homes but their own bedroom was in an unsatisfactory condition. For example:

R33 'House kept in an immaculate condition except the child's room which is just a store room and dumping ground with no proper bedding'.

In some instances, the state of the home could be viewed as contributing to the abuse. Examples include: R65 'The father is totally intolerant of any mess and will not allow the children to have any friends visit the home'; R84 'The family's maisonette is kept in an immaculate state and no toys are allowed because of the mess they might make'; R89 'The children have to do all the housework and keep the house immaculate'. Some homes were positively dangerous. One family, R78, lived in a renovated, council house described as 'Kept in a poor, dangerous condition eg dog faeces all over the house, glass and litter, no curtains, no carpets'.

\section{Comment}

There were substantially more children in the EA group and on the register with families facing accommodation problems and uncomfortable or unsatisfactory home conditions. The problems of poor housing and accommodation worries might add to the stress on parents which contributes to their abusive behaviour. Creighton (1992) noted that between 1988 and 1990, bad housing had been recorded in 14 percent of cases as a significant stress factor. However, in relation to the population survey it may be that, as with finances, accommodation issues were viewed as more of problem by children who were unhappy at home than those whose families were facing similar physical discomforts but who felt happy at home. 


\section{Socio-economic deprivation}

Three indicators of socio-economic deprivation were identified: financial deficits, housing problems and employment vulnerability (see Chapter 4). One point each was allocated to a) lack of money for essentials, b) housing problems and c) being in the vulnerable occupation classes (semi- or unskilled or benefit-dependent).

A respondent with a score of three points was therefore from a family which was likely to have experienced socio-economic deprivation. Those attracting two points were more vulnerable to socio-economic deprivation than those with only one point. Those with a zero score were unlikely to have experienced deprivation. Table 16 below illustrates the scores according to group.

Table 16. Population survey: Socio-economic deprivation score according to group.

\begin{tabular}{||c|cc|cc|cc||}
\hline \hline Deprivation Score & \multicolumn{2}{|c|}{ Not Abused } & \multicolumn{2}{|c|}{ Other Distress } & \multicolumn{2}{c||}{ Emotional Abuse } \\
\hline \hline 0 & 107 & $(58 \%)$ & 46 & $(38 \%)$ & 27 & $(22 \%)$ \\
\hline 1 & 60 & $(33 \%)$ & 56 & $(46 \%)$ & 63 & $(51 \%)$ \\
\hline 2 & 16 & $(9 \%)$ & 20 & $(16 \%)$ & 26 & $(21 \%)$ \\
\hline 3 & 0 & 0 & & 8 & $(6 \%)$ \\
\hline
\end{tabular}

Caution was exercised because the differences may have been a function of the age differences between respondents. The older ones might have viewed their families' financial and housing problems in a more negative light when contrasted with the relative affluence of recent years However, controlling for age, the EA group still scored consistently and significantly higher than the other two groups.

It would seem that the EA group were more vulnerable to socio-economic deprivation than either NA group (Mann-Whitney $U=3302.5, \mathrm{p}<0.001$ ) or the OD group (Mann-Whitney $U=5957, p<0.005$ ). This suggests that emotionally abused children are more likely to suffer socio-economic deprivation than those who are not emotionally abused. Nevertheless, nearly three-quarters of the EA group had no or only one deprivation 
indicator therefore emotional abuse cannot be said to be located only in families suffering socio-economic deprivation.

\section{Physical Disability Issues}

Subsumed under this section are chronic physical illnesses which can affect daily living. In relation to the population survey, the NA and EA groups did not differ significantly in relation to family members with physical disabilities. The figures as given in Table 17 below are too small to come to any firm conclusion.

Table 17. All groups: physical disability of a member of subject child's family.

\begin{tabular}{||l||ll|ll|ll||}
\hline \multirow{2}{*}{} & \multicolumn{3}{|l|}{ Population } & \multicolumn{2}{l|}{ survey } \\
\cline { 2 - 7 } & \multicolumn{2}{||}{ Not Abused } & \multicolumn{2}{|l|}{ Other Distress } & \multicolumn{2}{|l||}{ Emotional Abuse } \\
\hline \hline Parent & 7 & $(4 \%)$ & 4 & $(3 \%)$ & 3 & $(2 \%)$ \\
\hline Child & 3 & $(2 \%)$ & 3 & $(2 \%)$ & 5 & $(4 \%)$ \\
\hline No one & 172 & $(94 \%)$ & 114 & $(93 \%)$ & 115 & $(93 \%)$ \\
\hline
\end{tabular}

\begin{tabular}{|c|c|}
\hline \multicolumn{2}{|c|}{ Register cases } \\
\hline 15 & $(13 \%)$ \\
\hline 12 & (11\%) \\
\hline 58 & $(52 \%)$ \\
\hline
\end{tabular}

In each of the three population survey groups, NA, OD and EA there was one other family member such as a resident brother-in-law or uncle who had a physical disability. The 'child' can refer either to the respondent or to a sibling.

\section{Comment}

The difference in rates between the population survey and the register cases could be accounted for in alternative interpretations of the term 'disability'. The key workers included a number of conditions less readily recognised as a disability such as asthma, eczema and diabetes. It may be that the population survey respondents were thinking mainly of mobility or sensory impairment.

Another reason for the higher proportion in the registered cases may be due to increased contact with professionals in order to manage the disability. Greater professional scrutiny means that abuse is less easy to conceal. 
Illustrations from the register cases include:

R71 Mother has kidney problem, a lump on her breast and an abnormal smear but she will not have any further treatment or investigation.

R67 The mother learnt at birth that the baby boy was disabled and she could not come to terms with this for the first three years.

R104 A 13-year-old girl has spina bifida. Her extended family is in Africa. She came to England with her mother and sister for treatment. Her mother and sister blame her for the rejection of them by both sides of the extended family. She has no other relatives, no friends and does not go to school. Her only relationships are with her mother and sister both of whom verbally abuse her.

In the population survey, although the figures are very small some of the comments by respondents highlight issues for children in relation to disabilities. One person, No 225 , recorded that he had a hearing impairment and 'mum told me frequently she hated me and I was not her son. Sometimes a stigmatising disability was used against the child. No246 had a stammer and wrote 'I had a stammer and if I could not talk properly my father would tell me to shut up'. He was mimicked, bullied by his older brothers, witnessed violence and was threatened and also suffered from bullying by school teachers.

Zoe, who was interviewed, had spina bifida and she not only had to cope with her mother's verbal abuse, rejection and threats but also with discriminatory attitudes at school. Her first school, a convent boarding school, was a safe haven; the nuns were kind but also taught her to be independent. Then, aged 14, she moved to a day school 'there I had to constantly prove myself. They always emphasised my disability saying what I could not do. They were frightened if I fell over and hurt myself my father would sue, so they kept me wrapped in cotton wool'

One person with a disability cast a rather different light on the issue of emotional abuse. 
He was allocated to the other distress group and was not defined as emotionally abused. He had lost an eye in an accident and believed that he was so protected and 'spoilt' by his family that when he was adult he had a shock finding the rest of the world not as understanding and tolerant as his family.

The plight of some siblings of children with disabilities was highlighted by one respondent. R408 had a brother with a learning disability she wrote, 'Never felt loved Elder sister spoilt, brother needed a lot of attention'. She held her brother as well as her mother responsible for the emotional abuse.

\section{Learning disabilities}

Register cases.

In the register cases there were 11 families in which the parents had a substantial learning disability. There were very many others whose adverse childhood experiences had left them poorly educated. Of the children, 13 had a learning disability. In total $22(20 \%)$ families had at least one member with a learning disability.

\section{Population survey}

In relation to the population survey the number of families containing members with nonspecific learning disabilities (formerly termed 'mental handicap') could not be identified. This was because respondents appeared to make no distinction between non-specific and specific learning difficulties. Four respondents identified themselves as needing help with learning disability, indicating a confusion of terminology. In the NA group there were 10 $(5 \%)$ cases, in the OD group $11(9 \%)$ and in the EA group $12(10 \%)$ cases in which there was a member with a 'learning disability' of some sort.

\section{Mental Health}

Register Cases

Only those instances where help and treatment had been offered or there was reliable psychiatric assessment were recorded as mental health cases. Vague suspicions, general depressions, labels of 'personality disorder' and substance misuse without added mental 
health issues were all excluded. There were $56(50 \%)$ register families in which at least one parent had a mental health problem. There were 44 mothers which represented 76 percent of the people with mental health problems. None of the children were defined as having a recognised mental ill health problem

\section{Population survey}

In the population survey, there were significantly more family members who were deemed as needing help for mental health problems in the EA compared to the OD and NA groups $\left(X^{2}=33.52, d f=4, \mathrm{p}<0.001\right)$.

Overall there were more mothers suffering from mental health problems. In the NA group all the four parents were all mothers while in the EA group there were 15 mothers compared to seven fathers. However in the OD group there were seven fathers and five mothers. The total figures are given in Table 18 below.

Table 18. All groups: mental health problems recorded in member of subject child's family

\begin{tabular}{|c|c|c|c|}
\hline \multirow[b]{3}{*}{ Parent/s } & \multicolumn{3}{|c|}{ Population survey } \\
\hline & Not Abused & Other Distress & Emotional Abuse \\
\hline & $(2 \%)$ & $11 \quad(9 \%)$ & $22 \quad(18 \%)$ \\
\hline Other & $(2 \%)$ & $(5 \%)$ & $(9 \%)$ \\
\hline No one & $176(96 \%)$ & $105(86 \%)$ & $(73 \%)$ \\
\hline
\end{tabular}

\begin{tabular}{|c|c|}
\hline \multicolumn{2}{|c|}{$\begin{array}{l}\text { Register } \\
\text { Cases }\end{array}$} \\
\hline 53 & $(47 \%)$ \\
\hline 2 & $(2 \%)$ \\
\hline 57 & $(51 \%)$ \\
\hline
\end{tabular}

\section{Comment}

The finding of a substantial number mental ill health problems in the registered cases is not unexpected because families in difficulty are more likely to come to the notice of the 'authorities'. Furthermore, families referred for child protection investigation will normally be subjected to an assessment during which mental health problems are likely to be identified. However, the population survey results also demonstrate that mental ill-health, particularly in the parents, is a prominent issue in relation to emotional abuse. This 
does not appear to have been addressed in the literature and deserves further scrutiny.

\section{Substance Misuse}

Although alcohol is properly defined as a drug, problems relating to alcohol and to narcotics are examined separately because in Britain there are differences in both the legal response and societal attitudes to the consumption of alcohol and to other drugs. Smoking tobacco has been excluded although one respondent recorded her parents' smoking as a form of drug misuse. Apart from the broad division between alcohol and other drugs, the numbers are too small to make any further distinction between the different drugs used.

\section{Alcohol}

\section{Register cases}

In the registered cases, in 41 percent of the families one or more parents were deemed to have an alcohol misuse problem. This figure only represents those instances where helping agencies had offered treatment or where the parents had offended as a direct result of excess drinking. Those cases where the parents drank heavily but did not need help or had not offended were excluded. This was because 'heavy' drinking is a matter of judgement and 'suspected' drinking may have no real foundation.

\section{Population survey}

In the present population survey, only one father of a respondent in the NA group was identified as requiring help with an alcohol problem. This compares to three mothers and seven fathers ( $7 \%$ of the OD families) in the OD group and five mothers and 24 fathers ( $21 \%$ of the EA families in the EA group. In three families both parents had an alcohol problem. The differences between the NA, OD and EA group were significant $\left(X^{2}=42.6\right.$ $d f=2, \mathrm{p}<0.001$ ). The figures are summarised in Table 19. 
Table 19. All groups: alcohol problems recorded in parent of subject child.

\begin{tabular}{|c|c|c|c|}
\hline \multicolumn{2}{|r|}{ Population } & \multicolumn{2}{|l|}{ Survey } \\
\hline & Not abused & Other distress & Emotional Abuse \\
\hline Mother & 0 & 3 & 5 \\
\hline Father & 1 & 7 & 24 \\
\hline
\end{tabular}

\begin{tabular}{|l|}
\hline Register cases \\
\hline \hline 31 \\
\hline 26 \\
\hline
\end{tabular}

\section{Comment}

The numbers are two small for any definite conclusions to be drawn. Nevertheless, there are some issues that are worthy of comment. Problems relating to father figures are illustrated by the substantial increase between the NA and EA groups. In 19 percent of the EA families and in nearly a quarter $(23 \%)$ of the registered families, the father figure had a drink problem. However, the register cases also revealed a substantial problem relating to mothers. The figure of $31(28 \%)$ mothers with a drink problem in the register cases compares with 14 percent of the population of women from 1988 to 1993 between the ages of 25-44 whose alcohol consumption is 'above the recommended sensible levels' (Department of Health 1995b). Ettorre (1992) estimates only ' 2 per cent of the adult female population has a drinking problem' (p.36) and most of these do not have children. It appears that alcohol problems, in either or both parents, are a factor to take into account in cases of emotional abuse.

\section{Drug abuse}

Register cases

As with alcohol, drug misuse in relation to registered cases excluded cases of suspected consumption. The cases cited by the key workers involved more than the occasional recreational use of drugs. There were $27(24 \%)$ families affected by members substantially misusing drugs. This comprised 19 mothers, 17 father figures and four subject children. 
The problems of all forms of substance abuse were found mostly in the white British families. One father from the three Asian families had a drink problem but there were no substance abuse problems in these families. Two of the eight African Caribbean families had carers with drug problems but none relating to alcohol. Proportionally alcohol and drug misuse was distributed equally between the income groups.

\section{Population survey}

In relation to drug abuse (excluding alcohol and cigarettes) the numbers from the population survey were too small to be significant. It was noted that there were no families in the NA group in which this was an issue. In the OD group there were three parents (two mothers and one father) from two families. In the EA group there was one mother.

\section{Comment}

In an early study, Smith et al (1975) found no association with substance abuse in 214 physically abusing parents. More recently, Creighton (1992) found that drug abuse was a stress factor but not a prominent one. The Gulbenkian Foundation (1995) reported an increase, among both children and adults, in all forms of substance abuse and a growing concern particularly in the USA of the relationship between substance abuse and child maltreatment. The findings of the present study suggest, especially in view of the concerns of the Gulbenkian Foundation, that the relationship between emotional abuse and substance abuse, particularly by parents, requires further research.

\section{Bereavement and loss}

In order to avoid making the questionnaire too demanding for respondents, issues of family bereavement and loss were confined to the deaths of siblings and to any comments offered by respondents on other deaths. 
Child loss and deaths:

Table 20 below demonstrates the incidence of child deaths in the various populations.

Table 20. All groups: incidence of child deaths in subject child's family

\begin{tabular}{||l||cc|cc|cc||}
\hline \multirow{2}{*}{ Child deaths } & \multicolumn{3}{|c|}{ Population } & \multicolumn{2}{l|}{ survey } \\
\cline { 2 - 8 } & Not Abused & \multicolumn{2}{l|}{ Other Distress } & Emotional Abuse \\
\hline \hline Miscarriage & 19 & $(10 \%)$ & 10 & $(8 \%)$ & 24 & $(19 \%)$ \\
\hline Neonatal & 8 & $(4 \%)$ & 8 & $(7 \%)$ & 13 & $(10 \%)$ \\
\hline Post neonatal & 2 & $(1 \%)$ & 9 & $(7 \%)$ & 7 & $(6 \%)$ \\
\hline None & 154 & $(84 \%)$ & 95 & $(78 \%)$ & 80 & $(65 \%)$ \\
\hline
\end{tabular}

\begin{tabular}{||l|l|}
\hline $\begin{array}{l}\text { Register } \\
\text { Cases }\end{array}$ \\
\hline \hline $17(15 \%)$ \\
\hline 1 & $(1 \%)$ \\
\hline 9 & $(8 \%)$ \\
\hline 85 & $(76 \%)$ \\
\hline
\end{tabular}

In the register cases, although 85 families had not suffered a child death, a further 24 had suffered the permanent loss of one or more children either through long term removal of the children into care or because they had been permanently looked after by a relative. This left only $61(54 \%)$ of the subject families which had not suffered the loss of a child.

There is a significantly higher proportion of child losses including reported miscarriages in the EA group than in the NA and OD ones $\left(X^{2}=19.77, \mathrm{df}=4, \mathrm{p}<0.001\right)$. Post-natal deaths, discounting miscarriages, also feature more in the EA group $\left(X^{2}=12.08, \mathrm{df}=2\right.$, $\mathrm{p}<0.005$ ). This is likely to be a significant stressor for the family. 'To lose a child suddenly or as the result of a long and debilitating illness is an overwhelming experience for families' (Hill 1995 p.vii).

One example from the registered cases, R110, and the account of one interviewee, Pia, have been selected as illustrations of how the death of a child affects family functioning:

R110. The mother experienced four child deaths - two miscarriages, one still born and one son who lived to 17 years then died. Her most recent son was still surviving at the age of 13 . All the conceptions were the outcome of an incestuous relationship with her father. The surviving son was substantially over-protected. Aged 13, he weighed only 3 stone and his 
mother said that he was allergic to almost all food and kept him on a restricted diet. She dressed him in very young children's clothes such as a 'Noddy' cap and gave him 'Tommy Tipee' baby cutlery. The mother was convinced that her son would die when he too reached 17 and was trying to keep him as an eternal 'Peter Pan'.

Pia's family had also experienced a significant bereavement. She explained, 'My sister died when she was 2. She toddled out into the road with my elder brother. He was about 4 and he took her across the road and she was killed. He used to be physically abused by our father who blamed him but he also blamed himself for not having put a catch on the gate. She was our father's blue-eyed little girl, his favourite. He never recovered from her death'.

Terminations, although apparently sought by the mother, can still have a profound effect. For example, in R62 the mother had, according to the key worker, a traumatic termination which upset her for a long time.

In a number of the registered cases, the death of a previous sibling contributed to the reason for registration, such as R23 where the father had killed an earlier child. Although the present child was not thought to be at risk of physical harm, the emotional responses of the parents to the child was deemed inappropriate.

\section{Parental loss and deaths}

Some of the parents in the register sample had been traumatised by the deaths of their siblings, parents or close friends. For example:

R54 The mother's father died when she was aged 6 then her mother died when she was 11 years old. One brother died at birth. Another died recently in suspicious circumstances and her sister died of a heroine overdose. Her best friend committed suicide. 
Some of the population survey respondents acknowledged the distress that the death of their parent had caused them. The surviving parent's inability to cope with the situation had led to experiences bordering in the abusive, although two were allocated to the OD group. But there were situations where the death of a parent directly contributed to abuse. No390 wrote:

My mother died when I was nearly six. My father married again almost immediately to give me a mother. He and my stepmother did not get on well. My father often told me that if it hadn't been for me he would not be in this terrible relationship. If I was naughty, he would tell me how disappointed my own mother would have been in me and how I had let him down. He never kissed or touched me except to dry my hair.

Nobody ever talked to me about my mother dying. I was staying at my aunts when it happened and my father wrote a letter to tell me. My aunt read it to me. I thought I should not cry, I went to bed and I cried under my pillow so no one would know. I was fifteen before I knew what she had died of. I had to know when filling in a job application. I was frightened to ask because my mother was never mentioned, I had no photographs of her.

My father and stepmother never praised me. I was shabbily dressed and comfort ate. I always felt my father never really knew me. After he died two years ago I cried and cried because I was so hurt that he never told me that he cared about me... I feel that I could write pages and pages.

\section{Other losses}

In a few registered cases the loss of a partner through death or divorce was an important factor. In R58, the mother only had the subject child in order to have her partner's child. The partner died when the subject was 18 months old and the mother suffered a 'morbid grief reaction'. 


\section{Parental experience of childhood abuse.}

\section{Register cases}

It was possible to ask key workers about the parents experiences of childhood abuse because this is usually a component of assessment (Department of Health 1988, section 8.4). Their responses are illustrated by Table 21 .

Table 21. Register cases: parents' own childhood experience of abuse.

\begin{tabular}{|l|cc|ll||}
\hline & \multicolumn{2}{|c|}{ Father figure } & \multicolumn{2}{|c|}{ Mother figure } \\
\hline \hline multiple abuse & 12 & $(11 \%)$ & 37 & $(33 \%)$ \\
\hline physical abuse only & 12 & $(11 \%)$ & 6 & $(5 \%)$ \\
\hline physical neglect only & 1 & $(1 \%)$ & - & \\
\hline sexual abuse only & 4 & $(3 \%)$ & 20 & $(18 \%)$ \\
\hline emotional abuse only & 9 & $(8 \%)$ & 12 & $(11 \%)$ \\
\hline none & 12 & $(11 \%)$ & 11 & $(9 \%)$ \\
\hline not known & 62 & $(55 \%)$ & 26 & $(23 \%)$ \\
\hline
\end{tabular}

In 26 cases the mother's background was not known. This is a matter of some concern given the Department of Health guidelines and the fact that all the children had a mother figure. In 10 cases the workers had explored that mother's background and no abuse had been established. One mother had had a considerable burden as a young carer. This left 67 percent of the mothers who were known to have been abused. Examples of the mothers' experiences include:

R62 The mother's mother died when she was six. She was adopted and grossly abused by the adoptive parents. She was horse-whipped and made to kneel for hours on frozen peas.

R76 Mother's own mother was alcoholic and died when she was young. She was subjected to sexual abuse by her father when she was 13 and taken into care. 
The profile of the father figures was more complex as in many cases there were different fathers for different children in the family. In 34 percent of the families at least one father figure was known to have been abused but overall there was considerable uncertainty about many of the fathers' backgrounds.

\section{Population survey}

This was not an issue explored by the population survey although some of the interviewees reflected on their parents' own childhood experiences in the search for the reason for their parents' abusive behaviour towards them. For example Roy, whose father was very violent to his mother, reflected: 'My father was badly beaten by his step-mother, till her hands were blue. His real mother had walked out when my grandfather had an affair. My mother lived in a children's home until she was about 12'.

It was also possible to discuss with some of the survivors their reflections on their own parenting ability and that of any of their siblings who were abused and are now parents. Pia, for example, came from a large family and her brothers and sisters were all subjected to the same terrorisation by the father. There were however differences in the outcomes for the different children. The reason seem to be mostly the role in the family given to each child although temperament may have had a part:

Her oldest brother was held responsible by their father for her sister's death because when she was aged two and he four he took her across the road and she was hit by a car and killed. Pia explained 'he is now a competent manager but his childhood is still a burden for him and he is not close to anyone. He made a positive decision not to be abusive and is very good with his step-sons. Pia herself has suffered a series of abusive relationships. She has one son and has tried to ensure he is not abused. Her middle sister has not fared so well. 'She was seen as a replacement for the dead child. She has no self-esteem but has a serious drink problem. She went through a deep depression. She still has a very short fuse and will hit out at her own children. Her eldest girl aged 14 has been accommodated'. Pia's youngest sister 'still has relationship difficulties and has not married' Her youngest 
brother, seems to be coping well. 'He has made a decision not to be abusive and is a lovely husband and father'.

\section{Comment}

Abuse in the background of the parents appears to be an important factor. Of those cases where the parental background was known 88 percent of the mothers and 77 percent of the fathers had suffered at least one form of abuse during their childhood.

Conversely, when the volunteers from the population survey were interviewed there was little evidence of the 'intergenerational transmission' of abuse. The volunteers' own parents had had variable childhood experiences themselves and by no means all their parents appeared to have been abused.

The volunteers in turn had, in the main, been determined not to abuse their own children. Three of the 12 were not parents. Of the remaining nine, all had tried to respond to their children in a caring, responsive way, although three had had violent partners who had been abusive to themselves and their children. The 12 survivors all recognised the ways in which their parents' power was wielded abusively and could have been used differently, in a non-abusive way. All those survivors who had children were attempting to exercise their power in the non-abusive way that they identified. Several volunteers also recognised that they had to protect their children from mistreatment by their own abusive parents. Roy's father for example was now violent and threatening towards Roy's wife in front of their young children. Roy had without hesitation involved the police and taken out an injunction against his father so that his children did not witness any threats.

Herzberger (1993), while acknowledging that 'violence can be transmitted' (p.46), challenges the nonreflective acceptance of the cyclical hypothesis. The present study would support that challenge although not rejecting the hypothesis entirely. From the ecological perspective an abusive childhood might be one factor among others which render the parent vulnerable to adverse conditions. 


\section{Stressors - an overview}

Stress was likely to feature in the register cases because families experiencing material and personal difficulties are likely to be referred to professionals who are in a position to identify emotional abuse. It is therefore necessary to turn to the population survey for an indication of whether stress is higher in families in which emotional abuse occurs in comparison to those in which it does not.

As a guide to the relationship of stress to abuse, various stress factors identified in the population survey and itemised in Table 22 below were scored. The scores are summarised in Table 23 below. The death of a child, accommodation problems and each of the problems relating to family members (Questions 13 and 14, see Appendix 3) were allocated one point. Lack of money for essentials was allocated one point if this was 'sometimes' and two if 'always'. The final potential stress score was 9. This was not a comprehensive inclusion of all stressors on a family. Nevertheless, the scores were a broad indicator especially as other problems were reflected in those recorded, for example divorce and separation of the parents was often reflected in accommodation problems.

Table 22. Population survey: stressor score by type of stressor

\begin{tabular}{||l|ll|ll|ll||}
\hline \multicolumn{1}{|c|}{ Stressor } & \multicolumn{2}{|c|}{ Not Abused } & \multicolumn{2}{c|}{ Other Distress } & \multicolumn{1}{c||}{ Emotional Abuse } \\
\hline \hline Short of money: sometimes & 56 & $(31 \%)$ & 66 & $(56 \%)$ & 57 & $(24 \%)$ \\
\hline Short of money: always & 9 & $(5 \%)$ & 5 & $(4 \%)$ & 30 & $(24 \%)$ \\
\hline Accommodation problems & 7 & $(4 \%)$ & 14 & $(12 \%)$ & 26 & $(21 \%)$ \\
\hline Physical disability & 10 & $(6 \%)$ & 7 & $(6 \%)$ & 8 & $(6 \%)$ \\
\hline Learning disability & 10 & $(6 \%)$ & 11 & $(9 \%)$ & 12 & $(10 \%)$ \\
\hline Mental ill-health & 7 & $(4 \%)$ & 17 & $(14 \%)$ & 33 & $(27 \%)$ \\
\hline Alcohol abuse by parent & 1 & $(0.5 \%)$ & 10 & $(8 \%)$ & 29 & $(23 \%)$ \\
\hline Drug abuse by parent & 0 & 3 & $(2 \%)$ & 1 & $(1 \%)$ \\
\hline Child deaths & 29 & $(16 \%)$ & 27 & $(22 \%)$ & 44 & $(35 \%)$ \\
\hline \hline
\end{tabular}


Table 23. Population survey: number of stressors in respondents' childhood families

\begin{tabular}{|l||l|l|l||}
\hline no. stressors & not abused & other distress & emotional abuse \\
\hline \hline none & 96 & 29 & 14 \\
\hline one & 52 & 47 & 31 \\
\hline two & 28 & 31 & 39 \\
\hline three & 6 & 9 & 14 \\
\hline four & 0 & 4 & 12 \\
\hline five & 1 & 2 & 5 \\
\hline six & 0 & 0 & 5 \\
\hline seven & 0 & 0 & 2 \\
\hline eight & 0 & 0 & 1 \\
\hline nine & 0 & 0 & 1 \\
\hline \hline
\end{tabular}

Only 68 percent of the EA group's families experienced two or fewer recorded stressors compared to 96 percent and 89 percent of the NA and OD groups respectively. When the differences in the scores for stressors in the three groups were examined they were significant (Kruskal-Wallis $X^{2}=87.31 . \mathrm{df}=2, \mathrm{p}<0.001$ ). The ecological model would predict a trend from fewer stresses in the NA group to rather more in the OD group (containing some respondents who had suffered emotional abuse or family distress) to most in the EA group. This prediction was confirmed using the Jonckheere trend test, at a significance level of $\mathrm{p}<0.001(\mathrm{Z}=.3 .08)$

The number of negative experiences were also scored. One point was given for each type of negative experience ticked in the boxes for Question 23 Which if any of these things happened to you? For the total population of 429 cases there was a moderate positive correlation between the stressor score and negative experience score (Spearman $r .46$, $\mathrm{p}<0.001)$.

It appears that account has to be taken of the stressors experienced by families. Emotional abuse appears more likely to be located in families with instability and material and 
personal problems. Nevertheless, stress may not always be an essential ingredient because in over a tenth of the families in which emotional abuse occurred there was no apparent stress.

The statistical technique of discriminant function analysis was used to examine the prediction of group membership ('Not Abused' compared to 'Emotionally Abused') on the basis of several variables. Group membership was the nominal dependent variable. It was applied to two groups, NA and EA, derived from the population survey. The OD group was excluded because it contained people who would have been in the NA group had it not been for an encounter with a local bully. Other OD members might have been allocated to the EA group had they provided a little more information. The resulting group sizes were 183 (NA), and 124 (EA).

These 307 cases were then randomly allocated to two equal sub-groups using the random selection facility on SPSS. The discriminant function was estimated using the first 'selected' group - the 'analysis' sample. The second 'unselected' group (the holdout sample) was used to test the discriminant function. Using the classification findings for the holdout sample gives a more reliable indicator of the power of the discriminant function.

A stepwise discriminant functional analysis was performed using four discriminating variables as predictors of group membership. The stepwise method enabled the variables best able to contribute to the discrimination to be identified. The method for controlling the stepwise selection was Mahalanobis distance.

The choice of discriminating variables was informed by ecological theory, taking into account the ability of individual, independent variables to discriminate between abused and non-abused groups. The socio-economic deprivation (SED) score was used as the first discriminating variable. Inter-personal stressors (bereavement, illness, disability and substance misuse) were enumerated to provide the second discriminating variable. The number of caregiver changes was included as this appeared to reflect family disruption. Finally, family size was included on the basis that other studies, as well as the current one, 
have found larger families appear to be vulnerable (eg Creighton 1992). Some authorities (Tabachnick and Fidell 1989) appear to accept qualitative data, others (Kinnear and Gray 1994) advise against this. Norusis (1988) counsels against mixing different types of data. All the discriminating variables used in the analysis were numerical.

As there were only two groups, there was one discriminant function. Discriminating variables included, in order of their power to discriminate, socio-economic deprivation indicators, inter-personal stressors and finally the number of caregiver changes. Family size $(F=0.11737)$ was not included in the analysis after Step 3 after which there was no further computation (further details of the stepwise selection are provided in Appendix 5). The standardised discriminant function coefficients of the remaining variables were:

SED $\quad .51444$ (socio-economic deprivation score)

PERSON $\quad .50419$ (inter-personal stressors score)

NUMCH $\quad .39585$ (number of caregiver changes)

The discriminant function accounted for 31 percent of the variance between the abused and non-abused groups (Eigenvalue $=0.45, \mathrm{R}=0.56$, Wilks' Lambda $=0.69$ ). The findings were statistically significant $\left(X^{2}=53.1, \mathrm{df}=3, \mathrm{p}<0.001\right)$.

Overall, 75 percent of the selected cases and 70 percent of the unselected cases were correctly classified. Table 24 provides the classification results for both selected and unselected cases.

Table 24. Discriminant function analysis : classification results for analysis and holdout cases

\begin{tabular}{|c|c|c|c|c|c|c|c|c|}
\hline Actual Group & \multicolumn{8}{|c|}{ Predicted Group Membership } \\
\hline & \multicolumn{3}{|c|}{ Analysis } & \multicolumn{5}{|c|}{ Holdout } \\
\hline & $\begin{array}{l}\text { Number } \\
\text { Cases }\end{array}$ & $\begin{array}{l}\text { Not } \\
\text { Abused }\end{array}$ & $\begin{array}{l}\text { Emotional } \\
\text { Abuse }\end{array}$ & $\begin{array}{l}\text { Number } \\
\text { Cases }\end{array}$ & $\begin{array}{l}\text { No } \\
\text { Ab }\end{array}$ & & $\begin{array}{l}\mathbf{E m} \\
\mathbf{A b}\end{array}$ & $\begin{array}{l}\text { tional } \\
\text { se }\end{array}$ \\
\hline Not Abused & 92 & $8491 \%$ & $8 \quad 8 \%$ & 92 & 88 & $96 \%$ & 4 & $4 \%$ \\
\hline Emotional Abuse & 54 & $2852 \%$ & $\begin{array}{l}26 \\
48 \%\end{array}$ & 69 & 45 & $65 \%$ & 24 & $35 \%$ \\
\hline
\end{tabular}


The discriminant function was a better predictor than the variables individually. Table 25 illustrates the differences in overall and emotional abuse classification in the case of each independent variable, using the results for the 'unselected' cases.

Table 25. Discriminant function : comparison with individual independent variables

\begin{tabular}{|l|l|l|}
\hline & Overall \% correct classifications & \% EA correct classifications \\
\hline \hline Discriminant function & $70 \%$ & $35 \%$ \\
\hline Socio-economic deprivation & $61 \%$ & $20 \%$ \\
\hline Personal Stressors & $67 \%$ & $30 \%$ \\
\hline Changes of caregiver & $62 \%$ & $19 \%$ \\
\hline
\end{tabular}

\section{Comment}

Tables 24 and 25 show that the absence of, or low level of, a combination of negative socio-economic factors, personal stressors and caregiver changes is a good predictor of allocation to the NA group. It would seem that emotional abuse is very much less likely to occur in families with high levels of stability and low levels of both socio-economic pressures and personal stressors, such as illness, bereavement or disability. Despite this, the assertion that a combination of stressors and caregiver changes predict an increased risk of emotional abuse cannot be made with confidence. The discriminant function did not account for 69 percent of the variance. Furthermore, only just over a third of the EA group were correctly classified. This finding is not, however, unexpected because not all possible factors could be included in the analysis. Issues identified in the register cases suggest that additional variables such as a parental history of abuse and bonding problems may also be important.

Discriminant function analysis provides a general indication that certain variables in combination are better predictors of emotional abuse than variables considered individually. This has implications for policy makers and practitioners. In order to prevent emotional abuse, account has to be taken of socio-economic disadvantage as well as personal distress and family disruption rather than focussing on just one problem area. 


\section{OVERVIEW}

It is apparent that emotional abuse occurs in a wide variety of families and to varied types of children. It is not confined to particular cultural or socio-economic groups.

Nevertheless, there appears to be a trend for stress factors, with the exception of disability, to increase from the NA to the EA group and to feature prominently in the register cases. Yet while stress appears to be factor, it is not the total explanation because there are families in which abuse occurs where there is no identified stress and families in which there are appreciable stresses with no emotional abuse.

An alternative perspective is that pressures on a family may be felt and recorded as stress in those instances where the children feel emotionally abused, whereas the same stress may be dismissed lightly by non-abused children.

Nevertheless, there were indications of a higher levels of potential stress in both the emotional abuse cases and the register cases. Interpersonal and relationship difficulties were in evidence. In addition, material pressures such as poor accommodation and low economic status appear to be important factors. Given the identification of several predictive variables, discriminant function analysis could be used to develop a check-list in order to target resources towards those families in which emotional abuse is most likely to occur. There have been similar attempts to formulate checklists for other forms of abuse (eg Polansky et al 1983, Milner 1986, Waterhouse and Carnie 1992). There is an obvious attraction of a system which can have the appearance of a 'scientific' instrument. However, a substantial number of commentators advise caution. Researchers and practitioners (eg Lealman et al 1983, Jones et al 1987, Browne and Saqi 1988, Dingwall 1989, Ward and Wolverton 1990) have cast doubt on the reliability of these instruments. Corby (1996) warns 'Research into child abuse cases, though extensive still has far to go before it [a checklist system] can provide the type of certainty in prediction that would be acceptable to society' (p.21). Given the very limited research into emotional abuse there is even farther, than in other forms of abuse, to go before checklists can be introduced with 
confidence.

Nevertheless, Corby (1996) and Wald and Wolverton (1990) argue in favour of looking beyond linear causation to the interaction of number of factors. The use of discriminant function analysis indicated that emotional abuse is more likely to occur in those families where there is an interaction of environmental, personal factors and caregiver changes. This suggests that professional intervention has to take account of a multiplicity of issues instead of focussing on just a single element such as poor bonding or poverty. Furthermore, the absence of these issues in the families of non-abused respondents suggests that making material and interpersonal support universally available for all families at a primary level may help to prevent emotional abuse. 


\section{CHAPTER 7}

\section{FINDINGS: MANIFESTATION OF EMOTIONAL ABUSE}

In order to intervene, practitioners have to be able to recognise what forms of parental behaviour may be deemed abusive. A study of the literature (Chapter 3) demonstrated that most commentators favoured a definition which took account of parental behaviour. However, many commentators also acknowledged that the assessment of the manifestation of abuse in the child helps in the process of recognition and may provide a guide to the intervention required. Through expressions of distress or difficulty, children may be indicating needs which are not being met.

This chapter looks at signs of emotional abuse manifested in parental behaviours, issues of responsibility for the abuse and possible manifestations of abuse in the children.

\section{PARENTAL BEHAVIOUR}

Most of the information used in this chapter was gained from the registered cases although it was supplemented by the responses to the population questionnaire and comments from the survivors interviewed.

In response to the open question 'What parental behaviours were judged to be emotionally abusive', most key workers were able to identify, and give examples of, the behaviour deemed to be emotionally abusive but did not provide this information in a systematic way. This arbitrary provision reflects the problems of presenting emotionally abusive behaviour in a ordered, schematic manner. Physical and sexual abuse are typically conveyed chronologically or by type of injury or assault. Neglect is usually presented by measurable problems such as inadequate nutrition, poor hygiene or inadequate supervision. It is difficult to order emotional abuse in any of these ways. Often there is a cumulation of behaviours, such as persistent verbal abuse, rather than one notable, chronologically recorded event or a cluster of tangible, measurable signs. 
The parents' emotionally abusive behaviour was therefore noted down, using the key workers words, in whatever order they chose to provide it. However for the purpose of analysis, the behaviours were allocated to different categories. As Dey (1993), providing guidelines for the analysis of qualitative data, notes 'though some categories may be established in advance, these may still require confirmation in the data, while other categories or subcategories may be derived from the data' (p.97). This reflects the process of categorisation of parental behaviours in this study.

Ultimately, nine categories were devised (see Figure 5 below). The categories were initially based on five provided by Garbarino et al (1986). These were: terrorising, rejecting, isolating, ignoring and corrupting. The literature, initial workshops (see Introduction) and pilot provided examples which were not readily located within these original five categories. There were, for example, the instances of the adolescent girl whose head was shaved (Dean 1979) and the 8-year-old in a dog harness left tied to a parking meter (Yates 1982). Bates (1980) cites examples of children called 'derogatory names'. The category 'degrading' was added to include these type of public humiliations and denigrating verbal abuse. Zemdegs (1980) describes being placed constantly in a "nowin situation' while Garbarino and Garbarino (1986) portray some parental behaviour as emotionally 'sadistic'. To account for these 'tormenting' was added. Covitz (1986) provides a rich array of examples of children who have overwhelmingly too much or too little responsibility or who are scapegoated or used as weapons in adult conflicts. The category 'inappropriate roles' was devised to cover these examples. On the basis of one case in the pilot study where a child had been denied much needed counselling 'inappropriate treatment' was added. Finally, on the basis of discussions at the pilot stage, the term 'fear inducing' was substituted for 'terrorising' to include those instances where children were left in a state of fear and insecurity but where the term 'terrorising' was felt by professionals participating in the pilot to be too dramatic.

Additional illustrations of the behaviours were provided through the responses in the population survey to Question 23. The behaviours, as encountered and experienced by the victims, were matched to each category. In most instances the emotional impact was 
explicit because the statement started with the phrase 'Made to feel ...'. In other instances it is implicit, for example 'being made to feel humiliated in public' is phrased as an event ie 'Publicly humiliated'.

Abusive parental behaviours can also be viewed as a failure to meet children's needs. Maslow's (1970) model is a useful conceptualisation of this (see Chapter 1). The behaviours which are predominantly described by the key workers as acts of commission can also be described as acts of omission, a failure to provide. Figure 5 illustrates the association between the categories of parental behaviours identified by the key workers, with the emotional experience of these behaviours identified by the questionnaire respondents and Maslow's identification of needs.

Figure 5. Categorisation of emotionally abusive behaviours

\begin{tabular}{|c|c|c|}
\hline Category of behaviour & $\begin{array}{l}\text { Maslow's needs. } \\
\text { Failure to meet: }\end{array}$ & Experience of abusive behaviour \\
\hline Fear inducing & safety/security needs & $\begin{array}{l}\text { Made to feel frightened because of threats } \\
\text { Made fearful due to witnessing violence } \\
\text { Made to feel insecure }\end{array}$ \\
\hline Tormenting & safety/security needs & Made upset by relentless teasing \\
\hline Rejecting & belonging/love needs & $\begin{array}{l}\text { Made to feel no one cared for me } \\
\text { Made to feel unlovable } \\
\text { Not shown any affection } \\
\text { Made to feel completely unimportant }\end{array}$ \\
\hline Ignoring & belonging/love needs & $\begin{array}{l}\text { Made to feel I did not exist } \\
\text { Having my achievements ignored }\end{array}$ \\
\hline Isolating & belonging/love needs & $\begin{array}{l}\text { Not allowed to have any friends } \\
\text { Locked away for what seemed long periods }\end{array}$ \\
\hline Degrading & esteem needs & $\begin{array}{l}\text { Publicly humiliated } \\
\text { Having my achievements derided } \\
\text { Made to feel not good enough } \\
\text { Verbally abused }\end{array}$ \\
\hline Corrupting & esteem needs & Forced to commit crimes \\
\hline Inappropriate roles & need for fulfilment & $\begin{array}{l}\text { Burdened with too many responsibilities } \\
\text { Not allowed any real independence } \\
\text { Unfairly blamed for things }\end{array}$ \\
\hline $\begin{array}{l}\text { Inappropriate } \\
\text { treatment }\end{array}$ & need for fulfilment & \\
\hline
\end{tabular}


An independent judge (for details see Chapter 4) was employed to ensure that the basis for allocating the behaviours, cited by the key workers, to categories was rational and consistent.

\section{The categorisation process - register cases.}

The judge was sent a very brief summary of the case with sentences, as articulated by the key worker, describing each identified abusive parental behaviour, for example, 'Mother tells boy she will make him suffer like she used to suffer'. Using the categories - which were provided accompanied by a brief description and illustration of each category - the judge then coded each behaviour, for example $\mathrm{Fi}=$ Fear Inducing. The judge's coding was then compared to that given by the researcher. The judge was sent approximately every fifth case because this would ensure a spread of local authorities represented. There was however some slight adjustment to ensure a mix of 'group' and 'singled-out' children. The judge was finally sent twenty cases.

The inter-observer reliability test was used to determine degree of agreement between the judges. The level of inter-observer agreement was 80 percent. However, this included instances where an additional category was identified by the judge but not the researcher, or vice versa. For example, in R46 the statement 'subject blamed for everything that goes wrong' was coded as Inappropriate Roles (In) by both the judge and researcher but the judge also felt that this was Rejecting $(R)$ which the researcher had not included. This was therefore scored as one agreement and one disagreement. If these subsidiary categories are excluded, then out of the 176 statements there were only 12 which were differently coded. This gives an inter-observer reliability score of 93 percent.

The findings relating to the parental behaviour and the experience of that behaviour are presented in the next section.

\section{Types of abusive behaviour}

Figure 6 below gives an indication of the forms of abusive behaviour identified from the registered cases, plus the prevalence of each form. 
Figure 6. Register Cases: frequency of types of emotionally abusive behaviours

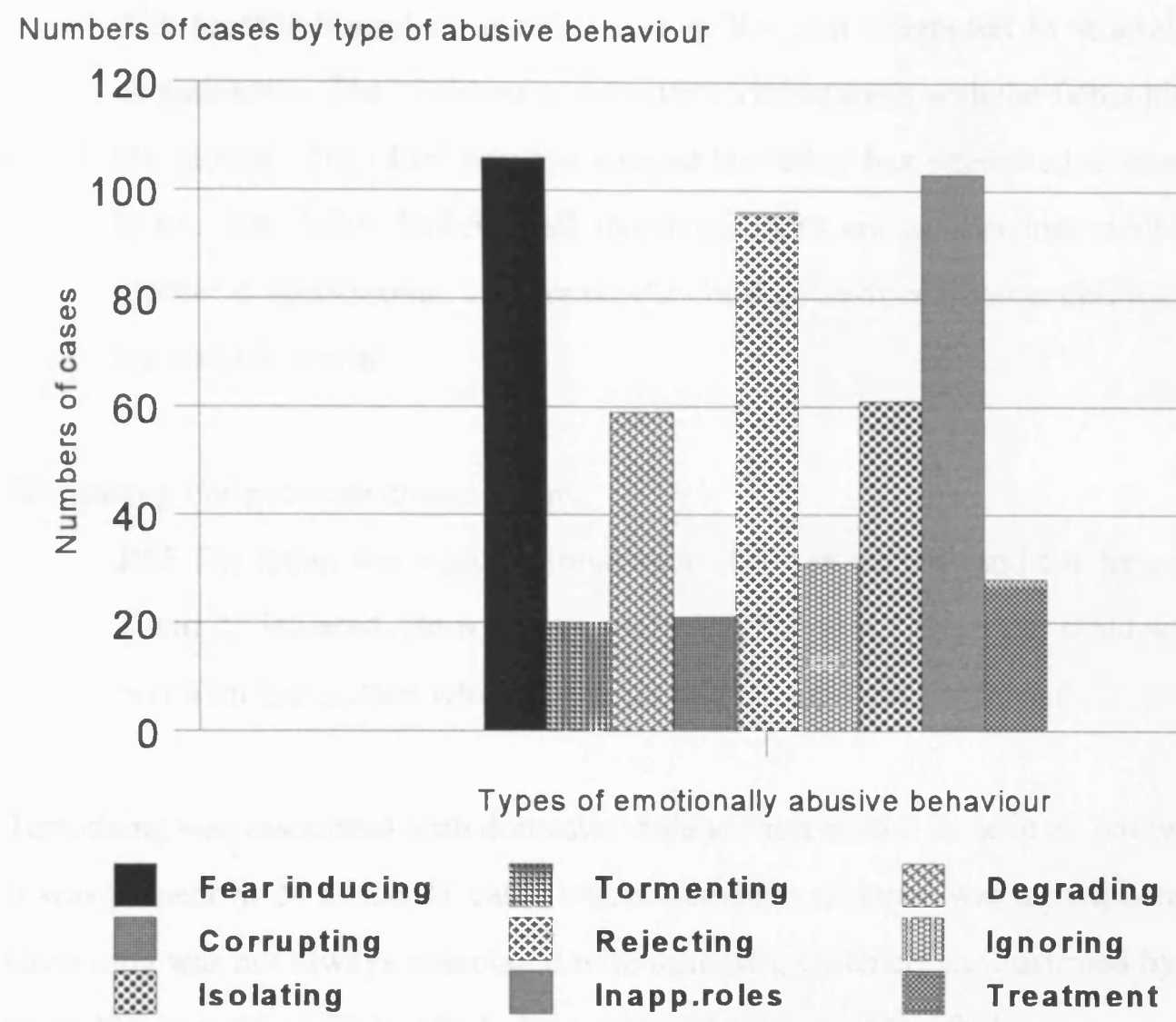

In the register cases the most frequently occurring behaviour was 'fear inducing', followed by 'inappropriate roles and responsibility', then by 'rejecting'. The least prevalent forms were 'tormenting' and 'corrupting'. The individual behaviours are examined in the next section.

\section{Fear Inducing}

Fear inducing was a very common category. It occurred in $106(95 \%)$ register cases. The term embraced several components. The first was 'terrorising' which was present in 73 cases $(65 \%)$. Examples of terrorising include:

R64. Both parents had a drink problem and the mother also abused prescribed drugs. The mother "would scream and shout uncontrollably at the children' On one occasion she was 'so zonked that the children had to pull her away from the fire as she was starting to burn'. 
R23 The father is legally defined as a psychopath. He served a long period in a special hospital after killing his first daughter when she was 4 weeks old. The mother binges on alcohol and in the past attempted to strangle an acquaintance. The 'children witness very violent rows with the father hitting the mother. The older boy has alleged his father has attempted to strangle him... The father believes all the neighbours are against him while the mother is agoraphobic. They make the children terrified of other children and the outside world'.

Witnessing violence can create terror:

R65 The father was a professional man who kept his wife and children, aged 4 and 2, isolated. He was very violent to his wife. 'The older child was in bed with his mother when his father came in and slit her throat'.

Terrorising was associated with domestic violence as a central issue in all but two instances. It was present in 24 of the 31 cases where domestic violence was a peripheral issue. But terrorising was not always associated with domestic violence, as illustrated by R64. There were 22 cases out of 52 in which domestic violence was not a factor.

The other component to fear inducing was creation of insecurity. The creation of insecurity embraced inconsistent care and temporary abandonment to inappropriate carers which were likely to leave the children in a condition of anxiety and uncertainty. Examples of the creation of insecurity which falls short of terrorising include:

R69 A mother with five children aged 14, 11, 9, 3 and 10 months. Their fathers have occasional contact. The 'mother invites all the local drunks and misfits back to the house. They would be abusive to the children for example "fuck off upstairs or I'll give you a slipper". The mother leaves them with all sorts of unvetted and unsuitable babysitters.'

In the population survey respondents were invited to respond to Question 23 'Which, if any of these things happened to you? ' by ticking boxes attached to twenty-one statements. 
'Fear inducing' was reflected in responses to three of these statements (see Appendix 3). The statements are given below. In this, and in all the subsequent subsections, the number and percentage refer to the proportion of the EA group who recorded experiencing this form of emotional abuse.

Made to feel frightened because of threats $78(63 \%)$

Made fearful due to witnessing violence $56(45 \%)$

Made to feel insecure

$88(71 \%)$

Lynn, in interview, gave an account of living in terror. Her father who, although never directly violent to her, could be menacing:

He would hold us, making a stabbing movement towards our eyes saying 'I could kill you'. He said he was Rasputin and stick cigarettes into himself and cut himself in front of us saying he was indestructible ... he would sit there with a knife waiting for one of us or mum to move.

It appears that living in terror and insecurity, even when the child is not directly assaulted, is a significant aspect of emotional abuse.

\section{Tormenting}

There were substantially fewer cases of tormenting with a total of $20(18 \%)$ registered cases. This was subdivided into 10 instances of 'vindictive teasing' and eight of 'mental torture' and two cases where both of the subgroups were present. An example of both is:

R100. A 14 year old girl lives with her mother and stepfather. She is not allowed to play or watch television. Her step-father "takes away her light bulb to stop her reading. She is kept on a very restricted diet. "Allergies" are used as the excuse for this. When the stepfather's children visit she has to watch them eating all sorts of treats - fresh bread, icecream and cakes - she is left eating rice cakes'.

Other examples of vindictive teasing include:

R68 When the girl aged 5 'goes for a shower her mother will deliberately put 
the hot tap on so the child suddenly has a cold shower or vice versa so the child is nearly burnt in a hot shower.

Examples of mental torture include:

R25. A father of three children would make children feel okay and then 'lay into them with criticism. He would drag out punishments and leave a jar of money and count it. He would then punish them if they weakened and took any of the money'.

R43 A father took the light bulbs out of a 9 year old boy's room and 'threatened to kill the child's dog'.

The statement in the population survey which reflected tormenting was:

Made upset by relentless teasing $53(43 \%)$.

Respondent No258 added:

'I believe some of my father's actions were a result of his own unstable childhood and tough upbringing. Other actions (the worst ones) were acts of mental cruelty'.

Neil, in interview, provided an example of petty torment:

'When it came to birthdays and Christmas, the other two [brothers] had presents and parties. I was lucky if I got a card'.

\section{Rejecting}

This was present in $96(86 \%)$ register cases. In 60 there was both active and negative rejection. In only 2 cases was there active rejection alone but in 34 cases there was only passive rejection. An example of active rejection is provided by:

R101. 'The mother is very negative about the girl (aged 9). She says she will end up a villain like her father who has been in a out of prison and whom the mother believes killed her brother.' 
Example of passive rejection on its own include:

R46 A girl aged 6 is given 'no cuddles, no warmth, fewer toys and clothes than her brothers. She 's bullied at school but was unable to tell her parents'.

R49 The parents of four children 'are unable to show affection or closeness, they have very few parenting skills and are unable to understand the children's needs being bound up in their own problems. There have been three house fires. In one their dog was killed. They have all been started by the children playing with fire and matches.'

The relevant statements in the population survey are:

$\begin{array}{lcc}\text { Made to feel no one cared for me } & 64 & (52 \%) \\ \text { Made to feel unlovable } & 58 & (47 \%) \\ \text { Not shown any affection } & 59 & (48 \%) \\ \text { Made to feel completely unimportant. } & 55 & (44 \%)\end{array}$

Gemma felt rejected: 'My mother never showed me any affection. In my teens there was a young student my mother had taken under her wing. The student was upset so my mother embraced her to comfort her. I wondered why she'd never been able to do this to me.'

The register cases demonstrate that rejection is common in both active and passive forms. This demonstrates how difficult it is, in emotional abuse cases, to distinguish acts of commission from those of omission.

\section{Ignoring}

This occurred in $31(28 \%)$ register cases. In 15 cases the children were not given any attention and in a further 11 cases the children were marginalised. In 5 cases the children experienced both forms of being ignored.

R5 The children, aged 6 months and 2 years, have to sit in darkness and when anyone visits they are always 'asleep'.The mother's child care is compartmentalised. She ignores them until it is time for her to feed or dress them as if she was 'taking them out of a box' - "now I feed you". Both 
children show frozen awareness'.

The relevant statements in the population survey are:

Made to feel I did not exist

$29(23 \%)$

Having my achievements ignored

$66(53 \%)$

Neil described how he was ignored and marginalised by his family.

'A typical scene, when my family was watching TV, was for my older brother and mother to sit close together and my father and younger brother to sit together. I was alone and isolated sitting on the floor'.

This is one of the few manifestations of abusive behaviour that is more in evidence the population survey than in the register cases. Because it is a passive form of abuse consisting mostly of acts of omission, it may be that it is more difficult for child welfare professionals to recognise ignoring behaviour in carers until the case reaches the extreme in the form of a 'not existing' child identified by Reder et al (1993).

\section{Isolating}

This was apparent in $61(54 \%)$ register cases. In the majority (52) of instances, children were prevented from socialising with other people. In 11 cases this was combined with being locked away. In the remaining nine cases the children were locked away but were in other ways allowed to socialise.

R94 The sister and brother aged 13 and 11 'are locked in their rooms for increasingly long periods. They have no light bulbs and their rooms were stripped so that there were no pictures, books, toys or comfort'.

R66 The children aged 2 and 1 were 'strapped into high chairs and buggies for hours to the extent that they could not walk or crawl. They are put to bed very early just to get them out of the way'.

Several children had to get into their pyjamas straight after school.

R96 The mother of a boy aged 9 'has to control everyone he sees ... he has 
to change straight into his pyjamas so that he cannot play with other children'

R95 A child of 12 has 'to put her night clothes on straight after school so she cannot play with friends and is ashamed if anyone visits'.

Other children were locked out of the house for long periods including an 8-year-old boy (R75) who was locked out naked.

Other children were prevented from socialising. This was particularly true of the cases where children were over-protected:

R4 The boy, aged 12, does not go to school. He has no friends, is very obese and rejected by his peers. 'Once he had a spot on his nose and another boy said he had AIDS so he just ran home'. He wets the bed and his mother does not appreciate he needs a wash in the morning. He is therefore called 'smelly' by his peers.

The statements in the population survey that reflect isolating are:

Not allowed to have any friends $20(16 \%)$

Locked away for what seemed long periods 10 ( $8 \%)$

Questionnaire respondent No5 wrote:

'I was locked outside in the garden all day when I was about 3 for being naughty ... My mum threw me out when I was 16'.

\section{Degrading}

This was a substantial category being reported in $59(53 \%)$ registered cases. There were two aspects, the first being denigrating verbal abuse and the second humiliation particularly in public. The overwhelming majority of cases (42 out of 59) had both aspects.

R77. A seven-year-old boy's step father will 'be verbally abusive and calls him all sorts of names especially in relation to his soiling. The subject always has to sit on the floor never a chair because the step-father maintains 
he will soil chairs. He is not allowed to touch anything that belongs to anyone else because "he will break it""

R68 A girl, aged 9, disclosed that she had been sexually abused by her brothers aged 14 and 11 . When her mother learned of allegations 'she said "you dirty fucking cunt, your're a liar". Even when medical evidence supported her story her mother's support was only token. She was verbally abusive to the girl and discussed her daughter's sexual abuse and personal details with the neighbours'.

Examples of humiliation without verbal denigration is provided by:

R86 The mother has a drink problem. Her 13-year-old daughter 'brought friends back and went up to her bedroom. The girls' clothes became wet because the mother had crashed out on her daughter's bed and wet it. The mother goes touting round the neighbours, many of whom are the children's friends which the children find embarrassing'.

The questions in the population survey relating to degrading, and the proportion of the EA group experiencing it are presented below:

$\begin{array}{lll}\text { Publicly humiliated } & 55 & (44 \%) \\ \text { Having my achievements derided } & 61 & (49 \%) \\ \text { Made to feel not good enough } & 93 & (75 \%) \\ \text { Verbally abused } & 53 & (43 \%)\end{array}$

Pia, whose father was a farmer, provided an example of public humiliation:

'I was well built as a child and my father would say "You've a backside like a cow". Once he took me to the potato weighing machine for a public weighing and subjected me to ridicule'.

\section{Corrupting}

This was one of the smaller groups affecting $21(19 \%)$ register cases. In 13 of these, the children were involved in criminal activities. In a further seven cases, the children were 
encouraged to abuse others. In the final case R62, the child was told it was a woman's lot to put up with violence and was encouraged to copy her mother's eating disorder.

Other examples of corrupting include:

M12 Father subjects the mother to 'gross humiliation. He takes his son everywhere including drug related expeditions'

M90 The boys are taught that they should fight the police and hit girls. They were encouraged to steal from shops. In the foster home they were surprised that the foster parents were buying things, expecting them to steal them.

M97 Mother asked girl aged 13 to pass drugs to people in prison. 'No one would suspect a child. The girl gives a detached description of drug taking. She was staying out late and having unprotected sex from the age of $12^{\prime}$.

In the population survey, corrupting was indicated by the statement:

Forced to commit crimes $5(4 \%)$.

Neil identified some of his experiences as corrupting:

I I became very isolated and my cousin picked this up. He started sexually abusing me when I was 9, giving me cigarettes and drink in exchange. By the time I was nearing my teens I had more or less left home. When I was 11, I was lifted by the police after smashing a camper van owned by Americans. I was sleeping rough and they were staying overnight in the field. I felt jealous and became angry so just thrashed out.'

\section{Inappropriate roles}

This was one of the largest groups representing $103(92 \%)$ register cases. It embraced several subgroups. In 36 cases there were several inappropriate roles forced on children. In a further 35 cases they were having to cope with too much responsibility. In five cases the children were overprotected and infantilised. In 11 cases they took on the role of family scapegoat. In the remaining 16 cases the children were treated as parcels or weapons often between or against estranged partners or against the 'authorities'. 
Children who had too much responsibility are exemplified by the following cases:

R29 A 6 year old girl who "has to clean herself up if she is sick or wets herself. She has to look after her parents and is the household drudge'.

R6. Oldest boy aged 8, witnessing domestic violence 'is the protector of his mother. He would get up in the middle of the night to ring the police. $\mathrm{He}$ feels he has to stay near to his mother to protect her. He takes responsibility for his three younger siblings'.

Examples of children who were scapegoated include:

R101. A mother of a girl aged 9 'blames her for everything and says if the girl was not there everything would be okay.'

R8 The girl, aged 15, had been sexually abused by her father. When she disclosed the father admitted the abuse then committed suicide. 'The mother blames the girl for the death of the father saying if she had not told anyone he would not be dead. It was all her fault.'

The statements in the population survey reflecting inappropriate roles are:

Burdened with too many responsibilities

Not allowed any real independence

Unfairly blamed for things

$\begin{array}{cc}53 & (43 \%) \\ 49 & (40 \%) \\ 58 & (47 \%)\end{array}$

It may be argued that many young people feel that they are not allowed independence and are unfairly blamed for things. However, of the remaining 305 questionnaire respondents, only $21(7 \%)$ recorded being deprived of any real independence and $12(4 \%)$ recorded being unfairly blamed by family members.

\section{Over protection}

This has been included in the inappropriate roles category, however it deserves special scrutiny because over-protection can be abusive or alternately it can be seen as simply overcautiousness by parents who are perhaps too loving rather than rejecting or exploitative. 
The concept of too much care and protection is illustrated by population survey respondent No28 who wrote:'The exact opposite at times can be equally disadvantageous. As a child I lost my eye in an accident, this, accumulated with the being the youngest member of the family, meant that I was in fact "spoiled". Everything I wanted I got. While I am certainly not complaining now there was a time when I found the conflict difficult to handle. Conflict in question being I couldn't understand why society did not treat me in the same respects as my family As a result I rebelled I may even still be rebelling'. He was allocated to the Other Distress category as it was by no means clear that his parents were using parental power inappropriately to meet their own needs.

There were however register cases where there was a clear inappropriate use of parental power. For example:

R10. A boy (white English) aged 8 is substantially over-protected by his mother. She still wipes his bottom and holds his penis when he urinates at home. At school he soils and wets himself because he does not know how to go to the toilet on his own. He is always dressed in very warm clothes which he cannot take off even for PE. He is not allowed to go swimming with the school in case he catches cold. He cannot stay for school dinners nor eat while in school in case he chokes. He rarely talks in school. Outside school, he is not allowed to play with other children.

\section{Inappropriate treatment.}

Twenty-eight $(25 \%)$ register cases were included in this category. This was a less obvious category than the preceding eight. Failure or refusal to ensure a child receives proper treatment could be identified as physical neglect. However, in most of the recorded cases the emotional issues predominate. For example, distressed children were prevented from receiving counselling. A child with learning disabilities was denied a social and developmental skills programme. In other instances, such as a child with hearing impairment, the failure to obtain treatment had an emotional and developmental impact rather than a strictly medical one. In three instances the children were forced to have what the case conference had deemed inappropriate treatment, including a teenage girl forced by a private therapist to wear nappies and crawl around the floor as part of 'regression therapy'. This was 
not reflected in a statement in the population survey although it could have been commented on in 'suffered something else not already mentioned'. One respondent No 43, for example, was sexually abused by her father and was forced, aged about 13 to have termination at around 5 months pregnancy'. She viewed her experiences as permanently damaging.

\section{RESPONSIBILITY}

The term 'perpetrator' which is a commonly used term in relation to child abuse is not appropriate in most cases of emotional abuse. Firstly, it suggests criminal activity which, although present in physical and sexual abuse, is rarely a factor in emotional abuse. Secondly, although suitable in relation to acts of commission, it is less appropriate to talk about perpetrating acts of omission. In cases of emotional abuse both acts are usually present. Thirdly, mothers tend to be the primary carers. They are therefore likely to be blamed for a child living in emotionally aversive circumstances and designated the 'perpetrator' whereas it became evident from the comments in the population survey that a father's failure to contribute to the care of the children was perceived as equally abusive.

This point came through the interviews with the survivors. Three held both parents responsible because both were directly abusive. In four cases, the father was abusive and the survivors viewed their mothers as disempowered by the fathers while attempting to do all they could to meet their children's needs. In five cases, one parent (four fathers and one mother) was directly abusive but the other parent was seen by the survivor as failing to use his or her parental power to ensure their welfare.

Jay, who was interviewed explained:

My father was a weak man in poor health who began to depend increasingly on drink. Mother was very cold and harsh. She would be violent to dad and hit us hard. My father was very passive and my mother had to take over the whole burden of caring for the family. She was overworked. When my father died a few years ago it hurt me that he had died without ever having told me he loved me. This really hurt. 
From the register R88 is a useful illustration of the problem of identifying responsibility:

Both parents completely ignore their 5 children aged one to 6 years old. They are packed to bed at 6.0 and have no toys or entertainment. They are very hungry. The eldest boy is aggressive, soils and wets and steals food. The mother who has given birth almost every year for the past six years is struggling to cope in a two-bedroomed council house with very little money and is asking for help. The father will not allow her to have any assistance but will not help her himself. He will not accept 'charity' but will not work or go on any employment scheme, consequently the family finances have been cut.

This is a case where the main responsibility is the father's because it is he who is misusing his parental power by failing to ensure his children's welfare. The mother has been disempowered by stress, poor health, poverty and the father's domination.

\section{Determining responsibility}

\section{Register Cases}

In telephone interviews, key workers were asked to identify who held parental power and whether or not the power holders were misusing it:

by exercising it in a burdensome, harsh or wrongful manner; or unjust or cruel treatment; or

by imposing unreasonable or unjust burdens.

This definition of the oppressive use of power is taken from the guidance given concerning the interrogation methods in the 1991 Criminal Justice Act. It appeared to be an appropriate definition covering most of the possible ways in which power could be inappropriately exercised.

In many instances of emotional abuse, the key workers considered that the parent figures, especially in cases of over-protection, domestic violence or where the parent's functioning was severely impaired by substance abuse, could not be described as being harsh or cruel but they were imposing unreasonable burdens on the children. An example is R20: 
The key worker was unsure about the appropriateness of the registration because the main problem was domestic violence. To an extent, both parents were responsible for this and the violence was reciprocal demonstrated by the fact that on occasions both parents had been arrested and kept in police cells. For most of the time the child aged 3 was ignored by them. The little girl was clearly frightened by the violence, ignored, left to her own devices and suffered considerable insecurity.

The key worker felt that neither parent was deliberately harsh or cruel but both parents were responsible for imposing unreasonable burdens on her.

In addition, workers were asked if any of the adults were objectifying the children disregarding their feelings, needs and essential human dignity. The reason for this was that it was anticipated that in most cases misuse of power would be combined with objectification of the child. However it was also possible that people who did not hold parental power on occasions had some responsibility for using the child for their own gratification. An example is provided by R73. The key worker commented that the whole family were responsible for making the child into an object:

A girl, aged 11, who witnessed a lot of marital violence between her parents, was parcelled between her grandparents, her father and stepmother and her mother and stepfather. 'The child is a battleground between the parents and grandparents who all want her but do not look at what she wants'. The girl wanted to live with her mother but the father's large extended family tried to exclude the mother. 'The girl is there to keep the adults happy and not vice versa.'

\section{Population survey}

The complexity involved in exploring issues of the abuse of power and the objectification of victims through a questionnaire proved daunting. Instead it was decided to simply ask those respondents who had indicated that they were abused or were subjected to negative experiences, who they believed was responsible. It was recognised that one parent might have been the primary abuser but that the other parent shared some responsibility for what 
happened. It was also recognised that some respondents may suffer several forms of abuse from several different sources. The issue of responsibility was therefore couched in the form of two questions: Question 24 'Who do you consider was most responsible for your mistreatment?' and Question.25 'Do you consider that any else was responsible and for your mistreatment?' (Appendix 3).

\section{Responsibility identified}

Table 26 below presents the findings on responsibility for the abuse. The data from the EA group of the population survey and the key workers are presented separately.

Table 26. All groups: Person deemed responsible for the abuse

\begin{tabular}{||l|ll|lc||}
\hline \hline Person deemed responsible for abuse & \multicolumn{2}{|l|}{ Population survey } & Register cases \\
\hline \hline Mother & 40 & $(32 \%)$ & 43 & $(38 \%)$ \\
\hline Father & 45 & $(36 \%)$ & 14 & $(13 \%)$ \\
\hline Both parents & 21 & $(17 \%)$ & 52 & $(46 \%)$ \\
\hline Combination including parents & 4 & $(3 \%)$ & 2 & $(2 \%)$ \\
\hline No one & 3 & $(2 \%)$ & 1 & $(1 \%)$ \\
\hline Other & 11 & $(9 \%)$ & - & \\
\hline
\end{tabular}

It can be seen from Table 26 that although a similar proportion of mother figures were held responsible by both the victims and key workers, considerably more fathers were held solely responsible for the abuse by the EA group respondents. The population survey respondents were also asked if anyone else was responsible for the abuse. Only 7 mothers were identified through this subsidiary question. If the people held primarily and secondarily responsible are considered together then the numbers of mothers rises to 47 but the number of fathers rises to 62 . Analysing all the possible combinations in which the parents were held responsible, the mother was held responsible to some extent in $73(59 \%)$ instances while the father was held responsible in $88(71 \%)$ instances. This is in contrast to the register cases where mothers were held responsible in 107 (96\%) cases and father figures in $68(61 \%)$ cases. 


\section{Comment}

These contrasting figures especially in relation to the greater representation of fathers in population survey may be accounted for by the different method of determining responsibility between the register sample and population survey.

Alternatively this may be a reflection of the theme increasingly raised in the literature (Milner 1993, Farmer and Owen 1995, Langeland and Dijkstra 1995) that professional workers are more concerned about parenting failure associated with mothers while father figures escape responsibility for abuse.

\section{MANIFESTATIONS IN THE CHILDREN}

This section examines the way in which emotional abuse may be manifested in child victims. Aspects of behaviour, development and appearance cannot, with certainty, be directly attributed to emotional abuse. However, the indicators discussed below are based on the professional opinions of key workers and the illustrations of the survivors of abuse.

\section{General Indicators}

Key workers were asked what, if any, were the indicators located in the child that led to the assessment that emotional abuse was present. In other forms of abuse indicators within the children are often central to the assessment. In physical abuse and neglect these usually focus on the child's appearance and development. However, in sexual abuse particularly after the Cleveland crisis more account was taken of children's disclosure and comments, as well as to a lesser extent, their behaviour (see Chapter 2). The indicators in this study were therefore categorised on those traditionally used in looking at the victims of other forms of abuse; developmental, behavioural, physical appearance, and comment by the child. These were pre-categorised and although key workers were initially asked an open question about signs in the children, any of the categories not mentioned were explored with the key workers.

While the key workers were asked specifically about the subject child, they were also invited to comment on any indicators in other children in the family. The figures in Tables 27 and 
28 below relate to cases. This means that in the 'only child' and 'singled-out' groups the signs are in an individual child. In the 'family group' the indicators refer to all those identified within the family. Recording 'cases' in this way was justified because this reflects the assessment process in which child protection workers take account of the general state of all the children in the family

Tables 27 and 28 below show respectively the proportions of cases evidencing indicators in each category and the numbers of categories in which the signs occurred. For example, R15 is a 5-year-old boy who, although bright, is underachieving educationally and lacks age appropriate social skills (developmental signs), soils in school and is 'wildly' behaved at home (behavioural signs), he was at times dressed in very expensive 'outfits' and at other times very poorly clothed (appearance) and has talked anxiously about his step-father and has described violence between his mother and step-father (comment by child). He therefore shows indicators in all four categories.

Table 27. Register cases: frequency of indicators in children identified by category.

\begin{tabular}{||l||c||}
\hline \hline & \multicolumn{1}{|c||}{ Total } \\
\hline Development & $46 \quad(41 \%)$ \\
\hline Behaviour & $92 \quad(82 \%)$ \\
\hline Appearance & $48 \quad(43 \%)$ \\
\hline Child comment & $58 \quad(52 \%)$ \\
\hline
\end{tabular}

Table 28. Register cases: frequency of indicators in children by numbers of categories

\begin{tabular}{||l|l||}
\hline & TOTAL \\
\hline \hline no signs & 4 \\
\hline signs in one category & 35 \\
\hline signs in two categories & 26 \\
\hline signs in three categories & 32 \\
\hline signs in four categories & 15 \\
\hline
\end{tabular}


Table 27 reveals that indicators in emotionally abused children are most likely to be related to behaviour. This is in contrast to physical abuse and neglect where appearance is the most likely manifestation (Jones et al 1987) and sexual abuse where comments or disclosures by children are common indicators (Doyle 1994).

The behaviour described by key workers ranged from extreme aggression to extreme withdrawal and frozen awareness. In R80 two boys were very aggressive and would fight with other children and they were verbally abusive especially to teachers. In contrast in R60 a 2-year-old girl was described as 'very withdrawn, timid and weepy'. Some children showed overt distress such as R85 in which the grandmother reported that her 2-year-old granddaughter was 'very distressed, screaming at night and disturbed, crying out "No mummy, no"'. In some cases children behaved differently in different contexts, for example a 7-year-old boy (R79) had been observed to be very demanding with substantial tantrums in the presence of his mother but at school he was quiet, well-behaved, compliant, an outsider and subject to bullying.

Development could include failure to reach milestones in very young children, or underachieving educationally in school age ones. It also included lack of social skills.

Appearance was often related to being too thin or obese. In some children the appearance was more general such as R88 'the children looked dishevelled and sad.'

Comments by children were sometimes explicit. In R25 the three children made comments like 'I have no love from home, I am always being criticised by my dad' 'I wish I had never been born' They had nothing positive to say about home life, they had no comfort, no praise and no fun when at home. Another 6-year-old girl, R29, said that she does not want to go home preferring to stay with her playtherapist whom she calls 'mummy'.

Within each category there may be several indicators. For example in the case of R79 above he had behavioural indicators but these had several manifestations including both demanding and withdrawn behaviours. 


\section{Suicide and self-harm.}

Although emotional abuse is not seen as immediately life-threatening in the way that physical abuse sometimes is, a recurrent theme was that of attempted suicide and self-harm among the victims.

There were $16(14 \%)$ register cases in which the subject child had attempted or threatened suicide or subjected themselves to substantial self-harm. The vast majority of these (10) were 'singled out' children. This represents 31 percent of the 'singled-out' children compared to 9 percent (2) of the 'only' children and 7 percent (4) of the 'group' children. The difference between 'singled-out' and 'group' children was significant $\left(X^{2}=9.079, d f=1\right.$, $\mathrm{p}<0.005)$.

Further scrutiny revealed that there were also two siblings of the 'group' children who had attempted or threatened suicide. This brought the number of children to 18 . Of these ten were girls and eight were boys. There was no statistical significance in this difference in sex ratio. It was however noted that the boys tended to engage in more 'active' suicide attempts. Two boys jumped out of windows, another played chicken on the roads. The girls tended to cut themselves or take overdoses, although one girl flung herself off a high staircase.

The self-harming/suicidal boys were generally younger than the girls. Their ages ranged from 6 to 14 years old with a mean average age of 9.9 years. The girls' ages ranged from 8 to 16 years with a mean average of 12.5 years. Children came from all income brackets and various different ethnic groups were represented.

There were no instances of self-harm or suicide attempts in the families where domestic violence was a central issue. This may be because the violence was so extreme that the family was having support. An alternative explanation is that domestic violence does not directly attack the integrity of the child if he or she is a witness rather than the subject of a direct physical, sexual or verbal assault.

It was not considered appropriate to ask questionnaire respondents if they had attempted or contemplated suicide. However, this information was sometimes volunteered. For example, 
respondent No241 wrote: 'Put down and made to feel inadequate and worthless ... Due to conditions throughout childhood and beyond I tried to commit suicide three times'

Pia, when interviewed, said 'I tried to hang myself when I was about 13 because I was so miserable'.

Neil explained, 'My misery was so great that when I was about 14 or 15 years old I started to self-harm about three or four times. I tried to hang myself but the rope was not long enough and I twisted my ankle. My family never knew. I also tried to overdose but vomited and slept it off. ‘

Of these three, Neil and No241 were 'singled-out' children. It appears that the risks of suicide are greater in children who are singled out for mistreatment. This is perhaps not surprising because the assault on the self-esteem of the one scapegoated, 'bad' child in the family is likely to be profound.

\section{Running away}

It was noted in the Lester Chapman case (see Appendix 1) that he was so miserable that he ran away to his eventual death. Running away was not a theme in either the register cases or the population survey although it was noted that Neil had more or less left home by his teens and was living rough. One of the few register cases was R64 in which the eldest girl aged 14 ran away to her father and settled well with him. Another is R25 where a 6 year old boy, whose mother keeps taking the children in and out of care, runs away so frequently that the social services have arranged 'on call' foster carers who are ready to look after him when he runs away from home.

\section{Endangering others}

The 6-year-old boy in R25 not only ran away but also tried to strangle his young brother with a belt and threw any objects to hand, particularly at other children's eyes. Survivors, Adam and Neil acknowledged that, as children, they had been violent and guilty of bullying others. However, in some cases the behaviour of abused children went beyond bullying to present serious dangers to others. 
Two boys and one girl committed arson. The first, R96, is a boy aged about 9 who lives alone with his dominating and controlling mother who is in her 50s. The paternal grandmother who is also emotionally abusive lives nearby. The boy's father, who is violent and threatening to both his wife and social workers, is in prison. The boy himself is a school bully, has harmed himself by biting and cutting. He has also set fires on several occasions and called the fire brigade. The second boy (R28) is also aged 9. He is the eldest in his family and is scapegoated and blamed for all the family's problems. He was thought to have set fire to a school cloakroom and when placed with foster carers he set fire to a car. In case R83 a girl was 12 at referral. She is now 16 with a 19 month old baby. While in a residential home she was prosecuted for arson. She is now in secure accommodation.

Four children threatened other people. In R69, a 14 year old boy was described as a school bully but he also threatened to kill himself and his mother. In R64 two brothers aged 12 and 7 years were known to be school bullies but in addition they were forcing younger children to eat cannabis, nearly killing one boy. They also threw another young boy into a pond and he almost drowned. Most of the children who could be described as 'dangerous' to others were boys although not exclusively so. The girl in R83 not only committed arson but also threatened to kill her baby.

On occasions children inadvertently placed other children in danger. For example, when a 10 year old boy in R53 tried to commit suicide by jumping out of a first-floor window, his little brother followed him and jumped too.

\section{Substance misuse}

Of the register cases, only one boy aged 14 (R89) was confirmed to have a drink problem. This boy had had to act as father of the family, keep the house immaculate and keep his mother company. There were however children who were drinking. One 6-year-old boy was recorded as 'drinking excessively'.

Three children were thought to be taking illegal drugs although because this is a criminal activity the secretive nature meant that it was difficult to confirm children's addiction. In R82 and R83, girls aged 14 and 16 respectively were strongly suspected to be taking drugs. In R3 
a girl of 13 started glue-sniffing once she was taken into residential care. There were other cases, R12, R90, R97, R107, where the children were involved by their parents in illicit drug activities as described in the section on 'corrupting'. Although there was no evidence the children themselves were using drugs there were concerns that in time they might become users.

In relation to the population survey, to minimize intrusive questions, respondents were asked if their carers, not the children in the family, had had a drink or drug problem. Despite this one respondent No317 identified both his father and his brother as having problems with substance abuse. Neil acknowledged he had had a drug problem, explaining in interview that he had been introduced to cigarettes and alcohol when he was aged about 9 by his 16-year-old cousin in exchange for sex. Subsequently alcohol and drugs provided an escape for him.

\section{Eating Problems}

\section{Register cases}

Among the registered cases were a variety of eating problems:

Underweight. There were seven cases of identified failure-to-thrive and one , R110, of a 13year-old boy suffering from anorexia nervosa. There were three border-line cases, R28, R84 and R88, all young children who were underweight, ate a lot of sugar and scavenged for food. The number of failure-to-thrive cases is probably not a reflection of the proportion of such registered cases because many would have been allocated to the 'neglect' category.

Obesity. This affected eight children. Two were girls, R103 and R104. Both were isolated and kept off school. They had older sisters who were faring better. Of the six boys, four were only children who were close to their mothers. The fathers were rarely in evidence. For example:

R96 is a 9-year-old boy whose father is in and out of prison. The boy is treated

'like a 2-year-old', he has to get into his pyjamas straight after school to stop him playing out, has to sleep in his mother's bed and the mother says she would 'like to get him inside' her again. He is smothered with kisses and cuddles by his mother and grandmother. 
Inappropriate eating patterns: The remaining eating problems included one girl $\mathrm{R} 82$ and one boy R88 whose weight fluctuated dramatically. In one family R25 whose father exercised a petty tyranny, the children all 'have an addiction to sweets' and the foster carers had considerable problems getting them to eat a balanced diet.

\section{Population survey}

It was considered too intrusive to ask questions about eating disorders in the population survey. Nevertheless, during interview, three of the twelve survivors revealed that they developed anorexia nervosa in their teens. They were Pia who was humiliated by her father publicly weighing her on potato scales, Gemma whose mother gave her food in place of love and Roy who witnessed severe physical and emotional abuse of his mother by his father.

Roy explained his father told him he was ' a waste of space, a fat slob. He used to make me eat food that I did not like and I would have to sit for a long time until I ate it up. This would make me sick. Began to overeat for comfort and became very fat. 19 stone. I had just started a YTS scheme when one of the guys made a cutting remark about my weight. I just stopped eating. Eventually, I was 6 stone and given six and a half months to live. I ended up in [psychiatric] hospital. It took me three or four years to get over it.'

\section{School career}

One sign appeared to be problems related to school. The register cases indicate that very many of the children had a chequered school career. Table 29 illustrates in how many families at least one school age child had a problem with schooling.

Table 29. Register cases: profile of school careers of subject child.

\begin{tabular}{||l|ll||}
\hline \multicolumn{3}{|c|}{ Registered Cases } \\
\hline \hline kept off school & 23 & $(21 \%)$ \\
\hline multiple problems & 38 & $(34 \%)$ \\
\hline under school age & 14 & $(12 \%)$ \\
\hline no problems identified & 37 & $(33 \%)$ \\
\hline
\end{tabular}


This shows that of the school-age subject children 62 percent had difficulties relating to their school career. But Table 29 may not reflect the true extent of the problem because of the children over school age without recorded problems, 11 are aged 4 or 5 so are only at the very beginning of their school career. In addition many of siblings of subject children in the 'group' cases also had problems with schooling.

Examples of school problems included:

R36. Girl (Irish) age 10 has been statemented and is in a special unit. She does not have a learning disability but is underachieving due to emotional pressures. In school she will not try anything new due to her fear of failure. She lives in a fantasy world revolving round the little mermaid.

R75. Boy (African Caribbean) aged 8 is bright, possibly 'gifted' but there are serious concerns in school. He is very physically aggressive to the teachers and pupils. But he can also become very upset. He once covered himself with coats and said that he wanted to die. His sister aged 13 had tried to commit suicide on school premises.

A number of children were particularly vulnerable to being bullied. Two children had had so many changes of school that their education had been severely disrupted.

Even in the group statistically defined as 'no problem identified' there were potential problems or issues that, although not specifically related to schooling, could have an impact on the child's educational opportunities.

Examples include:

R28. A boy aged 9 was described as doing well in school and read competently. He had no behavioural problems until there were allegations that he had set fire to a school cloakroom. These suspicions were increased when in care he was involved in setting fire to a car. 
R9 A 15 year old girl was described as an ' $A$ ' student who was obsessional about her school work, committing herself totally to study. She is almost over achieving. She has epileptic type fits which are stress induced and had one in the school toilet which caused problems because she is well-built and the teachers could not open the door. Her best friend was also abused and is similarly overworking.

This last case illustrates that there are a number of children for whom school is a sanctuary and achievements in school give them a sense of self-worth. Another girl (R27) aged 6 was described as 'bright and behaviour good in school although sometimes shows distress. School is a safe haven'.

This was also true of many of the survivors. Kate recalled 'We were always moving around but I always did well and I was in the top five of the class despite changing schools so often. I had had 16 different schools by the time I was 15. When I was 13 my swimming teacher found I was very good and I made the Olympic trials. This made my father proud of me'.

Joy similarly explained that, 'my father only gave me conditional love and one of the conditions was that I achieved academically. When it became evident I could do well on IQ tests and won county scholarships my father was proud of me.'

But a recurring theme was that several survivors hoped their scholastic efforts would win their parents approval only to meet with disappointment. Adam recalled that he passed the $11+$ exam to please his mother and hoped that his father would be proud of him: 'My father never praised me. He would not go to school open days although mum would go. He never read my school reports.'

Pia said: 'I was attractive and compliant and not disruptive therefore I managed to gain the favourable attention of teachers. My father would not recognise my achievements. When I got an A for history there was no acknowledgement but if I ever got a D my father would say what's D for - Dunce?' 
Sue fared even worse. She wrote in her questionnaire: 'mother being less well educated than I became, resented my going to grammar school and finally led to my leaving school in Lower Sixth Year to get a job'. In interview she explained 'Passing my 11+ was a shock to my mother and things started to go wrong from then on'. Her mother made her school life difficult by forbidding her to stay behind at school for activities so she became isolated. Her parents gave her no encouragement, never going to school for open days or parents' evenings. Her younger sister opted to go to the secondary modern school.

\section{No Evident 'Harm'}

What emerges from the register cases and to a lesser extent from the population survey is the differences in response of children who have suffered, ostensibly, very similar experiences. The other important feature is that in many cases the children appear to be functioning without problems. R87 demonstrates these points: the children were locked in their room for long periods so that they had to defecate on the floor. The father was very violent and drank heavily. The children were totally ignored by their parents, were shown no affection and were subjected to a lot of verbal abuse. The descriptions of the children were provided by the key worker:

* The eldest girl aged 11 has a severe hearing impairment which the parents ignore. She is extremely disruptive especially on the school bus. At other times she becomes very withdrawn.

* The boy aged 9 is very aggressive and will hit out at everyone.

* The middle girl aged 7, is bright, doing very well at school and seems to have no problems

* The youngest girl, aged 3, also has a severe hearing impairment. She is described as a 'witterer' and demands attention, whining until she gets some.

This has an implication for intervention because of the 'significant harm' requirement of the 1989 Children Act. This was illustrated in the case of a family reported by neighbours because an 8-year-old boy had been locked outside naked. The reported events were symptomatic of a catalogue of abusive behaviours. But the parents would not accept that 
anything was wrong and opposed any intervention. The boy was assessed and because he displayed no undue behavioural problems, was too frightened to say anything, was probably underachieving but was bright so coped with school and was adequately dressed and nourished there was no evidence of 'significant harm'. There was no possibility of obtaining a supervision order which the key worker felt was needed.

\section{OVERVIEW}

Space precludes a full discussion of the experiences suffered by the respondents in the Other Distress group. Many of these would constitute emotional abuse in the wider definition of Hart et al (1983. 1987) in which emotional abuse can be at the hands of anyone in a position of differential power to the victim. As evidenced by the OD group respondents, this can include bullying by peers as well as racism and homophobia often perpetrated by strangers or by 'society' in general. However, a general investigation of all forms of emotional abuse is not the objective of the present project which is confined to those cases most likely to come within the remit of child protection workers.

A major problem in identifying emotionally abusive behaviours is the difficultly of presenting them to other people in an ordered manner. The categorisation presented is a suggested format. Its application is further discussed in Appendix 4.

Unlike other forms of abuse, it is more difficult to determine a 'perpetrator'. Given the working definition, the key issue is with whom parental power is invested. Emotional abuse can include acts of omission - failure to promote the welfare of the children - as much as acts of commission. If the two features, parental power and the failure to use it, are seen as ingredients of emotional abuse then parents who 'opt out' can be seen to be as emotionally abusive as the parent who may commit most of the acts of commission.

It is not possible to state that emotional abuse causes certain developmental and behavioural problems in children. However, professionals and survivors alike felt able to identify indicators which they attributed to the abuse. The apparent impact on the children 
is similar to the impact of other forms of abuse on victims, with the exception of early sexualisation displayed by some sexually abused children (Berliner 1991). Some children show extreme distress such as self-harm and attempted suicide while others appear to suffer no ill-effects. However, as the survivors explained, even apparently unaffected children carry a burden well into adult life. There are illustrations in this chapter of an association between emotional abuse and deficiencies in the victims' behavioural, cognitive, affective and physiological functioning. In addition, there appeared to be an association with impaired social functioning of the victims as they were made to appear 'different', over-protected, isolated or prevented from socialising. Generally, the possible ill-effects of emotional abuse whether immediate or long term are sufficient to warrant intervention. Issues of intervention are examined in the next chapter. 


\section{CHAPTER 8}

\section{FINDINGS - INTERYENTION}

The objective of this chapter is to examine some of the broad features of intervention in relation to emotional abuse. Particular concerns include: how and from whom the cases become part of the child protection system; what is offered to the family; how many of the children were removed and the level of reliance on legal processes. There is also a brief evaluation of management and intervention into these cases to determine whether additional guidance for practitioners would be beneficial.

It is not the purpose of this study to look in detail at the management of emotional abuse cases in relation to processes and procedures. There have been recent studies which have examined this (Gibbons et al 1995, Farmer and Owen 1995). While these have dealt with all forms of child maltreatment, emotional abuse has been included as part of their wider remit.

\section{REFERRAL INFORMATION}

This section focuses solely on the register cases and their progress through the referral system. There were two aspects to the referral process, firstly the issue of who prompted the referral and secondly the reason for the matter being referred.

\section{Person or agency responsible for referral}

It was rarely clear exactly who bore responsibility for referral. Some families had been known for many years with mounting concern until a decision was taken to register the child. Here there was no identifiable source of referral or precipitating reason. These cases are designated 'already known' in Table 30 and 'ongoing problem' in Table 31.

In other cases expressions of concern emanated from several different sources. For example, in R1 a couple who had been informally caring for a girl contacted the authorities 
to inquire about formal fostering arrangements. At the same time the Family Court Welfare officer, who was involved in mediating between the mother and step-father, had picked up vague allegations of sexual abuse against the step-father and referred the matter to social services. In such cases, the first person or agency alerting the child welfare authorities of a problem were identified as the agent responsible for the referral. The sources are shown in Table 30 below.

Table 30. Register cases: source of referral by type of child

\begin{tabular}{||l||l|l|l||ll||}
\hline \multicolumn{1}{||l|}{ Person or agency making referral } & only child & singled out & family group & TOTAL \\
\hline already known & 1 & 4 & 15 & $20 \quad(18 \%)$ \\
\hline parent & 5 & 8 & 11 & $24 \quad(21 \%)$ \\
\hline child & 1 & 2 & 3 & 6 & $(5 \%)$ \\
\hline relative & 0 & 1 & 0 & 1 & $(1 \%)$ \\
\hline neighbour & 3 & 2 & 2 & 7 & $(6 \%)$ \\
\hline health visitor & 0 & 2 & 2 & 4 & $(4 \%)$ \\
\hline other medical & 3 & 4 & 7 & $14 \quad(13 \%)$ \\
\hline school/EWO & 7 & 4 & 5 & $16 \quad(14 \%)$ \\
\hline police & 2 & 4 & 12 & $18 \quad(16 \%)$ \\
\hline probation/family court welfare & 0 & 1 & 1 & 2 & $(2 \%)$ \\
\hline \hline
\end{tabular}

\section{Family member referrals}

Parents: Parents are the largest group, referring themselves to social services. This contrasts with Creighton's (1992) analysis where only one percent of parents in the emotional abuse category initiated procedures. This difference may be partly due to the fact that, although in both studies key workers provided the referral information, Creighton used slightly different terminology to explore the referral process. In the current study some instances of 'self-referral' from the parents were related to the child (eg R77 'the parents were asking for the child to be "cured"). However, some parents referred 
themselves because of a problem not directly related to the child, such as R49 where the mother had sought help for her addiction to drugs. In instances like this, the current study records the parent as the person starting the referral process, whereas in Creighton's study it would probably be social services, picking up concerns about the mother's drug habit, who would be defined as the 'initiating agency/person'. Nevertheless, by 1992 Creighton had noted a trend for more parents to initiate procedures, rising from 3 percent of referrals in 1988 to 10 percent in 1990 . This trend and the findings of the current study suggest a developing partnership between parents and social services.

Children: There are six cases in which children made a direct referral. Five were allegations of sexual abuse and in the sixth the child rang the police complaining of physical abuse. There were other cases in which the children indirectly made a referral, such as R102 where the eldest boy rang the police about an attack on his mother by her boyfriend. Although Creighton (1992) found no children initiated procedures in emotional abuse cases, they did refer themselves in instances of sexual and physical abuse. The current findings taken together with those of Creighton suggest that children are able to acknowledge and disclose physical and sexual abuse but have more difficulty recognising and reporting emotional abuse.

Grandparents: In R97, the child was staying with her grandmother when she made an allegation of sexual abuse against her brother. Although the child was the originator of the referral, the grandmother was the first person to refer the matter to social services. The only other family member to make a referral was another maternal grandmother concerned about physical abuse to her 4 year-old grandson

\section{Neighbours}

Neighbours referred children for a variety of reasons. In R13, the mother disappeared, abandoning the child to a neighbouring family. In R54, neighbours made a referral of general concern to the NSPCC. An 8-year old boy (R75) was reported by neighbours because he was locked outside his house naked for long periods. In R33, the neighbours were concerned about the mother's shouting and indications that the subject child was 
being locked in his room for a long time. In R25, neighbours alleged that the father punched one of the boys. A girl (R95), aged 7 years, was referred by neighbours who heard her screaming and saw her running outside the house in her underwear and hiding behind bushes. In the final case, the neighbours reported hearing screams.

\section{Health professionals}

In two cases where the health visitor was the referrer, the parents had been indirectly seeking help. For example in R12, the mother needed respite care for her other children when she gave birth to her most recent child. Given the prospect of three children under three being cared for by a father who was violent when 'high on alcohol and drugs', the health visitor felt that the mother could do with additional support. In the other cases the health visitor became concerned about issues such as 'rough handling' of the baby, poor home conditions or domestic violence.

Most other referrals in this section were from hospitals. On occasions, the concern was about a sibling who had received serious non-accidental injuries or about a subject child who had an injury which was accidental but symptomatic of parenting problems. In other instances, the child's or parents' behaviour alarmed hospital staff. For example, in R109, 'when her 3-year-old sister was hospitalized the hospital staff were very concerned about the subject. She was frozen and the step-father's behaviour to her was worrying them'. One hospital referral was for material help for a girl with spina bifida. Another case arose because a child had taken an overdose.

One referral came from a GP because arrangements had been made for the children to see a psychologist and they were not attending appointments.

\section{Schools and education welfare}

On occasions, the state of the children caused concern. For example, in R94 the school noticed that just two of the children from a large family were hungry and neglected when the other children seemed to be well looked after. The schools made a referral for emotional abuse in six of the 16 cases and other abuse in three with school problems being 
the reason for the remaining seven instances.

\section{Police and Probation Services}

The eighteen (16\%) referrals from the police, is considerably higher than the 2 percent recorded by Creighton (1992). Thirteen of the police referrals were for domestic violence. Creighton's study covers the period 1988-90. The current study was undertaken nearly four years later and coincided with the increasing recognition of domestic violence as source of risk to children and a form of emotional abuse (Mullender and Morley 1994). The increased police referrals might be a reflection of this recognition among the police.

\section{Reason for referral}

The categorised data on the reasons for referral are presented in Table 31 . The referrals for 'singled-out' children related predominantly to abuse (69\%) rather than for generalised family problems $(25 \%)$. In contrast, only 30 percent of the 'group' children were referred for abuse.

Table 31. Register cases: reason for referral by type of child

\begin{tabular}{|c|c|c|c|c|}
\hline \multirow[t]{2}{*}{ Reason for referral } & \multicolumn{4}{|c|}{ Register cases by Type } \\
\hline & only child & singled out & family group & TOTAL \\
\hline Emotional abuse & 7 & 9 & 6 & $22(20 \%)$ \\
\hline Emotional and other abuse & 2 & 2 & 2 & $6 \quad(5 \%)$ \\
\hline Other abuse & 4 & 11 & 9 & $24 \quad(21 \%)$ \\
\hline Domestic violence & 3 & 3 & 13 & $19 \quad(17 \%)$ \\
\hline Family member seeking help & 3 & 4 & 12 & $19 \quad(17 \%)$ \\
\hline Ongoing problem & 1 & 1 & 10 & $12(11 \%)$ \\
\hline School problems & 2 & 1 & 3 & $6 \quad(5 \%)$ \\
\hline Child offending/disturbed behaviour & 1 & 0 & 1 & $2 \quad(2 \%)$ \\
\hline Suspected Munchausen syndrome by proxy & 0 & 0 & 1 & $1 \quad(1 \%)$ \\
\hline Material help & 0 & 1 & 0 & $1 \quad(1 \%)$ \\
\hline
\end{tabular}




\section{Emotional abuse and other abuse.}

Reasons categorised as 'emotional abuse' were varied. In three cases, the children were abandoned by their parents and left with other carers who contacted social services. In two cases, the children were not receiving therapeutic treatment which was seen as symptomatic of wider emotional abuse. One mother (R51) said that she could not cope with her son and asked for him to be accommodated. In R54, the neighbours contacted the social services because the mother was discussing plans for her suicide in front of her children. Several children were referred because they were either locked away or outside the house for long periods, such as R25 in which three children were locked out of the house in the early hours of the morning when the youngest was only 5-years-old. In a further two cases, the mother had been drinking excessively and was behaving inappropriately towards the children.

An example of a combined emotional/other abuse category is that of R42 where the grandmother reported concerns about the emotional abuse of the subject child and suspicions of the physical abuse of his 4 -year-old brother.

The referrals for 'other abuse' were either unsubstantiated allegations or related to siblings or involved non-family members. For example, in R35 there were allegations that the aunt's boyfriend had sexually abused the subject. On investigation, it was found that the parent's rejection of the subject was the primary concern.

\section{Domestic violence}

An example of a referral for domestic violence is R40 where the father's threats to kill the mother and her new boyfriend were followed by an arson attack on the family home believed to be the work of the father.

\section{Family member seeking help}

There were 13 cases where the mother was 'unable to cope'. Most were asking for the child to come into care. One mother (R71) asked for adoption counselling before her baby was born. In R31, the subject went to visit the father and refused to return to the mother 
who sought assistance to get her daughter back. In contrast, in R32 the father had been deported following sexual offences against his daughter but the mother sought social services' help to get the father back home to England. A mother (R49) was seeking treatment for her own drug addiction problem while in R61 the father asked for help for the mother. Finally, in R22, an older sister attempted suicide and then sought support for herself and her sister.

\section{School problems}

Three referrals, R4, R68 and R82, were for non-attendance at school. A 10-year-old girl (R36) was isolated, making no progress and 'stuck out like a sore thumb' in school. A 9year-old subject boy (R39) was referred because of encopresis in school and his disclosures to teachers about violence between his parents. Another boy (R88) aged 6 was 'not functioning in school'. Six (5\%) cases seems a low referral rate given that 62 percent of the school-age children had non-attendance or other problems relating to school (see Table 29).

\section{Child Offending/Disturbed behaviour}

Only two subject children were referred for behavioural problems. One (R6) was a boy aged 8 who was referred for 'endless offences'. Factors in his family background were found to be domestic violence and parental substance abuse. The second (R10) was another 8-year-old boy who was overprotected and was referred for problems of day-time enuresis and encopresis.

\section{Munchausen syndrome by proxy}

Although there was only 'Munchausen syndrome by proxy' referral, it merits attention because of concerns about this problem (Meadow 1989). All the children in the family, aged from few months to 3 years old, made frequent trips to casualty. The children's persistent hospital admissions for 'social' reasons combined with the recurrent referrals to the duty paediatrician was deemed to be emotionally abusive. The mother herself was admitted to hospital frequently yet she had contradictory symptoms and no defined medical condition. 


\section{Material help}

There were several instances where parent themselves sought material help. These cases were included under 'family member seeking help'. However, in one case the family was from Africa and the mother had recently come to England with her two daughters. The younger one, for whom the mother was seeking treatment, had spina bifida. The hospital had originally referred the case to social services because the family had no income and no benefit entitlement.

\section{INTERVENTIONS OFFERED OR IMPOSED}

The word 'intervention' is used to encompass a variety of services and strategies including material help, specific treatment such as bereavement counselling or a general response such as monitoring the safety and well being of a child through regular social work visits.

This section is not a comprehensive review of the input of services. In relation to register cases, this has been examined by Gibbons et al (1995). The purpose of the present examination of resources offered is to provide insights into the range of interventions currently on offer. If only a narrow range of services were found to be offered to most families then, given the varied nature of emotional abuse and related family problems (see Chapters 6 and 7), a substantial issue for intervention would be the development of a wider range of intervention strategies. Furthermore, a finding that social workers were the only professionals involved in intervention would indicate that a prominent issue would be the involvement of other professions in the management of emotional abuse cases.

The key workers were asked what interventions and helping resources had been offered to the families. The emphasis was on those offered rather than those which had been accepted or implemented. This is was because an offered resource was an indicator of what was available and demonstrated the workers' recognition of family needs. 


\section{Types of intervention offered}

The key workers provided information about 46 different interventions. These have been clustered under fourteen sub-headings on the basis of the key worker statements. It is acknowledged that this clustering has disadvantages for example a key worker stating that 'help was given with substance abuse' was itemised as a type of intervention in its own right and yet it could also have be presented under 'medical support'. However the purpose of the sub-headings is to present the details given by the key workers in a more digestible format than a lengthy list. This aim of this section is to provide an overview of the interventions that are currently on offer to emotionally abused children and their families. Given the broad ranging nature of emotional abuse, the interventions offered would be expected to be equally broad ranging. Quantifiable information is provided to illustrate which interventions are the most prevalent. However, the aim is not to provide precise figures nor to give a detailed evaluation of current practice but to indicate the variety and balance of interventions.

Ten of the intervention clusters were usually provided by social service agencies or multidisciplinary teams and were therefore based on the focus of attention and type of problem. The remaining four clusters are agency specific. The fourteen clusters are:

Material assistance

Family work

Parenting skills

Individual work with child

Specific counselling

Group work

Day care

Respite care

Drug rehabilitation

Monitoring by social workers

Women's Aid/Refuges

Educational support

Medical support

Probation support

For all types of intervention, the statistical significance of any differences in the 
interventions offered based on the family's geographical location (County council or metropolitan area), colour, financial group and the type of subject child (singled-out or group) was explored. In most instances statistically significant differences were not observed and normally comment will only be made where a difference was found.

\section{Material assistance}

Over half $(53 \%)$ of the families were offered material help. This included help with finances, housing or transport. There was a significant difference $\left(X^{2}=11.3, \mathrm{df}=1\right.$, $p<0.001$ ) between the county council and metropolitan areas with only 35 percent of county council area families being offered material assistance compared to 67 percent of metropolitan area families. This may be due to the occurrence of significantly fewer $\left(X^{2}=6.41, \mathrm{df}=1, \mathrm{p}<0.05\right)$ accommodation problems in rural areas. An example of material help is:

R44. There were negotiations with the housing department because the family was housed in an unsuitable first floor council flat. The social services paid the mother's Poll tax, helped with other bills, sorted out her benefit entitlement and provided a washing machine, furniture, play pen, fireguard, child gate and nappies.

The descriptions given by the key workers about material help offered illustrates professionals' willingness to address the practical stresses and problems (highlighted in Chapter 6) faced by many families of emotionally abused children.

\section{Family work}

Family work was used to describe intervention with the whole family rather than separate services offered to different family members. This could range from formal family therapy in a clinical setting to less formal intervention such as arranging activities so that family members could enjoy sharing time together.

In total $56(50 \%)$ cases were offered family work. Key workers reported that parents often did not keep appointments at all or discontinued attending at an early stage. An example 
of family work is provided below:

R22. In a wealthy family, the mother tormented and terrorised her two daughters to the extent that both took overdoses. Meanwhile, the father, who was verbally abused and humiliated by the mother, drank heavily. The family were given extensive help through a 'family consultation clinic'. The eldest girl chose to remain in care but the younger girl is happier and hoping to go home.

\section{Parenting skills}

Training in parenting skills was offered in $46(41 \%)$ cases. Parentcraft can be part of family centre work so more parents may have had skills training than is suggested by the number recorded. In many cases parenting skills training was accepted when family work was rejected or not successful. For example:

R7. An assessment and family work package was offered to the family but the father declined this. The mother not only divorced the father but pressed charges for assault. The children's behaviour had become very disturbed due to witnessing violence against the mother from the father. In addition, one child had learning disabilities. The mother was helped to develop parenting skills and strategies to cope with the children's problem behaviours and developmental issues.

\section{Individual work with children}

In 70 cases $(63 \%)$ the children were offered some form of individual work. The type of work included psychotherapy, formal and intense play therapy by a qualified therapist for several years and art therapy (R69). One social worker saw a boy once a fortnight, engaging him in general play work designed to help him understand his experiences. In at least one case (R60), the social worker undertook life-story work. Two children in separate families had private individual therapists arranged by the parents. In one of these cases (R100) the activities of the private therapist were viewed by the child protection team as abusive. 
In some cases there appeared to be a failure to offer individual work to children who needed it. For example (R73) the child, who had witnessed marital violence, was subsequently 'parcelled' around between her grandparents, her mother and her estranged father. Although various forms of counselling and therapy were offered to the adults, no one proposed helping the child make sense of all the changes in her life. In other cases, for example R95, the child was offered individual support to counter abuse by their parents but those same parents refused to let the child have any support.

\section{Specific Counselling}

There were $36(32 \%)$ cases in which specific counselling was offered. This was subdivided into marital/partnership, bereavement or survivor counselling, anger management and 'other'. In only one case was bereavement counselling offered despite the fact that in 78 percent of the cases there had been a significant loss, including 32 cases where there were multiple losses. Similarly, in only $14(13 \%)$ cases, was survivor counselling offered although 113 parents were known to have been abused in childhood. Anger management was offered to the father in three cases in which domestic violence was central and partnership counselling was offered in a further six cases. This seems a low figure considering that marital violence was a factor in 60 (54\%) of the cases. Part of the apparent counselling shortfall can be explained by the fact that this may have been provided but not specified because it formed part of another intervention; for example, psychiatric or probation support might include bereavement or anger management counselling.

\section{Group work}

Group work was offered to children in 11 cases and the parents in 8 cases. Two families were offered several groups. In R16 the mother attended a group for mothers of abused children and was offered one for adult survivors while the child attended an evening activity group. In R60 one boy joined a group for sexually abused children while the father was offered a single male parent support group. 


\section{Day care}

Day care was usually in the form of a nursery or play group place for younger children and a playscheme or childminder place for school age children after school or in the holidays. Twenty seven families were supported with nursery or child minder places and nine were offered playschemes.

\section{Respite care}

This took three forms. Firstly, in 18 cases, there was a short break at a time of crisis for the child and parents where the child stayed for a few days in residential or foster care. In six of these cases the child had a learning or physical disability. In the remaining 12 there was a generalised family problem. The second form, offered to 14 families, was supportive foster carers whose job was not simply to accommodate the child for a temporary period but to help the parents and child through modelling or other specialised assistance.. Finally, ten families were offered a therapeutic residential unit for the child for a temporary period. In three of the ten families, one child had learning disabilities.

\section{Drug rehabilitation}

This was offered in $25(22 \%)$ cases. But in 41 percent of the cases one or both parents had an alcohol addiction problem and 21 percent had a drug addiction problem. In some instances the parents had been offered help with substance misuse in the past although not during the time that the child was on the register.

\section{Monitoring}

Government guidelines (Home Office 1991) require monitoring of all registered children. However, in some instances this was the main intervention. In one case (R9) teenage girls were abused by their wealthy father who refused all other help. Eventually, monitoring by a social worker became the only intervention possible. In a further 49 cases social work support combined with active monitoring was a key intervention. An example is:

R21. In this case the mother has schizophrenia. However when she becomes ill her own mother takes over the care of the children. The extended family has a support system and, given this, the children would 
not be on the register. The problem is that the step-father, who usually lives elsewhere, sometimes returns and is excessively violent. He has destroyed the house and held a knife to the subject's throat, threatening her. The main role of the child protection team is to monitor the support systems for the mother and children, ensuring that they are ready and working so that the children are protected when the step-father appears.

In very few cases were social services left as the sole agency giving support and monitoring the situation, R9 was one of the few exceptions.

\section{Women's Aid/Refuges}

Refuges were used by 12 women and one mother had the specialist support of a domestic violence unit. In R110 the mother moved to a women's refuge to escape her father. She had been sexually abused by him for nearly 40 years and had remained at home with him bearing him a son. In all the remaining cases the women were escaping violence from their male partner. One mother was Asian and the remaining 11 were white. There were significantly more offers of Women's Aid or refuges in the county council areas compared to metropolitan areas $\left(X^{2}=3.88, \mathrm{df}=1, \mathrm{p}<.05\right)$.

\section{Educational support}

A large proportion of the emotionally abused children had chequered school careers (see Chapter 7, Table 29). In some cases, where problems with schooling were identified, the children were receiving some form of additional educational help. However, as there were educational problems in 55 percent of the cases (see Chapter 7) and only 32 percent (36 cases) were offered educational help, there would appear to be a shortfall.

The help offered was support from educational welfare officers alone ( 3 cases) or with other support (15 cases), special needs support within mainstream provision (9 cases) or special schooling ( 9 cases). 


\section{Medical support}

This category included a wide range of medial supports and included community and school nursing, treatment for physical or mental conditions and clinical psychology. In total, $74(66 \%)$ families received medical support. In 29 cases there was multiple medical intervention. For example:

R23. The mother received help for her agoraphobia from a community psychiatric nurse. The father who, having killed his first daughter had been legally defined as a psychopath, received the services of a forensic psychiatrist. The health visitor was described as 'a very important figure for the mother, a confidante'.

Significantly more medical support $\left(X^{2}=4.68, \mathrm{df}=1, \mathrm{p}<0.05\right)$ was provided in the metropolitan areas (75\%) compared to county council areas (55\%). This is despite the fact that proportionally there were slightly more cases of mental and physical ill health $(76 \%)$ in the county areas compared to the metropolitan areas $(71 \%)$.

\section{Probation support}

This was provided in seven cases. In four instances, sexual or physical abuse had been perpetrated against other children by the father. In one case probation was involved because of the father's offending relating to domestic violence. In the remaining two cases the father was on probation for drink or drug related offences. In one case (R27) the father, who had contacted ChildLine because he was sexually abusing his nieces, was referred through probation to specialist treatment at the Gracewell clinic.

\section{Comment}

The first purpose of this section has been to see how far interventions offered in cases of emotional abuse are broad ranging. The type of child and family as well as the manifestations of emotional abuse are very varied (shown in Chapters 6 and 7). Therefore an equal variety of interventions are required. A narrow focus on just, for example, material help or intervention confined to counselling would seem to be inappropriate and, had this been the current practice, a marked change of strategy would have been required. 
But as Table 32 below demonstrates there already appears to be a considerable diversity and therefore a major change of strategy is unlikely to be required.

The second purpose of this section has been to examine whether intervention in emotional abuse is left largely to the social services or whether there is a shared multi-disciplinary response. Again the discussion above, summarised in Table 32 below indicates that current response is shared among the professions and therefore again a major change of policy does not appear to be required.

Table 32. Register cases: overview of interventions offered

\begin{tabular}{|l|l|l|l||}
\hline Type of intervention offered & County Council & Metropolitan Boro' & TOTAL \\
\hline \hline Material assistance & $35 \%$ & $67 \%$ & $57 \%$ \\
\hline Family work & $53 \%$ & $48 \%$ & $50 \%$ \\
\hline Parenting skills & $37 \%$ & $44 \%$ & $41 \%$ \\
\hline Individual work with child & $57 \%$ & $67 \%$ & $62 \%$ \\
\hline Specific counselling & $41 \%$ & $25 \%$ & $32 \%$ \\
\hline Group work & $20 \%$ & $11 \%$ & $15 \%$ \\
\hline Day care & $22 \%$ & $38 \%$ & $31 \%$ \\
\hline Respite care & $41 \%$ & $32 \%$ & $37 \%$ \\
\hline Drug rehabilitation & $16 \%$ & $27 \%$ & $22 \%$ \\
\hline Monitoring & $41 \%$ & $49 \%$ & $45 \%$ \\
\hline Women's Aid/refuge & $18 \%$ & $6 \%$ & $12 \%$ \\
\hline Educational support & $29 \%$ & $35 \%$ & $21 \%$ \\
\hline Medical support & $55 \%$ & $75 \%$ & $66 \%$ \\
\hline Probation support & $10 \%$ & $3 \%$ & $6 \%$ \\
\hline
\end{tabular}

\section{Numbers of interventions.}

The numbers of interventions per subject child identified by the key workers ranged from 2 to 19 . The two cases with only two interventions were both girls who had been abandoned by their parents and had been placed with foster carers. The fathers were not in contact with the children and the mothers moved on so frequently that sustained work 
by child protection professionals was impossible. The case with 19 interventions (R105) was not dissimilar in that it included a mother trying to cope with a daughter aged 5 years whom she was rejecting. However, the mother had not abandoned the child. Furthermore, because her twin sons had previously been removed due to physical abuse by a previous partner, the local authority was endeavouring to maximise the input of resources in the hope that the girl could remain in the mother's care. The child was showing considerable developmental delay and behavioural indicators including drawing pictures depicting terror. There were, therefore, a variety of services for her including speech therapy, a full time nursery place, community paediatric services, educational psychological assessment and direct therapy. The mother was given a full range of services including material help, psychiatric care, a disability care manager, specialist family centre input and social work support.

Significantly fewer interventions were offered in the county council areas (mean 6.4, SD 2.8, median 6) than in the metropolitan ones (mean 7.8, SD 3.1, median 7), (MannWhitney $U=1134.5, Z=2.41, p<0.05$ ). There were no clear reasons for this. Logistical issues such as transport difficulties in rural areas could account for the discrepancies. However, there was no significant difference in provision when interventions, such as group and family work which usually require transport, were examined. But there were significantly fewer offers of services which did not depend on transport (ie material assistance and medical support). Alternatively, it could be that key workers in rural areas described the intervention in more generic terms while those in metropolitan areas itemised interventions more specifically. Recent British research into interventions for abused children (Gough 1993, Department of Health 1995b) do not appear to have addressed the differences of provision between rural and urban areas, although Little and Gibbons (1993) highlighted socio-demographic features, including levels of service, affecting rates of registrations. Gibbons et al (1985) also noted differences in 'services provided post-conference' (p.111) between the eight different local authorities in their study. However, they did not identify a clear county council/metropolitan divide. Nevertheless, current research suggests that the intervention provided for emotionally abused children might be influenced as much by geographical area as by the children's 
needs and therefore differences in provision for abused children based on location might warrant further exploration.

\section{Removal and Legal Intervention}

Key workers were asked if, during the period of registration, one or more children in the family had been removed and, if so, under what circumstances.

During the period of registration no child in $26(23 \%)$ families was taken into care or accommodated for even a brief period. In a further 13 cases, the children were placed with relatives, usually under a voluntary arrangement or residence order. In 64 (57\%) families the children came into care temporarily. The distinction between temporary and permanent care was not always clear because in some instances although the plan was for rehabilitation the child protection team expressed doubts about the possibility of the child ever returning home. There were 12 cases where the children were in care permanently. Table 33 below shows the circumstances of removal in more detail.

Table 33. Reasons for removal from home - register cases.

\begin{tabular}{|c|c|c|}
\hline Reason for removal from home & & \\
\hline Temporarily at parent's or child's request & 21 & $(19 \%)$ \\
\hline Temporarily with parental agreement & 15 & $(13 \%)$ \\
\hline Temporarily, compulsorily & 17 & $(15 \%)$ \\
\hline Permanently at parent's or child's request & 11 & $(10 \%)$ \\
\hline Permanently with parental agreement & 2 & $(2 \%)$ \\
\hline Permanently, compulsorily & 7 & $(6 \%)$ \\
\hline To live with other separated birth parent. & 3 & $(3 \%)$ \\
\hline To live with relatives & 10 & $(9 \%)$ \\
\hline No removal & 26 & $(23 \%)$ \\
\hline
\end{tabular}

In the majority (55\%) of cases the children either did not come into care or were accommodated briefly by request or agreement. In a further $12 \%$ of cases the children went to live with other family members usually on a voluntary basis. Only $21 \%$ of 
children were removed compulsorily and most of these were returned home after a short period. There was no statistically significant difference in levels of compulsory removal between black and white families.

A very wide range of legal interventions was used. Table 34 shows the frequency of the legal measures in force at the time of the research. It does not however provide an overview of all the legal steps taken. Cases recorded as a 'care order' might have originated with an emergency protection order. Conversely, some of the protection and interim orders recorded at the time of the key worker interview might eventually become full care or supervision orders.

Table 34. Register cases: Legal steps taken

\begin{tabular}{|l|l||}
\hline \multicolumn{1}{|c|}{ Legal Steps taken } & Number of cases \\
\hline \hline Emergency protection order & 6 \\
\hline Police protection & 4 \\
\hline Interim Supervision order & 1 \\
\hline Supervision order & 1 \\
\hline Interim Care order & 7 \\
\hline Care order & 12 \\
\hline Care order already in force & 5 \\
\hline Child assessment order & 3 \\
\hline Family assistance order & 2 \\
\hline Criminal proceedings & 1 \\
\hline Prohibited steps & 1 \\
\hline High court care and control order. & 1 \\
\hline Residence order & 7 \\
\hline No legal action & 60 \\
\hline
\end{tabular}


Table 34 illustrates the wide range of legal interventions utilised. Despite the fact that the cases on the register are those likely to cause greatest concern (Gibbons et al 1995), coercive legal action was taken in only a minority of cases. Moreover, in several instances the legal action was initiated by family members rather than the 'authorities'. Gibbons et al (1995) in their study of the operation of the child protection system made a similar observation, "a "supportive" style of child protection with little use of legal intervention was the most commonly found'(p.94).

\section{Registration}

In October 1991 the register category of 'Grave Concern' which accounted for nearly half the registrations was abolished (Gibbons et al 1995). This was used either for siblings of children who were registered in other categories or for children in families in which there was considerable disturbance but where the children had not been clearly sexually or physically assaulted or neglected. One hypothesis in the present project was that emotional abuse was being used, not as a clearly defined category for cases in which abusive behaviour by carers could be clearly identified, but as a catch-all category for former 'grave concern' cases. This concern was heightened by the fact that while 1993 saw a significant decline in the number of grave concern cases, it also saw a substantial increase in the emotional abuse category cases (Department of Health 1995b).

However, these misgivings were not borne out by the interviews with the key workers. In all but one case they were able clearly to identify emotional abusive behaviour by the children's carers. In most cases there was a clear protection plan to counter the abuse, although three cases were still being fully assessed. In the one exception (R3) the key worker, despite feeling the child should not have been registered, had had to succumb to pressure from other agencies at the case conference. The key worker felt that bullying at school, rather than her parent's behaviour, had triggered her distress. 


\section{EVALUATION OF PRACTICE}

Important aspects of good practice include working in partnership with families, children and other agencies, and working in an anti-discriminatory manner.

\section{Working in partnership}

As reported above coercive action was taken in only a minority of cases. The workers across the authorities referred to the need to engage parents, remain child-centred and cooperate with other professionals.

Attempts to work with parents while showing non-judgemental attitudes is illustrated by the case of R12.

The father was a member of the British National Party. He was known to be a very violent man having already broken his wife's arm and ripped the radiator off the wall. He had 'reduced the mother to an automaton, a zombie'. The social worker, outreach worker, psychiatrist and health visitor offered support to both parents. It took six months to engage the father, who was angry and violent at first but, by the time of the interview, both parents were working with the professionals to address the issues of violence, drug misuse, child care and isolation. The key worker judged that this has resulted in better hygiene, less domestic violence, better relations with neighbours and overall a considerable improvement in the quality of life for the children.

There were however instances where attempts at working in partnership with the parents have led to a failure to act in the interests of the children. R26, for example, illustrates the point, conceded by the key worker, that simply acceding to parental requests is not the same as working in partnership with them:

Four children aged 8 to 2 years were shown little affection by their mother and step-father between whom was considerable domestic violence. The mother would only allow one child at home at a time therefore 'all the 
children regularly yo-yoed in and out of care'. The absent birth father paid $£ 15,000$ per year as long as the mother looked after at least one child. The four children showed distressed behaviour. For example, the 6-year-old boy drank alcohol, was excluded from school due to bullying and destructive behaviour, tried to strangle one of his brothers with a belt and threw objects into other children's eyes. The key worker acknowledged that intervention led to a decrease in the quality of life for the children 'because the mother is able to use the system for her own needs'.

\section{Anti-discriminatory practice}

There was no evidence of blatant instances of stereotyping, failing to take into account of contextual influences or of judgemental attitudes. Two issues emerged in relation to potential discrimination which the key workers were addressing. The first was 'motherblaming' and the second related to issues of intervention in black families.

\section{'Mother-blaming'}

Thompson (1993) observes 'given that women act as the lynchpin of the family in the domestic sphere it is likely that they will suffer the greatest effects and, indeed, be allocated the greater share of the blame' (p.47).

Creighton (1992) noted that although in 1988 in emotional abuse registrations 51 percent of the 'perpetrators' were mothers, there was an increasing trend for both parents to be implicated. By 1990 the proportion of both parents had risen from 11 percent to 31 percent while the proportion of mothers was down to 24 percent in 1990. Creighton comments 'Whether these trends reflect a genuine change in the individuals, or couples, seen as emotionally abusing their children over this period, or a change in the key worker's perceptions of caretaking responsibilities, and possible omissions, would require further, more detailed investigation' (p32).

In this present study, the key workers interviewed appear to be sensitive to the issues of 'mother blaming'. It has been noted (Chapter 7) that although mothers were often held 
responsible, in very many instances the key worker also identified the father as failing to use his parental power appropriately. This included instances where the child's natural father 'opted out'. As the survivor, Jay, indicated, one parent's indifference can be as emotionally hurtful and damaging as another parent's verbal assaults.

On the other hand, there is a discrepancy between the numbers of fathers held responsible by the key workers on the register cases and those recorded in the population survey. This could be due to the key workers' inappropriate allocation of blame to the mother. But equally it could be the failure of referral systems to pick up cases of fathers who wield parental power in an improper manner.

\section{Black and minority ethnic groups}

There was no evidence of key workers pathologising as 'abusive' child rearing practices which are simply different because each problem identified in a black or minority ethnic family was mirrored by a similar problem in a family from a white, majority ethnic group. There was one possible exception (R95) an African Caribbean heritage family who had become part of a religious sect and was claiming that their child was possessed by the devil. However, the key worker identified herself as from the same African Caribbean heritage and felt that the abuse was not related to cultural factors and concerns about abuse were appropriate. Moreover, similar abuse relating to religious cults has been identified in white families in the literature (Bottoms et al 1995). Farmer and Owen (1995) likewise found a comparable absence of 'discriminatory social work actions or attitudes' (p.321).

Turning to the management of cases, black families were offered as many interventions as white ones. The mean average was 7.2 for both groups with a median of 7 for both. Differences between the type of intervention offered to black families compared to white ones were not statistically significant. 


\section{Subjective Evaluation of Intervention}

\section{Register cases and key worker evaluation}

The key workers were first asked to evaluate whether or not professional intervention had led to an improvement in the quality of life for the children concerned including siblings of the subject child. Secondly, they were asked to comment whether, with hindsight, there could have been alternative more effective intervention. Their responses are summarised below in Tables 35,36 and 37.

Key workers were invited to give, among possible replies, the response ' cannot be evaluated or not known' to the question 'What do you judge are the effects of intervention on the subject child?' (See Table 35). However, in all cases they were clear about their evaluation of the intervention to date and did not use this option.

Table 35. Register cases: key worker evaluation of the effects of intervention on the subject child

\begin{tabular}{||l|l|l||}
\hline \multicolumn{1}{|c|}{ Effects of intervention on subject child } & number & percentage \\
\hline \hline Considerable improvement & 36 & $32 \%$ \\
\hline Moderate improvement & 31 & $28 \%$ \\
\hline Marginal improvement & 29 & $26 \%$ \\
\hline Maintaining status quo & 8 & $7 \%$ \\
\hline Marginal deterioration & 5 & $4 \%$ \\
\hline Moderate deterioration & 2 & $2 \%$ \\
\hline Considerable deterioration & 1 & $1 \%$ \\
\hline Cannot be evaluated/not known & 0 & $0 \%$ \\
\hline
\end{tabular}


Table 36. Register cases; key worker evaluation of the effects of intervention on siblings.

\begin{tabular}{||l|l|l||}
\hline \multicolumn{1}{|c|}{ Effects of intervention on siblings } & number & percentage \\
\hline \hline Improvement & 68 & $61 \%$ \\
\hline No effect or maintaining status quo & 14 & $13 \%$ \\
\hline Deterioration & 7 & $6 \%$ \\
\hline Not applicable & 23 & $20 \%$ \\
\hline
\end{tabular}

The key workers' views on whether or not, with hindsight, intervention could have been different are presented in Table 37 below. They were prompted to look not only at their own intervention but at the intervention which could usefully have been offered prior to their involvement. It was clarified that the question was not confined to social services intervention. The responses of the key workers fell into three categories as demonstrated in Table 37.

Table 37. Register cases: key worker evaluation of alternative intervention.

\begin{tabular}{||l|l|l||}
\hline With hindsight could things have been done differently? & number & percentage \\
\hline \hline No & 39 & $35 \%$ \\
\hline Yes, earlier and firmer intervention & 43 & $38 \%$ \\
\hline Yes, better or different resources & 30 & $27 \%$ \\
\hline
\end{tabular}

The workers who said that nothing could have been done differently did not necessarily make this evaluation because the intervention offered was satisfactory. In some cases the response was a pragmatic one; they recognised that although intervention was unsatisfactory the constraints were such that nothing else could have been done.

Most of the 43 key workers who recommended earlier and firmer intervention referred to the lack of any real guidance for emotional abuse cases. One worker commented that the 'Orange Book' (Department of Health 1988) did not to address the issues encountered by workers undertaking an assessment of emotional abuse. 
The responses indicating the need for better resources included cases where the parents themselves had been abused as children. The workers believed that if the parents themselves had received therapy as children, they would not now be in such difficulties as parents.

Several workers pointed to organisational constraints. They considered that a more flexible response was needed but that agency demands precluded this. One worker explained that the family were always having to have a change of worker either because they moved from area to area or because they had needs requiring a different specialist team. She had managed to retain the family for two years and had undertaken consistent work but she had had to battle with bureaucracy and elicit the support of her line-manager to do so. Several other workers pointed to the difficulties encountered by families who moved between different areas. One woman had temporarily moved to a different area to escape domestic violence. The family was now falling between the two areas for provision. One male key worker felt that the mother should have had a female worker.

\section{Population survey and survivor evaluation.}

In relation to the population survey, 23 percent (28) of the people who were emotionally abused recorded that they received help of some form during childhood. A further 4 percent (5) had been helped in adulthood. 6 percent (7) did not specify whether they had been helped or not. However, by far the majority 67 percent (84) had not received any help.

Of the respondents who had been offered assistance as children, four (14\%) felt that it had not been helpful with another two (7\%) believing it had made matters worse. Two people $(7 \%)$ were not sure whether or not it had helped and for four $(14 \%)$ it had been a mixed blessing. For the majority, $16(57 \%)$, however the assistance given was positive.

Respondent No83, for example, had recorded 15 abusive experiences. She had been rejected and humiliated by both parents 'taunted from an early age that I was hopeless, helpless and useless'. She witnessed violence and parental disputes and when eventually 
her parents divorced she was 'a pawn in their arguments'. She left home as soon as she was able and no longer had contact with either parent. She recorded receiving 'psychological help', which she felt had had a positive outcome.

There were a few examples of less effective help by professionals. No 242 was taken into care and placed with foster carers and then in a children's home. She was seen by psychiatrists, counsellors, social workers and doctors but felt that none of them helped.

Finally, there is evidence from the current study that the police are recognising the implications of domestic violence and referring children in these cases to social services. It appears however that there are problems if the matter comes to court. The difficulties are illustrated by Lynn who was the youngest survivor interviewed and recalled relatively recent incidents. She explained her father would be regularly violent, assaulting their mother and breaking their possessions: 'Mum pressed charges for assault but he was only given counselling and a caution. He went to counselling for one session. He has had several warnings. He has also had to pay damages but the court appearances are not effective. He is small and a wonderful actor. He puts on a little-old-man act as if he were the victim.' This supports the view of Kennedy (1992) who criticises provision for the victims of domestic violence. She writes, 'The spotlight must move to the courtroom where the problems are still considerable' (p.83).

\section{LIFE-LINES FOR CHILDREN}

In response to the opening interview question about what had helped them survive, the survivor volunteers provided details of supports or escapes that helped the survivors cope with their experiences. The various supports have been clustered into several categories: family members, schools, friends, professional help, religious groups, non-human lifelines. Most categories were self-evident, for example the mention of pet cats and dogs were naturally clustered under 'Non-human life-lines' in the subcategory 'Pets'. There were a few less obvious allocations and in these cases the process of categorisation was 
determined by the need to reflect the meaning of the life-line for the child. Therefore, some people who were not blood-relatives have been categorised under 'Family members' in the subcategory 'Aunts'.

Where appropriate additional comments from other questionnaire respondents are quoted in those instances where they share the interviewees coping methods.

\section{Family members}

Non-abusing parent: the current emphasis on partnership with parents (Cleaver and Freeman 1995), might give rise to the expectation that the survivors would have had a very supportive 'non-abusing' parent who was able to counter the abuse of the other parent. This was not the case. In four instances both parents were abusive. Kate observed that when her father was away 'mother became dominant in a negative way, similarly insisting on total obedience' Both Neil's parents were equally abusive. Pia described her mother 'she would hug us with clenched fists'. Una found her mother cold and unresponsive. In four cases the less abusive parent was seen as 'opting out' and failing to use power to support the child. In the final four cases the parent was seen as a co-victim who required care and protection from the interviewee.

Siblings: There was a similar lack of support from siblings. This, however, has to be treated with caution because in five instances there was a substantial gap of seven to twelve years between the interviewee and his or her sibling. In the cases of Kate, Adam, Joy and Pia the abuser pursued a policy of 'divide and rule' amongst family members so that siblings did not support each other. Neil was the result of an illicit liaison between his mother and another man during her husband's absence. Consequently, he was rejected by the family and his elder brother was as abusive as his parents although his younger brother tried to help him 'in secret'. In contrast, in Lynn's family there was a close supportive relationship between all the siblings. Pia was very close to her elder brother although she disliked her younger sister. It was noted that four of the twelve survivors had had siblings who died in childhood. 
Grandparents: In only one instance were grandparents important figures. Zoe lived with her grandparents during the 1939-45 war. She received no demonstrative affection from her parents but, although her grandparents were very strict, they were affectionate.

Aunts: The most important figure by far was the aunt. In six instances this was the parent's sister. For Roy, his mother's best friend acted as an aunt figure and has always supported him. In two instances, Sue and Gemma, the 'aunt' was a close neighbour. Sue had both a neighbour who acted as an aunt and her mother's sister who gave support. This aunt was also an important role model because she was very loving towards her own children. Her daughter, Sue's cousin also befriended her and was 'more of a sister than a cousin' Of the neighbour, Sue recalled:

I would visit her after school and pour out my heart to her. She would listen and would give me a big hug and help me calm down saying "It's not that bad". She was a shopkeeper and had treats at the back of the shop and would give me my favourite biscuits. She had boys of the same age as me. She always wanted girls so made a big fuss of me.

Other aunt figures provided a listening ear or a role model. Kate's home life was very strict and austere. Her aunt would send her pretty underwear which made her feel attractive. Similarly Una's aunt would tell her how attractive she was. Amy was made to wear her school uniform to parties because although her father was wealthy he was not prepared to spend money on 'inessentials'. Her mother was too frightened to defy her father but her father's eldest sister had no such qualms. When she found out what her brother was doing she made pretty dresses for Amy, insisting that she was allowed to wear them.

Neil had an 'uncle' figure. This was 'the local yob turned good. But he was kind to me, showed interest in me and taught me karate'. Adam potentially had an uncle figure in the form of an assistant scout master who took interest in him but he betrayed Adam's trust when he sexually abused him. 


\section{Schools}

For five survivors, Joy, Pia, Neil, Roy and Kate, a key teacher made a considerable difference to their self-concept. Three were sports teachers, one was a general year head and the fourth was a maths teacher who made Neil feel special. Four other survivors, Zoe, Amy, Gemma and Sue found school a safe haven, made good academic process and found the general approval of teachers helped their self-esteem. Zoe went to a Roman Catholic boarding school and found the nuns very caring and determined to give the children, many of whom were similarly abandoned by their parents, a taste of happiness. Joy was made Head Girl and 'the last year at school was just brilliant'

There was however a less positive side to schooling. Pia was sexually abused by a teacher who befriended her. One of Gemma's teachers also attempted to molest her. Lynne expressed amazement that despite her 'punk' appearance and her brother's excessively violent drawings no teacher showed any interest or curiosity about their background. Neil moved from a Glasgow school to a rural Highland one where he was labelled a troublemaker simply because of his Glaswegian accent. Roy's behaviour became quite disturbed and he was nearly expelled but again no one examined his behaviour in the context of his background. Adam and Una were largely overlooked at school. Una commented ' $I$ was very quiet and shy and would sit at the back of the class unnoticed. I was probably underachieving but I managed to get reasonable results and won a couple of awards. I just kept my head down'

\section{Friends}

Several of the children, Roy, Pia, Amy, Sue, Lynne and Kate were isolated and had no real same-age friends. Adam had no special friends but he found joining the Boy Scouts helpful until an Assistant Scout Master sexually abused him. For other interviewees, friends were very important. However, the friends were usually other disadvantaged children. The parents of Joy's friend drank excessively, Gemma's 'best' friend was being sexually abused and Zoe's friend was conceived illegitimately and was the scapegoat of her family. Neil made friends with another boy who was similarly outcast; unfortunately, one day they had a row 'I told him to fuck off and die. The next day he drowned and I felt responsible 
and very guilty. I had no one I could talk to about this'. Una was the exception because from the age of 15 she had a friend who was 'the little princess of her father. This man was very open and warm and I envied the closeness of my friend and her dad'

\section{Professional help}

Only three of the interviewees received professional help during their early life. Kate and her brother went to stay with an aunt who noticed how abnormally withdrawn they were. She had them seen by a child psychiatrist. However, he refused to offer any assistance because the parents would not be included in any therapy and his model of working was 'family therapy'. But Kate explained ' we were desperate for someone to listen to us, play therapy would have been wonderful but we were denied this because of beliefs about the "proper" way to help children'.

Joy fared rather better. Her behaviour at school became disruptive and she was referred to an educational psychologist. She felt very insulted by the referral. But the psychologist's report said that the underlying problem was that she was bored easily and needed challenges. The response of the school was to give her increased responsibilities and eventually make her Head Girl, all of which helped her.

Roy received help in his late teens when he suffered from severe anorexia nervosa. He was admitted to psychiatric hospital. Although this was not very supportive, he found subsequent attendance at a day hospital helpful. This was mostly due to peer support of people with similar problems but the professional workers helped to facilitate this process.

Pia and Adam had counselling as adults which they found helpful Amy became a professional counsellor and much of her training has led to self-healing. Finally, several of the helping professional interviewees reflected that their work had helped them to make sense of their experiences. They felt that their suffering was not without a purpose as they now had understanding and sensitivity to respond to other people's problems. 


\section{Religious groups}

Being accepted by a religious group was an important life-line particularly in adolescence and early adulthood for several survivors. This was true for Neil, Gemma, Amy, Kate and particularly Adam. He had very few life lines as a child and it is perhaps no coincidence that he is still in a distressed state. However, as a young man he went to an evangelical rally and found the level of acceptance by the church important, as is that of the Anglican community of which his wife is a member. He has also found counselling by a female lay Methodist minister very helpful. Kate explained that during her childhood her father was a Sunday School superintendent so then the church was not supportive. However, in adult life the church has given her a sense of the extended family. Zoe found acceptance of her by the Roman Catholic nuns at her convent school a positive experience.

One of the questionnaire respondents summarised her experiences (R235). All potential sources of help failed her. She holds school teachers as well as her parents responsible for her mistreatment with the comment 'Teachers very unkind'. She ran away and stayed with her grandmother. She was attracted to her uncle who was living with the grandmother. He had sex with her. She comments ' 16 at time so over age of consent, very confused about this ... was I abused? At the age of 19 she took an overdose. She finally added 'the only thing that helped me was becoming a Christian when I was aged 33.'

\section{Non-Human Life-Lines}

Pets: These appeared important. Roy and Sue had pet cats. Kate and Una had dogs. Una explained 'from about the age of 5 to 20 I had a dog. He was a brother and a friend. He was my world. He used to let me dress him up. Dad was very cruel to him and would beat him badly. I could comfort him. It meant that I wasn't the only one to be badly treated. I did not feel so guilty. When I gave birth to my first son, dad and my husband had him put down because they felt it was unhygienic. He was just gone when I came out of hospital. I was devastated.'

Toys: For a few of the survivors toys were important. Kate had a big teddy she told all her 
troubles to. Una made herself a domestic play area where she escaped to a 'happy family'. Gemma used figures of plasticine or cut-out, cardboard dolls to retreat into a happy imaginary world.

Books: Both Pia and Gemma read Famous Five books and this provided them with a group of imaginary friends. Similarly, Little House on the Prairie and Little Women provided Kate and Sue with imaginary substitute families. For Neil, Tolkein and for Lynne, science fiction enabled them to escape from reality. As young adults, several survivors found self-help books useful. Kate explained that books on how to be assertive and on positive thinking have helped her. Gemma similarly found a 'light-hearted book with cartoons for people surviving all forms of abuse' very helpful. Lynne used a book on children of alcoholic parents to help her understand her feelings.

Negative escapes: Several children used escapes which were functional at the time but which could have had negative effects. Neil used drinks and drugs to escape the misery of his life. Under- and over-eating was another way of escaping or gaining control of the situation. Roy nearly died through anorexia nervosa. As a boy he had over-eaten as a comfort as he tried to cope with his father's violence towards his mother. But later when he was in his teens and jeered by work colleagues he became anorexic. Gemma and Pia both became anorexic and bulimic. The ultimate escape is through death and two of the interviewees, Pia and Neil tried to hang themselves while Neil also took overdoses.

\section{OVERVIEW}

Seden et al (1996) evaluated social work intervention in child protection cases in the light of the implementation of the Children Act 1989. They came to the conclusion 'the practitioners displayed flexibility and creativity as they transferred their professionalism to the new situation' (p. 65). This is echoed in this study. There is evidence that despite the lack of guidance from the literature (Chapter 3) in relation to emotional abuse, the key workers, along with fellow child protection professionals, were offering an imaginative 
range of interventions, working in partnership with parents and other professionals and demonstrating evidence of anti-discriminatory practice. Garbarino et al (1986) recommended a broad eclectic approach to intervention (see Chapter 3) arguing because emotional abuse has many facets a single intervention is rarely appropriate. In the current project, there was evidence that a wide variety of interventions are being offered to emotionally abused children and their families.

On the other hand, most of the key workers were ready to acknowledge that there was room for improvement. Clearer assessment guidelines were needed so that intervention could occur earlier and be more focussed on the emotional abuse issues.

The accounts of survivors similarly demonstrated that there are ways of coping with emotional abuse which could usefully complement the interventions offered by protective agencies. They could also be used in cases where the parents or children themselves reject more formal assistance and intervention.

What appears to emerge from an analysis of the life-lines identified by the survivors is that they all had somebody or something that gave them unconditional positive regard (Rogers 1980, Mearns and Thorne 1988). These 'significant others' would listen (or in the case of teddies and pets, appear to listen) without making any judgement and without condemning the child. Aunts, in particular, appear to be able to side with the child without the conflict of loyalty that parents or grandparents might have. Abusive parents are less likely to be jealous or come into conflict with aunts than they might with their partner or own parents. Teachers, psychologists, friends and members of religious groups, similarly, are rarely involved in the family dynamics so are able to give unconditional, high regard without jeopardising relationships with parents. It may be less easy for social workers or family therapists who have to balance the often competing interests of different family members. The findings from the survivors' accounts are reflected in the words of Jacoby (1986) who noted that children could 'survive abuse' if 'they find someone - a teacher, an aunt or uncle - who makes them feel valuable and worthwhile' (p.6). 
Because the survivors are not representative of the general population, there are limits to the way in which the information provided by them can be generalised to a wider population. For example, it is not possible to conclude that, because nine of the survivors had supportive aunt figures, then 75 percent of the children in Britain are equally likely to have supportive aunts. Nevertheless, what the case study approach is able to do (Smith 1993 ) is to identify and explore issues or characteristics in a small population that might also be true of members of the wider population from which the cases are drawn.

The Department of Health (1995b) research summary of recent intervention was critical of certain aspects of child protection practice:

Myopia hindered discussion about a child's family. The common preoccupation was with the nuclear aspect, which more often than not consisted of a single female parent or involved step-parents ... On the other hand, the significance of wider patterns of kingship and other sources of emotional support was often overlooked (p.49).

The accounts given by the survivors in the current project suggest that an important aspect of intervention is the utilisation and promotion of 'wider patterns of kingship and other sources of emotional support' for emotionally abused children. 


\section{CHAPTER 9}

REYTEW AND IMPLICATIONS FOR POLICY AND PRACTICE.

This chapter reviews issues for intervention highlighted by the research. It looks at the five areas which required examination - definition, prevalence, location, manifestation and intervention itself - in the light of the findings. The implications of the research for intervention in cases of emotional abuse are discussed against the background of the research design and the social context in which child protection workers operate.

\section{OVERVIEW OF ISSUES RELATING TO THE PROJECT DESIGN.}

The validity of the findings and the implications for intervention highlighted by this project are confirmed, modified or brought into question by the strengths and limitations of the project design. This section evaluates aspects of the overall design then, in five subsections, examines in more detail the design strengths or deficiencies in each of the five areas of exploration - definition, prevalence, location, manifestation and intervention itself.

One overall strength is that the project has examined emotional abuse from different perspectives in a way that means these perspectives can be integrated. It does not therefore suffer from the problems inherent in examining officially recorded cases or retrospective accounts alone. Officially recorded cases will only reflect those cases which come to professional notice and engender concerns in professional workers. Brougham (1996) notes 'the processes which lead to registration are not value-free, but are influenced by and indeed contribute to, the structural inequalities present in society' (p. 21). But Creighton and Russell (1995) highlighted the problems of relying on childhood memories of adults. They noted in their study that some of their more paradoxical findings were 'probably a function of age and memory' (p.24). A comparison and integration of current, officially recorded cases with past experiences from sectors of the general population leads to a broader and possibly more accurate picture than would be the case if there had been reliance on only one of these data sources. 
This project has combined both quantitative and qualitative approaches. While it provides a statistically based framework in which to explore the issues, it also offers insights and a sense of the 'real' experiences of both working with emotional abuse and surviving it. These insights were gained though the unstructured aspects of the interviews with key workers and survivors. Jick (1983) notes that the multi-method type of triangulation can 'capture a more complete, holistic, and contextual portrayal of the unit (s) under study' (p.138).

However, Jick (1983) warns that it cannot be assumed that multi-method triangulation can guarantee to 'exploit the assets and neutralize, rather than compound the liabilities' (p. 138). There are weaknesses that may be common to several methods or a deficiency in one method which may not be compensated for by the strengths of another. In this project much of the data was provided through the subjective opinion of various respondents such as the judgements of key workers or the autobiographical memories of the questionnaire respondents. Conclusions based on opinion and hindsight, even when these are from different sources, have to be regarded with a measure of circumspection.

There are general concerns about the use of a student population. Fox and Gilbert (1994), commenting on their research on women who suffered childhood trauma, wrote 'Since college students could be expected to be fairly well-functioning, women who suffered most severely from childhood trauma may have been excluded from this study' (p.856). A similar comment could be made about the population survey in the present project. It may well have excluded some of the people whose emotionally abusive experiences were among the most damaging. However, some balance was achieved by using the registered cases for comparison, because the referral and registration process (Farmer and Owen $1995)$ inevitably encompasses children with some of the most potentially harmful experiences.

In his exploration of the research findings relating to sexual abuse, Finkelhor (1986) also expressed concern about using student populations. However, when he compared the findings in studies using student population samples to those using other sectors of the 
community the differences were not great. He commented:

Victims of sexual abuse might be underrepresented among college student samples because college students are middle class and because the psychological impairment of abuse may interfere with educational attainment. Empirical findings, however do not support this hypothesis (p.28)

This means that research exploring emotional abuse using college populations may be sufficiently representative to allow a degree of generalisation to the wider community.

In the current study, samples were drawn from three different sections of students, 'Undergraduates', helping 'Professionals' undertaking in-service training and 'Access' students. There were statistically significant differences in age, gender and social class between the three sections. Therefore controls for these three potentially confounding variables were introduced into the analysis of findings. Drawing from three different sections of students ensured that the overall sample reflected a broad range of ages, social classes and educational experiences.

Another limitation of the population study is that potential respondents to the questionnaire were volunteers; no student was obliged to fill it in and return it. In addition, the survivor interviews were based entirely on people willing to volunteer. Banister et al (1994) warn 'The types of people who choose to take part in psychology studies tend to be younger, brighter, friendlier, less conventional or authoritarian, but with a strong need for approval' (p.7). Because of the interdependence of temperament and vulnerability to abuse (Anthony and Cohler 1987) as well as parenting and personality (Adorno et al 1950, Baumrind 1991), it could be that certain types of emotional abuse were excluded by 'volunteer characteristics'.

This project was limited in terms of scale and the representative nature of the samples used. Extensive funding was not available and therefore it had to be tailored to budgetary confines. It could be argued that a topic should not be studied if funding for an ideal 
methodology cannot be obtained. However, given the very limited funding for social work research this could mean that less attractive or interesting topics never benefit from systematic scrutiny. The comparative dearth of research and recent articles (Doyle 1996a) specifically into emotional abuse demonstrates that this is not an area which to date has excited great interest. Yet this study has pointed to the distress and sense of being 'permanently damaged' experienced by the victims of emotional abuse. This is therefore an area which is legitimately the concern of child protection professionals and as such deserves the attention of researchers.

Fuller and Petch (1995) argue that social work researchers should not feel that the sampling devices they can adopt are in some way inferior. Rather, the necessity is for a clear understanding of what can be concluded from the sample under scrutiny' (p.41). The rest of this chapter, while acknowledging the limitations of the design and the nature of the samples used, examines what can realistically be concluded from the data collected.

One strength of the project was that missing data was not a substantial problem. The telephone interviews of key workers were effective in eliciting answers to all sections. Having a pre-arranged interview time meant that they were able to obtain the case files before the interview and most had read through them in preparation. As Fuller and Petch (1995) note in relation to a similar project:

Certainly in terms of time and travel the telephone proved to be a successful medium for gathering data; social workers seem particularly comfortable with this instrument, judging by the inordinate amounts of time they spend on it' (p72)

There was also a relatively high overall response rate of 85 percent to the questionnaires. This to, some extent, offsets the problems of 'volunteer characteristics'. Most people handed back a completed questionnaire. In addition, the courses were either selected at random or, in the cases of the Access and Professional groups, all available courses occurring in a defined location and time span were encompassed. The courses were not chosen on the basis of factors (eg being involved in research themselves) which may have 
encouraged a good response rate. Therefore the representative nature of the responses may be as good as one using a community-based sample in which there was a poor response rate, 'Those who do not respond may be from a distinct subgroup whose responses might have been very different' (Fuller and Petch 1995 p. 66). The response rate of between 83 percent and 87 percent across the three groups diminishes the likelihood that a substantial subgroup has been excluded from this study.

One final general observation is that many participants, whether key workers, survivor interviewees or questionnaire respondents, provided detailed responses to open questions. Therefore, the data provided was more informative than had been anticipated, given the apparent difficulties of researching the subject suggested by the comparatively limited number of relevant research projects (see Chapter 3). As a consequence, not all of the information provided can be incorporated into this study. Examples have been restricted to one or two for each topic where very many more could have been provided. In particular, a substantial number of examples were given by the questionnaire respondents who were allocated to the 'Other Distress' group. It has been beyond the scope of this study to look in detail at their experiences. Issues such as bullying in schools and homophobic or racist attacks by neighbours are valid areas of exploration in relation to emotional abuse in its widest context. But these areas are beyond the parameters of the present study. The information from people allocated to the Other Distress group indicates that these are important areas for future research.

Issues raised by the research findings in relation to the specific areas of definition, prevalence, location, manifestation and intervention are addressed in the next five subsections. 


\section{OVERVIEW OF FINDINGS}

\section{Definition}

The working definition for this project was adapted from one originally provided by Hart et al (1983). As a reminder, it is given below:

Emotional abuse of children, as the sole or main form, consists of acts of omission and commission which are judged on the basis of a combination of community standards and professional expertise to be psychologically damaging. Such acts are committed by parent figures who are in a position of differential power that renders the child vulnerable. Such acts damage immediately or ultimately the behavioural, cognitive, affective and physical functioning of the child.

This definition has echoes of the widely accepted operational definition for child sexual abuse provided by Schechter and Roberge (1976):

The involvement of dependent, developmentally immature children and adolescents in sexual activities they do not truly comprehend, to which they are unable to give informed consent or that violate the social taboos of family roles ( $\mathrm{p} 129$ ).

In both definitions there is the concept of unequal power and the misuse of power ('dependent, developmentally immature children') between abuser and abused. Account is also taken of the cultural and social contexts 'community standards' or 'violate the social taboos of family roles'.

The project confirmed that the constituent parts of the definition provide useful guidelines in relation to the nature of emotional abuse. These are itemised and discussed below:

* Descriptions of emotional abuse, reported by key workers and survivors, included acts of both omission and commission. Therefore passive rejection, ignoring, failure to safeguard children from terrifying or burdensome situations (where this would have been possible) all constitute emotionally abusive acts of omission. Direct threats, active rejection and denigration were all deemed emotionally abusive acts of commission. Some activities like locking children away or preventing them from socialising involve a mixture 
of omissions and commissions.

* Issues of power and responsibility were important. There was only one case on the register where very little real abuse of power by the parents could be identified. Similarly, in the interviews with the twelve survivors, abuse of parental power was clearly indicated. They could all identify ways in which parental power could have been used differently in a non-abusive way. All those survivors who were now parents themselves were attempting to use their power in the non-abusive ways that they had identified.

* It became apparent that the impact of the abuse of parental power is damaging in either the short or longer term, and often both.

Judgements about what constituted emotionally abusive experiences, responsibility and the damaging nature of emotional abuse, were made by both professionals and by nonprofessionals, including survivors who had suffered these experiences. There did not appear to be a wide divergence between the professional and survivor perspectives. There were some dissimilarities between the perspectives concerning the role of the father in families. Fewer instances where the father was solely responsible were recorded by professionals compared to the respondents in the population study. Commentators in the literature (Stark and Flitcraft 1988, Milner 1993, Langeland and Dijkstra 1995) have noted that in abuse cases generally the extent of the role of fathers has not been acknowledged by professionals and researchers. The finding in this project would suggest that this might also be true of emotional abuse and is an area worthy of further scrutiny.

The essential features of the working definition appear to be shared by professionals and respondents to the population survey. Therefore, with one modification, the working definition for this project might usefully be adopted as an operational definition for practitioners.

The suggested modification relates to the list of potential damage to functioning. The tangible sequelae of physical abuse is likely to be in the form of injuries such as bruises, 
broken bones and burns (Speight 1989). However, the current study showed that in contrast in emotional abuse cases actual injuries were less prominent than the physical effect of abuse on growth, development and appetite. This supports other research suggesting emotional abuse has an adverse effect on metabolic and endocrine function (Skuse 1989b, Iwaniec 1995). 'Physiological' therefore appears to provide a more accurate description and is an appropriate substitute for 'physical'. Furthermore, in the present study social isolation of the victims, evidenced by problems relating to peers and teachers in school, difficulties in forming friendships and lack of confidence in social settings, was recorded as a possible outcome of abuse. Therefore it seems appropriate to add 'social' to the list of functions impaired by abuse.

From the outset, both practitioners (see Introduction) and commentators in the literature (see Chapter 3 and McGee and Wolfe 1991a, 1991b) expressed concern about the lack of an operational definition for researchers, policy makers and practitioners. One outcome of the present research is a suggested operational definition to address this apparent deficiency. The suggested definition for future use by researchers, policy makers and practitioners is:

Emotional abuse of children consists of acts of omission and commission which are judged on the basis of a combination of community standards and professional expertise to be psychologically damaging. Such acts are committed by parent figures who are in a position of differential power that renders the child vulnerable. Such acts damage immediately or ultimately the behavioural, cognitive, affective, physiological or social functioning of the child.

A number of commentators (Lourie and Stephano 1978, Haugaard 1991, McGee and Wolfe 1991a) advocate different definitions for alternative purposes. In response to this, the above definition could be modified to take account of different circumstances. For example, the present purposes of registration would require practitioners to add ' where it is the main or sole form of abuse'. In order to cover broader aspects of emotional abuse such as extra-familial racism or peer bullying, the phrase 'individuals, individually or collectively' could be substituted for 'parent figures'. The definition could be modified to 
cover the emotional abuse of dependent adults by substituting the word 'adult' or 'victim' in place of 'child'. Similarly, practitioners who feel that it is 'adultism [to describe] all people under 18 as children' (Lebacq and Boylan 1997) could use Hart et al's term 'children and young people'.

On occasions, a more concrete version of the definition might be required. A comprehensive list of abusive behaviours was earlier identified (see Chapter 7 and the 'Practice Guide' in the Post Script). Therefore, a suggested addition would be 'examples of psychological maltreatment include acts of fear inducing, tormenting, rejecting, ignoring, isolating, degrading, corrupting, burdening with inappropriate roles and refusing the child appropriate therapy'.

The first objective of this study was 'to offer an operational definition of emotional abuse of children'. The suggested definition above has been offered as an outcome of the current project.

\section{Prevalence}

A rate of 29 percent was identified. Nevertheless, this study does not claim an absolute prevalence rate. Even within the present study more stringent criteria produced rates of 17 and 10 percent (see Chapter 5). This variable rate has implications for intervention which will be discussed below in the section on intervention. From the findings of this project, it is argued that emotional abuse is likely to be sufficiently prevalent and distressing for its victims to require a response at all levels from helping professionals, policy makers and society in general to prevent the distress and damage caused by this form of abuse.

The problems of gaining an exact prevalence rate are acknowledged. Ghate and Spencer (1995) observe that the comprehensive planning of services requires a survey of the 'general population rather than one based on clinical or other special populations' (p.1). As other commentators (Creighton 1992, Brougham 1996) have noted, it is not possible to derive a reliable prevalence rate from registered cases. Meanwhile, the student population used for the survey was not representative of the general British population. 
The 29 percent rate might be an overestimation because students might have had high expectations of themselves and their parents. But, given the extensive school-related problems revealed in the present study (see Table 29, Chapter 7), the rate could equally be an underestimate because, despite the inclusion of Access students, the student sample might have excluded those whose educational opportunities have been impaired by emotional abuse.

The accuracy of the prevalence rate is also brought into question because the population survey was a subjective evaluation of the respondents' emotional experiences. Because of this the rate of 29 percent could simply reflect the discrepancy between contemporary ideas of childhood and the reality of children's experiences. The examination of the social construction of childhood (see Chapter 1) indicated that one contemporary view of childhood is of several happy, safe years of innocence separate from, and uncontaminated by, the realities and responsibilities of adulthood. It could be that many of the respondents who defined themselves as 'emotionally abused' were comparing the reality of childhood with this idealised expectation and construction of childhood. They may have been more influenced than the 'non-abused' group by images of happy, safe children portrayed and projected through the media and societal communications. People complaining of emotional abuse might simply be more aware of the disparity between real life and an idealised concept of childhood. However, a substantial proportion of the respondents recorded that they had suffered long term, even permanent, damage from their experiences. Expressing dissatisfaction with childhood experiences, which does not have direct implications for self-esteem, is very different from conceding that these experiences have caused substantial damage to the self.

It is acknowledged that people may re-interpret earlier events in order to make sense of their current situation. There may be little difference between the childhood experiences of the non-abused and emotional abuse groups, instead the real difference may lie in respondents' current feelings of worth and achievement. However, the descriptions of abusive experiences in some of the written comments and in the verbal descriptions given by the survivors were very similar to those of children who had been registered (see 
Chapter 7). The respondents' recognition of damage combined with the descriptions of experiences which mirror recorded cases, casts doubt on the idea that the EA group were merely unable to distinguish the difference between reality and the ideal or that they were reinterpreting the past.

It is important to note that the recorded prevalence of sexual abuse in the present study is similar to the rate recorded by Baker and Duncan (1985) and the rate for physical abuse similar to the findings of Creighton and Russell (1995). The similarity of the rates for other forms of abuse between this and other accepted studies supports the view that prevalence rates between students and community populations are comparable and that it is possible to have confidence in the current findings.

Finally, as La Fontaine (1990) points out, 'the recognition of a serious social problem need not depend on the percentage of those affected being exact to the last decimal point' (p. 47). When it was estimated that sexual abuse was a rare occurrence (Weinberg 1955) there was little provision for victims. Since widespread publication of the 'discovery' of the probable higher prevalence of sexual abuse (Finkelhor 1986, Baker and Duncan 1985, La Fontaine 1990), there have been proposed or implemented changes in government guidelines and policy (DHSS 1988), in specialised treatment and prevention programmes (Gough 1993) and the plea (MacLeod and Saraga 1988, Kitzinger 1994) that the societal structures that render women and children vulnerable to sexual exploitation are dismantled. The present study makes a similar contribution in relation to emotional abuse. It indicates that account needs to be taken of this form of abuse when policies, treatment or prevention programmes and social structures relating to abuse are considered.

The second objective of this study was, 'to provide an estimate of the prevalence of emotional abuse, where it is the main or sole form of abuse'. As an outcome of the current research a prevalence rate of 29 percent is suggested as a useful guide to the extent of emotional abuse. 


\section{Location}

The project attempted to identify those situations, including the type of child, parent and family in which emotional abuse is likely to occur.

\section{Characteristics of emotionally abused children}

The findings of the current project suggest that there is no particular 'type' of child who is emotionally abused. All children can be potential victims of emotional abuse. Although, no studies to date have fully explored the type of child that might be vulnerable, the present study reinforces the indications (Creighton 1992, Jones and McCurdy 1992) that emotional abuse occurs in approximately equal proportions between the genders and touches all age groups. In line with other commentators (Banks 1992, Verdugo et al 1995), there is evidence that some children suffer from both intrafamilial emotional abuse and extrafamilial discrimination. Additionally, the data obtained in the study showed that, as identified by Jones and Jones (1987), Reschly and Graham-Clay (1987) and O'Hagan (1993), racism, within or outside the family, can be considered a form of emotional abuse.

While children of all ages were represented in the register cases, age proved a particular problem from various aspects. It became apparent from the current study that it is difficult to determine when emotional abuse starts. In physical and sexual abuse there may have been previous 'minor' assaults or 'grooming' which means that the onset of abuse is earlier than the recorded incident but, with these forms of abuse, it is easier to pin-point a time when the abuse started and an age at which children appear to be vulnerable. This was not possible in emotional abuse cases. In the register analysis there was often a long period of mounting concerns with no clear reason for action at a particular point. Similarly, the respondents in the population survey had difficulty identifying exactly when the abuse started and stopped. Although there were some damaging individual incidents, such as the public weighing of Pia, the abuse was often a process rather than a series of incidents.

Another age-related problem was created by a deficiency in the questionnaire design. At the outset it had seemed attractive to divide the age bands neatly into 20 year intervals. In addition it seemed appropriate to distinguish the 'teenage' respondents from those who 
were in their twenties. But, in the event, it proved inappropriate to treat respondents aged just 20 differently from the 19-year-olds who were having the same experiences of leaving home for the first time. A categorisation of ages which took account of these features of the population would have been more enlightening.

Nevertheless, controls for age were implemented in the analysis of the population survey and this revealed that age rarely affected the findings relating to the majority of variables. Where there were differences in experiences recorded by younger people compared to older ones it was difficult to determine whether these were due to the accuracy of recall, mature reflection or changing patterns of parenting.

One key problem of location relating specifically to the register survey was the complexity of disentangling 'cases' from children. In the 'only' and 'singled-out' categories the figures referring to cases also refer to a specific child. But in the 'group' category all the children in the family could have been affected. Therefore it is possible that far more children witnessed domestic violence, for example, than the figure relating to cases suggests. It might have been possible to use a device similar to Brougham (1996) in which 22 children from 11 families were analysed. However Brougham was analysing case files. In the present project, her system was not feasible. The pilot interviews had demonstrated the need, for reasons of confidentiality and clarity, to identify one subject child thereby avoiding having to use family names .

There was some evidence that children whose conception and birth presented difficulties might be slightly more vulnerable to scapegoating and rejection. This has already been acknowledged in relation to physical abuse (Jones et al 1987). Theories of bonding and attachment (see Kennell et al 1976) appear to be worthy of further exploration in relation to the emotional abuse of 'singled-out' children.

\section{Parental and family characteristics}

Compared to many of the emotional abuse research projects to date (see Chapter 3 ) the present study could be described as large scale. Nevertheless, when family characteristics 
were divided into several categories, the scale was too small for firm conclusions to be drawn. For example, the numbers of people from each of the identified minority ethnic groups, whether in the population survey or register cases, were too small for any real analysis of issues relating to ethnicity. It became apparent however that, as with sexual abuse (Finkelhor 1986), emotional abuse can be found in families from a wide range of ethnic and cultural groups.

Similarly, determining the location of emotional abuse in terms of socio-economic class could not be examined in detail because of small cell sizes. Moreover, the composition of adult members of families sometimes changed over time making it difficult to determine whose occupation should count towards the classification. In addition, the extended time span and changing parental occupational status meant that the effects of unemployment, a factor associated with child abuse (Jones et al 1987, Krishan and Morrison 1995) could not be examined in detail. This would require a longitudinal study.

However, the study appears to indicate that, as Covitz (1986) observed, emotional abuse can be found in wealthy professional or managerial families. Yet, as Furnell et al (1988) found, it was also in evidence in poorer families from the unskilled occupational groups.

One limitation of the present project is that it was not always possible to make the analysis of register cases comparable with the population survey. A clear example is provided by the question relating to family income. The key workers could usually provide details of current income level, whereas the income level of the respondents' family during childhood in the population survey was not comparable to present day prices and would, in any case, change over the 18 years of childhood. Nevertheless, the comparison of the two samples supports the findings of other researchers (Garbarino and Kostelny 1992, Coulton et al 1995, Krishan and Morrison 1995) and indicates that children in families suffering financial pressures may be more vulnerable to emotional abuse.

The degree of sensitivity required for the population survey meant that some issues could not be addressed explicitly. It was deemed too demanding to incorporate inquiries about 
domestic violence, attempted suicide or family bereavement beyond sibling deaths in the questionnaire. It might have been possible to include an open question asking respondents to record any family distress not covered by other questions. However, without a specific question, doubts would have remained about the contributions. These issues were unlikely to be reported fully in the population survey yet they were evidently important features of the register cases. They are worthy of further exploration in future research because, apart from domestic violence which is receiving greater attention (Mullender and Morley 1994, also see below), there is little evidence from the literature that issues like self-harm (Madge 1996) and bereavement have been studied specifically in relation to emotional abuse.

Both the register and population survey encompassed events over years rather than taking a snap-shot of children at a specific time. For this reason, it has not been possible to quantify certain aspects. For example, unlike Creighton's (1992) study, it was not possible to state how many abused children were living with 'single mothers' because several children had changes of carer over time. Given the ongoing debate about the plight of children cared for by single mothers (Dobson 1996) this might have been useful. In the present study there were shifts in household composition in many families over time. Initially there might be both parents in the household, then one parent caring alone followed by a step-parent moving in, - and sometimes out again.

Both this project and the literature (eg Covitz 1986) suggest that emotional abuse can occur in almost any type of family in terms of socio-economic and cultural background, family composition and size. However, in both the register cases and in the population survey, families which experienced interpersonal distress, caregiver changes and socio-economic pressures appeared to feature prominently in cases of emotional abuse. There were, however, families in the EA group that appeared not to be vulnerable to adverse socioeconomic factors. Ecological theorists, examining child abuse, emphasise the interrelationships between interpersonal and environmental factors. However, many (eg. Garbarino and Kostelny 1992, Coulton et al 1995, Krishan and Morrison 1995) have tended to scrutinise socio-economic pressures on families while paying less attention to bereavement and family disruption. The links between intra- and interpersonal factors and 
emotional abuse is an area which could benefit from additional research.

The third objective of this study was 'to increase understanding of the location and the context in which emotional abuse, as the main or sole form of abuse, occurs. The present project has provided information about the location of emotional abuse which supplements the limited information provided by other researchers (see Chapter 3 ).

\section{Manifestation}

Key workers provided abundant examples of what they assessed to be signs of emotional abuse in the victims. These included developmental deficiencies, worrying aspects of the children's appearance or statements that they made and behavioural problems. In some instances the children's behaviour posed a threat to their own or other people's lives. Although it is difficult to disentangle the contribution to behavioural problems of material environment, emotional abuse and other personal distress, the survivors interviewed bore witness to the direct link between the experience of abuse and behaviour such as suicide attempts or inability to eat.

Despite this, the signs of emotional abuse may not appear as immediate damage to the victims because, although the majority of children had at least one sign of distress, there were several children in the register survey who did not appear to be showing any such signs. The interviews with some of the survivors also demonstrated how children can continue to appear unaffected to observers but carry a burden of distress and hurt which is experienced as damaging, if not at the time, then in the longer term. This same phenomenon has been recognised in cases of sexual abuse. Survivors like Sylvia Fraser (1989) and Joy Spring (1987) have revealed how no one suspected they were abused given the 'normality' of their appearance and behaviour as children. However, their autobiographies reveal their long term burden of hurt and distress.

Conversely, the population survey also revealed several respondents who did not define themselves, and were not designated, as 'emotionally abused' but who nevertheless 
described considerable distress as a result of 'societal' abuse such as homophobic attitudes or as an outcome of grievous life events such as the death of a parent. Unlike sexual abuse where sexualised behaviour in a young child is likely to be caused by sexual exploitation, emotionally distressed behaviour may have many other causes such as traumatic life events or peer bullying and other abuse external to the family.

Therefore, because some emotionally abused children appear to be 'invulnerable' while some non-abused children can be profoundly distressed by other events, it seems more appropriate to assess emotional abuse on the basis of parental behaviour. Nevertheless, signs in children are important both to support the judgement of abusive parental behaviour and to indicate the type of help the children might require. Brougham (1996) noted the lack of plans for therapeutic intervention for emotionally abused children. Further research could usefully be undertaken into the impact of emotional abuse on the victims, their consequent needs and appropriate therapeutic responses.

One conclusion that can be drawn from the research is that an assessment of parental behaviour requires taking into account both acts of omission and of commission. This was already a theme emerging from the literature and has been illustrated further by this project. Examples from the literature and this project demonstrate that behaviours such as locking a child away involves both doing something (locking) and not doing other acts (making contact).

The idea that failure to meet children's needs, using Maslow's framework (see Figure 2, Chapter 1), constitutes abuse through acts of omission was introduced when examining the manifestation of emotional abuse (see Chapter 7). The application of this framework is discussed further in relation to the proposed Practice Guide (see the Post Script and Appendix 4). This appears to be a useful way of conceptualising acts of omission and was discussed by Kell (1993) in an unpublished thesis. Further exploration of Maslow's framework is suggested as a potentially useful additional conceptual instrument for practitioners undertaking emotional abuse assessments. 
The assessment of parental behaviour also addressed issues of power, as suggested by McLeod and Saraga (1988). In the current study, a number of register cases and information from several respondents in the Other Distress group demonstrated that some parents are disempowered by factors such as poverty, other people or illness. Lynn, for example, commented 'My mother was very much a victim'. Such parents may have little power to misuse so they are not appropriately described as 'abusive'. But their children may nevertheless be burdened, distressed and exploited. In such cases it could be argued that responsibility rests with other people or society and social policies in general which do not provide adequately for parents who suffer domestic violence, poverty or are chronically ill or disabled.

Finally, commentators have attempted to classify emotionally abusive behaviours. In the course of this project, it was found that even one of the most comprehensive models provided by Garbarino et al (1986) had limitations. An alternative with nine categories has been offered as a result of the present project. These are neither 'fixed' nor definitive categories. Instead, they are designed to help practitioners identify abusive behaviours and cluster them so that, in contrast to a haphazard list of concerns, they can be conveyed more readily and coherently.

The fourth objective was 'to increase understanding of the manifestation of emotional abuse in both abusers and the abused'. The current project has provided information to supplement the limited information in the literature (see Chapter 3) about parental behaviours that can be deemed emotionally abusive, as well as offering a categorisation of these behaviours. The current research has also suggested that there are a range of indicators of emotional abuse in children although some can appear to be 'unaffected' by their experiences. 


\section{INTERVENTION}

This section looks specifically at this project's contribution to intervention and the conclusions that can be drawn in relation to responding to emotional abuse.

It is acknowledged that the present study cannot give answers to all the questions of intervention. There will always be the 'border-line' cases. Practitioners are familiar with these when managing other forms of abuse (see Chapter 2). There are for example those cases of parents who seem remarkably clumsy when handling their babies. There is no certainty about defining such cases as physical abuse and often practitioners can do little but give what advice they can and hope the child does not suffer a subdural haematoma (Jones et al 1987). Similarly, case conferences can be divided in cases of sibling sexual activities with those who define it as abuse opposed by those who believe it is 'childish play' (Doyle 1995).

In emotional abuse cases it will not always be easy to distinguish abuse from other misfortune. There is also the concept of 'goodness of fit'. Some of the cases in allocated to the Other Distress group suggested uneasy family relationships rather than abuse. A useful illustration of this is the autobiography of Blake Morrison (1993). His father was an outgoing, robust man and 'an offensively, no-nonsense doctor' (p.91). His son was a quiet, introspective person who suffered at the hands of his father's effusiveness. This could be seen as case of emotional abuse because his father should perhaps been more sensitive to his son's needs. But a more gregarious, expansive son would have enjoyed his father's bonhomie rather than being humiliated by it. This could be viewed as more a case of a mis-match of personalities and temperaments rather than abuse.

Having acknowledged these dilemmas, the following sections examine issues of intervention for those instances which can be more clearly identified as emotional abuse.

A fundamental consideration is whether or not any intervention at all is required. In the 
population sample, 29 percent were deemed to have experienced emotional abuse by carers and a further 28 percent identified emotional abuse by others. It is possible that some of the remaining 43 percent were 'in denial' and failing to recognise the abuse they had suffered (a point considered by Ghate and Spencer 1995 in relation to child sexual abuse). It could be argued that, if between 60 and 70 percent of children are subjected to emotionally damaging treatment, then what they are experiencing is not abuse but part of the maturing process preparing them for the realities of life. If this is the case it could be argued that no intervention is required. We simply accept that in Hobbes' (1615) words, life is 'solitary, poor, nasty, brutish and short' (p.82) and children might as well learn that lesson sooner rather than later. Alternatively, it might be appropriate to adopt the apparent attitude of pre-war French parents, as observed by Dolto (1955) and Wolfenstein (1955). They noted that, unlike the 'American' construct of the early years as a time of play and enjoyment, the French attitude appeared to be that childhood was a austere preparation for a sensuous and enjoyable adult life, 'It is with the prospect of these pleasures that the individual has served his hardworking childhood' (Wolfenstein 1955 p.116)

However, the idea that one sector of society should be allowed to suffer is antithetical to social work values (CCETSW 1995). The Code of Ethics states, 'Basic to the profession of social work is the recognition of the value and dignity of every human being irrespective of ... age ... "Age" does not mean old age only' (British Association of Social Workers 1996). The profession does not discriminate between different sectors in society in its commitment to promote social welfare.

Accepting therefore that social workers have a legitimate task in attempting to intervene in cases of emotional abuse, the next section examines possible responses and interventions at the levels proposed for prevention by Hardiker et al (1991) (outlined in Chapter 2).

The findings of the current research suggest that there are different levels of response to emotional abuse required. In the population survey, 10 percent indicated that they suffered substantial abuse because they ticked ten or more manifestations of abusive behaviour and 
believed that they suffered long term damage. However, others had far fewer adverse experiences. These cases will not all require the same blanket response.

The interviews with survivors similarly indicated that different levels of response are needed. Lynn and Roy both indicated that while their father's violence to their mother was a central issue, their situation was compounded by societal attitudes which dismissed the seriousness of domestic violence (see Chapters 6 and 8). Similarly, Kate suffered from her parents' tyrannical regime but this regime was facilitated by contemporary attitudes which judged children who sat immobile and mute for long periods to be the products of 'good parenting'. Here again intervention at different levels are required.

Both intervention and prevention can be considered at three levels:

Tertiary - intervening when abuse is clearly in evidence to ensure it does not happen again or cause more damage than necessary.

Secondary - intervention when abuse is a potential or at an early stage to prevent it from occurring or becoming more serious.

Primary - to ensure that abuse does not occur.

\section{Tertiary/Residual Intervention.}

At a tertiary level of intervention resources are targeted only at those children who are in imminent danger of admission to care. In the present study, the register included several children who were removed into care usually because of the parents' total rejection. There were also some situations, on the register and in the survivor interviews, which could be seen as life-threatening because of the children's self-harming behaviour. However, the majority of emotionally abused children are not in immediate danger. Instead, they are children whose needs, over a prolonged period, are not being met. There is the danger therefore that intervention only at a tertiary level will fail to provide a service for most emotionally abused children.

In the current study it was found that criminal proceedings in relation to the abuse were 
rarely taken again the parents. Some commentators have recommended that the whole of the present system of child protection procedures is dismantled. Hawker (1995), for example, suggests that there should only be an investigation agency for criminal assaults against children. This may serve the needs of physically and sexually abused children but because emotional abuse is rarely seen as life-threatening and equally rarely involves criminal assaults, those who are emotionally abused are unlikely to receive a service especially if the prevailing social policy approach is 'Residual' (Hardiker et al.1991). Under this policy approach (see Chapter 2), intervention is only offered in those instances where very high risks are identified. It may therefore only be possible to dismantle the present procedures and ensure that emotionally abused children receive a service within social policy contexts that view the state as having a role in enhancing the welfare of all children.

The comments of a few of the key workers interviewed suggested that, because of rigid gate keeping in relation to the provision of resources, some cases were defined as high risk and requiring registration simply because the needs of a particular child could not be met in any other way. This concurs with the findings of Farmer and Owen (1995). They recorded that many children living in less than adequate circumstances were brought into the child protection system after a minor incident as a result of the recognition of the families need for 'practical and emotional support' (p.164). But this strategy is far from ideal because, as the authors explain, these families found the system stigmatising and morally discrediting.

The comments of key workers about the need for different and earlier intervention suggests that the current investigative process and register system require amendment. The findings of the current research reflect those of Sharland et al (1995) who revealed that the longer term needs of registered children are not met. One of the outcomes of their research and recent related projects (Department of Health 1995b) is a recommendation there should be greater emphasis on children 'in need' of support services (Children Act 1989 s.17, see Chapter 2) rather than on child protection strategies. This means that children could receive a service for as long as their needs dictated, rather than the present situation 
revealed by the key workers in the current study (see Chapter 8), which is all too often to offer intervention only while the child is deemed 'at risk'. An adaptation of Maslow's identification of 'need' may be worth further exploration because before a 'needs-led' assessment policy can be implemented a framework for determining 'need' has to be in place.

\section{Secondary/Institutional Intervention}

In this approach those children who are defined as 'in need' and/or who might be seriously abused if the situation deteriorates, are targeted for specific services. These are often children in families who suffer from pressures ostensibly unrelated to abuse but which increase the likelihood of maltreatment occurring. Cleaver and Freeman (1995) noted that 56 percent of the families in their study could be categorised as either 'multi-problem' or 'acutely distressed' families. These required intervention for other issues apart from the abuse. In the present project, classifying families under these headings was not one of the research objectives. Nevertheless, it was evident that many families, particularly the 'group child' cases experienced additional pressures. While not all difficulties which might contribute to abuse can be dealt with in depth here, three issues are the subject of current interest and warrant closer scrutiny in the context of emotional abuse. These are: domestic violence, young carers and children of substance dependent parents.

Domestic violence: Some key workers and survivors provided evidence that children who witness domestic violence were emotionally abused because parents perpetrating such violence were not only misusing their power against the other parent but were also failing to ensure the children were not unjustly burdened by the events they witness. There is increasing recognition of the emotionally aversive impact on children of witnessing domestic violence (Mullender and Morley 1994, Jaffe et al 1995, McClosky et al 1995, Brandon and Lewis 1996). Moreover, domestic violence is widespread, with up to one in three women suffering violence at the hands of their partners (Dominy and Radford 1996). It would therefore be inappropriate to register all children witnessing domestic violence. In some cases, especially where domestic violence is frequent, intense or excessive, full child protection strategies are required. But for many cases greater general support within 
society for the victims is required.

The registered cases revealed that the police were responding constructively to domestic violence. They were aware of the risks to the children and referred cases for further investigation (see Tables 30 and 31). It was also evident that Women's Aid and Refuges were a resource for some families. But, as Lynn's account (Chapter 8) demonstrated, the lack of support for domestic violence victims appears to be related more to the courts than the police or social and other support services.

Young carers: Services for children acting as carers have been the subject of recent research and innovative projects (Dearden and Becker 1995, Frank 1995). What emerged from this study is the plight of children who were having to meet the needs of parents with mental health problems. This is not to argue that all parents with these types of problem are abusive. There were however considerable burdens on some of the children and there were echoes of the findings of research by Frank (1995) who observed, 'more children caring for a relative with a "visible" illness eg a physical disability, were identified than those caring for a parent with a mental health problem or drugs or alcohol related illness. It proved difficult to identify the needs of young carers in these latter categories' (p. 56). The relevant literature and findings of the current project highlight the importance of further research into the issues for children with parents with less visible illnesses and disabilities.

Substance dependency: The study indicates that alcohol misuse may be a factor in the emotional abuse of children. This was also the finding of a similar study, examining specifically the impact of parental substance abuse, undertaken by Wright et al (1992).

In the present project it was revealed that mothers, as much as the father figures, need help and support with this problem, although there are likely to be differences in the dynamics of men's and women's excess drinking (Ettorre 1992). It has to be considered how far services meet the different needs of women. Chan (1996) researched the topic and found social stigma, drinking in secret and inappropriate provision prevented women from 
seeking help. Where these women were also mothers the problems were compounded.

Issues like domestic violence, young carers and parents with substance misuse problems are now receiving attention from researchers (eg Mullender and Morley 1994, Dearden and Becker 1995, Frank 1995, Chan 1996). The present project has highlighted the fact that these issues warrant further exploration specifically in relation to the emotional abuse.

\section{Application of findings to direct social work practice}

Many of the key workers referred to the lack of any real guidance when assessing and planning intervention for emotional abuse cases (see Table 37, Chapter 8). They commented that this lack increased the danger of intervention being too little, too late or inappropriately targeted. In pursuit of the objective of contributing to intervention, consideration was therefore given to applying the findings directly to practice. The production of a practice guide is one way of meeting the demands for guidance which is directly targeted at practitioners. It is acknowledged that focusing on practitioners is not the only method of contributing to intervention, hence the wider perspectives discussed in this chapter, but in this section the concept of a practice guide is presented as one possible direct contribution. Full details of the proposed guide are given in the Post Script.

The Guide reflects the findings of this project and addresses the concerns detailed by practitioners and discussed in the literature (see Introduction and Chapters 2 and 3). An operational definition and related issues such as power, intent, cultural aspects and the distinction between emotional distress and abuse are examined. This is followed by suggestions for intervention including registration and how to identify and communicate behaviours which constitute abuse within the framework of the categorisation devised earlier (see Chapter 7). There is also a discussion of the needs of children, assistance to families, challenging oppression and identifying life-lines and support for children.

The guide presented in the Post Script is a preliminary proposal. It would need considerable piloting, testing and evaluation before it could be generally disseminated. In order to determine whether or not this is a possible way forward, the practice guide was 
given to six child care social work teams and they were asked to use it and comment on its usefulness. Their evaluation and comments are given in Appendix 4.

\section{Lifelines}

Most of the survivors had a mentor who proved vital to their well being. All, except Adam, identified either an aunt or teacher or both who had given them special attention and had valued them. These had been supplemented by friends, pets or siblings. For some children there were also imaginary people in books or toys. It seems that all these figures in the children's lives gave them in the words of Rogers (1980) 'unconditional, positive regard'(p. 116). These were people (preferably real but imaginary would also do) who gave the children a feeling of being valued and of being accepted for themselves. This accords with Jacoby's (1986) view that people, such as teachers, aunts or uncles, can give children a sense of worth 'despite what their parents say'.

Ecological theorists Garbarino and Gilliam (1980) and more recent researchers such as Coohey (1996) have focussed on the social isolation of parents as one of the necessary conditions for abuse. But what has emerged from the interviews with survivors is that an important factor in emotional abuse appears to be the social isolation of the children. An essential strategy to counter emotional abuse therefore appears to be the provision for children of a network of people who can provide 'unconditional' positive regard. The implications of isolation for children suggested as an issue worth further investigation. This is especially true for those children whose disabilities restrict their independence and was clearly illustrated by a girl with spina bifida (R104) in the registered cases.

Professional workers may be able to intervene effectively by ensuring that children who are emotionally abused have some life-lines. There may be already ones in place that the practitioner can preserve and strengthen. For other children life-lines may have to be created. This concept of life-lines is similar to Hart's (1988) recommendation, in his discussion of prevention, that children should have protectors and mentors in both their home and the community. 
One of the concerns voiced by the practitioners (see Figure 1) was that removal from home may be as emotionally distressing as the abuse itself. The indicators from this research are that this could be the case if the child is separated from an important life-line such as a close and supportive sibling or a much loved pet.

\section{Primary/Developmental Intervention.}

The discriminant function analysis indicted that emotional abuse was least likely to occur in families which were perceived to be free of socio-economic deprivation, personal distress and disruption. It therefore seems that maximising material and personal support for families could result in primary prevention of emotional abuse. This primary intervention can be in the form of supportive services for all families such as the Penn Green community project in Corby where all parents and children in the community are welcome to join in and do not have to be 'referred' because they have a 'problem' (Hardiker et al 1991).

At a primary prevention level, not only can families be universally supported but the wellbeing and protection of children can be directly promoted. The findings of the current project suggests that all children benefit from having adults separate from parents, such as aunts and teachers, who can provide a supportive network. 'Protective Behaviours' (Briggs and Russell 1994, Elliott 1994) is a programme which can be used for any sector of the population but has been adapted for children. It emphasises the need for children to have a network of at least four adults, in addition to parent figures, who can provide support. There are other programmes designed for all children, whether or not they have been abused or are 'at risk' such as Kidscape (Elliot 1985) which teaches them that they have rights, especially the right to protection.

A more fundamental intervention may be also required. Hart (1988) looking at prevention, acknowledged the role of environmental stress and isolation but he emphasised the need for children to assert their rights. He recommends as the starting point a positive ideology of children. This next section examines this recommendation. 


\section{Social Construction of Childhood}

Just as helping professionals are challenging discrimination and disrespect of other groups (Thompson 1993) so they need to demand that children are treated with dignity and respect. The challenge in relation to children has barely started (Franklin 1995). The example provided by Pia is a useful one. Her father had no hesitation in humiliating her in public by weighing her on potato scales. It is doubtful that he would have escaped public opprobrium had Pia not been a child but instead had been her father's mother. Langone (1992) emphasises the importance of respect 'Respect, the opposite of psychological abuse, entails showing esteem, consideration and courtesy toward others. It necessarily implies that the person toward whom respect is directed is seen as having inherent value, is a subject with whom one relates rather than an object one manipulates' (p.209)

The high level of denigration and humiliation suffered by children, both inside and outside their families, revealed by the current study suggests children as a whole are not held in great respect. One contribution to the prevention of emotional abuse could be, as suggested by Hart (1988) a reconstruction of the concepts of child and childhood. The emphasis at present, according to Hendrick (1990) and Holt (1975), and reflected in the current research, is on what children should not do. They are denied respect as are other sectors of society that are often found to be the least economically productive - older 'retired' people, those with substantial disabilities and to a lesser extent women, especially single mothers. Eastman (1994) notes 'Children, people with disabilities or mental health problems and older people are all perceived as dependent; they are all equal members of society yet are often perceived as unequal partners by those who are considered "normal" and productive' (p.71)

There is an image of children as possessions, as incomplete people who can be treated by their parents and other adults in any way they chose short of excessive injury or sexually exploitation (Holt 1975). They are marginalised in the media and in political debate (Lansdown 1994). This marginalisation could usefully be challenged in a manner similar to the way it is being contested in the case of older people (Eastman 1994), abused wives 
(White 1985) and people with disabilities (Craft and Brown 1989). Much of the emotional abuse is 'unintentional' in that there has been little opposition to parents' rights to use their children as scapegoats or emotional buttresses (Farmer and Owen 1995). Consequently, as the responses to the questionnaires showed, many parents do so without thinking about either the consequences or morality of their behaviour.

The fifth objective of this study was 'to explore issues of intervention. This includes an examination of current responses and identification of interventions which appear to be helpful, thereby providing guidance for future intervention'. The findings of the current research suggest that there can be a variety of interventions offered at the different levels of response. Ensuring that emotionally abused children have supportive life-lines is a major recommendation emerging from this study. In terms of primary prevention, in the current project, the finding about the extensive nature of emotional abuse suggests support for Hart's (1988) recommendation for a positive ideology of children.

\section{CONCLUSION}

Here it is appropriate to return to the concerns of professionals outlined in Figure 1. Addressing the first concern, it has proved possible to define emotional abuse. It is acknowledged that few definitions which are short enough to be serviceable can totally encompass very complex issues. Nevertheless, the one originally provided by Hart et al. (1983) and adapted for this study, may with minor amendments form the basis of a credible operational definition.

There are other issues which can never be clearly resolved. These include the identification of a clear 'base-line' between the acceptable and the unacceptable, the intangible nature of much emotional abuse and the fact that many parents are inadvertently abusive at times. However, these are issues which, as the survey of the historical context of abuse illustrated (Chapter 2), professionals have learned to 'live with' in other forms of abuse. For example, many years on from the Lester Chapman case, there is still no clear base-line in England 
indicating what is acceptable and unacceptable physical punishment. Ten years after the Cleveland crisis, there are still rarely tangible physical signs present in sexual abuse. The difficulties of resolving these issues of identifiable base-lines and intangibility have not prevented intervention in other forms of abuse. Similarly, they should not form the basis of inaction in cases of emotional abuse. The evidence from the register cases in the present project is that in identified cases professionals, at least in the participating Local Authorities, are not inactive and are offering a wide range of responses.

This project has addressed and resolved some of the remaining issues. Firstly, issues of intent are not of primary importance - just as in physical abuse few parents intend to break their babies' bones (Jones et al 1987). Instead they use parental power inappropriately either to meet their own needs or because they fail to recognise their children's needs. What appears to be essential is how parental power is being used. This issue is amplified in the Practice Guide (see the Post Script and Appendix 4).

This project has demonstrated that there are very many intervention steps that can be taken before removal is required. It has been shown that the recognition that emotional abuse is occurring does not lead inevitably to legal action and removal (see Tables 33 and 34, Chapter 8) There are many positive interventions, particularly the identification, strengthening or provision of 'life-lines' for children, which can be employed. Long-term, forcible removal only occurred in cases of very real danger to the children or where rejection by their parents was total.

From a theoretical perspective, the ecological approach enables policy makers and practitioners to address problems at a range of levels from the intrapersonal to the wider social contexts. It enables them to recognise that individual deficiencies, environmental stress and the way children are viewed by society are all factors in cases of emotional abuse. The 'sufficient' conditions and the two 'necessary conditions' identified by Garbarino and Gilliam (1980) have been shown to be present. In relation to the 'necessary conditions' an understanding of the power relations between parents and children is essential to an identification of abuse while issues of social isolation of children appear to 
be important when determining appropriate intervention.

It is concluded that emotional abuse, defined as acts of omission and commission by carers in a position of power that damages the child immediately or in the longer term, is widespread. It may well affect over a quarter of the child population. It can occur to any sort of child in any kind of family although those in families which are subject to disruption and stress are likely to be more vulnerable. The discriminant function analysis indicated that the lower the environmental/material stress, personal distress and family disruption the lower the likelihood of emotional abuse occurring. This indicates the importance of intervention at a primary level.

The project has indicated that intervention can usefully be undertaken across all levels, primary, secondary and tertiary, although its feasibility at certain levels depends to some extent on the social policy context. In order to ensure that some of the victims have a service whatever the social policy context, the present register system could usefully be retained. But 'needs led' intervention is also necessary to cater for those children and families with specific issues that require a response.

The research indicated that present intervention could be improved. A Practice Guide (see the Post Script), incorporating some of the emerging themes of the project, is one possible way forward, although this requires further exploration and evaluation.

Nevertheless, not all the dilemmas facing practitioners intervening in cases of emotional abuse can be resolved, just as dilemmas remain in relation other forms of abuse.

An important finding was that informal life-lines can be very important for children and professional workers' intervention could usefully include the identification, preservation, and strengthening of existing life-lines and provision of appropriate ones for children who do not have any.

Given that a quarter of the child population could be suffering emotional abuse at the hands 
of carers and possibly a further quarter from people outside the home then intervention has to be more global than just working with specific families. This can take the form of challenging discriminatory attitudes to children so that they are afforded respect and consideration by members of their family, their community and society at large.

It is recognised that this project is, among other recent studies (Brougham 1996) the beginning rather than the conclusion of research into emotional abuse. As Banister et al (1994) state, in relation to non-experimental research 'the findings of the study are as fragile and mutable as real life is' (p.11). The understanding of other forms of abuse has been served well by the contributions of unpretentious projects across a range of populations worldwide, from which common themes have emerged. Emotional abuse requires a similar range of studies. The present project is therefore one contribution in the search for a more complete appreciation of the issues. Its findings confirm many of those of earlier projects. In addition, it has clarified some of the apparently contradictory findings of earlier research such as Furnell et al's (1988) focus on socially deprived families compared to Covitz's (1986) studies of wealthy ones. It has expanded on earlier work as in the case of Garbarino et al's (1986) categorisation of abusive behaviours. Finally, it has provided some relatively new insights such as the role of interpersonal stressors, the problems of social isolation, not just for parents but also for the victims, and the importance of supportive life-lines for children in cases of emotional abuse. 


\section{POST SCRIPT}

"TOW'ARDS A PRACTICE GUTIDE FOR INTERVENTIION

This Post Script includes an example of a proposed Practice Guide in full. The suggested sections of the Guide are presented, in this Post Script, in two parts: recognition, and intervention. Before reproducing each part the rationale and main features of the various sections are briefly discussed.

The proposed Guide has to achieve a balance between being long enough to contain all the essential issues but short enough to be read by busy practitioners. Complex issues have to be presented as clearly as possible but in doing so some of the subtleties are inevitably lost. The Guide is therefore a compromise between the ideal and the realistic.

An evaluation of the Guide provided by practitioners is detailed in Appendix 4 . 


\section{PRACTICE GUIDE. PART 1 - RECOGNITION}

\section{Introduction and Definition.}

The first page (following acknowledgements and contents pages) explains what the guide contains but makes it clear that this is not a substitute for any existing general guides such as Protecting Children (Department of Health 1988) which at the time of writing is the definitive practice guide in the assessment of general child abuse cases.

There is a note on terminology because practice guides have to be sensitive to discriminatory language but terms can become outdated or inappropriate. By making a statement on terminology this problem is acknowledged.

\section{Power Issues}

The section on power issues is designed to help practitioners identify the different forms of power possessed by children's carers which they may not be using appropriately. It also assists in the recognition of those parents who do not any significant power. Some, for example, are substantially disempowered by illness or disability and have to rely on their children as 'carers'. Such parents may not be directly abusive but their children may nevertheless be 'in need'.

The final sentence in the section on 'power issues' defines the ways in which the use of power can be oppressive, based on the definition used in the Criminal Justice Act 1991. It includes not just cruel or harsh treatment but also the use of power in an unjust or burdensome manner. This reflects the views of many of the key workers in cases where the parents had problems relating the mental ill-health or substance misuse. The burden and injustice of having to cope with parents' unpredictable or unreliable behaviour was seen as emotionally abusive even in the absence of overt cruelty or harshness.

\section{Intent}

One matter of considerable concern discussed in the literature by a range of commentators is how far parents who do not 'intend' harm can be defined as abusive. This is likely to be 
a dilemma for practitioners particularly where the parents' situation evokes sympathy and understanding and is therefore explicitly addressed.

\section{Cultural Aspects}

Because child abuse can be seen to be socially constructed, parental behaviours which require intervention can vary between generations or cultures. Furthermore, Britain is a multi-cultural society and there will be differences in child rearing patterns which are to be respected. But account also has to be taken of 'cultural relativism' (Dingwall et al 1983, Channer and Parton 1990, Gambe et al 1992) ie accepting all practices to which the word 'culture' is attached thereby leaving children from some backgrounds unprotected.

\section{Emotional Distress}

The guidelines in Working Together (Home Office 1991) could appear to suggest that a child has to demonstrate the effects of abuse before protective action can be taken. However, as in sexual abuse cases, emotionally abused children should be deemed in need of protection even if they are showing no signs of distress or harm; it is the behaviour of the adults that is the cause of concern because of its potentially damaging effect on the child (either immediately or in the longer term).

Here it is argued that practitioners should respond to emotional abuse in a way similar to the response to sexual abuse, acting to protect the child if there is evidence of the misuse of parental/carer power. The section points to the importance of identifying abuses of power by the children's carers regardless of the children's behaviour. Notwithstanding, a child's distress may confirm the conclusion that psychological mistreatment is present.

\section{Determining the presence of emotional abuse}

The next section summarises the debate and provides practitioners with a series of questions in order to make an assessment of emotional abuse.

The first part of the Practice Guide is provided in the next eight pages. 


\section{Page 1}

\section{EMOTIONAL ABUSE OF CHILDREN}

\section{PRACTICE GUIDE}

\section{INTRODUCTION}

This practice guide contains suggestions for ways of responding to instances of potential child emotional abuse within the family context. It is designed to supplement rather than replace other guides such as the 'Orange' book (Protecting Children. Department of Health 1988).

Notes on terminology:

Every attempt has been made to avoid words and phrases that are discriminatory or likely to cause offence. However words which may be acceptable at one time may be less so later. There may be terms which although allowable when this guide was devised are less acceptable by the time the practitioner comes to use it. In such cases the users of the guide are asked to substitute more appropriate ones.

In books, articles and reports, authors sometimes use the word 'it' when referring to a child or baby. This is a reflection of the objectification and dehumanisation of children by our society. In any report prepared by a practitioner a child however young should be referred to as 'he' or 'she', as appropriate. Where the child's gender is unknown there are various conventions such as ' $\mathrm{s} / \mathrm{he}$ ', or 'he or she' that can be used. 


\title{
Page 2
}

\section{PART 1 - RECOGNITION}

\section{DEFINITION}

The following working definition is adapted from Hart et al (1983)

\begin{abstract}
Emotional abuse of children consists of acts of omission and commission ${ }^{1}$ which are judged on the basis of a combination of community standards and professional expertise ${ }^{2}$ to be psychologically damaging. Such acts are committed by parent figures who are in a position of differential power ${ }^{3}$ that renders the child vulnerable. Such acts damage immediately ${ }^{4}$ or ultimately the behavioural, cognitive, affective, physiological and social functioning of the child.
\end{abstract}

\section{Comments on the definition:}

1. Physical and sexually abusive behaviour consists predominantly of acts of commission actions done to the child - eg hitting, shaking, burning, poisoning, raping, touching, photographing. Physical neglect consists predominantly of acts of omission - things that are not done for the child - not feeding, not cleaning, not keeping safe. Emotional abuse consists of both. For example a rejecting parent may not give any cuddles or show any warmth (omission) but will also push away the child who is seeking a cuddle or comfort (act of commission).

2. It is important to take account of the 'community standards' which includes the family's cultural context, as well as professional opinion about what children require in order to thrive.

3. The issue of the use or misuse of parental power will be addressed in the next section.

4. In making an assessment, the immediate harm to a child should be assessed as well as the potential damage to the child's functioning in the future. The purpose of child protection is not just to ensure that children will grow up to be adequate citizens and/or parents but to protect them from unnecessary physically or emotionally painful experiences in the 'here-and-now'. 


\section{Page 3}

\section{POWER ISSUES}

Parents have considerable power over their children. Charles Handy (1985) identifies six types of power in organisations. These can be adapted to the family situation. The six forms are:

\section{Physical power}

Parents are in a position to exert considerable physical power over their children. In England and Wales they are allowed by law to physically assault or restrain their children in efforts to control or train them. The only restriction is that parents have to demonstrate that what they have done is 'reasonable'. Parents probably have more physical power over their offspring than any other set of citizens over any other group.

\section{Resource power}

Parents usually have substantial resource power in relation to their children. Children can rarely own anything in their own right. Most are completely dependent on their parents for shelter and material needs. Parents are also usually the main source of nonmaterial resources such as security, approval, affection and praise.

\section{Position power}

Parents are given by law considerable power over most aspects of their children's lives. Even though children are required to have some form of formal education parents can decide not to send their children to school if they can provide alternative education at home. In more recent times older children, if competent, can have some say in their medical treatment (Gillick $v$. W. Norfolk and Wisbeach AHA). But generally those in the position of 'parent' are given by the law substantial power over their children.

\section{Expert power}

Parents being older are usually more knowledgable than their children. Generally knowledge is power and their knowledge and greater experience of life often gives parents substantial control over their children.

\section{Personal power}

Parents can exert considerable personal power over their children. Many children feel affection and attachment to their parent. Moreover, if they are able to see their parents as 'admirable' then they (the children) are often able to see admirable qualities reflected in themselves. Children therefore have a 'vested interest' in viewing their parents in the most favourable light possible. 


\section{Page 4}

\section{Subversive or negative power}

This is often the only power that children, particularly younger ones, can exert. But parents who feel they lack other forms of power either in relation to their children, family members or the 'authorities' may exert subversive power. It is more likely to be used when people are in a state of low morale, stress, irritation or frustration

\section{Examining issues of power}

Oppression is about the abuse or misuse of power or failure to use it appropriately by those in a position of power over other people. An oppressive or abusive act occurs when, not only is power misused, but the victims are also treated as objects - that is their needs, rights and human dignity are disregarded.

It is useful to bear in mind a quotation from Montgomery (1989).

'Lawyers might be more comfortable with a distinction drawn between neglect and abuse which was based on the distinction between acts and omissions but in the context of protecting children's welfare this distinction is unattractive. Omission may be just as damaging as positive acts, As parents clearly have an obligation to care for their children., there is no conceptual difficulty in accepting that their duties include positive obligations to promote the well-being of children and not just a requirement to refrain from injuring them.'

Parents are therefore given extensive power to maintain and enhance the welfare of their children. If they abuse, misuse or fail to use it appropriately then potentially there is an abusive situation. An oppressive use of power can be described as the exercise of power in a harsh, cruel, unjust, or wrongful manner or the imposing of unreasonable or unjust burdens (Criminal Justice Act 1991). 


\section{Page 5}

\section{ISSUES OF INTENT}

One issue that child protection professionals might have to consider is how far to take account of the parents' intention to abuse. Sometimes it is difficult to label behaviour 'abusive' if the parents appear to be unaware of the negative consequences of their behaviour. This is particularly true of emotional abuse cases because the results are not as tangible as a bruise or broken bones. However, the primary evaluation is whether or not the child has been mistreated.

It is perhaps worth considering how cases of physical abuse are evaluated. There are many physical abuse cases where the parents did not intend any harm. Indeed those where the parents set out with a desire to inflict pain and injury on their offspring are very rare In many instances the parents had no intention to harm but do so because of:

* a sudden loss of control which, particularly with a small baby, may result in serious damage.

* a gradual build up of pressure; before the parents fully appreciate what is happening, they have moved from a single slap to increasingly more serious assaults.

* the parents' profound belief that they have to 'discipline' their children and do not appreciate that using weapons and inflicting injury could be construed at 'abusive'.

* parents inflicting injury due to 'diminished' responsibility.

In none of these instances do the parents intend harm and yet clearly a child is abused if a skull fracture or extensive bruising is sustained, for which the parents are responsible. Similarly, with emotional abuse, the parents may not intend harm. But if their behaviour results, or could potentially result, in humiliation, fear, isolation, deep unhappiness or other potential harm to the child's sense of well-being then emotionally abuse is present.

Intent does not therefore play a crucial role in the initial assessment nor in the judgement about whether or not child protection measures are needed. Where intent does become important is when assessing the what could be offered to the family. An estranged parent who 'deliberately' sets out to humiliate a child in order to hurt their partner will require one type of response. The agoraphobic parent who is so frightened of being left alone that the child is imprisoned in the home without education, entertainment or friendship will require a very different response. 


\section{Page 6}

\section{CULTURAL ASPECTS}

There is the danger that child care practices and family organisation within minority or less powerful groups are seen, not as different, but as less good and even abusive. It is important not to judge practices which are different from the mainstream as abusive just because they are different. Conversely, it is important not to define a behaviour as 'non-abusive' just because it is practised by the majority of people. But the need to be sensitive to cultural differences, does not mean that all practices found in families of minority cultural groups are automatically non-abusive. While there are practices which may not be part of the mainstream but are appropriate within a particular cultural context, Ahmad (1989), Channer and Parton (1990) and Gambe et al (1992) all warn against using a desire not to appear 'racist' as an excuse for failing to protect black children. What needs to be looked at are the reasons for the practice and whether or not caregiver power is being used to enhance the welfare of children.

The examples provided below have been chosen with care. They are very unlikely to reflect decisions that have to be taken by child protection workers in order not to prejudice decisions in similar individual cases. They are used to illustrate a decision making process rather than specific decisions.

Examples:

1. Wealthy British families have traditionally sent their children to boarding school often from an early age. The parents may be using their power to give their children what they believe is the 'best start in life'. They will probably do all in their power help the children overcome homesickness and make them feel wanted and loved. Here, whatever the personal doubts of the social scientist about the desirability of boarding schools, the parents' actions are not seen as abusive, given the cultural contest. However, in some instances it is made apparent to the children that they have been sent away because they are not loved or wanted. In this case the parents' actions are basically rejecting and emotionally abusive.

2. Buchi Emecheta (1978) provides an example of marriage arrangements within the Nigerian Ibuza culture of the 1950s. Although not directly within the realm of present day child protection work it illustrates different arrangements for young people, which range from the appropriate to the abusive. Post-pubertal girls were married to young men who would pay a 'bride price' for their future wife. The main character in Emecheta's book, a girl of about thirteen, had a with a loving relationship with her father. She hoped to 'marry well, a rich man of whom her father would approve and who would be able to afford an expensive bride price'. (p.12). This was an arrangement welcomed by all parties and, within the cultural context, would not be construed as abusive. However, in the case described by Emecheta the girl's father died and, in return for her uncle's care and protection, the girl was expected to be married to the 'highest' bidder. This could be seen as on the borderline of abuse, with the girl being used as an object for sale. Nevertheless this was within the accepted custom and was a means of ensuring that she was provided for, rather than being alone and unprotected. However, she was kidnapped and nearly forced into marriage by members of a neighbouring powerful family. This was clearly abusive because this particular family misused physical power without any regard to the girl's well-being.

It is therefore important to understand the reasons for the particular practice and to analyse how power is being used within a particular culture. While 'culture' or 'tradition' should not be used as an excuse for abuse, child care practices which are different from the mainstream should not automatically be seen as emotionally abusive. 


\section{Page 7}

\section{EMOTIONAL DISTRESS}

Very few people emerge from childhood without having experienced some emotional distress. Substantial emotional harm and distress can occur through life crises such as family bereavement or parental separation. Children can also be emotionally harmed by traumatic events such as being involved in a serious road accident. These events would not constitute emotional abuse. There are however some instances of life-crises or traumatic incidents where emotional abuse is present.

Example: Parents who divorce would not be deemed emotionally abusive if they did all in their power to identify and meet the needs of their children. The children may be emotionally distressed, even emotionally harmed but not abused. But they would be considered abused if the parents misuse their power over the children and treating them as objects; using them for example as weapons against the estranged parent or as parcels to be passed around to pacify the warring parties. Equally abusive would be parents who constantly put their own needs firmly before those of their children.

Because there are many reasons why children may appear unhappy and distressed. It is not good practice to determine that a child is emotionally abused on the basis of disturbed behaviour alone. A useful example is that of autistic children. Once it was argued that 'refrigerator' parents were to blame for their condition. It was assumed that because the child appeared to be so emotionally damaged the parents - especially the mother - must have been emotionally abusive. (Bettleheim 1967) But there is a counter argument that children who are born autistic are difficult to cuddle and relate to and therefore the parents find that the child seems less upset if they become more distant and less demonstrative (Faulkner and Lewis 1995).

There therefore need to be other factors present, in addition to the child's behaviour. These can include:

* some evidence of abusive behaviour on the part of the parent which cannot be explained as an appropriate response to the child. For example, the parents are seen to push away a young child who is seeking comfort and a cuddle;

* complaints by the child, siblings or other witnesses that the parent is behaving inappropriately. For example, a lodger reporting that a child is locked away in a room for long periods, a child saying he is terrified when 'daddy hits mummy';

* evidence from the child's appearance that all is not well. For example, signs of nonorganic failure-to-thrive or children who look pale, unkempt and unhappy in contrast to their siblings who seem happy and healthy.

But it is important to bear in mind that a child can be emotionally abused without showing any disturbed behaviour. Emotionally abused children, like those who are sexually abused can compartmentalise their experiences and appear 'normal'. 


\section{Page 8}

\section{DETERMINING THE PRESENCE OF EMOTIONAL ABUSE}

In order to determine if emotional abuse is present the following questions have to be asked:

Who holds parental power? In theory and in practice

How are those who hold power using it? Are they using it to enhance the welfare of the child/ren?

Are they using it in the following ways?

A harsh manner (eg rigid, severe punishments for minor infringements)

A cruel manner (eg tormenting, threatening)

An unjust manner (eg scapegoating)

A wrongful manner (eg involving child in criminal activity)

Imposing unreasonable or unjust burdens (for example: expecting child to take adult roles and responsibilities, using the child for company to the detriment of the child's welfare)

Any of these would constitute a misuse of power - whether intentional or not.

Are any of the people with parental power partially or wholly disempowered by:

Another person/people

Racist attacks and other forms of societal discrimination.

Poverty

Housing/accommodation problems

Ill health: physical or mental

Disability

Bereavement or other significant loss

What can be done about altering the balance of power?:

* empowering carers disempowered by circumstances

* disempowering a carer who is misusing power

* giving more parental power to a carer who is using it to benefit the children

NB It might be helpful to use a diagram to demonstrate the issues of power and how they need to be altered. 


\section{PART 2 - INTERVENTION}

The guidance on intervention falls into seven sections. Each of these is briefly discussed below.

\section{Registration}

The process of registration was discussed in relation to procedures set up after the mid1970s 'discovery' of child abuse (see Chapter Two). This section discusses the decisions about registration as a protective measure in relation to emotional abuse.

Not all abuse cases are registered. Prevalence studies of child sexual abuse (see Finkelhor 1986) suggest up to 60 percent of the child population could suffer from some form of sexual abuse. It would be inappropriate to register nearly two thirds of the child population. Similarly, given a possible prevalence rate of 29 percent, revealed by the current research project, it would be unrealistic to register all cases of emotional abuse. Therefore, choices have to be made. This section suggests some other factors, in addition to the presence of emotional abuse, that could be considered.

\section{Describing and communicating abusive behaviour}

The next section offers a categorisation of abusive behaviours. The classification of parental behaviours does not have to be rigid, but some rational categorisation is useful in order to convey information to other people.

Unlike physical abuse or sexual abuse where there may be events or accounts of events which can be given sequentially or chronologically, in emotional abuse there are often diffuse concerns only a few of which can be presented chronologically. Moreover, emotional abuse can rarely be clustered under physical features unlike neglect where aspects of care can be itemised - feeding, cleanliness, clothing or supervision. Therefore a way of clustering concerns into categories of abusive behaviour is likely to promote the production of more lucid reports and facilitate communication. 


\section{Children in need}

Increasingly there is concern that the apparent preoccupation with 'risk' means that children who have needs but are not defined as being at 'high-risk' are not receiving services (Department of Health 1995b)

This section encourages practitioners to examine children's needs, because even if abusive parental behaviours cannot be modified, it may be possible to ensure that children's needs are met through alternative sources.

The model is based primarily on that provided by Maslow (1970). His model has however been substantially modified. Firstly, the category 'Fulfilment needs' has been substituted for 'Self-actualising'. Maslow himself argues that 'self-actualising' is the province of maturity and all the examples he provided were people in their second half-century at the time of his writing. 'Fulfilment' can be applied to all ages and can be objective or subjective. With babies, it may be a matter of objective assessment of fulfilment such as reaching their milestones. In older children, it may be a subjective sense of achievement, mastery and of self-fulfilment.

Because Maslow did not intend to provide an assessment framework for child care workers, his main headings have been supplemented by guidance from Cooper's (1985) concept of 'good-enough' parenting plus some examples provided by this project..

\section{Providing Assistance}

The section on 'Providing Assistance' gives suggestions for ways in which assistance can be provided for children and families. It is not a comprehensive discussion but instead is a list of prompts for practitioners. It serves as a reminder of the various options for intervention.

\section{Challenging Oppression}

Helping professionals have been in the vanguard of challenging oppression and discrimination. Thompson (1993) provides a history of how this has come about. This 
section is designed to prompt child protection workers to continue to address these issues in relation to emotional abuse of children

\section{Lifelines and Supports for Children}

The interviews with survivors revealed the importance to children of certain lifelines which can be readily overlooked by adults. For example, the significance of aunt figures and pets have not featured largely in the literature on helping abused children. This section offers suggestions for lifelines based on the insights provided by the survivors. But it also includes some of the less 'safe' escapes espoused by children who had no other lifelines at certain points in their lives.

\section{Summary of Intervention}

A summary of intervention is provided as a quick reference and as a conclusion to the guide.

The second part of the Practice Guide is provided in the next nine pages. 


\section{Page 9}

\section{REGISTRATION}

\section{PART 2 - INTERVENTION}

Even if it is established that abuse has occurred, in some instances it might be more appropriate to respond to the case as one of a 'child in need' rather than to implement a full child protection response, including registration. The registration system is not designed to include every abused child and presently no all cases of physical and sexual abuse are registered. Similarly, it would be injudicious to register all emotional abuse cases. In one survey (Doyle 1996b), 29 percent of the respondents identified themselves as emotionally abused by their parents during their childhood. But registering nearly a third of the child population is not a practical option. Therefore, choices have to be made.

Local procedures will determine which cases are to be registered but consideration could be given to the following criteria

1. Life threatening situations:

i) where the child is so unhappy he or she is likely to, or has already, attempted to commit suicide; ii) where the child may be caught up in serious violence between adults in the household;

iii) where children are showing signs of non-organic failure-to-thrive or eating disorders which render their physical condition precarious;

iv) where young children are left to fend for themselves or are locked out of the house and left to wander the streets;

2. Extreme forms of abuse. For example in a domestic dispute, children witnessing their father slitting their mother's throat, leaving her for dead.

3. When emotional abuse can be clearly identified as the main form but in addition:

i) there are other forms of abuse which may escalate

ii) other children in the household have been subjected to other forms of abuse.

4. Where there are wide ranging concerns which individually may not be serious but collectively provide a bleak outlook and where a large number of agencies require coordination.

5. Where the parents are unable or unwilling to accept the consequences of their behaviour and the situation is likely to deteriorate without the vigorous intervention of child protection workers.

It is, however, recognised that some cases might be registered because, having identified a family needing resources, the only way that practitioners can ensure that sufficient resources are forthcoming is by registering the children. 


\section{Page 10}

\section{COMMUNICATING CONCERNS}

With instances of emotional abuse it is sometimes difficult to convey to other people precisely what is happening. But it is necessary in case conference reports, discussions with parents and children, and in court reports to be precise in identifying the behaviours which can be defined as abusive and which require modification. The following is a categorisation of parental behaviour which may prove useful as a framework for identifying and presenting abusive behaviour.

\section{Parental/ Carer Behaviour Requiring a Response.}

\section{Fear Inducing}

Terrorising: eg holding child hostage with a knife to his or her throat.

Creating insecurity: eg constantly leaving the child with lots of different 'strange' carers.

\section{Tormenting}

Vindictive teasing: eg constantly turning off lights when a child is trying to do homework. Petty-minded mental torture: eg making a hungry child watch other people eat, threatening to destroy a child's favourite pet/toys.

\section{Degrading}

Humiliating: eg shaming or embarrassing in front of other people Denigrating: eg vilification and verbal abuse

\section{Corrupting:}

Criminalising: eg taking children on burglaries, getting children to carry or sell drugs Destructive modelling: eg a violent father encouraging his son to treat all women with derision and hit sister and mother.

\section{Rejecting}

Active: eg telling a child she is unwanted

Passive: eg not giving a child emotional warmth, praise and/or cuddles 


\section{Page 11}

\section{Ignoring}

Not giving child any attention eg 'mother just feeds and waters him but nothing else'. Marginalising: eg a child pushed to the fringes of his or her family, a child is always last when anything is being given out.

\section{Isolating}

Locking away: eg in room/cupboard/outside house for long periods.

Prevented from socialising eg a mother was always drunk and her uncontrolled behaviour meant her daughter felt she could not invite friends back to her house.

\section{Inappropriate roles}

Scapegoating: eg a child is blamed for all family's ills or constantly blamed for siblings' behaviour.

Child used as an object: eg as a parcel bundled between separated members of family or used as a weapon against their other parent or 'the authorities'.

Overprotected or treated as a much younger child

Taking on too much responsibility: eg having to act for carer for ill/disabled parent because their parent is too proud to accept help despite available alternatives. *

* NB But this is not abuse by parents when those parents genuinely have no option but to accept the assistance of their children because of the failure of society to provide the family with adequate support.

\section{Inappropriate Treatment}

Preventing child from having appropriate 'treatment' eg hearing impairment of a child ignored.

Forcing child to have inappropriate treatment eg Munchausen syndrome by proxy.

NB Some cases of inappropriate treatment or the failure to give treatment may be construed as physical abuse or neglect. But when the treatment relates directly to the psychological well-being of the child then it could be included as a form of emotional abuse. 


\section{Page 12}

\section{MEETING CHILDREN'S NEEDS}

Emotionally abused children can be seen to be those whose needs are not being met. Part of the response therefore has to be to determine their emotional requirements and ensure that they are being satisfied.

One way of identifying their needs is by examining the children's behaviour and listening to what they are saying. But children can respond to similar forms of emotional abuse in very different ways. Some children may appear to be unaffected. An alternative is to examine systematically which needs the parents are already meeting, which can be provided by the parents if they are given assistance and which need to be supplied by someone else.

The following form provides a format for this examination. It is based on Maslow's (1970) outline of basic human needs but draws upon the work of the paediatrician Cooper (1985) and recent research (Doyle 1996b) for examples of how those needs might be manifested in children.

\section{Physiological Needs}

Examples: physical care including warmth, shelter, hygiene, adequate food and rest.

\section{Safety/Security Needs}

Examples: protection from danger, security, continuity of care. For younger children, a predictable environment, consistent patterns of care and daily routine, simple rules and consistent controls. For adolescents, a reliable, safe base to return to.

\section{Belonging/Love Needs}

Examples: affection including physical contact, admiration, tenderness, patience, time, making allowances for annoying behaviour, general companionship and approval. Knowledge of their family's cultural heritage

\section{Esteem Needs}

Examples: teaching adequate social behaviour. Provision of a model for children to copy in honesty and concern and kindness for others. Positive identity especially for children against whom the majority society discriminates eg those who are Black, those with disabilities, older children who have a homosexual orientation. Positive knowledge of their absent parent and cultural heritage. Praise and encouragement to strive to do better.

\section{Need for Fulfilment}

Examples: stimulation of innate potential by praise, encouragement and promotion of educational opportunities. Providing younger children with responsibility in small things with a gradual increase. Encouraging independence especially for older children. 


\section{Page 13}

\section{PROVIDING ASSISTANCE}

Working with the parents is, wherever possible, the primary objective. The principles of anti-discriminatory and anti-oppressive practice are also essential ones to follow.

There are a number of ways that families can be assisted short of permanent removal of the abused children. The following are a number of ways indicated by a survey of professionals working with registered abuse cases and by adult 'survivors' of childhood emotional abuse. The following suggestions are not mutually exclusive nor are they an exhaustive list. There are many other helping strategies which have either not been included or only mentioned fleetingly. It is also important to offer a range of appropriate services. If one is not acceptable to various family members, it is possible that an alternative one will be.

\section{Responding to associated problems:}

Emotional abuse is moderately correlated to stress. Therefore, ways of relieving stresses on families is one useful intervention. There are also a number of specific problems that reoccur and appear more frequently in abusive families than in non-abusive ones. These associated problems include:

i) mental ill-health especially in the parent figure;

ii) domestic violence;

iii) substance misuse by one or both parent figures;

iv) family bereavement and loss, especially loss of other children.

Responding to these problems by, for example, providing sensitive counselling for bereaved parents or treatment for a mental health problem will help to alleviate some of the family distress.

\section{Material Assistance}

Many of the families have financial constraints, low incomes and housing problems. They can be helped substantially by provision of household items, financial support and negotiations with housing authorities. It is important to recognise that many parents living in poverty and stress have very little power to exert in their child's interests. Their life may be a daily struggle to meet their children's physiological requirements and they have very few resources, including time and energy, with which to meet other needs.

\section{Family and Group Work}

This can include working in dyads or with more than two members. It can range from assistance with parenting skills for parents, formal family or group therapy or multiple facilities provided by family centres. In some cases children or adults can join groups of people with similar problems. In other cases especially in larger families, the siblings can be worked with as a group.

\section{Individual Work}

One survivor (Doyle 1996b) recalled the devastating experience of being taken to a child psychiatrist who said that because the parents would not 'cooperate' with family therapy he could do nothing. It is important to offer individuals specific help. Children in particular benefit from being able to express their fears, emotions and opinions through individual play work. Parents who were themselves abused may well welcome individual counselling to come to terms with their own experiences of abuse. 


\section{Page 14}

\section{CHALLENGING OPPRESSION}

Much emotional abuse stems from discriminatory attitudes in society. Children are rarely treated with respect. Denigrating behaviour towards children, which would be totally unacceptable if shown towards adults, (see Holt 1975) is often tolerated and even encouraged by some commentators.

Black children in addition have to cope with racism - which is clearly a form of emotional abuse - within society. Gambe et al. (1992) provide a useful example of emotional abuse by a teacher although there are many other adults, besides teachers, who reflect similarly abusive attitudes and behaviour to children in general and to black ones in particular.

Other groups of children will also encounter discrimination. Margaret Kennedy $(1989,1990)$ shows how abused Deaf children already have to cope with negative messages. Children with other disabilities will have to cope with similar prejudices against them. Research (Doyle 1996b) has also shown that young people who are gay suffer considerable emotional abuse due to homophobic attitudes in society. All girls and women suffer from sexist attitudes and inequalities. In a society that values attractive, slim, clever people, children who have an unconventional or awkward appearance, those who are overweight and those who have learning difficulties including dyslexia will suffer taunts and abuse from children and adults alike. Finally, many children will have to cope with multiple oppressions. For example, in Doyle's 1996 study, a black girl with a severe disability also suffered multiple emotional abuse and discrimination.

The task of child protection workers only makes sense if emotional abuse at all levels, within the family, in other care settings such as school and in society in general are challenged. This includes helping professionals themselves examining how far they reflect discriminatory attitudes. 


\section{Page 15}

\section{LIFELINES FOR CHILDREN}

In one survey (Doyle 1996b) the most important help that survivors either had or wished they had had was 'someone who would believe me' 'someone whom I could talk to' and 'someone who would listen'.

The following lifelines have been identified during interviews with people who had been emotionally abused as children and expressed the wish to share their experiences so that other children could be helped in the future.

\section{Important others}

The most important single survival factor was that each child had at least one person who gave unconditional, positive regard; someone who thought well of the child and made him or her feel important.

\section{The 'non-abusing' parent:}

Parents rarely fulfilled a supportive role. Firstly, it is difficult in emotional abuse cases to determine who the 'non-abuser' is. Survivors recall that often one parent was actively rejecting or persecuting while the other was passively rejecting. Even where there was clearly only one abusive parent, the other was either 'off the scene' or was so disempowered by the abuser that he or she could offer little support to the child.

\section{Siblings}

Siblings often fulfilled the role of life-line and support. In a few cases the abuser pursued a policy of 'divide and rule' amongst family members so that siblings did not support each other. However, where there is a close supportive relationship this should be preserved. Evidence from the research of Dunn (1995) showed that when there are adverse family circumstances siblings can support each other. Berridge and Cleaver (1987) also found that placement breakdown was less likely when siblings were placed together or had frequent contact. This again suggests that siblings can provide mutual support. If children have to be taken into care, then as far as possible siblings should be placed together. Just as there is now an active search for black foster and adoptive carers, similarly there should be active recruitment of substitute carers who are willing and able to foster sibling groups.

\section{Extended family members particularly aunt figures}

The aunts were usually mother's sister but also included 'adopted' aunts who were family friends and neighbours. They appear to be key figures in providing unconditional positive regard. They looked on with sympathy and did their best to alleviate the children's lot. These 'aunt' figures appeared to be the main source of support for the majority of survivors.

\section{Teachers and other people who work with children}

Examples of people working with children included scout masters and sports coaches. Teachers and others not only gave unconditional positive regard but they also augmented and valued the children's skills thereby enhancing their self-confidence. On the negative side there were one or two examples of teachers and others befriending vulnerable children and then sexually abusing them. 


\section{A close friend}

Page 16

This was often someone who was also suffering abuse or other problems. There was mutual understanding and sympathy. The friend could counter the isolation felt by abused children.

\section{Religious groups}

Several interviewees acknowledged that being accepted by a religious group was an important life-line particularly in adolescence and early adulthood. The message, according to the interviewees, from these groups was one of unconditional, positive regard ie 'God loves you just for yourself'. Groups with this message offer important support and validation for people who have been despised and denigrated by others.

\section{Non-Human Life-Lines}

Some non-human life-lines were important in either providing imaginary non-judgemental, positive, high regard or in rendering comfort and a temporary escape from reality.

\section{Pets}

These were very important. Often they were dogs who were also abused by the parent and so provided the child with the role of comforter. Pets gave children unconditional affection and would listen to all their woes, anger and upset without being judgemental.

\section{Toys}

Rather like pets, toys such as 'big teddy' would also seem to listen without being critical. Children could imagine that the toys were giving unconditional positive regard. Children would also role play out their problems using dolls or other representational toys.

\section{Books}

For the lonely, isolated child, shunned by peers at school as 'odd', stories such as the 'Famous Five' provided a group of friends. Similarly, Little House on the Prairie and Little Women provided substitute families. Other books removed the child completely from reality so that the Hobbit and science fiction were popular life-lines.

\section{Drugs/alcohol}

Substance use is a recognised way of escape. It is not just the prerogative of adults. One of the interviewees recalled using them from the age of nine. Children may well use them as life-lines if they have nothing else to help them survive the pain.

\section{Eating disorders}

This can include over-eating, anorexia nervosa and bulimia. One of the interviewees who nearly died through anorexia nervosa was male. As a boy he had over eaten as a comfort as he tried to cope with his father's violence towards his mother. But later when he was in his teens and jeered by work colleagues he became anorexic.

\section{Self-harm/suicide}

People can relieve some of their emotional pain by inflicting physical pain on themselves. For some children especially in early adolescence the only way they can see of escaping their emotional anguish is through death. Two of the interviewees tried to hang themselves. The danger of suicide in emotionally abused children should not be underestimated. 


\section{Page 17}

\section{SUMMARY OF INTERVENTION}

\section{Identify and rectify abuse of power}

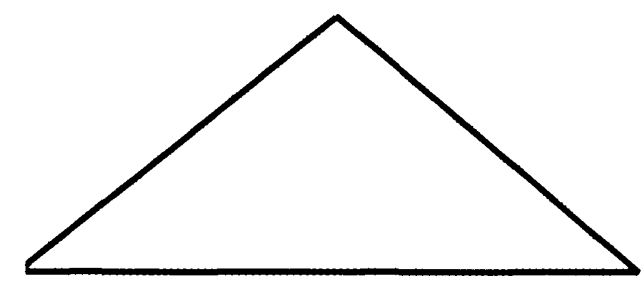

Identify and stop acts of commission

\section{Identify acts of omission and ensure child's needs met.}

\section{Steps in responding to emotional abuse}

Having established that emotional abuse is present the following steps are taken:

1. The most serious and distressing acts of commission are stopped eg if an eight year old boy is stripped naked and locked out of his house for long periods then measures have to be taken to ensure that this does not happen again,

2. Abuses of power are addressed. Some carers and children may have to be empowered while other people might be given less power over the child.

3. The child is helped to overcome the immediate aftermath of their experiences - in many cases this will mean that he or she is listened to and believed.

4. The child's needs are identified and planning undertaken to ensure that they are met. They can be met by:

i) parents - with assistance and support;

ii) supplements to parental care - eg members of the extended family, day nursery, school, friends, activities, pets.

iii) substitute carers.

5. Lesser acts of commission are stopped.

6. The child is helped to cope with past experiences, understand the present situation and develop strategies for the future - through individual play work or counselling, or through group work including work strengthening sibling relationships, if appropriate.

7. Reoccurrence of abuse is prevented by:

i) changes within the carers

ii) ensuring the child has life-lines

iii) challenging discriminatory attitudes to that child specifically and to all children generally. 
Appendices 
APPENDIX 1 - INQUIRY REPORTS INTO CHILD DEATHS

Listed by name of child who was the subject of the Inquiry.

Beckford (1985) A Child in Trust London: Borough of Brent

Bagnall (1973) Report of Working Party of Social Services Committee Inquiry into Circumstances Surrounding the Death of Graham Bagnall and the role of the County Social Services. Salop: County Council

Bagnall (1973) Report of a Committee of the Hospital Management Committee into the Circumstances Leading up to the Death of Graham Bagnall Insofar as the Hospital Authority were Concerned. Shrewsbury: Group Hospital Management Committee.

Chapman (1979) Lester Chapman Inquiry Report Berkshire County Council

Clarke (1979) The Report of the Committee of Inquiry into the Actions of the Authorities and Agencies Relating to Darryn James Clarke London: HMSO

Colwell (1976) Children at Risk: Joint Report of the County Secretary and Director of Social Services. Lewes: East Sussex County Council

Gates (1982) Report of the Inquiry into the Death of Lucy Gates. London Borough of Bexley and Bexley Health Authorities.

Henry (1987) Whose Child? The Report of the Panel Appointed to Inquire into the Death of Tyra Henry. London Borough of Lambeth.

Koseda (1986) Report of the Review Panel ... into the Death of Heidi Koseda. London Borough of Hillingdon

Menheniott (1978) Report of the Social Work Service of the DHSS into Certain Aspects of the Management of the Case of Stephen Menheniott. London: HMSO

Meurs (1975) Report of the Review Body Appointed to Enquire into the Case of Stephen Meurs. Norfolk County Council

Naseby (1973) Report of the Commission of Enquiry Set Up to Enquire into the Circumstances Surrounding the Admission Treatment and Discharge of Baby David Lee Naseby. Staffordshire Area Health Authority 
O'Neill (1945) Report by Sir William Monckton on the Circumstances Which Led to the Boarding Out of Dennis and Terence O Neill and Bank Farm Miserley. London: HMSO

Page (1981) Malcolm Page. Report of a Panel Appointed by the Essex Area Review Committee. Essex County Council and Essex Area Health Authority .

Paul (1993) Paul: Death Through Neglect. London: The Bridge Child Care Consultancy

Piazzani (1974) Report of the Joint Committee Set Up to Consider Co-ordination of Service Concerned with Non-Accidental Injury to Children. Essex County Council and Essex Area Health Authority .

Pinder (1981) Child Abuse Enquiry Sub-committee Report Concerning Christopher Pinder/Daniel Frankland. Bradford Area Review Committee

Sukina (1991) Sukina: An Evaluation Report of the Circumstances Leading to Her Death. London: The Bridge Child Care Consultancy

Woodcock (1984) Report on the Death of Shirley Woodcock. London Borough of Hammersmith and Fulham 
Identification code: $\mathrm{m}$

Interview Schedule

general family structure at time of referral:

subject $m / f$ age

mother age

mother/sub age

father age

father/sub age

sibs $1 \mathrm{~m} / \mathrm{f}$ age

$\mathrm{ab} /$ not

$2 \mathrm{~m} / \mathrm{f}$ age

$a b /$ not

$3 \mathrm{~m} / \mathrm{f}$ age

$a b /$ not

$4 \mathrm{~m} / \mathrm{f}$ age

$a b /$ not

Other relatives

Are these supportive

Is the family isolated?

general significant family details:

Income

income group: low/low middle high/high

main wage earner occupation.

class: working I:u/middle I:u/upper

housing: inadequate/adequate

status of housing: homeless/ council/ priv.rent/ own occ./ other.

state of home: dangerous/unsanitary/satisfactory/immaculate

main cultural heritage/s:

significant religious/political beliefs? 
significant health/disability factors:

learning disability

physical disability

substance abuse:

agoraphobia

mental illness

obsessiveness

other

family history of abuse:

maternal:

paternal:

significant loss/bereavement

circumstances of birth (bonding failure):

premature

difficult birth

wrong gender

other.

other possible bonding disruption

reason for referral to social services department/NSPCC: 
parental/caregiver behaviour defined as abusive in the following possible categories:

physical neglect

physical abuse

sexual abuse

emotional abuse:

COMMISSION

fear inducing/terrorising

tormenting

humiliating

isolating

active rejecting

denigrating

creation of insecurity

corrupting

inappropriate roles/responsibility

other.

\section{EXPLICIT OMISSION}

passive rejection

ignoring

absence of medic/psych t'ment

other 
indicators in child:

developmental milestones

achievements

behaviour:

home

school.

friends/rel

sub care

appearance

statements/witness of child

other.

Relationships:

family with extended family

neighbours.

friends

professionals

Subject: with parents

with siblings

with sign. others

between parents

between parents and siblings

between other siblings

others 
management of case:

support/treatment offered

removal of child temporary/permanent

Care proceedings considered / taken / granted

Significant harm evidence

Did the intervention appear to:

1) lead to marginal/considerable improvement in quality of life for child

2) maintain status quo

3) lead to marginal/considerable decrease in quality of life for child

4) cannot be measured/not known.

Any known effects of intervention on other children in household.

Other intervention that, with hind sight, would have been appropriate

Evidence of abuse of power?

Evidence of objectification of children? 


\section{Research Project into Psychological Maltreatment}

At Nene College in conjunction with the University of Leicester, we are undertaking research into the psychological maltreatment of children. We are seeking both a range of perspectives and points of view in order to find ways of ensuring that children who are emotionally abused are not left to suffer in silence and are given the best help possible.

I would be grateful if you would be willing to answer some questions on the topic. The questionnaire can be answered anonymously. Your answers will be treated as confidential. The replies to the questionnaire will only be seen by one researcher and destroyed as soon as they are collated. No identifying details such as names or addresses are required.

Please feel free to fill in as much or as little of the questionnaire as you wish. Any comments will be gratefully received. Please do not worry about whether or not the information is relevant. We are interested in all the views and experiences that you would like to share including for example emotional abuse by other children, baby-sitters or adults who were not related. Whether or not you fill in the questionnaire please could you return it to the box provided at the end of the session.

Many thanks

Celia Doyle

Senior Lecturer, Nene College

Researcher, School of Social Work, University of Leicester 
Most of the questions below can be answered by circling the answer which applies to you. Other questions ask for a short comment.

1. Please circle your gender: male / female

2. Please circle your age: Under 20 / 20-39 / 40-59 / over 60 .

3. What is your ethnic origin, please circle: British / Other European / Asian / African African Caribbean / Other, please specify....

4. Do you consider yourself to be: Black / White / Other (please circle)

5. Who was responsible for looking after you during your childhood? Please circle (If you had a change of carers please indicate your age for example 'Both parents from birth to 5 . Foster carers 5 to 7 . Mother only 8 to 18')

Both parents

Foster carers

Mother only

Father only

Mother and stepfather

Father and stepmother.

Other relatives, please specify

Residential care (eg children's home), please indicate type.

Other carers, please specify who

6. Were you adopted? YES/NO, if yes from what age

7. In your family were you?:

the only child / eldest child / a middle child / youngest child

8. If not the only child, how many: brothers did you have?

sisters did you have?....

9. Did you have any brothers or sisters die as babies or children, include any miscarriages if known? YES/NO If yes please give details

10. Who else lived in your household?

11. What was the employment, if any, of your parents or main carers, please give more than one if appropriate

12. How often during your childhood were your carers short of money for essentials:

always / sometimes / never. 
13. During your childhood did any of your carers have:
an alcohol abuse problem? YES/NO. If yes, who?
a drug addiction problem? YES/NO. If yes, who?
a gambling compulsion? YES/NO. If yes, who?

14. During your childhood did you or anyone with whom you lived:

require help with a learning disability? YES/NO. If yes, who?

require help with a physical disability? YES/NO. If yes, who?

require help with mental health problems? YES/NO. If yes, who?

15. During your childhood did your carers have any housing or accommodation problems? YES/NO If yes, please give brief details

16. As a child do you recall physical conditions in the home as mostly: comfortable / uncomfortable.

17 If physical conditions were uncomfortable was it because conditions were too messy / too immaculate / other, please specify.

18. Do you remember your childhood as mostly: Happy / unhappy

19. Do you think that you were physically abused? YES/NO. If yes, please give brief details

20. Do you think that you were physically neglected? YES/NO. If yes, please give brief details

21. Do you think that you were sexually abused? YES/NO. If yes, please give brief details

22. Do you think that you were emotionally abused? YES/NO. If yes, please give brief details 
23. Which, if any of these things happened to you? Please tick appropriate box/es.

Made to feel frightened because of threats
Made fearful due to witnessing violence
Made upset by relentless teasing
Publicly humiliated
Having my achievements derided

Locked away for what seemed long periods [ ]

Made to feel no-one cared for me [ ]

Made to feel unlovable [ ]

Made to feel not good enough [ ]

Made to feel insecure [ ]

Burdened with too many responsibilities [ ]

Not allowed any real independence [ ]

Forced to commit crimes [ ]

Unfairly blamed for things [ ]

Not shown any affection [ ]

Made to feel completely unimportant [ ]

Made to feel I did not exist [ ]

Having my achievements ignored [ ]

Verbally abused. (Please give examples below) [ ] 
If you ticked any of the boxes in question 23 please answer questions 24 to 34 . If not please turn straight to question 35.

24. Who do you consider was most responsible for your mistreatment?

25. Do you consider that anyone else was also responsible for your mistreatment? YES/NO. If yes, please indicate who.

26. How old can you remember being when it first started?

27. How old were you when it stopped?

28. Was anyone else in your family mistreated? YES/NO, If yes please give brief details

29. Did you try to tell anyone? YES/NO. If yes what happened?

30. Was any help given to you? YES/NO. If yes please could you give brief details.

31. Did the help given make the situation better for you? YES/NO

32. Was there any other help that you would have liked to have had?.

33. If you answered 'NO' to question 29 , what do you think might have helped?

34. If you wish to add any other details about your treatment please feel free to write below and overleaf.....

35. Which of these phrases describes how you feel your experiences in childhood have affected you in later life?

Please tick only one

No effect [ ]

Damaging at the time but no medium or long term effect [ ]

Damaging for a long time but not permanently damaging [ ]

NOTE

Permanently damaging [ ]

Thank you for answering these questions.

Whether or not you can recall being abused, answering these questions may have woken poignant memories. If you need to talk about these then please remember that the College student counselling service is available. 
(Additional end sheet for mature students)

\section{PART 2}

Whether or not you can recall being abused, answering the questions may have woken poignant memories. If you need to talk about these then please remember that the College student counselling service is available.

One of the purposes of the research project is to give those people who suffered emotional abuse a voice. They are some of the best people to ensure that appropriate help is given to children who are being emotionally abused.

If you feel that - although you were not significantly physically or sexually mistreated - you were emotionally abused and would be willing to be interviewed then please could you fill in a name/nickname and telephone number by which you can be contacted.

The interviews will be either over the telephone or face-to-face, depending partly on your own preference and partly on the practicalities and resources available.

Please note that no identifying details will be published. Individuals names and numbers will not be passed on to anyone else. I will be the only person to have your name and number if volunteered and I will dispose of them as soon as I have made contact and interviewed you. Once I have made contact with you, your name will not be linked to the details given.

Name/nickname

Telephone number (including STD code)

Many thanks for your help 


\section{PRACTICE GUIDE EVALUATION.}

In order to determine whether or not the concept of a Practice Guide, as detailed in the Post Script, would be a welcome and useful tool for practitioners dealing with emotional abuse cases, an small scale evaluation was undertaken.

\section{Procedure}

The Practice Guide was given to teams in two participating local authorities. Their directors and other senior managers had agreed to original involvement in the interview stage of the research and had also agreed to being involved in further activities. The two were chosen on the basis that they were the two areas with the largest populations and proportionally the greatest number of children on the register in the emotional abuse category. It was therefore likely that within the given time scale of four months each team would deal with at least one case, or would have recently handled an appropriate case.

There were three teams in each local authority. In the first authority there were only three teams and so each was given a practice guide. In the second authority there has been a recent reorganisation from four to eight teams. Several of these teams were encountering difficulties such as the loss or long term sickness of key staff members. This meant that the three teams with the fewest problems were asked to participate.

Once the agreement of the team had been obtained, the team leader or child protection specialist, whichever was appropriate as advised by the team, was given the Practice Guide and a questionnaire to fill in and return. They were asked to use it with a current case or, if there was no appropriate case, then to reflect on its usefulness had they had it at the time of their involvement in a recent case. All respondents replied anonymously although they were asked to indicate which local authority. This was to ensure account was taken of the limitations of the study in the event of not all the teams replying and only one local authority being represented in the final analysis. In the event this was an unnecessary precaution because all the teams returned the questionnaires. 


\section{Results}

In only one team was the evaluation used retrospectively. In three cases it was used in assessing a new case and two recorded it was very helpful with the third person recording quite helpful. Two teams also used it in planning a new case and four teams also used it in forward planning for an ongoing case. These all recorded that the guide was quite helpful. None, at any stage, found it either a mixed blessing or unhelpful

The rest of the response to the questionnaires was analysed using a scoring system for each section and looking at the comments for a more general overview.

The usefulness of each section. The scores for each section are illustrated in the table below.

The four grades were allocated the following scores

Very helpful $=4$

Quite helpful =3

Mixed blessing $=2$

Not helpful $=1$

Each section therefore could attract a maximum of 24 points. A score in the 20 s would indicate the section was very helpful. A score of around 18 would indicate a quite helpful section. A score around 12 would be a mixed blessing and one around 6 points would not be a helpful section. Table 38 below illustrates the results. 
Table 38. Practitioners' evaluation of sections of Practice Guide

\begin{tabular}{||l|l||}
\hline The definition & 23 \\
\hline Power issues & 23 \\
\hline Examining issues of power & 22 \\
\hline Cultural aspects & 21 \\
\hline Determining presence of emotional abuse & 22 \\
\hline Registration & 19 \\
\hline Communicating concerns & 21 \\
\hline Meeting children's needs & 17 \\
\hline Providing assistance & 19 \\
\hline Life-lines for children & 23 \\
\hline Summary of intervention & 22 \\
\hline
\end{tabular}

The respondents were asked to identify the most and least helpful sections. Two respondents mentioned more that one most helpful section. Three respondents cited the discussion about the power issues 'It was great to clearly look at parent's power bases'. Two cited the section on lifelines. The other sections cited once were the definition, issue of intent, cultural aspects, communicating concerns and determining the presence of emotional abuse. Only one respondent identified a least helpful section, this was 'Meeting children's needs'.

In response to the questions about the guide being 'user friendly' and 'clearly written', all were positive with comments such as it clearly outlined all the issues and then neatly summarised them' 'Well spaced and in short sections which kept attention'.One respondent did however ask that the headings be made clearer.

Respondents were asked if any of the terminology was, in their opinion, discriminatory. Five thought there was no discriminatory terminology. The sixth felt that the phrase 'stable family unit' in the section on children's needs could be discriminatory because there were many different forms of child care which did not exist under the category 'family unit'. 
Respondents were asked if they had suggestions for improvement. There were three respondents who made suggestions. One would have liked to see the providing assistance section extended with more ideas for direct work with children and adults. Another two suggested more on recognition and the signs of emotional abuse.

Finally the teams were asked if, given the incorporation of the improvements they had suggested, they would use it again. They all said yes and five respondents added comments. These were:

* A guide such as this is a long overdue addition to the child protection 'tool kit'.

* We will certainly use the guide if we have future cases

* Yes, really helpful in analysing and presenting a care for emotional abuse.

* Yes definitely - great to have a practice guide that moves away from just the Assessment model and also helps to consider treatment and more importantly ways of evaluating what has been done.

* Found guide a very useful tool.

\section{OVERVIEW}

Practitioners were asked to evaluate whether or not the Practice Guide was a useful way forward. The evaluation at this stage was on a very small scale. It represents the completion of the central objective of the present project which is the enhancement of knowledge to facilitate intervention. But it also represents the beginning of a process of applying the understanding which could be developed on a larger scale beyond the scope of the present project.

The Practice Guide overall had a positive response although there are areas, particularly the section on children's needs and the appendices, which could usefully be revised. But the limitations of the evaluation are acknowledged. The scale is too small for complete credibility to be attached to the results. It would also have been preferable for all the teams to have used the guide in conjunction with several current cases over a longer time period. However, the production of a definitive, exhaustive and perfected guide was not the objective of the present research. Instead it was to gather information to indicate possible ways of intervening effectively. The Practice Guide is one tangible suggestion which given the positive evaluations may be worth pursuing as one way forward. However, this is not the only possible response to emotional abuse. 


\section{Emotional of Children}

\section{Evaluation of Practice Guide}

For which local authority or agency do you work?

Please tick or circle your choice of answer as appropriate. Please also feel free to add any comments about the usefulness of the practice guide.

1. In which circumstances did you use the practice guide?

(If you used it with more than one case or at several stages of the same case please tick as many responses as is appropriate)

* To assist in the assessment of a new case.

* To help with the planning of a new case.

* To help in the forward planning of an ongoing case.

* To evaluate a case in helping to decide on closure.

* Retrospectively to evaluate intervention in a 'closed' case.

2. How helpful did you find it in the following circumstances?

Please circle the appropriate ' $x$ '

\begin{tabular}{|c|c|c|c|}
\hline $\begin{array}{l}\text { Very } \\
\text { helpful }\end{array}$ & $\begin{array}{l}\text { Quite } \\
\text { helpful }\end{array}$ & $\begin{array}{l}\text { 'Mixed } \\
\text { blessing' }\end{array}$ & $\begin{array}{c}\text { Not } \\
\text { helpful }\end{array}$ \\
\hline
\end{tabular}

$\begin{array}{lccccc}\text { * Assessment of new case } & \mathrm{x} & \mathrm{x} & \mathrm{x} & \mathrm{x} & \mathrm{x} \\ \text { * Planning new case } & \mathrm{x} & \mathrm{x} & \mathrm{x} & \mathrm{x} & \mathrm{x} \\ \text { * Forward planning } & \mathrm{x} & \mathrm{x} & \mathrm{x} & \mathrm{x} & \mathrm{x} \\ \text { * Evaluation pre-closure } & \mathrm{x} & \mathrm{x} & \mathrm{x} & \mathrm{x} & \mathrm{x} \\ \text { * Retrospective evaluation } & \mathrm{x} & \mathrm{x} & \mathrm{x} & \mathrm{x} & \mathrm{x}\end{array}$




\section{How helpful did you find the following sections?}

If you had more than one case different sections may have been more or less helpful depending on the case so please feel free to circle more than one ' $x$ ' per question.

\begin{tabular}{|c|c|c|c|}
\hline $\begin{array}{l}\text { Very } \\
\text { helpful }\end{array}$ & $\begin{array}{l}\text { Quite } \\
\text { helpful }\end{array}$ & $\begin{array}{l}\text { 'Mixed } \\
\text { blessing' }\end{array}$ & $\begin{array}{l}\text { Not } \\
\text { helpful }\end{array}$ \\
\hline
\end{tabular}

* The 'Definition'

$x$

\section{$x$}

$\mathrm{X}$

* Power Issues

* Examining Issues of Power

* Cultural Aspects

* Determining Presence

* Registration

* Communicating Concerns

* Meeting Children's Needs

* Providing Assistance

* Life Lines for Children

* Summary of Intervention $x$

$x$

$x$

$x$

$x$

$x$

$x$

$x$

$x$ $x$

X

x

$x$

$x$

$x$

$x$

$x$

$x$

$x$

$x$

X

$x$

$x$

$x$

$x$

$x$

$x$

x

$x$

\section{X}

X

$x$

$x$ $x$

X

X

$x$

$x$

$x$

$x$

$x$

$x$

$x$

$x$

4a. Overall which section did you find most helpful?

4b Overall which section did you find least helpful?

4c. Do you have any suggestions for improving this section? 


\section{General Observations}

Please circle 'yes' or 'no' as appropriate and any other comments you wish to add

5. Did you find the guide 'user friendly'. ie relatively easy to understand and use? YES / NO

Comment

6. Did you find that the guide was clearly written?

YES / NO

Comment

7. Was any of the terminology used, in your opinion, discriminatory?

YES / NO

Please specify

8. Have you any other suggestions for improving the guide?

YES / NO

If yes please specify

9. Given that any suggestions for improvement are incorporated, would you be willing to use the guide again in the future?

YES / NO

Comment.

10. Do you have any other comments?

YES / NO

If yes please add comments below and, if necessary, overleaf.

Thank you very much indeed for completing the questionnaire.

Please could you return it to: 


\section{Appendix 5}

\section{Discriminant Function Analysis: Supplementary Information.}

In this study discriminant function analysis was used as an exploratory tool to identify potentially useful variables in NA and EA group separation. A stepwise entry was used. This section provides further details of the results of the stepwise entry of the four identified variables. The method chosen for the entry was Mahanobis distance. In this, the variable with the largest $\mathrm{D}^{2}$ is selected for entry in the next step. Therefore, details of both the $\mathrm{F}$ and $\mathrm{D}^{2}$ values are given.

\section{At the outset:}

Minimum tolerance level $=0.001$ [at no stage did the tolerance level of any of the variables fall below this].

Minimum $\mathrm{F}$ to enter $=3.84$

Maximum $F$ to remove $=2.71$

\section{Variable labels:}

$\mathrm{FAM}=$ family size

$\mathrm{NUMCH}=$ number of caregiver changes

PERSON $=$ number of personal and interpersonal stressors

$\mathrm{SED}=$ social economic deprivation score.

Variables not in analysis after Step 0:

$\begin{array}{lll} & \text { F to enter } & \mathrm{D}^{2} \\ \text { FAM } & 10.38 & 0.305 \\ \text { NUMCH } & 28.68 & 0.843 \\ \text { PERSON } & 34.07 & 1.001 \\ \text { SED } & \mathbf{3 4 . 1 2} & \mathbf{1 . 0 0 3}\end{array}$

Variable in analysis after Step 1:

SED

$$
\mathrm{F}=34.12
$$

Variables not in analysis after Step 1:

$\begin{array}{lcl} & \text { F to enter } & \mathrm{D}^{2} \\ \text { FAM } & 1.22 & 1.047 \\ \text { NUMCH } & 12.87 & 1.474 \\ \text { PERSON } & \mathbf{1 7 . 6 4} & \mathbf{1 . 6 4 9}\end{array}$




\section{Appendix 5}

Variable in analysis after Step 2:

$\begin{array}{lll}\text { PERSON } & F=17.64 & D^{2}=1002 \\ \text { SED } & F=17.69 & D^{2}=1001\end{array}$

Variables not in analysis after Step 2:

$\begin{array}{lcl} & \text { F to enter } & D^{2} \\ \text { FAM } & 0.93 & 1.652 \\ \text { NUMCH } & \mathbf{6 . 3 4} & \mathbf{1 . 9 1 1}\end{array}$

Variable in analysis after Step 3:

$\begin{array}{lll}\text { NUMCH } & F=6.34 & D^{2}=1.65 \\ \text { PERSON } & F=10.87 & D^{2}=1.47 \\ \text { SED } & F=11.61 & D^{2}=1.45\end{array}$

Variables not in analysis after Step 3:

$\begin{array}{ccl} & \text { F to enter } & \mathrm{D}^{2} \\ \text { FAM } & 0.003 & 1.911\end{array}$

The F level of FAM was below 3.84 therefore insufficient for further computation.

Table 39. Discriminant function analysis: summary table

\begin{tabular}{llllll} 
Variable & $\begin{array}{l}\text { Wilks' } \\
\text { Lambda }\end{array}$ & Significance & $\begin{array}{l}\text { Minimum } \\
\mathbf{D}^{2}\end{array}$ & Significance & $\begin{array}{l}\text { Discr. funct'n } \\
\text { coefficients }\end{array}$ \\
\hline \multirow{2}{*}{ SED } & .808 & $\mathrm{p}<0.0001$ & 1.003 & $\mathrm{p}<0.0001$ & .5144 \\
PERSON & .720 & $\mathrm{p}<0.0001$ & 1.649 & $\mathrm{p}<0.0001$ & .5042 \\
NUMCH & .689 & $\mathrm{p}<0.0001$ & 1.911 & $\mathrm{p}<0.0001$ & .3959 \\
\hline
\end{tabular}




\section{Comment}

Although the sequence in which variables are selected for entry is not necessarily the same as their relative importance of discriminators, it can be seen from the stepwise entry and the discriminant function coefficients of the remaining variables that SED

contributes most to the discriminating power of the function but PERSON follows this closely so that both socio-economic factors and interpersonal stressors play an important role in distinguishing emotionally abusive families and those who are not. The number of caregiver changes is a less powerful but nevertheless useful variable. Family size, in conjunction with the other three variables, has little power to discriminate. 
Referemees 


\section{REFERENCES}

Abel, G. G., Becker, J. V., Mittleman, M. (1987) 'Self-reported sex crimes of nonincarcerated paraphiliacs'. Journal of Interpersonal Violence 2 (1) pp3-25

Adcock, M., White, R. and Hollows, A. (1991) Significant Harm. London: Significant Publications

Adorno, T. W., Frenkel-Brunswik, E., Levinson, D. and Sanford, R. N. (1950) The Authoritarian Personality. New York: Harper Row.

Agathonos-Georgopoulou, H. (1992) 'Cross-cultural perspectives'. Child Abuse Review 1 (2) pp. $80-88$.

Ahmad, B. (1989) 'Protecting Black children from abuse' Social Work Today 8 June p.24.

Ahmad, B. (1990) Black Perspectives in Social Work. Birmingham: Venture Press.

Ahmed, W. I. U. and Sheldon, T. A. (1993) '"Race" and statistics' in M. Hammersley (ed) Social Research: Philosophy, Politics and Practice. London: Sage

Ainsworth, M. and Wittig, A. (1969) 'Attachments and exploratory behaviour of one-year-olds in a strange situation' in Foss, B. M. (ed) Determinants of Infant Behaviour Vol 4 London: Methuen.

Alaszewski, A. and Manthorpe, J. (1993) 'Quality and the Welfare Services: a literature review'. British Journal of Social Work 23 (6) pp.653-665

Alcock, P. (1993) Understanding Poverty London: Macmillan.

Allport, G. (1951) The Use of Personal Documents in Psychological Science. Bulletin 49. New York: Social Science Research Council (cited in Smith, J. 1993 'The case study' in Bayne, R and Nicolson, P eds Counselling and Psychology for Health Professionals. London: Chapman and Hall.) 
Anderson, E. W. and Trethowan, W. H. (1967) Psychiatry 2nd edition London: Baillere Tindall and Cassell.

Angelou, M. (1984) I Know Why the Caged Bird Sings. London: Virago

Anthony, E. J. and Cohler, B. J. (eds) (1987) The Invulnerable Child. New York: Guildford Press

Aries, P. (1962) Centuries of Childhood (translator R Baldick). London: Jonathan Cape

Arlin, P. K. (1975) 'Cognitive development in adulthood: a fifth stage?' Developmental Psychology: 11 pp. 602-606.

Ayoub, C. C. and Milner, J. S. (1985) 'Failure to thrive: parental indicators, types and outcomes' Child Abuse and Neglect 9 (4) pp.491-500.

Baily, T. F. and Baily, W. H. (1986) Operational Definitions of Child Emotional maltreatment: Final Report. Washington, D C, National Centre on Child Abuse and Neglect: US Government Printing Office.

Baine, O. and Sanders, M. (1990) Out in the Open: A Guide for Young People Who Have Been Sexually Abused. London: Virago.

Baker, A. W. and Duncan, S. P. (1985) 'Child sexual abuse: a study of prevalence in Great Britain'. Child Abuse and Neglect.9 (4) pp.457-468.

Baltes, P. B., Reese, H. W., Hayne, W. and Lipsitt, L. P. (1980) 'Life span developmental psychology' Annual Review of Psychology 31 pp. $65-110$.

Bandura, A. (1965) 'Influence of model's reinforcement contingencies on the acquisition of imitative responses.' Journal of Personality and Social Psychology 1 pp. 589-95.

Bandura, A. (1973) Aggression: A Social Learning Theory. Englewood Cliffs, NJ: Prentice Hall. 
Banister, P., Burman, E., Parker, I., Taylor, M. and Tindall, C. (1994) Qualitative Methods in Psychology. Buckingham: Oxford University Press.

Banks, N. (1992) 'Mixed-up kid’. Social Work Today. 10 September 1992 pp. 12-13.

Bannister, A. (1992) 'Set up for abuse'. Community Care. 17/24 December 1992

Barclay, P. M. (1982) Social Workers Their Role and Tasks. London: NISW/Bedford Square Press.

Bass, E. and Davis, L. (1990) The Courage to Heal. London: Cedar

Bastian, P. (1994) 'Great Britain: family care in the United Kingdom' in M. Gottesman (ed). Recent Changes and New Trends in Extrafamilial Child Care: An International Perspective London: Whiting \& Birch/FICE. pp. 68-77

Batchelor, J. and Kerslake, A. (1990) Failure to Find Failure to Thrive. London: Whiting and Birch

Bates, R. P. (1980) 'Child abuse and neglect: a medical priority' in Volpe, R., Breton, M. and Mitton, J. (eds) The Maltreatment of the School-Aged Child Lexington Massachusetts: Lexington Books.

Baumrind, D. (1991) 'To nurture nature' Behavioural and Brain Sciences. 14 p.386.

Behlmer, G. K. (1982) Child Abuse and Moral Reform in England 1870-1908. Stanford CA. Stanford University Press.

Bell, S. (1988) When Salem Came to the Boro. London: Pan

Bell, S. (1990) Shaw's Annotated Acts: The Children Act 1989. Crayford: Shaw and Sons.

Belsky, J. (1980) 'Child maltreatment: an ecological intergration' American Psychologist. 35 pp. 83-96. 
Ben (1991) Things in My Head Dublin: Blendale Publishing

Benedict, R. (1955) 'Continuities and discontinuities in cultural conditioning - 1938' in M. Mead and M. Wolfenstein (eds) Childhood in Contemporary Cultures. Chicago: University of Chicago Press.

Beresford, P., Kemmis, J. and Tunstill, J. (1987) In Care in North Battersea. London: North Battersea Research Group.

Bergen, R. K. (1993) 'Interviewing survivors of marital rape: doing feminist research on sensitive topics' in C. M. Renzetti and R. M. Lee (eds) Researching Sensitive Topics. Newbury Park, CA: Sage.

Berkshire County Council (1979) Lester Chapman Inquiry Report. Berkshire:BCC

Berliner, L. (1991) 'Treating the effects of sexual assault' in K. Murray and D. A. Gough (eds) Intervening in Child Sexual Abuse. Edinburgh: Scottish Academic Press.

Berridge, D. and Cleaver, H. (1987) Foster Home Breakdown. Oxford: Blackwell.

Besharov, D. J. (1981) 'Toward better research on child abuse and neglect: making definitional issues an explicit methodological concern' Child Abuse and Neglect 5 pp.383-390.

Bettleheim, B. (1967) The Empty Fortress: Infantile Autism and the Birth of Self. New York: Free Press.

Bloch, D. (1979) "So The Witch Won't Eat Me": Fantasy and the Child's Fear of Infanticide. London: Burnett Books.

Bolton, F. G. Jr., Morris, L. A. and MacEachron, A. E. (1989) Males At Risk: The Other Side of Child Sexual Abuse. Newbury Park: Sage.

Boswell, J. (1989) The Kindness of Strangers: the Abandonment of Children in Western Europe from Late Antiquity to the Renaissance. Harmondsworth: Penguin. 
Bottomore, T. (1991) Classes in Modern Society (2nd edition) London: Routledge.

Bottoms, B. L., Shaver, P. R., Goodman, G. S. and Qin, J. (1995) 'In the name of God: a profile of religion-related child abuse'. Journal of Social Issues 51 (2) pp. 85-111.

Bourton, A. (1991) 'No intention to abuse - recognising emotional abuse'. Journal of Law and Practice. 2 (1) pp.45-50.

Bourton, A.. and Burnham, L. (1992) 'Looking for clues’. Social Work Today 23 (40) pp. 16-17.

Bowlby, J. (1951) Maternal Care and Mental Health. Geneva: World Health Organisation

Bowlby, J. with Ainsworth, M. (1965) Child Care and the Growth of Love 2nd edition Harmondsworth: Penguin.

Boyden, J. (1990) 'Childhood and the policy makers: a comparative perspective on the globalization of childhood' in A. James and A. Prout (eds). Constructing and Reconstructing Childhood. London: The Falmer Press.

Brandon, M. and Lewis, A. (1996) 'Significant harm and children's experiences of domestic violence'. Child and Family Social Work. 1 (1) pp. 33-42.

Brannen, J (ed) (1992) Mixing Quantitative and Qualitative Research. London: A Brigower.

Brassard, M. R. and Gelardo, M. S. (1987) 'Psychological maltreatment: the unifying construct in child abuse and neglect'. School Psychology Review 16 (20) pp. 127-136

Brassard, M., Germain, R. and Hart, S (eds) (1987) Psychological Maltreatment of Children and Youth New York: Pergamon Press.

Bridge Child Care Consultancy (1991) Sukina: An Evaluation Report of the Circumstances Leading to Her Death. London:The Bridge Child Care Consultancy 
Bridge Child Care Consultancy (1993) Paul: Death Through Neglect. London:The Bridge Child Care Consultancy.

Briggs, F. and Hawkins, R. M. F. (1994) 'Choosing between child protection programmes'. Child Abuse Review 3 (4) pp 272-283.

Bronfenbrenner, U. (1979) The Ecology of Human Development: Experiments by Nature and Design. Cambridge, Mass.: Harvard University Press

Brougham, S. (1996) 'The Professional Response to Cases of Emotional Abuse'. Unpublished MA Dissertation. School of Social Work, University of Leicester.

Browne, K and Saqi, S. (1988) 'Approaches for screening for child abuse and neglect' in Browne, K., Davies, C and Stratton, P (eds). Early Prediction and Prevention of Child Abuse. Chichester: Wiley.

Browne, K. D. and Lynch, M. A. (1995) 'Child abuse and its modes of transmission.' Child Abuse Review 4 (1) pp. 1-3

Bryman, A and Burgess, R. G. (1994) 'Reflections on qualitative data analysis' in Bryman, A and Burgess, R. G (eds). Analyzing Qualitative Data. London: Routledge

Bullock, R., Little, M and Millham, S. (1992) 'The relationship betweem quantitative and qualitative approaches in social policy research' in Brannen, $\mathrm{J}$ (ed) Mixing Quantitative and Qualitative Research. London: A. Brigower.

Burnett, B. B. (1993) 'The psychological abuse of latency age children: a survey'. Child Abuse and Neglect, 17 (4) pp. 441-454.

Burns, T and Stalker, G. M. (1966) The Management of Innovation. London: Tavistock

Buss, A. H. and Plomin, R. (1984) Temperament: Early Developing Personality Traits. Hillsdale, New Jersey: Lawrence Erlbaum. 
Butler-Sloss, E. (1988) Report of the Inquiry into Child Abuse in Cleveland 1987. London: HMSO

Cameronchild, J. (1978) 'An autobiography of violence'. Child Abuse and Neglect 2 pp. 139-49.

Campbell, B. (1988) Unofficial Secrets London: Virago

Carter, J. (1983) Families Without Hope: Emotional Abuse and State Intervention Western Australia: Department for Community Welfare.

Cashmore, E. E. (1988) Dictionary of Race and Ethnic Relations London: Routledge

Cassam, E. and Gupta, H. (1992) Quality Assurance for Social Care Agencies - A Practical Guide. Harlow: Longman

CCETSW (1989) Rules and Requirements for the Diploma in Social Work. Paper 30. London: Central Council for Education and Training in Social Work

CCETSW (1992) The Requirements for Post-Qualifying Education and Training. Paper 31. Revised edition. London: Central Council for Education and Training in Social Work

CCETSW (1995) Rules and Requirements for the Diploma in Social Work. Paper 30. Revised edition. Working copy. London: Central Council for Education and Training in Social Work

Cerezo, M. A. and D'Ocon, A. (1995) 'Maternal inconsistent socialization: an interactional pattern with maltreated children'. Child Abuse Review 4 (1) pp 14-31

Chan, P. (1996) 'Pride of place'. Community Care (1104) 1-7 February p.27

Channer, Y. and Parton, N. (1990) 'Racism, cultural relativism and child abuse' in Violence Against Children Study Group. Taking Child Abuse Seriously. London: Unwin Hyman

Chasnoff, I. J., Burns, W. J and Schnoll, S. N. (1986) 'Maternal neo-natal incest'. American Journal of Orthopsychiatry. 4 pp.577-580. 
Cheetham, J. (1994) 'The social work research centre at the University of Stirling: a profile'. Research on Social Work Practice 4 (1) pp.89-100.

Cheetham, J., Fuller, R., McIvor, G. and Petch, A. (1992) Evaluating Social Work Effectiveness. Buckingham: Open University Press

Chess, S. and Thomas, A. (1982) 'Infant bonding: mystique and reality'. American Journal of Orthopsychiatry. 52 pp. 213-221

Chibucos, T. and Kail, P. (1981) 'Longitudinal examination of father-infant interaction and infant-father interaction'. Merrill Palmer Quarterly 27 pp. 81-96.

Children's Legal Centre (1988) 'August 15 1987: When the beating has to stop'. Childright 30 pp.11-14.

Children's Society (1995) Couldn't Care More. A Study of Young Carers and Their Needs London: The Children's Society.

Claussen, A. H. and Crittenden, P. M. (1991) 'Physical and psychological abuse: relations among types of maltreatment' Child Abuse and Neglect 15 pp. 5-18

Cleaver, H. and Freeman, P. (1995) Parental Perspectives in Cases of Suspected Child Abuse. London: HMSO

Clyde, J. J. (1992) The Report of the Inquiry into the Removal of Children from Orkney in February 1991. Edinburgh: HMSO

Colby, A., Kohlberg, L., Gibbs, J and Lieberman, M. (1983) 'A longitudinal survey of moral development'. Monographs of the Society for Research in Child Development $\mathbf{4 8}$

Cole, P. (1986) 'Children's spontaneous control of facial expression'. Child Development $57 \mathrm{pp}$. $1309-21$ 
Cook, D. A. (1991) 'College students from emotionally neglectful homes' New Directions for Student Services. $\mathbf{5 4}$ pp.77-90

Coohey, C. (1996) 'Child maltreatment: testing the social isolation hypothesis'. Child Abuse and Neglect 20 (3) pp 241-254

Coolican, H. (1994) Research Methods and Statistics in Psychology. (2nd edition) London: Hodder and Stoughton.

Cooper, C. (1985) 'Good-enough, border-line and bad-enough parenting' in M, Adcock and R, White (eds). Good Enough Parenting. London: BAAF

Corby, B. (1987) Working With Child Abuse. Milton Keynes: Open University Press

Corby, B. (1992) 'Alternative theory bases in child protection' in Stainton Rogers, W., Hevey, D., Roche, J. and Ash E. (eds). Child Abuse and Neglect: Facing the Challenge (2nd edition) London/ Milton Keynes: Batsford/Open University

Corby, B (1996) 'Risk assessment in child protection work' in Kemshall, H and Pritchard, J (eds) Good Practice in Risk Assessment and Risk Management. London: Jessica Kingsley.

Cornford, F. M. translator (1941) The Republic of Plato. Oxford: Clarendon Press

Coulshed, V. (1990) 'Submit and survive’ Social Work Today.15 March 1992 pp.22-23.

Coulson, M. (1995) 'Models of memory development' in Lee, M and Das Gupta, P (eds) Children's Cognitive and Language Development. Oxford: Blackwell.

Coulton, C. J., Korbin, J. E., Su, M. and Chow, J. (1995) 'Community level factors and child maltreatment rates'. Child Development 66 pp, 1262-1276.

Covitz, J. (1986) Emotional Child Abuse: The Family Curse. Boston: Sigo 
Craft, A. and Brown, H. (1989) 'Postscript' in Brown, H. and Craft, A (eds) Thinking the Unthinkable: Papers on Sexual Abuse and People with Learning Difficulties. London: FPA Education Unit.

Creighton, S. J. (1980) Child Victims of Physical Abuse 1976. NSPCC: London

Creighton, S. J. (1984) Trends in Child Abuse. NSPCC: London

Creighton, S. J. (1992) Child Abuse Trends in England and Wales 1988-1990. NSPCC: London

Creighton, S. J. (1993) 'Children's homicide: an exchange'. British Journal of Social Work 23 (6) pp. 643-644.

Creighton, S. J. and Noyes, P. (1989) Child Abuse Trends in England and Wales 1983-1987 NSPCC: London

Creighton, S. and Owtram, P. (1977) Child Victims of Physical Abuse NSPCC: London

Creighton, S. J. and Russell, N. (1995) Voices from Childhood. London: NSPCC

Crittenden, P. M. (1992) 'Children's strategies for coping with adverse home environments. An interpretation using attachment theory'. Child Abuse and Neglect 16 (3) pp 329-344.

Curtis, M. (1946) Report of the Committee on the care of Children Cmnd. 6922 London: HMSO

Darwin, A. (1872) The Expression of the Emotions in Man and Animals London: Murray (cited in Harris, P. L. 1989 Children and Emotion Oxford: Blackwell)

Dasen, P. R. (1977) Piagetian Psychology: Cross-Cultural Contributions. New York: Gardener Press

Davis, A. R. (ed.) (1962) The Penguin Book of Chinese Verse (translators R. Kotewall and N. L. Smith). Harmondsworth: Penguin 
Davis, P. (1996) 'Threats of corporal punishment as verbal aggression: a naturalistic study'. Child Abuse and Neglect 20 (4) pp 289-304

Dawkins, R. (1976) The Selfish Gene. Oxford: Oxford University Press

Dawood, N. J. (translator) (1990) The Koran. Harmondsworth: Penguin

De Chateau, P. (1987) 'Parent-infant socialization in several Western European countries' in Osofsky, J. D. (ed). The Handbook of Infant Development (2nd edition). New York: Wiley

de Mause, L. (1976) 'The evolution of childhood' in de Mause, L. (ed) The History of Childhood: The evolution of Parent-Child relationships as a Factor in History. London: Souvenir Press

de Younge, M. (1981) The Sexual Victimization of Children. Jefferson, N.C: McFarland \& Co. Inc.

Dean, D. (1979) 'Emotional abuse of children' Children Today 8 (4) pp. 18-20.

Dearden, C. and Becker, S. (1995) The National Directory of Young Carers Projects and Initiatives. Loughborough: University of Loughborough, Young Carers Research Group.

Dearing, R. (1996) Review of 16-19 Qualifications. Interim Report. London: Department for Education and Employment.

Denham, A. (1981) Malcolm Page. Essex: Essex County Council

Department of Health (1988) Protecting Children. London: HMSO

Department of Health (1991) Working with Child Sexual Abuse.. London: HMSO

Department of Health (1992) Choosing with Care. London: HMSO

Department of Health (1995a) Health and Personal Social Services Statistics for England 1995 edition. London: HMSO 
Department of Health (1995b) Messages From the Research. London: HMSO

Department of Health (1995c) The Challenge of Partnership in Child Protection. London: HMSO

Department of Health and Social Security (DHSS) (1972) The 'Battered Baby' Syndrome: An Analysis of Reports Submitted by Medical Officers of Health and Children's Officers. London:DHSS.

Department of Health and Social Security (DHSS) (1980) Child Abuse: Central Register Systems. LASSL (80) 4, HN (80) 20.

Dey, I. (1993) Quantitive Data Analysis. London: Routledge

Dillman, D. A., Gallegos, J and Frey, J. H. (1976) 'Reducing refusal rates for telephone interviews'. Public Opinion Quarterly. 40 pp. 66-78

Dingwall, R. (1989) 'Some problems about predicting child abuse and neglect' in Stevenson, O (ed) Child Abuse: Public Policy and Professional Practice. Hemel Hempstead: Harvester Wheatsheaf.

Dingwall, R., Eekelaar, J and Murray, T. (1983) The Protection of Children: State Intervention and Family Life. Oxford: Blackwell

Dobson, R. (1996) 'Lone parents: The prying game’ Community Care. 5th June (1122) p.12-13.

Dolto, F. (1955) 'French and American children as seen by a French child analyst' in Mead, M. and Wolfenstein, M. (eds) Childhood in Contemporary Cultures. Chicago: University of Chicago Press.

Dominelli, L. (1988) Anti-Racist Social Work. London: Macmillan.

Dominy, N. and Radford, L. (1996) Domestic Violence in Surrey: Developing an Effective InterAgency Response. London: Roehampton Institute. 
Donaldson, M. (1978) Children's Minds. London: Fontana/Collins.

Donaldson, M. (1992) Human Minds: An Exploration. Harmondsworth: Allen Lane.

Doyal, L. and Gough, I. (1991) A Theory of Human Need. London: Macmillan.

Doyle, C. (1985) The Imprisoned Child Occasional Paper No.3. London: NSPCC.

Doyle, C. (1990) Working with Abused Children. London: Macmillan.

Doyle, C. (1994) Child Sexual Abuse: A Guide for Health Professionals. London: Chapman and Hall.

Doyle, C. (1995) Helping Strategies for Child Sexual Abuse. London: National Children's Bureau.

Doyle, C. (1996a) 'Current issues in child protection: an overview of the debates in contemporary journals'. British Journal of Social Work 26 (4) pp. 565-575.

Doyle, C. (1996b) 'Psychological maltreatment: research findings and implications for practice.' Paper presented to 11 th International Conference on Child Abuse and Neglect. University College, Dublin. 18-21 August 1996.

Doyle, C. (1996c) 'Sexual abuse by siblings: victims' perspectives.' Journal of Sexual Aggression 2 (1) pp. 17-32.

Dunn, J. (1995) 'Studying relationships and social understanding' in Barnes, P. (ed.) Personal, Social and Emotional Development of Children. Oxford: Blackwell

Dunn, J. and Kendrick, C. (1982) Siblings: Love, Envy and Understanding. Cambridge Mass.: Harvard University Press

Dunn, J., Kendrick, C. and MacNamee, R. (1981) 'The reaction of first-born children to the birth of a sibling: mother's reports'. Journal of Child Psychology and Psychiatry 22 pp.1-18 
Dunn, J. and Munn, P. (1985) 'Becoming a family member: family conflict and the development of social understanding in the first year'. Child Development 50 pp.306-18

Earls, F. and Jung, K. G. (1987) 'Temperament and home environment characteristics as causal factors in the early development of child psychopathology'. Journal of the American Academy of Child and Adolescent Psychiatry 26 pp.491-498.

Eastman, M. (1994) 'Dependency or interdependency? Is the concept of "dependent abuse" helpful' in Eastman, M. (ed.) Old Age Abuse: A New Perspective (2nd edition). London: Chapman and Hall.

Egeland, B. (1991) 'From data to definition' Development and Psychopathology 3 pp.37-43

Egeland, B. and Erickson, M.F. (1987) 'Psychologically unavailable caregiving' in Brassard, M. R., Germain, R. B. and Hart, S. N. (eds) Psychological Maltreatment of Children and Youth New York: Pergamon Press. pp.110-121

Eibl-Eibesfeldt, I. (1975) Ethology: The Biology of Behaviour (2nd edition). New York: Holt, Rinehart and Winston.

Eichler, M. (1988) Non-sexist Research Methods. Boston, Mass: Allen and Unwin.

Ekman, P. (1971) 'Universals and cultural differences in facial expressions of emotion' in Cole, J. K. (ed) Nebraska Symposium on Motivation. Nebraska: University of Nebraska Press.

Elliott, M. (1985) Keeping Safe: A Practical Guide to Talking with Children. London: Bedford Square Press

Elliott, M. (1994) 'Evaluation of "Protective Behaviours" and "Keeping Ourselves Safe". Commentary on Briggs and Hawkins'. Child Abuse Review 3 (4) p. 284.

Elmer, E. (1977) Fragile Families, Troubled Children. Pittsburgh: University of Pittsburg Press. 
Elmes, B. (1995) 'Don't equal opportunities apply to transsexuals?' Professional Social Work August p. 5

Emecheta, B. (1978) The Bride Price. London: Fontana.

Ennew, J. (1986) The Sexual Exploitation of Children. Cambridge: Polity Press.

Erikson, E. H. (1965) Childhood and Society. Harmondsworth: Penguin.

Ettorre, E. (1992) Women and Substance Use. New Brunswick, NJ: Rutgers University Press

Everitt, A., Hardiker, P., Littlewood, J. and Mullender, A. (1992) Applied Research for Better Practice. London: Macmillian.

Fairburn, G. (1995) 'Exams with a ten minute rule'. The Times Higher Education Supplement 1182 June p.13.

Farber, E. A. and Egeland, B. (1987) 'Invulnerability among abused and neglected children' in Anthony, E. J. and Cohler, B. J. (eds) The Invulnerable Child. New York: Guildford Press

Farmer, E. and Owen, M. (1995) Child Protection Practice: Private Risks and Public Remedies. London: HMSO

Faulkner, D. and Lewis, B. (1995) 'Psychological intervention: Down's syndrome and autism' in Bancroft, D. and Carr, R. (eds.) Influencing Children's Development. Oxford: Blackwell.

Fawcett, J (1988) 'Setting the framework for a long-term project'. Social Work Today. 31 March pp. 12-13.

Finkelhor, D. (1979a) 'What's wrong with sex between adults and children?' American Journal of Orthopsychiatry 49 (4) pp. 692-700.

Finkelhor, D. (1979b) Sexually Victimised Children. New York: Free Press. 
Finkelhor, D. (1984) Child Sexual Abuse: New Theory and Research. New York: The Free Press

Finkelhor, D. (1986) A Sourcebook on Child Sexual Abuse. Newbury Park, CA: Sage

Finkelhor, D., Williams, L. M and Burns, N. (1988) Nursery Crimes: Sexual Abuse in Day Care. Newbury Park: Sage.

Fischer, K. W., Kenny, S. L. and Pipp, S. (1990) 'How cognitive processes and environmental conditions organize discontinuities in the development of abstractions' in Alexander, C. and Langer, E. (eds.) Higher Stages of Human Development: Perspectives on Adult Growth. New York: Oxford University Press. .

Fishbein, H. D. (1984) The Psychology of Infancy and Childhood: Evolutionary and CrossCultural Perspectives. Hillsdale, New Jersey: Lawrence Erlbaum Associates

Flax, J. (1990) Thinking Fragments: Psychoanalysis, Feminism and Postmodernism in the Contemporary West. Berkeley: Los Angeles

Fogarty, M. (1980) 'Emotional abuse to be included in registers' Social Work Today 12 ( 1) p.4

Fortin, P. J. and Reed, S. R. (1984) 'Diagnosing and responding to emotional abuse within the helping System' Child Abuse and Neglect 8 pp. 117-118.

Fox, K. M. and Gilbert, B. O. (1994) 'The interpersonal and psychological functioning of women who experienced childhood physical abuse, incest and parental alcoholism' Child Abuse and Neglect 18 (10) pp. 849-858.

Francis, J. (1995) 'Stand by me' Community Care Issue 1081 17-23 August pp.18-19

Frank, J. (1995) Couldn't Care More. London: The Children's Society.

Franklin, B (ed) (1995) Children's Rights: A Handbook of Comparative Policy and Practice. London: Routledge. 
Fraser, S. (1989) My Father's House. London: Virago.

Freeman, M. (1993) 'Laws, conventions and rights'. Children and Society 7 (1) pp 37-48.

Freud, A. (1981) 'A psychoanalyst's view of sexual abuse by parents' in Mrazek, P. B. and Kempe, C. H. (eds.) Sexually Abused Children and Their Families. Oxford: Pergamon.

Freud, S. (1916-17) Introductory Lectures on Psychoanalysis. Harmondsworth: Penguin.

Frey, J. H. (1989) Survey Research by Telephone. Newbury Park CA: Sage.

Frude, N. (1996) 'Ritual abuse: conceptions and reality'. Clinical Child Psychology and Psychiatry. 1 (1) pp. 59-77.

Fryer, P. (1984) Staying Power: the History of Black People in Britain. London: Pluto Press

Fuller, R. and Petch, A. (1995) Practitioner Research. Buckingham: Open University Press.

Furnell, J. (1986) 'Emotional abuse of children: a psychologist's contribution to legal establishment'. Medical Science Law 26 (3) pp.179-184.

Furnell, J. (1991) 'Evidence of significant emotional harm'. Adoption and Fostering. 15 (4) pp. $116-118$.

Furnell, J. R. G., Dutton, P. V. and Harris, J. (1988) “"Emotional abuse” referrals to a Scottish children's panel reporter over five years'. Medical Science Law 28 (3). pp.219-226.

Fyvel, T. R. (1961) The Insecure Offenders. Harmondsworth: Penguin.

Gambe, D., Gomes, J., Kapu, V., Rangel, M. and Stubbs, P. (1992) Improving Practice with Children and Families. London: CCETSW.

Garbarino, J. (1978) 'The elusive "crime" of emotional abuse'. Child Abuse and Neglect. 2 pp. 89-99. 
Garbarino, J. and Ebata, A. (1983) 'The significance of ethnic and cultural differences in child maltreatment'. Journal of Marriage and the Family. November 1983, pp.773-783

Garbarino, J. and Garbarino, A. C. (1986) Emotional Maltreatment of Children (2nd edition). Chicago: National Committee for the Prevention of Child Abuse.

Garbarino, J. and Gilliam, G. (1980) Understanding Abusive Families. Lexington, Mass: Lexington Books.

Garbarino, J., Guttmann, E. and Wilson Seely, J. (1986) The Psychologically Battered Child San Francisco: Jossey Bass.

Garbarino, J. and Kostelny, K. (1992) 'Child maltreatment as a community problem'. Child Abuse and Neglect 16 (4) pp. 454-464

Garbarino, J. and Vondra, J. (1987) 'Psychological maltreatment: issues and perspective' in Brassard, M. R., Germain, R. B. and Hart, S. N. (eds) Psychological Maltreatment of Children and Youth. New York: Pergamon Press. pp. 25-44

Garrison, E. G. (1987) 'Psychological maltreatment of children: An emerging focus for inquiry and concern' American Psychologist 42 (2) pp.157-159.

Gelles, R. and Cornell, C. (1985) Intimate Violence in Families. Beverly Hills: Sage

George, C. (1996) 'A representational perspective of child abuse and prevention: internal models of attachment and caregiving'. Child Abuse and Neglect 20 (5) pp. 411-424.

Gergen, K.J. (1991) The Saturated Self New York: Basic Books

Ghate, D. and Spencer, L. (1995) The Prevalence of Sexual Abuse in Britain. London: HMSO

Giaretto, H. (1976) 'Humanistic treatment of father-daughter incest' in Helfer, R. E. and Kempe, C. H. (eds) Child Abuse and Neglect: The Family and the Community. Cambridge Mass: Ballinger 
Gibbons, J., Conroy, S. and Bell, C. (1995) Operating the Child Protection System. London: HMSO

Gibran, K. (1923). The Prophet (annotated edition by S Bushrui 1995). Oxford: Oneworld

Gibson. A. and Lewis, C. (1985) A Light in the Dark Tunnel. London: Centre for Caribbean Studies.

Gibson, E. J. and Walk, R. K. (1960) 'The visual cliff' Scientific American 202 pp.67-71

Gil, D. (1970) Violence Against Children Cambridge Mass: Harvard University Press

Gil, D. G. (1971) 'Violence against children' Journal of Marriage and the Family. November 1971, pp. 637-648.

Gilligan, C. (1977) 'In a different voice: womens' conception of self and morality'. Harvard Educational Review 47 pp. 481-517.

Giovannoni, J. (1991) 'Social policy considerations in defining psychological maltreatment' Development and Psychology 3 pp.51-59.

Giovannoni, J. M. and Becerra, R.M. (1979) Defining Child Abuse New York: The Free Press

Gittins, D. (1993) The Family in Question. 2nd edition. London: MacMillan

Glaser, D (1993) 'Emotional abuse' in Hobbs, C. J. and Wynne, J. M (eds) Clinical Paediatrics:

Child Abuse. London: Bailliere Tindall. pp.251-268

Goldstein, J., Freud, A. and Solnit, A. (1973 and 1979) Beyond the Best Interests of the Child. New York: Free Press

Goldstein, J., Freud, A. and Solnit, A. (1980) Before the Best Interests of the Child. Burnett Books: 
Gordon, D. S., Derricourt, N., Johnson, D., Kerr, I. and Purcell, R. (1988) 'Evaluation of community social work'. Practice 2 (3) pp.256-268

Gottesman, M. ed (1994) Recent Changes and New Trends in Extrafamilial Child Care. London: Whiting and Birch.

Gough, D. (1993) Child Abuse Interventions. London: HMSO

Gray, J. A. (1990) 'Brain systems that mediate both emotion and cognition'. Cognition and Emotion. 4 (3) pp 269-288.

Gross, A. B and Keller, H. R. (1992) 'Long-term consequences of childhood physical and psychological maltreatment'. Journal of Aggressive Behaviour 18 pp 171-185

Gross, D and Harris, P. L. (1988) 'Understanding false beliefs about emotion'. International Journal of Behavioural Development. 11 pp.475-88

Gross, R. D. (1992) Psychology: The Science of Mind and Behaviour 2nd edition London: Hodder \& Stoughton

Grusec, J.E. and Walters, G. C. (1991) 'Psychological abuse and child rearing belief systems' in Starr, R. H. and Wolfe, D. A. (eds) The Effects of Child Abuse and Neglect. London: The Guildford Press pp.186-202

Grylls, D. (1978) Guardians and Angels: Parents and Children in Nineteenth Century Literature. London: Faber and Faber.

Gulbenkian Foundation (1995) Children and Violence. London: Calouste Gulbenkian Foundation.

Haj-Yahia, M. and Shor, R. (1995) 'Child maltreatment as perceived by Arab students of social science in the West Bank'. Child Abuse and Neglect 19 (10) pp.1209-1220.

Hallet, C. and Stevenson, O. (1980) Child Abuse: Aspects of Interprofessional Co-operation. London: George Allen and Unwin. 
Hallet, C. (1995) 'Child abuse: an academic overview' in Kingston, P. and Penhale, B. (eds). Family Violence and the Caring Professions.London: Macmillan

Hammersley, M. (1992) 'Deconstructingthe qualitative-quantitative divide' in Brannen, J. (ed) Mixing Quantitative and Qualitative Research. London: A Brigower.

Handy, C. (1985) Understanding Organisations. 3rd edition. Harmondsworth: Penguin

Hanks, H. and Hobbs, C. (1993) 'Failure to thrive - a model for treatment' in Hobbs, C. J. and Wynne, J. M. Clinical Paediatrics: Child Abuse. London: Bailliere Tindall pp.101-120

Hardiker, P., Exton, K. and Barker, M. (1991) 'The social policy contexts of child care'. British Journal of Social Work 21 pp 341-359

Harding, L. F. (1991) Perspectives in Child Care Policy. Burnt Mill, Harlow: Longman

Harlow, H. (1959) 'Love in infant monkeys'. Scientific American 200 (6) pp.68-74.

Harris, P. L. (1989) Children and Emotion. Oxford: Blackwell

Harris, P. L., Olthof, T.,Terwogt, M. and Hardman, C. (1987) 'Children's knowledge of the situations that provoke emotion'. International Journal of Behavioural Development 10 pp.31944

Hart, S. N. (1988) 'Psychological maltreatment: emphasis on prevention'. School Psychology International. 9 pp 243-255

Hart, S. N. and Brassard, M. R., (1987) ‘A major threat to children's mental health: psychological maltreatment'. American Psychologist 42 (2) pp. 160-165.

Hart, S. N., Brassard, M. R. and Germain, R. B. (1987) 'Psychological maltreatment in education and schooling' in Brassard, M. R., Germain, R. B. and Hart, S. N. (ed) Psychological Maltreatment of Children and Youth. New York: Pergamon Press. pp. 217-242 
Hart, S. N., Germain, R. B., and Brassard, M. R. eds (1983) Proceedings Summary of the International Conference on Psychological Abuse of Children and Youth. Indiana University: Office for the Study of the Psychological Rights of the Child.

Hart, S. N., Germain, R. B. and Brassard, M. (1987) 'The challenge: to better understand and combat psychological maltreatment of children and youth' in Brassard, M., Germain, R. B. and Hart, S. N. (eds). Psychological Maltreatment of Children and Youth. New York: Pergamon Press. pp. 3-24

Harter, S. and Buddin, B. (1987) 'Children's understanding of the simultaneity of two emotions: a five-stage developmental acquisition sequence'. Developmental Psychology 23 pp. 388-99

Haskett, M. E., Marziano, B and Dover, E. R. (1996) 'Absence of males in maltreatment research: a survey of recent literature'. Child Abuse and Neglect. 20 (12) pp. 1175-82.

Haugaard, J. J (1991) 'Defining psychological maltreatment a prelude to research or an outcome of research?' Development and Psychopathology 3 pp.71-77

Hayes, N. (1994) Foundations of Psychology. London: Routledge

Heger, R. L. and Youngman, J.J. (1989) 'Toward a causal typology of child neglect'. Children and Youth Services Review. 11 pp. 203-220.

Helfer, R. E., McKinney, J and Kempe, R. (1976) 'Arresting or freezing the developmental process' in R. E. Helfer, C. H. Kempe and W. F. Mondale (eds). Child Abuse and Neglect. Cambridge, Mass.: Ballinger.

Hendrick, H. (1990) 'Constructions and reconstructions of British childhood: an interpretative survey, 1800 to the present' in James, A. and Prout, A. (eds). Constructing and Reconstructing Childhood. London: The Falmer Press

Hendrick, H. (1992) Child Welfare: England 1872-1989. London: Routledge

Herbert, M. (1991) Clinical Child Psychology. Chichester: John Wiley and Sons 
Herman, J. (1981) Father-Daughter Incest. Cambridge, Mass.: Harvard University Press

Herzberger, S. (1993) 'The cyclical pattern of child abuse: a study of research methodology' in Renzetti, C. M. and Lee, R.M. (eds). Researching Sensitive Topics. Newbury Park, CA: Sage.

Hickox, A. and Furnell, J. R. G. (1989) 'Psychosocial and background factors in emotional abuse of children'. Child Care, health and Development 15 (4) pp. 227-240.

Higgins, G. (1994) 'Children's accounts' in Mullender, A. and Morley, R. (eds) Children Living with Domestic Violence. London: Whiting and Birch.

Higher Education Statistics Agency (1996) Data Report. London: HESA.

Hill, L. ed (1995) Caring for Dying Children and their Families. London: Chapman and Hall.

Hillman, M. (1993) Children Transport and the Quality of Life. London: Policy Studies Institute

Hobbes, T. (1615) Leviathan (edition edited by M. Oakshot) Oxford: Basil Blackwell.

Hobbs, C. (1992) 'Pediatric intervention in child protection'. Child Abuse Review 1 (1) pp. 5-18

Hobbs, C. and Wynne, J. (1986) 'Buggery in childhood - a common syndrome of child abuse'. The Lancet 4 Oct pp.792-6

Hobbs, C. and Wynne, J. M. (1993) 'The evaluation of child sexual abuse' in Hobbs, C. and Wynne, J. M. (eds). Bailliere's Clinical Paediatrics: ChildAbuse. London: Bailliere Tindall.

Hockey, J. and James, A. (1993) Growing Up and Growing Old: Ageing and Dependency in the Life Course. London : Sage

Hocking, E. (1994) 'Caring for carers: understanding the process that leads to abuse' in Eastman M (ed) Old Age Abuse: A New Perspective 2nd edition. London: Chapman and Hall. 
Hoffman, M. L. and Saltzein, H.D. (1967) 'Parent discipline and the child's moral development'. Journal of Personality and Social Psychology 5 pp. 45-57

Holman, R. (1980) Inequality in Child Care. London: Child Poverty Action Group

Holman, R. (1988) Putting Families First. Prevention and Child Care. Basingstoke: Macmillan

Holt, J. (1975) Escape from Childhood: The Needs and Rights of Children. Harmondsworth: Penguin

Home Office (1991) Working Together under the Children Act 1989. London: HMSO

Hopper, E. (1994) 'Perinatal death' in Hill, L. (ed). Caring for Dying Children and Their Families. London: Chapman and Hall.

Hughes, W. H., Patterson, W. J. and Whalley, H. J. (1986) Report of the Committee of Inquiry into Children's Homes and Hostels. Belfast: HMSO

Hull, D. H. (1969) Film in the Third Reich Berkley CA: Berkley

Hunter, S. (1990) 'Not standing on feelings'. Scottish Child Oct/Nov 1990 pp.30-31

Hyman, C. A. (1980) 'Families who injure their children' in Frude, N. (ed) Psychological Approaches to Child Abuse. London: Batsford

Imam, U. F. (1994) 'Asian children and domestic violence' in Mullender, A. and Morley, R (eds) Children Living with Domestic Violence. London: Whiting and Birch.

Iwaniec, D., Herbert, M. and Slukin, A. (1988) 'Helping emotionally abused children who fail to thrive' in Browne, K., Davies, C. and Stratton, P. (eds) Early Prediction and Prevention of Child Abuse. Chichester: Wiley and Sons pp.229-244

Iwaniec, D. (1995) The Emotionally Abused and Neglected. Child Chichester: Wiley 
Jackson, D.D. and Weakland, J. (1961) 'Conjoint family therapy’ Psychiatry 24 pp. 34-45

Jacobs, M. (1992) Sigmund Freud. London: Sage

Jacoby, S. (1986) 'Emotional child abuse: the invisible plague'. Empathetic Parenting Summer pp. 3-6

Jaffe, P. G., Wolfe, D. A. and Wilson, S. K. (1995) Children of Battered Women. Newbury Park: Sage.

James, A. and Prout, A. (1990) 'Re-presenting childhood: time and transition in the study of childhood' in James, A and Prout, A. (eds) Constructing and Reconstructing Childhood. London: The Falmer Press

Jennings, A. G. and Armsworth, M. W. (1992) 'Ego development in women with histories of sexual abuse'. Child Abuse and Neglect 16 (4) pp. 553-565.

Jick, T. D. (1983) 'Mixing qualitative and quantitative methods: triangulation in action' in Van Maanen, J. (ed). Qualitative Methodology. Newbury Park, CA: Sage.

Jinadu, M. K., Daramola, S. O. and Ikpatt, S. F. (1982) 'Some factors affecting mother-child relationships following low birthweight delivery in a Nigerian sociocultural environment'. Child Abuse and Neglect 6 (1) pp.57-62

Johnson, N. (1995) 'Domestic violence: an overview' in Kingston, P. and Penhale, B. (eds) Family Violence and the Caring Professions. London: Macmillan

Jones, D. N. (1979) 'Report of the Nottinghamshire Special Unit' in NSPCC (1979) The Special Units: A Discussion (Unpublished Report)

Jones, D. N., Pickett, J., Oates, M. R. and Barbor, P. (1987) Understanding Child Abuse. 2nd edition. London: MacMillan 
Jones, E. D. and McCurdy, K. (1992) 'The links between types of maltreatment and demographic characteristics of children'. Child Abuse and Neglect 16 (2) pp. 01-216

Jones, R. L. and Jones, J. M. (1987) 'Racism as psychological maltreatment' in Brassard, M. R., Germain, R. B. and Hart, S. N. (eds) Psychological Maltreatment of Children and Youth. New York: Pergamon Press. pp. 146-158

Julian, V. and Mohr, C. (1979) 'Father-daughter incest: profile of the offender'. Victimology 4 (4) pp 348-360.

Junewicz, W. J. (1983) 'A Protective posture toward emotional neglect and abuse' Child Welfare LX11 (3) pp.243-251.

Kagan, J. (1988) 'Temperamental contributions to social behaviour'. American Psychologist 44 pp. 668-74.

Kahan, B. (1994) 'Great Britain: review of recent trends in residential and extrafamilial care of children and young people' in Gottesman, M. (ed). Recent Changes and New Trends in Extrafamilial Child Care: An International Perspective. London: Whiting \& Birch/FICE.

Kavanagh, C. (1982) 'Emotional abuse and mental injury: a critique of the concepts and a recommendation for practice'. Journal of the American Academy of Child Psychiatry 21 (2) pp.171-177

Kay, E. (1988) 'Professional perspectives'. Journal of Social Welfare. Law 2 p.94

Kell, I. J. (1993) Attitudes to Psychological Maltreatment of Children. PhD Thesis. Goldsmith's College, University of London.

Kellmer Pringle, M. (1974) The Needs of Children.. London: Hutchinson (reprinted in. Lee, C. L. (ed) 1978 Child Abuse: a Reader and Sourcebook. Milton Keynes: Open University Press.)

Kelly, D. and Warr, B. eds (1992) Quality Counts: Achieving Quality in Social Care. London: Whiting and Birch/Social Care Association 
Kelly, S. J. (1988) 'Ritualistic abuse of children: dynamics and impact'. Cultic Studies Journal 5 (2) pp. 228-36

Kempe, C. H. (1978) 'Sexual abuse, another hidden pediatric problem'. Pediatrics 62 (3) pp.382-9

Kempe, C. H. and Helfer, R. E. eds (1968) The Battered Child. Chicago: University of Chicago Press

Kempe, C.H., Silverman, F. N., Steele, B. F., Droegemueller, S.. and Silver, H. K. (1962) 'The battered child syndrome'. Journal of the American Medical Association. 181 (1) pp.17-24.

Kendall-Tacket, K. A. and Eckenrode, J. (1996) 'The effects of neglect on academic achievement and disciplinary problems: a developmental perspective'. Child Abuse and Neglect. 20 (3) pp 161170.

Kennedy, H. (1992) Eve Was Framed: Women and British Justice. London: Chatto \& Windus

Kennedy, M. (1989) 'The abuse of Deaf children' Child Abuse Review 3 (1) pp.3-6

Kennedy, M. (1990) 'The Deaf child who is sexually abused - is there a need for a dual specialist?' Child Abuse Review 4 (2) pp.3-6

Kennell, H., Voos, D. and Klaus, M. (1976) 'Parent-infant bonding' in Helfer, R. E. and Kempe, C. H. (eds) Child Abuse and Neglect: The Family and the Community. Cambridge Mass: Ballinger

Kershaw, C. (1986) 'Failure to thrive: analysis of a problem matrix'. Child Abuse Review 1 (2) pp.10-11.

Kinnear, P. R. and Gray, C. D. (1994) SPSS for Windows Made Simple. Hove, East Sussex: Lawrence Erlbaum Associates.

Kirkwood, A. (1993) The Leicestershire Inquiry 1992. Leicestershire: Leicestershire County Council 
Kitzinger, J. (1990) 'Who are you kidding? Children, power and the struggle against sexual abuse' in James, A. and Prout, A. (eds) Constructing and Reconstructing Childhood: Contemporary Issues in the Sociological Study of Childhood. London: The Falmer Press

Kitzinger, J. (1994) 'Challenging sexual violence against girls: a social awareness approach'. Child Abuse Review 3 (4) pp 246-258

Kitzinger, J. and Skidmore, P. (1995) 'Playing safe: media coverage of child sexual abuse prevention strategies'. Child Abuse Review 4 (1) pp.47-56

Klein, G. (1985) Reading into Racism. London: Routledge, Kegan and Paul.

Klinnert, M. (1984) 'The regulation of infant behavior by maternal facial expression' Infant Behaviour and Development 7 pp. 447-65

Klopfer, P. H., Adams, D. K. and Klopfer, M. S. (1964) 'Maternal imprinting on goats'. Proceedings of the National Academy of Sciences

Klosinski, G. (1993) 'Psychological maltreatment in the context of separation and divorce'. Child Abuse and Neglect 17 (4) pp.557-565.

Kohlberg, L. (1976) 'Moral stages and moralization: the cognitive developmental approach' in Lickona, J. (ed). Moral Development Behaviour: Theory, Research and Social Issues. New York: Holt, Rinehart and Winston

Kohlberg, L. and Ryncarz, R. (1990) 'Beyond justice reasoning moral development and considerations of a seventh stage' in Alexander, C. and Langer, E. (eds) Higher Stages of Human Development: Perspectives on Adult Growth. New York: Oxford University Press. .

Korbin, J. (1978) 'Changing family roles and structures: a cross cultural perspective' in Launderdale, M.L, Anderson, R.N. and Cramer, S.E. (eds) Child Abuse and Neglect: Issues on Innovation and Implementation. Proceedings of the Second Annual Conference on Child Abuse and Neglect. April 1977 Vol. 1. Washington DC: US Department of Health, Education and Welfare. 
Krishan, V. and Morrison, K. B. (1995) 'An ecological model of child maltreatment in a Canadian province'. Child Abuse and Neglect 19 (1) pp. 101-114

Krugman, R. D. and Krugman, M. K. (1984) 'Emotional abuse in the classroom'. AJDC 138 pp. 284-286

Kuono, A. and Johnson, C. F. (1995) 'Child abuse and neglect in Japan: coin-operated-locker babies'. Child Abuse and Neglect 19 (1) pp. 25-32

La Fontaine, J. S. (1990) Child Sexual Abuse. Cambridge: Polity Press

La Fontaine, J. S. (1994) The Extent and Nature of Organised and Ritual Abuse. London: HMSO

Lacharite, C., Ethier, L. and Couture, G. (1996) 'The influence of partners on parental stress of neglectful mothers.' Child Abuse Review 5 (1) pp.18-33

Lamb, M. E. ed (1987) The Father's Role: Cross-cultural Perspectives. Hillsdale, NY: Lawrence Erlbaum.

Land, H. (1976) 'Women, supporters or supported' in Barker, D and Allen, S (eds) Sexual Divisions and Society: Process and Change. London: Tavistock.

Langone, M. D. (1992) 'Psychological abuse' Journal of Cultic Studies 9 (2) pp. 206-218

Langeland, W and Dijkstra, S. (1995) 'Breaking the intergenerational transmission of child abuse: beyond the mother-child relationship'. Child Abuse Review 4 (1) pp 4-13.

Langlois, J. (1986) 'From the eye of the beholder to behavioural reality: development of social behaviours and social relations as a function of physical attractiveness' in Herman, C.P. , Zanna, M.P. and Higgins, E.T. (eds) Physical Appearance Stigma and Social Behaviour. The Ontario Symposium Vol 3. Hillsdale NJ: Erlbaum

Lask, B. (1987) 'Family therapy'. British Medical Journal. 294 pp. 203-204 
Lau, A. (1991) 'Cultural and ethnic perspectives on significant harm: its assessment and treatment' in Adcock, A., White, R. and Hollows, A. (eds) Significant Harm. Croydon, London: Significant Publications.

Lawson, E. (1985) The Leeways Report. London: London Borough of Lewisham

Lazoritz, S. and Shelman, E. A. (1996) 'Before Mary Ellen'. Child Abuse and Neglect 20 (3) pp. 235-238

Lealman, G., Haigh, D., Philips, J., Stone, J. and Ord-Smith, C. (1983) 'Prediction and prevention of child abuse - an empty hope?' Lancet i pp. 1423-4.

Lebacq, M. and Boylan, J. (1997) Children and Young People's Rights: a Social Work Context. (In press).

Lee, R. M. and Renzetti, C. M. (1993) 'The problems of researching sensitive topics: an overview and introduction' in Renzetti, C.M. and Lee, R. M (eds). Researching Sensitive Topics. Newbury Park, CA: Sage.

Leeding, A. E. (1976) Child Care Manual for Social Workers 3rd edition. London: Butterworths.

Leisnik-Oberstein, M. (1983) 'Denial of reality: a form of emotional abuse' Child Abuse and Neglect 7 pp. $471-472$

Leisnik-Oberstein, M., Koers, A. J. and Cohen, L. (1995) 'Parental hostility and its sources in psychologically abusive mothers: a test of the three-factor theory' Child Abuse and Neglect 19 (1) pp. $33-50$

Levy, A. and Kahan, B. (1991) The Pindown Experience and the Protection of Children. Staffordshire: Staffordshire County Council.

Lewis, C. (1986) On Becoming a Father. Milton Keynes: Open University Press 
Li, C. K., West, D. J. and Woodhouse, T. P. (1990) Children's Sexual Encounters with Adults. London: Duckworth.

Light, P. H., Buckingham, N. and Robbins, H. (1979) 'The conservation task as an interactional setting'. British Journal of Educational Psychology 49 pp. 304-10

Litterer, J. A. (1983) The Analysis of Organisations. 2nd edition London: John Wiley

Little, M. and Gibbons, J. (1993) 'Predicting the rate of children on the Child Protection Register'. Research, Policy and Planning 10 (2) pp.15-18

Locke, J. (1690) The Second Treatise of Government (revised and edited by J W Gough 1966) Oxford: Basil Blackwell

Lodge, K ed (1990) Social Services Year Book 1990/91. Harlow, Essex: Longman

Loftus, E. F. (1993) 'The reality of repressed memory' American Psychologist 48 pp. 518-537.

Loftus, E. F., Miller, D. G, and Burns, H. J. (1978) 'Semantic integration of verbal information into a visual memory'. Journal of Experimental Psychology: Human Learning and Memory. 4 pp. 19-31.

Lorenz, K. (1943) 'Die Angebornen Formen mogicher Erfahrung'. Zeitschrift fur Tierpsychologie 5 pp. 233-409 (cited in Cole M and Cole S R (1993) The Development of Children 2nd edition New York: Scientific American.

Lorenz, K. (1967) On Aggression. London: Methuen and Co.

Lorenz, K. (1970) Studies in Animal Behaviour. London: Methuen

Lourie, I. S. and Stephano, L. (1978) 'On defining emotional abuse: results of an NIMH/NCCAN Workshop' in Launderdale, M.L, Anderson, R.N. and Cramer, S.E. (eds) Child Abuse and Neglect: Issues on Innovation and Implementation. Proceedings of the Second Annual Conference on Child Abuse and Neglect. April 1977 Vol. 1. Washington DC: US Department of Health, Education and Welfare. 
Lutz, C. (1988) Unnatural Emotions: Everyday Sentiments on a Micronesian Atoll and their Challenge to Western Theory Chicago: University of Chicago Press

Lynch, M. and Oustead, C. (1976) 'Residential therapy: a place of safety' in Helfer, R. E. and Kempe, C. H. (eds) Child Abuse and Neglect. Cambridge, Mass. Ballinger

Lynch, M. A. and Roberts, J. (1977) 'Predicting child abuse: signs of bonding failure in the maternity hospital'. British Medical Journal 1 pp.624-626

Lyon, C. (1981) 'From Diagnosis to Evidence' Journal of Social Welfare Law 2 pp. 88-93.

MacFarlane, K. (1970) 'Cindy's poem' by Cindy and put into words by K. MacFarlane (reprinted in A L Horton, Johnson B L, Roundy L M and Williams D (1990) The Incest Perpetrator. Newbury Park, CA: Sage.)

MacLeod, M. and Saraga, E. (1988) 'Challenging the orthodoxy: towards a feminist theory and practice'. Feminist Review 28 pp.16-55.

MacVeigh, J. (1982) Gaskin London: Jonathan Cape

Madge, N. (1996) 'Suicidal behaviour in children and young people' Highlight No.144. London: National Children's Bureau.

Mancoske, R. J., Standifer, D. and Cauley, C. (1994) 'The effectiveness of brief counseling services for battered women'. Research on Social Work Practice 4 (1) 53-88.

Manning, N. (ed). (1985) Social Problems and Welfare Ideology. Aldershot: Gower.

Margolin, L. (1992) 'Child abuse by mother's boyfriends'. Child Abuse and Neglect. 16 (4) pp.541-552.

Marsh, C. (1982) The Survey Method. London: George Allen and Unwin. 
Marsh, P. and Fisher, M. (1992) Good Intentions: Developing Parnership in Social Services. York: Joseph Rowntree Foundation.

Marshall, G., Rose, D., Newby, H. and Vogler, C. (1988) Social Class in Modern Britain London: Unwin Hyman

Mascaro, J. translator (1962) The Bhagavad Gita Penguin: Harmondsworth

Maslow, A. H. (1970) Motivation and Personality 2nd Edition New York: Harper Row

Mason, D. (1995) Race and Ethnicity in Modern Britain. Oxford: Oxford University Press.

Mason, J. (1994) 'Linking qualitative and quantitative data analysis' in Bryman, A. and Burgess, R.G. (eds) Analyzing Qualitative Data. London: Routledge

Masson, J. and Morris, M. (1992) Children Act Manual. London: Sweet and Maxwell.

Masson, J. (1995) Lecture for Session 1 Diploma in Child Protection Studies /Short Course in Child Protection Law, University of Leicester.

May, T. (1993) Social Research Buckingham: Open University Press.

Maziade, M., Cote, R., Thiverge, J., Boutin, P. and Berner, H. (1989) 'Significance of extreme temperament in infancy for clinical status in preschool years. I Value of extreme temperament at 4-8 months for predicting diagnosis at 7 years.' British Journal of Psychiatry 154 pp. 535-543

McCloskey, L. A., Figueredo, A. J. and Koss, M. P. (1995) 'The effects of systemic family violence on children's mental health'. Child Development. 66 pp. 1239-1261.

McDevitt, S. (1996) 'The effect of news media on child abuse reporting'. Child Abuse and Neglect. 20 (4) pp. 261-274.

McFayden, A., Hanks, H. and James, C. (1993) 'Ritual abuse: a definition' Child Abuse Review 2 (1) pp.35-41 
McGee, R..A and Wolfe, D. A. (1991a) 'Psychological maltreatment: toward and operational definition' Development and Psychopathology 3 pp. 3-18.

McGee, R. A. and Wolfe, D. A. (1991b) 'Between a rock and a hard place: where do we go from here in defining psychological maltreatment' Development and Psychopathology 3 pp 119-124

Meadow, R. ed (1989a) ABC of Child Abuse. London: British Medical Journal.

Meadow, R. (1989b) 'Munchausen syndrome by proxy' in Meadow, R. (ed) ABC of Child Abuse. London: British Medical Journal

Mearns, D. and Thorne, B. (1988) Person Centred Counselling in Action. London: Sage

Mezey, G., Vizard, E., Hawkes, C. and Austin, R. (1991) 'A community treatment programme for convicted sex offenders: a preliminary report.' Journal of Forensic Psychiatry 2 (1) pp.11-25.

Melton, G. B. and Thompson, R. A. (1987) 'Legislative approaches to psychological maltreatment' in Brassard, M. R, Germain, R. B. and Hart, S. N. (eds) Psychological Maltreatment of Children and Youth New York: Pergamon Press. pp. 203-216.

Mies, M. (1983) 'Towards a methodology for feminist research' in Bowles, G. and Klein, R. D. (eds). Theories of Women's Studies. London: Routledge and Kegan Paul.

Miller, A. H. (1978) 'Negotiations for hostages: implications from the police experience'. Terrorism 1 (2) pp 125-146

Miller, A. (1981) Prisoners of Childhood. New York: Basic Books

Miller, A. (1987) For Your Own Good: The Roots of Violence in Child-Rearing. London: Virago Milliham, S., Bullock, R., Hosie, K. and Haak, M. (1986) Lost in Care Aldershot: Gower Milner, J. (1986) The Child Abuse Potential Inventory: Manual. 2nd edition. Webster, NC: Psytec. 
Milner, J. (1993) 'A disappearing act: the differing career paths of fathers and mothers in child protection investigations'. Critical Social Policy 13 (2) pp.46-68.

Minty, B. and Patterson, G. (1994) 'The nature of child neglect'. British Journal of Social Work. 24 pp. 733-748.

Minuchin, S. (1974) Families and Family Therapy Cambridge Mass: Harvard University Press

Moeller, T. P. and Bachmann, G. A. (1993) 'The combined effects of physical, sexual, and emotional abuse during childhood: long-term health consequences for women'. Child Abuse and Neglect 17 pp. 623-640.

Montessori, M. (1970) The Child and the Family (translator N. Rockmore Cirillo) Chicago: Henry Regnery Company.

Montgomery, J. (1989) 'The emotional abuse of children'. Family Law 19 pp.25-29.

Morris, A., Giller, H., Szwed, E. and Geach , H. (1980) Justice for Children. London: Macmillan Morris D (1967) The Naked Ape Harmondsworth: Penguin

Morrison, B. (1993) And When Did You Last See Your Father? London: Granta Books

Mrazek, P. B. (1981) 'Group psychotherapy with sexually abused children' in Mrazek, B. P. and Kempe, C. H. (eds). Sexually Abused Children and Their Families. Oxford: Pergamon

Mrazek, P. B. and Bentovim, A. (1981) 'Incest and the dysfunctional family system' in Mrazek, B. P. and Kempe, C.H. (eds). Sexually Abused Children and Their Families. Oxford: Pergamon

Mulford, R. M. (1958) 'Emotional neglect of children: a challenge to protective services' Child Welfare October. pp. 19-24

Mullender A and Morley R (1994) 'Context and content of a new agenda' in Mullender, A. and Morley, R. (eds) Children Living with Domestic Violence. London: Whiting and Birch. 
Muller, R. T., Hunter, J. E. and Stollak, G. (1995) 'The intergenerational transmission of corporal punishment: a comparison of social learning and temperament models'. Child Abuse and Neglect 19 (11) pp. 1323-1335

Mullins, L. J. (1989) Management and Organisational Behaviour 2nd edition London: Pitman

Murray, L. (1992) 'The impact of post-natal depression on infant development' Journal of Child Psychology and Psychiatry 33 pp.543-61

Nakashima, I. I. and Zakus, G. E. (1977) 'Incest: review and clinical experience' Pediatrics 60 (5) pp. 696-701.

Nasjleti, M. (1980) 'Suffering in silence: the male incest victim'. Child Welfare 59 pp 269-275.

National Children's Homes (1994) Hidden Victims London: NCH Action for Children

Navarre, E. L. (1987) 'Psychological maltreatment: the core component of child abuse' in Brassard, M., Germain, R. and Hart, S. (eds) Psychological Maltreatment of Children and Youth New York: Pergamon Press. pp.45-58

Nesbit, W. (1991) 'Emotional abuse: vulnerability and developmental delay' Developmental Disabilities Bulletin 19 (2) pp. 66-80

Newberger, E. H and Bourne, R (1978) 'The medicalization and legalization of child abuse' American Journal of Orthopsychiatry. 48 (4) p. 593-607.

Newson, J. and Newson, E. (1968) Four Years Old in an Urban Community. London: Allen and Unwin.

Ney, P. G. , Fung, T. and Wickett, A. R .(1994) 'The worst combinations of child abuse and neglect' Child Abuse and Neglect 18 (9) pp. 705-714 
Nicholas, K. B. and Bieber, S. L. (1994) 'Perceptions of mothers' and fathers' abusive and supportive behaviours'. Child Abuse and Neglect 18 (2) pp.167-178

Norusis, M. J. (1988) SSPS-X Advanced Statistics Guide. Chicago: SSPS Inc.

NSPCC (1975) Register of Suspected Non-Accidental Injury. London: NSPCC

NSPCC (1979) The Special Units: A Discussion. (Unpublished Report)

NSPCC (1985) Annual Report. London: NSPCC

Nursten, J. and Smith, M. (1996) 'Believe or disbelieve? With particular reference to satanist abuse'. Child Abuse Review 5 (4) pp. 253-262.

O' Brian, C. and Lau, L. S. W. (1995) 'Defining child abuse in Hong Kong'. Child Abuse Review 4 (1) $\mathrm{pp} 38-46$.

O' Hagan, K. (1993) Emotional and Psychological Abuse of Children. Milton Keynes: Open University Press.

O' Hagan, K. (1995) 'Emotional and psychological abuse: problems of definition' Child Abuse and Neglect. 19 (4) pp. 449-462

O’Regan, T. (1990) 'Emotional abuse within a changing legal framework' Journal of Child Law. July/Sept. pp. 119-125.

Oaklander V (1978) Windows to Our Children New York: Real People Press

Oakley, A. (1981) 'Interviewing women: a contradiction in terms' in Roberts, H. (ed) Doing Feminist Research. London: Routledge and Kegan Paul.

Olafson, E., Corwin, D. L. and Summit, R. C. (1993) 'Modern history of child sexual abuse awareness'. Child Abuse and Neglect. 17 (1) pp.7-24 
Orchard, B. and Fuller, R. C. eds (1966) The Holy Bible. London: Catholic Truth Society

Panksepp, J. (1990) 'Gray zones at the emotion/cognition interface: a commentary' Cognition and Emotion. 4 (3) pp 289-302.

Parker, R. (1995) 'A brief history of child protection' in Farmer, E. and Owen, M. (eds) Child Protection Practice: Private Risks and Public Remedies. London: HMSO

Parsloe, P. and Stevenson, O. (1978) Social Services Teams: The Practitioner's View. London: HMSO

Parton, N. (1985) The Politics of Child Abuse. London: MacMillan

Parton, N. (1992) Governing the Family. London: Macmillan

Parton, N. and Thomas, T. (1983) 'Child abuse and citizenship' in Jordon, B. and Parton, N. (eds). The Political Dimenstions of Social Work. Oxford: Basil Blackwell.

Patterson, G. R. (1982) Coercive Family Processes. Eugene, Or: Castilia

Patterson, P. and Thompson, M. (1980) 'Emotional abuse and neglect: an exercise in definition' in Volpe, R., Breton, M. and Milton, J. (eds) The Maltreatment of the School Aged Child. Lexington Mass: Lexington Books

Pearce, J. W. and Pezzot-Pearce, T. D. (1994) 'Attachment theory and its implications for psychotherapy with maltreated children'. Child Abuse and Neglect 18 (5) pp 425-439

Pelton, L. H. (1978) 'Child abuse and neglect: the myth of classlessness'. American Journal of Orthophsychiatry 48 (4) pp. 608-617.

Pemberton, D. A. and Benady, D. R. (1973) 'Consciously rejected children'. British Journal of Psychiatry 123 pp. 575-578. 
Penhale, B. and Kingston, P. (1995) 'Social perspectives on elder abuse' in Kingston, P. and Penhale, B. (eds) Family Violence and the Caring Professions. London: Macmillan

Phillipson, C. and Biggs, S. (1995) 'Elder abuse: a critical overview' in Kingston, P. and Penhale, B. (eds). Family Violence and the Caring Professions.London: Macmillan

Philpot, T. (1995) 'Uncertain ground'. Community Care Issue 1067 11-17 May p.1

Piaget, J. (1983) 'Piaget's theory' in Mussen, P. H. (ed). Handbook of Child Psychology Vol 1 Theory and Methods. New York: Wiley

Pietrzak, J., Ramler, M., Renner, T., Ford, L. and Gilbert, N. (1990) Practical Program

Evaluation: Examples from Child Abuse Prevention. Newbury Park: Sage

Pilcher, J. (1995) Age and Generation in Modern Britain. Oxford: Oxford University Press

Polansky, N., Ammons, P and Weathersby, B. (1983) 'Is there an American standard of child care?' Social Work 28 pp.341-346.

Pollock, L. (1983) Forgotten Children: Parent-Child Relations from 1500 to1900

Cambridge: Cmbridge University Press.

Postman, N. (1983) The Disappearance of Childhood. London: W H Allen.

Preston-Shoot, M. (1995) personal communication

Preston-Shoot, M. and Williams, J. (1988) 'Evaluating the effectiveness of practice'. Practice 1 (4) pp. 393-405

Pritchard, C. (1992) 'Children's homicide as an indicator of effective child protection: a comparative study of western European statistics'. British Journal of Social Work 22 (6) pp. 663684 . 
Pritchard, C. (1993) 'Re-analysing children's homicide and undetermined death rates as an indication of improved child protection: a reply to Creighton'. British Journal of Social Work 23 (6) pp. 645-652.

Pritlove, J. (1990) 'Evaluating a group for mothers under stress'. Practice 4 (2) pp. 80-95

Quinn, P. (1988) Cry Out. Eastbourne:Kingsway Publications.

Ranney, E. C. and Cottone, R. R. (1991) 'Emotional abuse in the family: the need for awareness and treatment'. Journal of Mental Health Counselling 13 (4) pp. 435-448.

Reder, P., Duncan, S. and Gray, M. (1993) Beyond Blame: Child Abuse Tragedies Revisited. London: Routledge

Reid, I. (1977) Social Class Differences in Britain. London: Open Books.

Renzetti, C. M. and Lee, R. M. eds (1993) Researching Sensitive Topics. Newbury Park, CA: Sage.

Reschly, D. J. and Graham-Clay, S. (1987) 'Psychological abuse from prejudice and cultural bias' in Brassard, M. R., Germain, R. B. and Hart, S. N. (eds) Psychological Maltreatment of Children and Youth. New York: Pergamon Press. pp. 137-145

Richardson, S. and Bacon, H. eds. (1991) Child Sexual Abuse: Whose Problems? Reflections from Cleveland. Birmingham: Venture Press

Rickford, F. (1993) 'Down memory lane'. Community Care 24 June (972)

Rickford, F. (1995) 'The ones who get away'. Community Care Issue 1085 7-13 September

Ritchie, J. and Spencer, L. (1994) 'Qualitative data analysis for applied policy research' in Bryman, A. and Burgess, R. G. (eds) Analyzing Qualitative Data. London: Routledge

Rogers, C. R. (1980) A Way of Being. Boston Mass: Houghton Mifflin 
Rohner, R. P. and Rohner, E. C. (1980) 'Antecedents and consequences of parental rejection: a theory of emotional abuse'. Child Abuse and Neglect 4 pp 189-198.

Roll, L. (1995) 'Sticks and Stones: A Study of the Emotional Abuse of Children' MSW dissertation. University of York.

Ronnau, J. and Poertner, J. (1989) 'Building consensus among child protection professionals' Social Casework. September pp 428-435

Rosaldo, M. (1984) 'Toward an anthropology of self and feeling' in Schweder, R. A. and Levine, R. A. (eds) Culture Theory: Essays on Mind, Self and Emotion. Cambridge: Cambridge University Press

Rosenberg, M. S. (1987) 'New directions for research on the psychological maltreatment of children'. American Psychologist 42 (2) pp. 166-171.

Rouf, K. (1991a) Into Pandora's Box London: The Children's Society

Rouf, K. (1991b) Black Girls Speak Out London: The Children's Society

Rousseau, J. J. (1762) The Social Contract and Discourses (translated and edited by G. D. H. Cole. 1913). London: Dent \& Sons

Rowe, J., Hundleby, M. and Garnett, L. (1989) Child Care Now: A Survey of Placement Patterns. London: BAAF.

Royal College of Psychiatrists (1982) 'Definitions of emotional abuse' Bulletin of the Royal College of Psychiatrists. May pp. 85-7.

Rutter, M. (1981) Maternal Deprivation Reassessed. 2nd edition. Harmondsworth: Penguin

Saarni, C. (1984) 'An observational study of children's attempts to monitor their expressive behaviour'. Child Development 55 pp. 1504-13 
Salter, A. (1988) Treating Child Sex Offenders and Victims: A Practical Guide. Newbury Park: Sage

Sapey, R. (1995) 'Why the New Right reigns supreme on ideology'. Professional Social Work May p. 6

Saunders, P. (1990) Social Class and Stratification. London: Routledge

Schechter, M. D and Roberge, L. (1976) 'Child Sexual Abuse' in Helfer, R and Kempe, C. H. (eds) Child Abuse and Neglect: The Family and the Community. Cambridge, Mass.: Ballinger pp.127-142

Scottish Child and Family Alliance. (1991) In the Child's Best Interests. Edinburgh: HMSO

Seden, J., Hardiker, P and Barker, M. (1996) 'Child protection revisited: balancing state intervention and family autonomy through social work processes'. Child and Family Social Work. 1 (1) pp. 57-66.

Seebohm, F. (1968) Report of the Committee on Local Authority and Allied Personal Social Services London: HMSO

Seed, L. (1973) The Expansion of Social Work in Britain London: Routledge and Kegan Paul

Seiber, J. E. (1993) 'The ethics and politics of sensitive research' in Renzetti, C. M. and Lee, R. M. (eds). Researching Sensitive Topics. Newbury Park, CA: Sage.

Seiber, J. E and Stanley, B. (1988) 'Ethical and professional dimensions of socially sensitive research.' American Psychologist. 43 pp. 735-741.

Shahar, S. (1990) Childhood in the Middle Ages. London: Routledge

Sharland, E., Jones, D., Aldgate, J., Seal, H. and Croucher, M. (1995) Professional Intervention in Child Sexual Abuse. London: HMSO. 
Shengold, L. (1989) Soul Murder. New Haven, Connecticut: Yale University Press

Singer, M. I., Hussey, D. and Strom, K. J. (1992) 'Grooming the victim: an analysis of a perpetrator's seduction letter'. Child Abuse and Neglect 16 (6) pp. 877-886

Skuse, D. H. (1989a) 'Emotional abuse and neglect' in Meadow. R. (ed). ABC of Child Abuse. London: British Medical Journal

Skuse, D. H. (1989b) 'Emotional abuse and delay in growth' in Meadow, R (ed) ABC of Child Abuse. London: British Medical Journal.

Smith, J. (1993) 'The case study' in Bayne, R. and Nicolson, P. (eds) Counselling and Psychology for Health Professionals. London: Chapman and Hall.

Smith, M. (1996) Personal communication.

Smith, M., Bee, P., Heverin, A. and Nobes, G. (forthcoming) Parental Control within the Family: The Nature and Extent of Parental Violence to Children. London: Thomas Coram Research Unit.

Smith, P. T. (1978) 'Towards a new perspective' in Launderdale, M.L, Anderson, R.N. and Cramer, S.E. (eds) Child Abuse and Neglect: Issues on Innovation and Implementation. Proceedings of the Second Annual Conference on Child Abuse and Neglect. April 1977 Vol. 1. Washington DC: US Department of Health, Education and Welfare.

Smith, S. M., Hanson, R. and Noble, S. (1975) 'Parents of battered children: a controlled study' in Franklin, A. W. (ed) Concerning Child Abuse. Edinburgh: Churchill Livingstone.

Social Services Inspectorate (1992) Committed to Quality: Quality Assurance in Social Services Departments London: HMSO

Solberg, A. (1990) 'Negotiating childhood: Changing construction of age for Norwegian children' in James, A. and Prout, A (eds) Constructing and Reconstructing Childhood. London: Falmer Press 
Soothill, D. and Gibbens, T. C. N. (1978) 'Recidivism of sexual offenders: a re-appraisal'. British Journal of Criminology 18 (3) 267-276

Sorce, J. F., Emde, R. N., Campos, J. J. and Klinnert, M. D. (1985) 'Maternal emotional signalling: its effects on the visual cliff behavior of 1-year-olds'. Developmental Psychology 21 pp.195-200.

Speight, N. (1989) 'Non-accidental injury' in Meadow, R. (ed). ABC of Child Abuse. London: British Medical Journal.

Spring, J. (1987) Cry Hard and Swim. London: Virago

Stainton-Rogers, R. (1992) 'The social construction of childhood' in Stainton Rogers, W., Hevey, D. , Roche, J. and Ashe, E. (eds) Child Abuse and Neglect: Facing the Challenge. 2nd edition London: Batsford

Stark and Flitcraft, A. H. (1988) 'Women and children at risk: a feminist perspective on child abuse'. International Journal of Health Services 18 pp. 97-118.

Starr, R. H. and Wolfe, D. A. eds (1991) The Effects of Child Abuse and Neglect. London: The Guildford Press

Stern, C. (1987) 'The recognition of child abuse' in Maher, P. (ed) Child Abuse: The Educational Perspective. Oxford: Basil Blackwell.

Stevenson, O (1992) 'Social work intervention to protect children: aspects of research and practice' Child Abuse Review 1 (1) pp.19-32.

Stevenson, O. (1995) 'The pit and the pendulum' Professional Social Work. February p.4

Stevenson, O. (1996) 'Emotional abuse and neglect: a time for reappraisal'. Child And Family Social Work 1 (1) pp. 13-18

Storr, A. (1970) Human Aggression Harmondsworth: Penguin 
Sullivan, P. M., Scanlan, J. M., Brookhouser, P. E., Schulte, L. E. and Knutson, J. F. (1992) 'The effects of psychotherapy on behavior problems of sexually abused deaf children'. Child Abuse and Neglect 16 (2) pp. 297-308

Summit, R. C. (1983) 'The child sexual abuse accommodation syndrome'. Child Abuse and Neglect. 7 pp.177-193.

Symmonds, C. (1980) The Complete Works of William Shakespeare. London: Atlantis

Szur, R. (1987) 'Emotional abuse and neglect' in Maher, P. (ed) Child Abuse: the Educational Perspective Oxford: Basil Blackwell pp.104-126

Tabachnick, B. G. and Fidell, L. S. (1989) Using Multivariate Statistics. 2nd edition. New York: Harper Collins.

Taylor, S. (1992) 'How prevalent is it?' in Stainton Rogers, W., Hevey, D. , Roche, J. and Ashe, E. (eds) Child Abuse and Neglect: Facing the Challenge. 2nd edition London: Batsford

Thoburn, J. (1980) Captive Clients: Social Work with Families Home on Trial. London: Routledge Kegan Paul

Thomas, A. and Chess, S. (1977) Temperament and Development. New York: Brunner-Mazel.

Thomas, A. and Chess, S. (1982) 'Temperament and follow-up to adulthood' in Porter. R. and Collins, G. (eds). Temperamental Differences in Infants and Young Children. London: Pitman.

Thompson, M. and Jacobs, J. E. (1986) 'Failure to thrive: emotional aspects'. Child Abuse Review 1 (3) pp.22-25.

Thompson, N. (1993) Anti-discriminatory Practice. London: Macmillan

Thompson, R. A. (1991) 'Defining psychological maltreatment: research and policy perspectives'. Development and Psychopathology 3 pp. 93-102 
Tizard, B. and Hodges, J. (1978) 'The effect of of early institutional rearing on the development of eight year old children'. Journal of Child Psychology and Psychiatry 19 pp.99-118.

Townsend, P. (1979) Poverty in the United Kingdon: a Survey of Household Resources and Standards of Living. Harmondsworth: Penguin.

Trad, P. V. (1995) 'A case of suspected child abuse by an adolescent mother: the use of short-term psychotherapy'. Child Abuse Review 4 (2) pp. 114-128.

Trowell, J. (1983) ‘Emotional abuse of children' Health Visitor 56 pp.252-255

Utting, W. (1991) Children in the Public Care. London: HMSO

Vachss, A. (1997) 'You carry the cure in your own heart' Emotional Abuse Scars Into Childhood htt://www.infi.net/ susanf/emotabus.htm.

Vargas, N. A., Lopez, D., Perez, P., Zuniga, P., Toro, G. and Ciocca, P. (1995) 'Parental attitude and practice regarding physical punishment of school children in Santiago de Chile' Child Abuse and Neglect 19 (9) pp.1077-1082.

Verdugo, M. A., Bermejo, B. G. and Fuertes, J. (1995) 'The maltreatment of intellectually handicapped children and adolescents'. Child Abuse and Neglect 19 (2) pp. 205-216

Vizard, E. (1987) 'The historical and cultural context of child abuse' in Maher, P. (ed) Child Abuse: the Educational Perspective. Oxford: Basil Blackwell

Vizard, E. (1989) 'Child sexual abuse and mental handicap: a child psychiatrist's perspective' in Brown, H. and Craft, A (eds) Thinking the Unthinkable: Papers on Sexual Abuse and People with Learning Difficulties. London: FPA Education Unit.

Volpe, R., Breton, M. and Mitton, J. eds (1980) The Maltreatment of the School-Aged Child Lexington Massachusetts: Lexington Books.

Von Bertalanffy, L. (1973) General Systems Theory Harmonsworth: Penguin 
Vygotsky, L. S. (1978) Mind in Society Cambridge, Mass.: Harvard University Press.

Wald, M. and Wolverton, M. (1990) 'Risk assessment: the emperor's new clothes?' Child Welfare. 69 pp.483-511.

Walker-Andrews, A. S. (1986) 'Intermodal perception of expressive behaviors : relation of eye and voice?' Developmental Psychology 22 pp.373-77

Wallston, K. A and Shelton Smith, M. (1994) 'Issues of control and health: the action is in the interaction' in Penny, G. N., Bennett, P and Herbert, M (eds) Health Psychology: A Lifespan Perspective. Chur, Switzerland: Harwood Academic Publishers.

Walmsley, S. (1989) 'The need for safeguards' in Brown, H. and Craft, A (eds) Thinking the Unthinkable: Papers on Sexual Abuse and People with Learning Difficulties London: FPA Education Unit.

Ward, A. (1992) 'Caring for other people's children' in Stainton Rogers, W., Hevey, D., Roche, J. and Ashe, E. (eds) Child Abuse and Neglect: Facing the Challenge. 2nd edition London: Batsford

Waterhouse, L. and Carnie, J. (1992) 'Assessing child protection risk' British Journal of Social Work. 22 pp.47-60.

Watts, V. (1988) 'Professional perspectives' Journal of Social Welfare Law 2 pp. 94-98.

Weddell, M. (1958) Child Care Pioneers. London: Epworth

Weinberg, S. K. (1955) Incest Behaviour New York: Citadel Press

White, E. C. (1985) Chain, Chain, Change: For Black Women Dealing with Physical and Emotional Abuse. Washington: The Seal Press 
Whiting, L. (1978) 'Emotional neglect of children' in Launderdale, M.L, Anderson,R.N. and Cramer S.E. (eds) Child Abuse and Neglect: Issues on Innovation and Implementation Proceedings of the Second Annual Conference on Child Abuse and Neglect. April 1977 Vol. 1. Washington DC: US Department of Health, Education and Welfare.

Wiehe, V. R. (1990) Sibling Abuse Lexington Mass.: Lexington Books

Willmott, P. (1967) The Consumer's Guide to the British Social Services Harmondsworth: Penguin.

Wilson, E. O. (1975) Sociobiology: The New Synthesis Cambridge, Mass: Harvard University Press

Wilson, M. K. (1995) 'A preliminary report on ego development in nonoffending mothers of sexually abused children'. Child Abuse and Neglect 19 (4) pp. 511-518.

Wilson, M. and Daly, M. (1987) 'Risk of maltreatment of children living with stepparents' in Gelles, R. J and Lancaster, J. B (eds). Child Abuse and Neglect: Biosocial dimensions. New York: Aldine de Gruyter.

Winnicott, D. W. (1964) The Child, the Family and the Outside World. Harmondsworth: Penguin.

Wolfenstein, M. (1955) 'French parents take their children to the park' in Mead, M. and Wolfenstein, M. (eds). Childhood in Contemporary Cultures. Chicago: University of Chicago Press.

Woodhead, M. (1990) 'Psychology and the cultural construction of children's needs' in James, A. and Prout, A. (eds). Constructing and Reconstructing Childhood. London: The Falmer Press

Woodhead, M., Barnes, P., Miell, D. and Oates, J. (1995) 'Developmental perspectives on emotion' in Barnes, P (ed) Personal, Social and Emotional Development of Children. Oxford:Blackwell. 
Wright, E. O. (1978) Class, Crisis and the State. London: New Left Books.

Wright, E. O. (1985) Classes. London: Verso.

Wright, L. S., Garrison, J., Wright, N .B. and Stimmel, D. T. (1992) 'Childhood unhappiness and family stressors recalled by adult children of substance abuse' Alcoholism Treatment Quarterly 8 (4) pp. $67-80$.

Wyatt, G. and Higgs, M. (1991) 'The medical diagnosis of child sexual abuse: the paediatrician's dilemma' in Richardson, S. and Bacon, H. (eds). Child Sexual Abuse: Whose Problem? London: Venture Press.

Wyre, R. (1992) 'Gracewell Clinic' in Stainton Rogers, W., Hevey, D. , Roche, J. and Ashe, E. (eds) Child Abuse and Neglect: Facing the Challenge. 2nd edition. London: Batsford

Yates, A. (1982) 'Legal issues in psychological abuse'. Clinical Pediatrics 21 (10) pp.587-590

Young, L. (1964) Wednesday's Child: a Study of Child Neglect and Abuse New York: McGrawHill

Yule, V. C. (1985) 'Why are parents tough on children?' New Society 27 September pp.444-446.

Zemdegs, J. (1980) 'Outraged: what it feels like to be an abused child' in Volpe, R., Breton, M. and Mitton, J. (eds) The Maltreatment of the School-Aged Child. Lexington Massachusetts: Lexington Books.

Zuravin, S. J. (1991) 'Research definitions of child physical abuse and neglect: current problems' in Starr, R. H. and Wolfe, D. A (eds) The Effects of Child Abuse and Neglect. London: The Guildford Press pp.100-128. 